\title{
Green Innovation: an empirical analysis of technology, skills and policy
}

Author:

Doctoral advisors: Davide Consoli

Nicolò Barbieri

Valencia, January 2019 



\section{Acknowledgements}

\section{Thesis' acknowledgements}

I often said that I would not be able to do a thesis alone, and this is still the case, because this thesis was not an individual effort. It would not have been possible without the help of many people. First and foremost, I would like to record my deepest gratitude to my supervisors, Davide Consoli and Nicolò Barbieri. They introduced me to the world of econometrics and they have been very supportive throughout this process. Davide, being the local, was always available to discuss my questions. I often recalled Socrates' saying "I know that I know nothing" while we were having delightful conversations.

This thesis is also a collective effort that has already resulted in some academic papers, and hopefully in more collaborations. I would like to thank my co-authors for their essential work and insightful conversations realised some- 
times in precarious conditions over skype, namely Angelica Sbardella, Lorenzo Napolitano, Gianluca Orsatti and Francesco Quatraro. Their contribution is detailed in the section below.

I would also like to thank all the past and current members of INGENIO [CSIC-UPV] for their support, in particular Antonio, Isabel, Jordi, Richard, Fernando, Pablo, Ignacio, Elena, Sandra, Victoria and all the PhD students for sharing tips and tactics during the $\mathrm{PhD}$ process.

I would also like to thank participants of the RISIS project, in particular Lionel Villard, with whom I discovered the interesting world of geographic information systems.

This thesis is also the result of the use of free and open source software, of which I am a grateful user. I want to thank the community for creating such great tools as MariaDB, Python, R, QGIS, Latex and GNU/Linux.

Finally, I would like to thank my family, and in particular Coralia, for unconditional support before and during this thesis.

Thanks to you all.

\section{Chapter's acknowledgements and co-authorship}

Chapter 3 is adapted from a paper co-authored with Angelica Sbardella, Lorenzo Napolitano, Nicolò Barbieri and Davide Consoli, titled "Green Technology Fitness" and published in Entropy (Sbardella, Perruchas, et al., 2018). Together 
with my co-authors, I would like to thank the three anonymous reviewers who provided useful comments and suggestions.

Chapter 7 is derived from a paper co-authored with Gianluca Orsatti, Davide Consoli and Francesco Quatraro, titled "Public procurement, local labour markets and green technological change: Evidence from US Commuting Zones". I would like to thank them for taking on board a non-economist and introducing him to the world of econometrics. This paper was in the process of revision and resubmission to Environmental and Resource Economics when this thesis was completed.

Chapter 5 and 6 are based on papers co-authored with Davide Consoli and Nicolò Barbieri. The first one is titled "Specialisation, diversification and the ladder of green technology" and has been submitted to Research Policy, the second one "Specialization, diversification and environmental technology life-cycle" is under review for Economic Geography. Both papers and this dissertation would not have been possible without the contribution and dedication of Davide and Nicolò, to whom I would like to reiterate my heartfelt gratitude. 



\section{Abstract}

The foreseeable outcomes of the transition towards low-carbon economies are multiple and affect in different ways policy-makers, world regions, firms and consumers. It has long been acknowledged that at the core of this transition stand environmental innovations which are developed to enhance the long-term sustainability of economic growth.

The main pillars of this study are two. First, environmental challenges are different, and so are the responses that are needed to tackle them. The main consequence of this is that the current focus on green technology as a homogeneous block of undifferentiated entities is misleading.

Second, the adaptation of production and distribution systems is ultimately carried through by human labour and analysing the transition to environmentally sustainable societies requires a thorough understanding of how work activities 
are designed, implemented and changed to accommodate new policy imperatives and/or new technological opportunities.

Empirical evidence on either of these two pillars is scant or fragmented. The present thesis seeks to fill these gaps through the development of a database on green innovations, of a measure of the life cycle of green technologies, and of the corresponding explorations to scrutinize the relation between green technology production, the territories' characteristics and skills' base of labour market over time and space.

The dataset is created identifying green patent in PATSTAT 2016a database using ENV-TECH classification (OECD, 2016) and geolocalizing their inventors. The result is a database covering green innovation worldwide from the $19^{\text {th }}$ century to 2015, even if the period studied is smaller: 1970-2010.

This dataset permits a first overview of green technologies evolution over time and space, where we can see differences in terms of country evolution and among technologies in terms of complexity, maybe related with the presence of an heteregeneous body of emerging and mature technologies.

To explore further this hypothesis, we develop a methodology to measure technology life cycle stages, and we apply it to understand the patterns of evolution of green technology production at country level. We find that capabilities are more important than wealth to diversify in green innovation, and mature green technologies are positively associated with specialization.

We continue the exploration of the relation between local capabilities, life cycle and patent activity in US federal states where we discover that green innovation 
is more associated than innovation in general with the recombination of distant knowledge, especially in early phases of the life cycle.

Finally, we investigate at US commuting zones level the effects of public procurement on green innovation, taking into account local capabilities again, but using labour market skills instead of knowledge recombination variety. We find that green public procurement has a positive and significant effect, in particular in territories with an important share of abstract skills in labour population. 



\section{Resumen}

Los resultados previsibles de la transición hacia economías con bajas emisiones de carbono son múltiples y afectan de diferentes maneras a los responsables del diseño y la gestión de las políticas públicas, las regiones del mundo, las empresas y los consumidores. Se ha reconocido que en el centro de esta transición están las innovaciones medioambientales que se desarrollan para mejorar la sostenibilidad a largo plazo del crecimiento económico.

Los principales pilares de esta tesis son dos. En primer lugar, los desafíos ambientales son diversos, al igual que las respuestas que se necesitan para afrontarlos. La consecuencia principal de esto es que el enfoque actual en la tecnología verde como un bloque homogéneo de entidades indiferenciadas es engañoso. En segundo lugar, el trabajo humano es lo que en última instancia lleva a cabo la adaptación de los sistemas de producción y distribución. En consecuencia, analizar la transición hacia sociedades sostenibles desde un punto 
de vista medioambiental exige una comprensión profunda de cómo se diseñan, implementan y cambian las actividades laborales para acomodarse a nuevos imperativos políticos y / o nuevas oportunidades tecnológicas.

Las evidencias empíricas sobre uno o ambos pilares son escasas o fragmentadas. La presente tesis trata de llenar estas lagunas desarrollando una base de datos global sobre "patentes verdes", una medida del ciclo de vida de las tecnologías y las consiguientes investigaciones para analizar la relación entre la producción de tecnologías verdes, las características del territorio y la base de competencias de la mano de obra en el tiempo y el espacio.

El primer paso es la identificación de patentes verdes en PATSTAT 2016a utilizando la clasificación ENV-TECH (OECD, 2016) y geolocalizando sus inventores. El resultado es una base de datos que cubre la innovación mundial desde el siglo XIX hasta 2015, aunque el periodo estudiado es menor: 1970-2010.

Este conjunto de datos permite una primera aproximación a la evolución de las tecnologías verdes en el tiempo y el espacio, donde podemos apreciar diferencias en la evolución de los países y entre las tecnologías desde el punto de vista de la complejidad, quizás relacionadas con la presencia de un cuerpo heterogéneo de tecnologías emergentes y maduras.

Para entrar más a fondo en esta hipótesis, desarrollamos una metodología para medir las etapas del ciclo de vida de las tecnologías, y la utilizamos para entender los patrones de producción de tecnologías verdes a nivel de países. Encontramos que las capacidades son más importantes que la riqueza para diversificarse en 
innovación verde, y que las tecnologías maduras están positivamente asociadas con la especialización en estas tecnologías.

Continuamos la exploración de la relación entre las capacidades locales, el ciclo de vida y la producción de patentes en los estados federales de Estados Unidos donde descubrimos que la innovación verde esta más asociada con la recombinación de conocimientos distantes, en particular al principio del ciclo de vida.

Finalmente, investigamos los efectos de las compras públicas sobre la innovación verde al nivel de las "commuting zones" (áreas urbanas funcionales) de Estados Unidos, tomando en cuenta de nuevo las capacidades locales, pero esta vez utilizando las competencias del mercado laboral en lugar de la variedad de la recombinación del conocimiento. Descubrimos que la compra pública verde tiene un efecto positivo y significativo, en particular en territorios con una parte importante de competencias abstractas en la población activa. 



\section{Resum}

Els resultats previsibles de la transició cap a economies baixes en emissions de carboni són múltiples i afecten de diferents maneres als responsables del disseny i la gestió de les polítiques públiques, les regions del món, les empreses i els consumidors. S'ha reconegut que en el centre d'aquesta transició estan les innovacions mediambientals que es desenvolupen per a millorar la sostenibilitat a llarg termini del creixement econòmic.

Els principals pilars d'aquesta tesi són dos. En primer lloc, els desafiaments ambientals són diversos, igual que les respostes que es necessiten per a afrontarlos. La conseqüència principal d'això és que l'enfocament actual en la tecnologia verda com un bloc homogeni d'entitats indiferenciades és enganyós. En segon lloc, el treball humà és el que en última instància porta a terme l'adaptació dels sistemes de producció i distribució. En conseqüència, analitzar la transició cap a societats sostenibles des d'un punt de vista mediambiental exigeix una 
comprensió profunda de com es dissenyen, implementen i canvien les activitats laborals per a acomodar-se a nous imperatius polítics i / o noves oportunitats tecnològiques.

Les evidències empíriques sobre un o ambdós pilars són escasses o fragmentades. La present tesi tracta d'omplir aquests buits desenvolupant una base de dades global sobre "patents verdes", una mesura del cicle de vida de les tecnologies i les consegüents investigacions per a analitzar la relació entre la producció de tecnologies verdes, les característiques del territori i la base de competències de la mà d'obra en el temps i l'espai.

El primer pas és la identificació de patents verdes en PATSTAT 2016a utilitzant la classificació ENV-TECH (OECD, 2016) i la geolocalització dels seus inventors. El resultat és una base de dades que cobreix la innovació mundial des del segle XIX fins a 2015, encara que el període estudiat és menor: 1970-2010.

Aquest conjunt de dades permet una primera aproximació a l'evolució de les tecnologies verdes en el temps i l'espai, on podem apreciar diferències en l'evolució dels països i entre les tecnologies des del punt de vista de la complexitat, probablement relacionades amb la presència d'un cos heterogeni de tecnologies emergents i madures.

Per a entrar més a fons en aquesta hipòtesi, desenvolupem una metodologia per a mesurar les etapes del cicle de vida de les tecnologies, i la utilitzem per a entendre els patrons de producció de tecnologies verdes a nivell de països. Trobem que les capacitats són més importants que la riquesa per a diversificar-se 
en innovació verda, i que les tecnologies madures estan positivament associades amb l'especialització en aquestes tecnologies.

També explorem la relació entre les capacitats locals, el cicle de vida i la producció de patents en els estats federals dels Estats Units on descobrim que la innovació verda està més associada amb la recombinació de coneixements distants, en particular al principi del cicle de vida.

Finalment, investiguem els efectes de les compres públiques sobre la innovació verda al nivell de les "commuting zones" (àrees urbanes funcionals) dels Estats Units, prenent en compte de nou les capacitats locals, però aquesta vegada utilitzant les competències del mercat laboral en lloc de la varietat de la recombinació del coneixement. Descobrim que la compra pública verda té un efecte positiu i significatiu, en particular en territoris amb una part important de competències abstractes en la població laboral. 



\section{Résumé}

Les résultats prévisibles de la transition vers des économies sobres en carbone sont multiples et affectent de différentes façons les décideurs politiques, les régions du monde, les entreprises et les consommateurs. Il est reconnu depuis une quarantaine d'années qu'au centre de cette transition se situent les innovations environnementales qui émergent pour améliorer la durabilité de la croissance économique sur le long terme.

Les principaux piliers de cette thèse sont au nombre de deux. Premièrement, les différents enjeux environnementaux ne sont pas homogènes, ils sont constitués de phénomènes ayant un impact local ou global, à court ou moyen terme, ce qui amène des réponses variées. Par conséquent, le principe qui consiste à analyser les technologies vertes comme un bloc homogène est trompeur. Deuxièmement, ce sont les travailleurs qui réalisent in fine l'adaptation des systèmes de production et de distribution. Ainsi, étudier la transition vers des 
sociétés durables d'un point de vue environnemental requiert de comprendre la manière de concevoir, implémenter et changer les activités professionnelles en réponse aux nouveaux impératifs politiques, économiques, réglementaires et normatif et/ou aux nouvelles opportunités technologiques.

Les données empiriques sur l'un ou l'autre de ces piliers sont éparses ou fragmentées. La présente thèse cherche à combler ces lacunes grâce au développement d'une base de données sur les technologies vertes, d'une identification des phases de leur cycle de vie, et des explorations correspondantes pour analyser la relation entre la production de brevets de ces technologies vertes, les caractéristiques du territoire et la base de compétence du marché du travail dans le temps et dans l'espace.

Le jeu de données est créé en identifiant les brevets "verts" dans la base PATSTAT 2016a grâce à la classification ENV-TECH (OCDE, 2016) et en géolocalisant leurs inventeurs. Il couvre ainsi l'innovation verte mondiale depuis le $\mathrm{XIX}^{e}$ siècle jusqu'à 2015, bien que la période étudiée soit plus courte : 1970-2010. On considère une technologie produite dans un pays lorsque des brevets de cette technologie y sont déposés, l'intensité de cette production étant mesurée grâce au nombre de familles de brevet définies selon INPADOC.

Cette base de données permet une première approximation de l'évolution des technologies vertes dans le temps et l'espace, qui met en lumière des différences en matière d'évolution des pays et entre les technologies du point de vue de la complexité, peut-être dues à la présence d'un groupe hétérogène de technologies émergentes et arrivées à maturité. 
L'approfondissement de cette hypothèse, à partir de la méthodologie développée pour identifier les étapes du cycle de vie des technologies, et de la compréhension des profils de production de technologies vertes au niveau des pays, aboutit au résultat que les compétences sont plus importantes que la richesse pour se diversifier dans ces technologies, et que la spécialisation dans ces technologies se fait statistiquement plus dans des technologies arrivées à maturité.

Nous continuons l'exploration de la relation entre les compétences locales, le cycle de vie et la production de brevets dans les États fédéraux des États-Unis au cours de laquelle nous trouvons que l'innovation verte est davantage associée à la recombinaison de blocs de connaissance sans lien entre eux que l'innovation en général, particulièrement au début du cycle de vie.

Enfin, nous investiguons les effets des achats publics sur l'innovation verte au niveau des aires urbaines fonctionnelles ("commuting zones") des États-Unis, en prenant en compte les compétences locales, mais en utilisant les compétences du marché du travail au lieu de la variété de la recombinaison des blocs de connaissance. Nous découvrons que l'achat public vert a un effet positif et significatif sur l'innovation verte, en particulier dans les territoires ayant une partie importante de compétences tacites dans la population active. 



\section{Contents}

Abstract vii

Resumen $\quad$ xi

Resum $\quad$ Xv

Resumé $\quad$ xix

Contents $\quad$ xxiii

1 Introduction 1

2 Building a dataset on Green Technologies 13

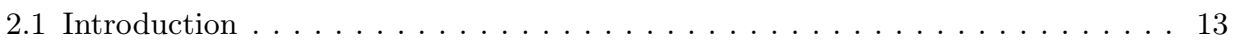

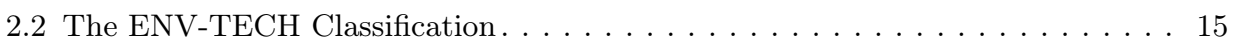

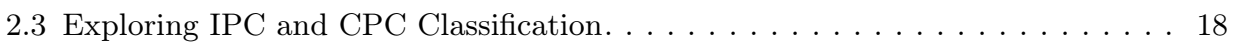

2.4 Geolocalisation of Inventors . . . . . . . . . . . . . . . . . . . . 23

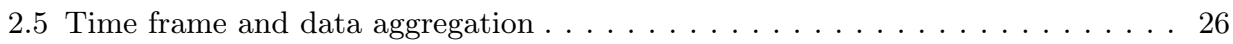




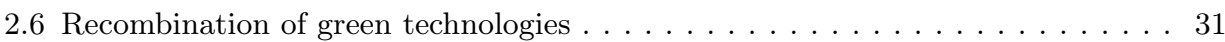

3 Exploratory analysis over time and space $\quad 37$

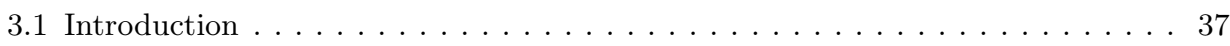

3.2 A Fitness Approach to Green Technology. . . . . . . . . . . . . . . . . . . 40

3.3 Column Selection and Technological Sector Fitness . . . . . . . . . . . . 43

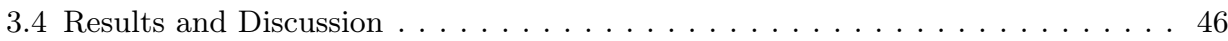

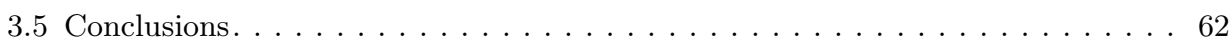

4 The life cycle of technologies $\quad 65$

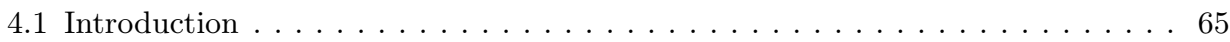

4.2 Industry life cycle and agglomeration economies $\ldots \ldots \ldots \ldots \ldots$

4.3 Approaching the technology life cycle with network analysis . . . . . . . . . . 72

4.4 A proposition of technology life cycle stages . . . . . . . . . . . . . . 76

5 Green specialisation and diversification across countries $\quad 87$

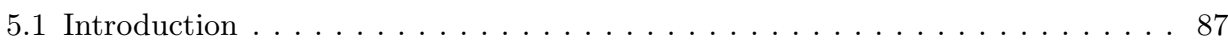

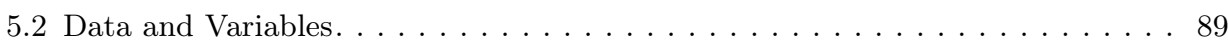

5.3 Empirical Analysis . . . . . . . . . . . . . . . . . . . . . 94

5.4 Results and discussion $\ldots \ldots \ldots \ldots \ldots \ldots \ldots$

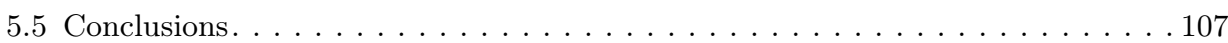

6 Co-evolution of green technologies and the knowledge base 109

6.1 Introduction . . . . . . . . . . . . . . . . . . . . . . . . . . 109

6.2 Technology life cycle in the regional knowledge production function . . . . . . . 114

6.3 Empirical application . . . . . . . . . . . . . . . . . . . . . . . . 116

6.4 Econometric results . . . . . . . . . . . . . . . . . . . . . . . . . . . 124

6.5 Conclusions. . . . . . . . . . . . . . . . . . . . . . . . 130

7 Public procurement and local labour markets 131

7.1 Introduction . . . . . . . . . . . . . . . . . . . . . . . . . . . 131 


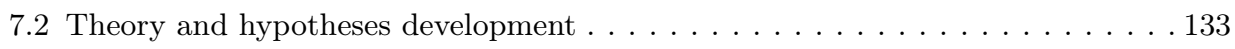

7.3 Research design . . . . . . . . . . . . . . . . . . . 136

7.4 Results . . . . . . . . . . . . . . . . . . . . . . . . 148

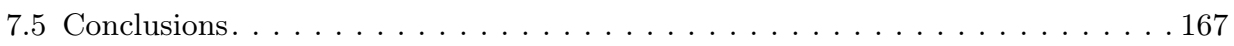

8 Conclusions 173

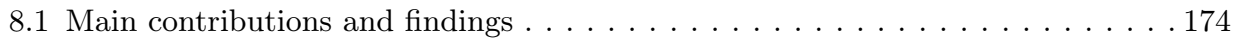

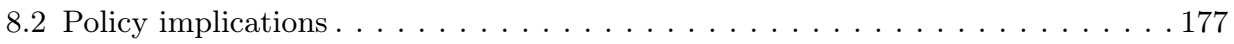

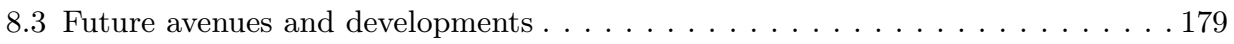

9 Appendix 181

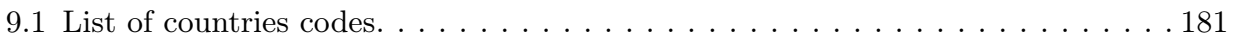

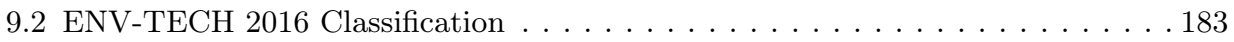

$\begin{array}{ll}\text { Bibliography } & 195\end{array}$ 



\section{List of Tables}

$2.11 \&$ 2-digit ENV-TECH codes and labels . . . . . . . . . . 17

3.1 Top innovators in the most complex green technologies. . . . . 56

3.2 Top innovators in the least complex green technologies. . . . . . 57

4.1 Life cycle stages . . . . . . . . . . . . . . . . . 77

4.2 Life cycle stages of green technologies . . . . . . . . . . . 84

4.3 Technology maturity ranking . . . . . . . . . . . 85

5.1 Main Descriptive Statistics . . . . . . . . . . . . . . . . 95

5.2 Results of the Econometric Model . . . . . . . . . . . . . 98

5.3 Regression results with technology life cycle . . . . . . . . . 99

6.1 Descriptive statistics . . . . . . . . . . . . . . . 123

6.2 Regression results . . . . . . . . . . . . . . . . . 127

6.3 Regression results over the life cycle . . . . . . . . . . . . . 129 
7.1 Effect of total green procurement on GT stock (2001-2011) . . 149

7.2 Effect of GPP for products on GT stock (2001-2011) . . . . 150

7.3 Effect of GPP for services on GT stock (2001-2011) . . . . . . 151

7.4 Effect of total GPP and task composition on GT stock (2006-2011)154

7.5 Effect of GPP for products and task composition on GT stock $(2006-2011) \ldots \ldots \ldots \ldots \ldots$

7.6 Effect of GPP for services and task composition on GT stock $(2006-2011) \ldots \ldots \ldots \ldots \ldots \ldots$

7.7 Effect of GPP on GT stock: mitigation and adaptation (2001-2011)160

7.8 Effect of total GPP and task composition on GT-mitigation stock $(2006-2011) \ldots \ldots \ldots \ldots 16 \ldots$

7.9 Effect of GPP for products and task composition on GT-mitigation stock $(2006-2011) \ldots \ldots \ldots \ldots$. . . . . . . . . 162

7.10 Effect of GPP for services and task composition on GT-mitigation stock $(2006-2011) \ldots \ldots \ldots \ldots$

7.11 Effect of total GPP and task composition on GT-adaptation stock $(2006-2011) \ldots \ldots \ldots$. . . . . . . . . . 164

7.12 Effect of GPP for products and task composition on GT-adaptation stock (2006-2011) . . . . . . . . . . . . . 165

7.13 Effect of GPP for services and task composition on GT-adaptation stock $(2006-2011) \ldots \ldots \ldots \ldots$. . . . . . . . 166 


\section{List of Figures}

2.1 Example of the CPC classification for range Y02E10/70-766 . . 19

2.2 Evolution of the number of green patent families by ENV-TECH families, $1850-2015 \ldots \ldots \ldots \ldots 21$

2.3 Evolution of the indexed number of green patent families by ENV-TECH families, 1850 - 2015. . . . . . . . . . 22

2.4 World map of inventors' localisation for green patent families filled until $1990 \ldots \ldots$. . . . . . . . . . . . . 25

2.5 World map of inventors' localisation for green patent families filled after $1990 \ldots \ldots \ldots \ldots \ldots$

2.6 Evolution of the countries' contribution to green technologies. . 27

2.7 Yearly green classes, applications, and active countries. . . . . . 29

2.8 Yearly frequency of green technology classes . . . . . . . . . 30

2.9 Clusters of green technologies for time period 1970-1986 . . . . 32

2.10 Evolution of the clusters of green technologies [1970-2010] . . . 33

3.1 Example of the influence of column selection on fitness and complexity rankings . . . . . . . . . . . . . . 44 
3.2 Time evolution of the green fitness ranking of countries from 1980 to $2010 \ldots \ldots \ldots$

3.3 Time evolution of green complexity ranking of ENV-TECH technologies from 1980 to $2010 \ldots \ldots$. . . . . . . . 50

3.4 Correlation between green fitness ranking and per capita GDP over the time interval $1980-2010 \ldots \ldots$. . . . . . . . 52

3.5 3-digit $\mathbf{M}(2010,10)$ with rows and columns ordered by green fitness and green complexity . . . . . . . . . . . . 53

3.6 Composition of national green technology baskets . . . . . . . 58

3.7 The three-dimensional relation between export fitness, GDP per capita, and green fitness . . . . . . . . . . . 60

4.1 Knowledge base of green technology 5.2 - Capture or disposal of greenhouse gases other than $\mathrm{CO}_{2}(1970-1994) \ldots \ldots . . .73$

4.2 Evolution of the knowledge base of green technology 5.2 - Capture or disposal of greenhouse gases other than $\mathrm{CO}_{2}$ (1970-2010) . . 74

4.3 Evolution of the knowledge base of green technology 4.1 - Renewable energy generation $(1970-2010) \ldots \ldots . \ldots 75$

4.4 Evolution of a selection of Green Technologies (1971 - 2010) . . 80

4.5 Selected green technologies by stage of life-cycle, 2001-2010 . . 82

4.6 All green technologies by stage of life-cycle, 2001-2010 . . . . . 83

5.1 Diversification probabilities according to the characteristics of technologies and countries. . . . . . . . . . . . . . 104

5.2 Specialization probabilities according to the characteristics of technologies and countries. . . . . . . . . . . . . 104

6.1 Quintiles of green and total patent families per million inhabitants (average 1980-2010) . . . . . . . . . . . 117

6.2 Quintiles of green patent families per million inhabitants over technology life cycle stages (average 1980-2009) . . . . . . . . 121 
6.3 Distribution of green and total patent families over quintiles of different type of variety (average 1980-2009) . . . . . . . 125

7.1 Geographic distribution of GT patents, 2000-2011 (quintiles) . . 139

7.2 Geographic distribution of GPP expenditures, 2000-2011 (quintiles)142

7.3 Geographic distribution of task-intensive occupations, 2005 (quintiles $\ldots \ldots \ldots \ldots \ldots \ldots \ldots$

7.4 A.M.E. of GPP on total GT stock with $95 \%$ CIs . . . . . 168

7.5 A.M.E. of GPP on GT-mitigation stock with 95\% CIs . . . . 169

7.6 A.M.E. of GPP on GT-adaptation stock with $95 \%$ CIs . . . . 170 



\section{Chapter 1}

\section{Introduction}

Since the second half of the $20^{\text {th }}$ century, there has been an increasing concern among academics, policy makers and the general population about climate change and disappearing biodiversity. In 1992, the United Nations Conference on Environment and Development (also known as the Rio de Janeiro Earth Summit) finalized an agreement signed by more than 150 countries, called the United Nations Framework Convention on Climate Change (UNFCCC), with the goal of "stabilizing greenhouse gas concentrations in the atmosphere at a level that would prevent dangerous anthropogenic interference with the climate

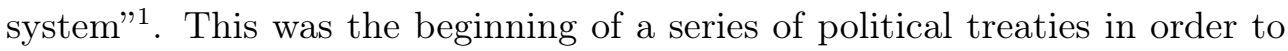
achieve a sustainable transition, the last of these agreements being the "Paris

\footnotetext{
${ }^{1}$ available at http://unfccc.int
} 
Agreement", signed by 196 countries at the $21^{\text {st }}$ Conference of the Parties of the UNFCCC in 2015. The "Paris Agreement" main objective is to enhance the global response to the threat of climate change by keeping a global temperature rise below $2^{\circ} \mathrm{C}$ above pre-industrial levels before the end of this century.

On the scientific side, the Intergovernmental Panel on Climate Change (IPCC) was established in 1988 by the World Meteorological Organization (WMO) and the United Nations Environment Programme (UNEP) to cover "scientific, technical and socio-economic information relevant to understand the scientific basis of risk of human-induced climate change, its potential impacts and options for adaptation and mitigation." (Principles Governing IPCC Work, 2010 ${ }^{2}$ ). The special report of this body, published in October 2018, explains that consequences of an increase of the global temperature by $1.5^{\circ} \mathrm{C}$ are worse than expected, and that humanity needs to implement massive and urgent policies to accelerate the transition toward sustainable economies by the next few years, in order to remain under an increase of $2^{\circ} \mathrm{C}$ (Leahy, 2018).

The prospective costs of non-action are high considering that, for example, air and water pollution pose serious threats to human health, or that loss of biodiversity and depletion of agricultural resources imperil the global supply of food (see i.e. Haines and Patz, 2004; Patz et al., 2005; McMichael, Woodruff, and Hales, 2006). What's more, these risks are interconnected in ways that could trigger a chain of events with potentially higher social and economic costs - for example, water scarcity and temperatures rise may induce large-scale involuntary migration. Scholars and policy-makers agree that multilateral

\footnotetext{
${ }^{2}$ https://www.ipcc.ch/
} 
and multilevel responses are required to contain the degradation of the global environment and prevent further risks. As Ayres and Bergh (2005) [p. 116] put it, "economic growth must be accompanied by structural change, which implies continuous introduction of new products and new production technologies, and changes in [energy] efficiency and de-materialization".

Far from ignoring the limitations and the intrinsic difficulties of a 'technological fix' (Sarewitz and Richard Nelson, 2008), accelerating the development and diffusion of new low-carbon technologies remains a staple of any strategy aimed at dealing with climate change (Stern, 2007; Johnstone et al., 2012). Successful policy would call upon a broad portfolio of technologies and of competences, due to the wide range of activities and sectors that generate greenhouse-gas (GHG) emissions.

The analysis of the nature, the sources and the diffusion of eco-innovation is at the centre of an intense debate among academics and policy makers alike. The broad consensus is that accelerating the development of new low-carbon technologies and promoting their global application are crucial steps, albeit not the only ones, towards containing and preventing GHG emissions (OECD, 2011). As a vast literature shows, policies for green innovation confront a diverse array of barriers. The first is that uncertainty on the appropriability of the prospective environmental benefits (A. B. Jaffe, R. G. Newell, and R. N. Stavins, 2005; R G Newell, 2010) due to clean technologies adds to the classic underinvestment due to free riding on R\&D (Arrow, 1962; Nelson, 1959), thus creating a "double externality". Other barriers to the diffusion of green technology may arise from systemic failures - such as i.e. lack of skills, weak 
institutions - that hinder knowledge flows and, thus, the efficiency of R\&D and innovation efforts (OECD, 2003).

Spatial features also matters for the innovation process. It has long been established that the generation and diffusion of knowledge, prime engines of innovation, stem from the recombination of existing ideas (Romer, 1994; Weitzman, 1998) among agents that have limited access to information, and imperfect capacity to absorb, process, and respond to new information (W. Cohen and Levinthal, 1990). A key point is that economic development builds on existing local capabilities to generate distinctive technological and industrial profiles (D. L. Rigby and Essletzbichler, 1997), and such a distinctiveness is shaped by the composition of knowledge, that is, the number of underlying inputs and the interdependence between them (Frenken and Ron A Boschma, 2007; Neffke, Henning, R. Boschma, et al., 2011). The greater and more diverse the spectrum of know-how, the more complex the domains to which this knowledge is applied, be they products (Hidalgo and Hausmann, 2009; Cristelli, Gabrielli, et al., 2013), industries or technologies (Balland and D. Rigby, 2017). As a consequence, information exchange confronts costs that increase with the diversity of the attendant knowledge base. Put otherwise, higher coherence between activities facilitate the growth of knowledge and increase the likelihood of innovation (Atkinson and Stiglitz, 1969; Chatterjee and Wernerfelt, 1991). These characteristics point to potential weaknesses and systemic failures in the growth and diffusion of knowledge, especially when mismatches in the incentives of private and public research organisations become barriers to the diffusion of necessary competences. 
The dynamics of local knowledge mirror, of course, those of physical technology. The literature has analysed the latter through the lenses of the life cycle heuristic proposed by William J Abernathy and J. M. Utterback (1978) and further refined by S. Klepper (1996) and J. Utterback (1994). At early stages, variety is highest and each prototype technology carries a set of characteristics whose effectiveness cannot be judged ex-ante because, at least in evolutionary accounts of the story, the selection environment co-evolves together with the contestants (Adner and Kapoor, 2015; Barbieri, Marzucchi, and Rizzo, 2018). As technology moves towards maturity, the inferior variants are selected out, industry structures consolidate and the knowledge base acquires a configuration based primarily on routine activities to the detriment of explorative ones. Underlying the dynamics of the knowledge base stands the adaptation of supporting institutional structures in the form of new training and research, regulatory regimes, government infrastructure (Nelson, 1994; Vona and Consoli, 2015).

As the comprehensive review by Barbieri, Ghisetti, et al. (2016) shows, existing literature falls short in at least one of these dimensions. Prior efforts at comprehensively mapping the spatial distribution of inventive activities in environmental technologies are limited to most advanced economies (i.e. Jean Olson Lanjouw and Mody, 1996; Veugelers, 2012; Costantini and Mazzanti, 2012; Fankhauser et al., 2013; Calel and Dechezleprêtre, 2016) and disregard the influence of country-specific characteristics. Other scholarly work focuses on either individual countries (Calel and Dechezleprêtre, 2016; Marin, 2014; Gagliardi, Marin, and Miriello, 2016) or on specific technological domains - 
predominantly energy (David Popp, 2002; Fischer and Richard G Newell, 2008; Nesta, Vona, and Nicolli, 2014). In our view, the lack of engagement with issues concerning how countries build green innovation capabilities, and how such a capacity differs along the gradient of economic development, is a major shortcoming for both policy and scholarly debates. There is a gap in the development of green technologies over time and over space as well as in the relative state of development of each of the attending subdomains. These gaps are in part due to insufficient data availability about their evolution over time and space, including precise geographical information.

The first goal of this dissertation is to create a dataset on green technologies. Chapter 2 develops a structured database using PATSTAT (European Patent Office data set for statistical analysis) and the ENV-TECH classification of environmental related technologies. This database contains an exhaustive list of green patents published worldwide since the $19^{\text {th }}$ century as well as the geolocalisation of inventors, which can be projected to different level of geographical agglomeration depending on the domain of interest (countries, regions, urban areas, cities, etc.).

Once the dataset is created, we draw a first global mapping of the evolution of green technologies (chapter 3). In this chapter, we use the Economic Fitness Complexity (EFC) approach to analyse the complexity evolution of green technologies and inventor's countries. In terms of geography, as expected developed countries are the main contributors to green innovation, but we also observe a rise of some Asian and west European countries. On the technology side, an important versatility of complexity ranking evolution is detected, 
maybe due to an heterogeneity among technologies in term of maturity. We also gain a first insight about mid-income countries' capacity in green innovation production: countries exporting complex products are able to produce complex green technologies, meaning that wealth is not necessarily a barrier to green innovation.

A shortcoming of the specialized literature is that all green technologies are treated as a homogeneous body. This is a major obstacle to be able to appreciate their relative stage of development, especially for what concerns policy. Chapter 4 fills this gap by elaborating an identification of the life cycle stages. This is based on the heuristic proposed by William J Abernathy and J. M. Utterback (1978) and further refined by S. Klepper (1996) and J. Utterback (1994). The first part of the chapter focuses on the recombination of the knowledge base of green technologies using network analysis, to develop in a the second part a methodology to identify life cycle stages based on patenting activity and geographical ubiquity. In the following chapters, we build on this methodology and analyse the patterns of diversification and specialisation in green innovation in relation to the technology life cycle (chapter 5) and the variety of the knowledge base associated with it (chapter 6).

More precisely, Chapter 5 fills a gap in the literature concerning the relation between green technology and capabilities of countries. There are already studies about environmental technologies and the characteristics of territories, we still miss a systematic analysis of all the green technologies and countries' contributions. Therefore, this chapter investigates country characteristics associated with the development of green technologies along the technology 
life cycle. It elaborates an empirical analysis of temporal and geographical distribution of green innovation, replicating the methodology proposed by Petralia, Balland, and Morrison (2017) and extending it to green technology, by identifying firstly patterns of specialization and diversification in environmental related technologies, and secondly adding to the model the life cycle stage of green innovation produced. The analysis confirms one of the results obtained in chapter 3: wealth is less a barrier for countries to diversify in green technologies than not having competencies in neighbouring technologies. This is coherent with previous literature, although our result differs from Petralia, Balland, and Morrison (2017): they found that diversification is strongly associated with development stage of countries, while we found a strong association with technology maturity. We also find that countries move along cumulative paths of specialization, and toward more complex technologies.

After the discover of a significant and positive effect of existing capabilities in neighbouring technologies to the diversification in green technologies, we investigate in chapter 6 the intrinsic regional capabilities using the recombination knowledge variety. This approach has already been used by Carolina Castaldi, Frenken, and Los (2015) at US federal states level but not specifically for green innovation. Therefore, the objective of this chapter is to analyse whether and to what extent regional related and unrelated knowledge variety matter for the development of technology, and whether their influence differs along the various stages of the technology life-cycle. To address these questions, we frame the analysis in the context of economic geography under the premise that climate change is a global phenomenon with markedly local manifestations, 
and that regions and countries differ significantly both in their exposure to climate events as well as in their ability to respond to them. In a first step, we compare the association between the variety of the knowledge base (Frenken and Ron A Boschma, 2007; Carolina Castaldi, Frenken, and Los, 2015) and green innovation versus all innovations. In a second step, we explore this association alongside the life cycle of green technologies. This analysis yields two main findings: green patent production is more associated with unrelated variety of the knowledge base than the production of all the patents, and emerging stages of technology are more correlated with unrelated variety than maturity, which is more associated with related variety.

Finally, in chapter 7, we explore the effects of public policies on green innovation taking into account local capabilities, but rather than using the variety of the knowledge recombination, we employ a typology of skills that are relevant in the labour market. Green technologies are a specific sort of innovations that are featured by the well-known double externality problem (Rennings, 2000). Like any other kind innovation, one source of externalities is related to the non-appropriability and non-exclusivity of technological knowledge. In addition, green technologies are expected to yield social gains due to their positive impact on the environment. This represents a positive externality for which firms are not expecting to be paid. In such a framework, public intervention may play a crucial role to prevent sub-optimal investments in green innovation to take place. For this reason, most of the empirical literature on the determinants of eco-innovations focuses on how policymakers can influence their generation and adoption, with specific attention to the design of regulatory 
frameworks setting binding constraints for polluting firms. According to the inducement hypothesis, firms decide to introduce eco-innovations to comply with stringent regulatory frameworks, to save the costs that they should incur to keep on polluting (Johnstone et al., 2012). This mechanism is known in the literature as "regulatory push/pull" effect, because regulation can stimulate the demand for green technologies (pull effect), and hence make investments in their generation profitable (push effect). Advancements in the green knowledge base in upstream sectors are a key condition for the demand by firms in downstream sectors to be satisfied. To date, nobody has explored explicitly the connection between green policies and the skill structure of the attending labour market. This is relevant to understand whether and to what extent the local endowment of knowledge magnifies or not the positive impulse of policy. Technology push and demand pull deployment policies are therefore strictly intertwined (Requate, 2005; Horbach, 2008; Ghisetti and Quatraro, 2013; Costantini, Crespi, et al., 2015). Using data of public procurement in the US, we explore the effects of green public procurement on green innovation in US commuting zones. In a second phase, we characterize human capital in these territories using a framework developed by (Autor, Levy, and Murnane, 2003) which use occupational-task data to check whenever public procurement effect is affected by the type of task performed. We find that green public procurement exerts a significant and positive impact on green innovation, in particular when public procurement is aimed at services. We also find that the prevalence of high-level skills (i.e. management, engineering, social interaction) in the territory is positively associated to the generation of green innovation, compared to routine or manual skills. 
Summing up, the thesis identifies the following gaps and addresses them as follows:

- the lack of complete and transversal information about green innovation in chapter 2

- the missing global mapping of the evolution of green technologies in chapter 3

- the differentiation of green technologies using life cycle stages in chapter 4

- how countries build their green innovation capabilities in chapter 5

- which local capabilities are associated with green technologies production along the life cycle is addressed in chapter 6

- the effect of public procurement on green innovation according to local skills is finally addressed in chapter 7 .

While it is acknowledged that the topic is complex and no single piece of work can address the possible issues at hand, the present thesis makes a novel contribution to knowledge by investigating the determinants of the evolution of green innovation. It first provides an overview of green technologies evolution over space and time, then proposes a measure of the technology life cycle to analyse patterns of diversification and specialisation and the knowledge base associated, in order to identify appropriate territory configurations to foster green innovation taking into account its heterogeneous nature. Finally, it explores if public procurement can promote environment-related technologies according to the characteristic of the labour market. 



\section{Chapter 2}

\section{Building a dataset on Green}

\section{Technologies}

\section{$2.1 \quad$ Introduction}

The analysis of green technologies requires a method to measure their evolution. Because patent is a legal protection form of inventions recognized by a large majority in the world, patent data is a well-known proxy to study technology development, taking into account its limitations (see e.g., Griliches, 1990; Jean O Lanjouw, Pakes, and Putnam, 1998; Arts, Appio, and Van Looy, 2013). 
A patent is, as defined by the United States Patent and Trademarks Office (USPTO), “... the right to exclude others from making, using, offering for sale, selling or importing the invention". The applicant receives this right in exchange to publish information about its invention. In so doing, the inventor has an exclusivity right during enough time to make its invention profitable and he contributes to the spread of new ideas. This disclosure has been used by academics to understand the evolution of technologies.

This source of information carries benefits and shortcomings. Patents provide highly disaggregated details of each invention, in particular the location of the inventor and the characteristics of the invention which are essential to the analysis proposed here. In addition, prior research has pointed out that patents provide a good indicator of research and development activities, as applications are usually filed early in the research process (Griliches, 1990). In this study, we use groups of patent, or families, on related inventions that have been filed in various countries to track diffusion of knowledge across countries (e.g. Jean Olson Lanjouw and Mody, 1996). While we acknowledge that not all inventions are patented, the characteristics of intellectual property rights (IPR) regimes underlying patenting activities are likely to have a significant effect on the propensity to search and develop inventions (W. M. Cohen, Richard R Nelson, and Walsh, 2000; Ginarte and Park, 1997). Further, compared to other domains, the regulatory framework plays a particularly important role in the case of environmental technologies (Adam B Jaffe, Richard G Newell, and Robert N Stavins, 2002; D. Popp, R. Newell, and A. Jaffe, 2010). 
Although information on patents is freely available, there is no database with precise geographic information about inventors' locations that specifically targets green technologies. Some organizations provide free datasets like USPTO, the National Bureau of Economic Research (NBER) or the Organisation for Economic Cooperation and Development (OECD), but they are restricted to some countries or to some kind of patents. To create our dataset about green technologies, we use PATSTAT 2016a, a database produced by the European Patent Office (EPO) which contains bibliographical patent data from over 90 countries. In this database, we use ENV-TECH classification (OECD, 2016) to identify green patent applications (see section 2.2) through the IPC/CPC classification. Then, we improve and geocode inventor's location of these green patents (see section 2.4).

Finally, in the last section of this chapter, we will explore possible time frame and data aggregation to use in the analysis developed along the following chapters, and then we will realise a first description of green technologies using network analysis.

\subsection{The ENV-TECH Classification}

Patents are considered as environment-related according to the ENV-TECH classification developed by the Organisation for Economic Co-operation and Development (OECD) (Haščič and Migotto, 2015)․ . The ENV-TECH classification, based on the International Patent Classification (IPC) and the Collaborative Patent Classification (CPC), features eight environmental families, separated

\footnotetext{
${ }^{1} \mathrm{ENV}-\mathrm{TECH}$ list is available in the appendix, section 9.2
} 
in 3 different areas: environmental management (1), water-related adaptation technologies (2), and climate change mitigation technologies (from 4 to 9). Even if "Biodiversity protection and ecosystem health" (3) is mentioned in the classification, its patent search strategy is not available yet.

ENV-TECH is a hierarchical classification, families cited above are the first level of aggregation (1 digit). Each family is divided in groups (2 digits) and sub-groups (3 digits). Not all the groups are divided sub-groups, and 3 subgroups include a lower level (4.6.1, 8.2.5 and 9.1.2). Table 2.1 presents the list of ENV-TECH families and groups. 


\begin{tabular}{|c|c|c|}
\hline Code & 1-Digit Class Description & 2-Digit Class Description \\
\hline 1 & ENVIRONMENTAL MANAGEMENT & \\
\hline 1.1 & & Air pollution abatement \\
\hline 1.2 & & Water pollution abatement \\
\hline 1.3 & & Waste management \\
\hline 1.4 & & Soil remediation \\
\hline 1.5 & & Environmental monitoring \\
\hline 2 & WATER-RELATED ADAPTATION TECHNOLOGIES & \\
\hline 2.1 & & Demand-side technologies (water conservation) \\
\hline 2.2 & & Supply side technologies (water availability) \\
\hline 4 & $\begin{array}{l}\text { CCMTS RELATED TO ENERGY GENERATION, } \\
\text { TRANSMISSION OR DISTRIBUTION }\end{array}$ & \\
\hline 4.1 & & Renewable energy generation \\
\hline 4.2 & & Energy generation from fuels of non-fossil origin \\
\hline 4.3 & & $\begin{array}{l}\text { Combustion technologies with mitigation potential } \\
\text { (e.g., Using fossil fuels, biomass, waste, etc.) }\end{array}$ \\
\hline 4.4 & & Nuclear energy \\
\hline 4.5 & & $\begin{array}{l}\text { Efficiency in electrical power generation, transmis- } \\
\text { sion or distribution }\end{array}$ \\
\hline 4.6 & & Enabling technologies in energy sector \\
\hline 4.7 & & $\begin{array}{l}\text { Other energy conversion or management systems } \\
\text { reducing GHG emissions }\end{array}$ \\
\hline 5 & $\begin{array}{l}\text { CAPTURE, STORAGE, SEQUESTRATION OR DIS- } \\
\text { POSAL OF GREENHOUSE GASES }\end{array}$ & \\
\hline 5.1 & & $\mathrm{CO}_{2}$ capture or storage $(\mathrm{CCS})$ \\
\hline 5.2 & & $\begin{array}{l}\text { Capture or disposal of greenhouse gases other than } \\
\text { carbon dioxide }\left(\mathrm{N}_{2} \mathrm{O}, \mathrm{CH}_{4}, \mathrm{PFC}, \mathrm{HFC}, \mathrm{SF}_{6}\right)\end{array}$ \\
\hline 6 & CCMTS RELATED TO TRANSPORTATION & \\
\hline 6.1 & & Road transport \\
\hline 6.2 & & Rail transport \\
\hline 6.3 & & Air transport \\
\hline 6.4 & & Maritime or waterways transport \\
\hline 6.5 & & Enabling technologies in transport \\
\hline 7 & CCMTS RELATED TO BUILDINGS & \\
\hline 7.1 & & Integration of renewable energy sources in buildings \\
\hline 7.2 & & Energy efficiency in buildings \\
\hline 7.3 & & $\begin{array}{l}\text { Architectural or constructional elements improving } \\
\text { the thermal performance of buildings }\end{array}$ \\
\hline 7.4 & & Enabling technologies in buildings \\
\hline 8 & $\begin{array}{l}\text { CCMTS RELATED TO WASTE WATER TREATMENT } \\
\text { OR WASTE MANAGEMENT }\end{array}$ & \\
\hline 8.1 & & Wastewater treatment \\
\hline 8.2 & & Solid waste management \\
\hline 8.3 & & $\begin{array}{l}\text { Enabling technologies or technologies with a poten- } \\
\text { tial or indirect contribution to GHG mitigation }\end{array}$ \\
\hline 9 & $\begin{array}{l}\text { CCMTS IN THE PRODUCTION OR PROCESSING } \\
\text { OF GOODS }\end{array}$ & \\
\hline 9.1 & & Technologies related to metal processing \\
\hline 9.2 & & Technologies relating to chemical industry \\
\hline 9.3 & & $\begin{array}{l}\text { Technologies relating to oil refining and petrochem- } \\
\text { ical industry }\end{array}$ \\
\hline 9.4 & & Technologies relating to the processing of minerals \\
\hline 9.5 & & $\begin{array}{l}\text { Technologies relating to agriculture, livestock or } \\
\text { agroalimentary industries }\end{array}$ \\
\hline 9.6 & & $\begin{array}{l}\text { Technologies in the production process for final in- } \\
\text { dustrial or consumer products }\end{array}$ \\
\hline 9.7 & & $\begin{array}{l}\text { Climate change mitigation technologies for sector- } \\
\text { wide applications }\end{array}$ \\
\hline 9.8 & & $\begin{array}{l}\text { Enabling technologies with a potential contribution } \\
\text { to GHG emissions mitigation }\end{array}$ \\
\hline
\end{tabular}

Table 2.1: 1 \& 2-digit ENV-TECH codes and labels. Groups without sub-groups are mentioned in italic type. 
In this dissertation, ENV-TECH is the key element to define green technologies. We discuss later in this chapter (section 2.5) what is the most accurate level (1, 2 or 3 digits) to use in order to carry out this research.

\subsection{Exploring IPC and CPC Classification}

International Patent Classification (IPC) and Cooperative Patent Classification (CPC) are two widespread technology classification systems employed by patent offices to classify the patent documents based on the technological areas in which they claim to be novel. Both systems exhibit a hierarchical structure that describes the technical content of the patents in progressively finer detail at lower levels of aggregation. IPC was defined by the Strasbourg Agreement in 1971 to be used by the World International Patent Organization (WIPO). CPC is a collaborative effort between the European Patent Office (EPO) and the United States Patent and Trademark Office (USPTO), based on the European Classification System (ECLA), which was based, in turn, on IPC, and used since 2013 by EPO and USPTO. IPC and CPC shares a lot of sections, but $\mathrm{CPC}$ is more detailed in certain domains.

ENV-TECH associates each green technology with a series of IPC and CPC codes, although it does not provide an exhaustive list of codes. For example, ENV-TECH 4.1.1 "Wind energy" is associated with CPC codes "Y02E10/70766", thus we need to explore the CPC classification to retrieve all the codes beneath and between Y02E10/70 and Y02E10/766. Moreover, as shown in figure 2.1, CPC classification is not straightforward: not all the numbers 


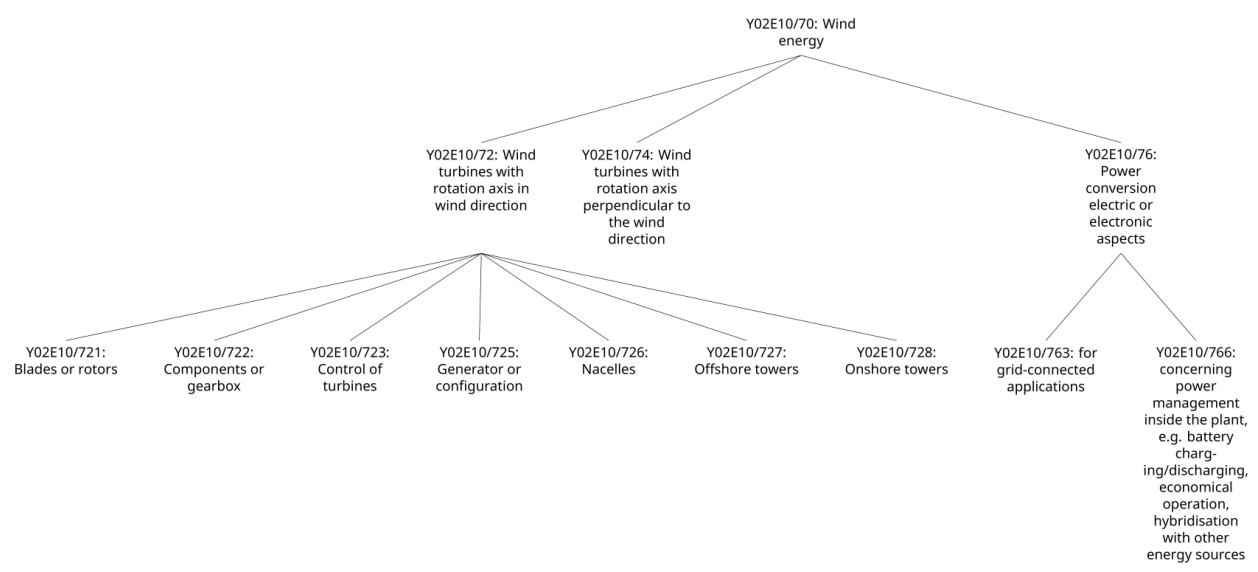

Figure 2.1: Example of the CPC classification for range Y02E10/70-766

exist in $\mathrm{CPC}$ between 70 and 766, only 72, 74, and 76, and some of these codes have "children codes", which are not only even numbers. In the same example, Y02E10/72 have 7 subclasses: 721, 722, 723, 725, 726, 727,728. IPC classification is ordered in a similar manner with less ramifications.

The first task to enable the identification of green patents in PATSTAT is to create an exhaustive list of all the IPC and CPC codes from ENV-TECH. We developed a Python script to explore an API (Application Programming Interface) that provides information about IPC and CPC codes, in particular about their "children" and "parent" codes, and was created by National ICT Australia Ltd (NICTA) in 2013 (available at https://github.com/NICTA/ t3as-pat-clas) and adapted to the 2016 edition of these classifications by a github user called cambialens (https://github.com/cambialens) ${ }^{2}$. This script

\footnotetext{
${ }^{2}$ This setup was later used by the CORTEXT team to build patent descriptions from IPC. Details are available at https://github.com/cortext/patstat/tree/master/nomenclatures/ipc_ descriptions\#setting-up-the-virtual-machine
} 
gives us the entire list of IPC and CPC codes associated with ENV-TECH codes.

Since ENV-TECH exploits both IPC and CPC $\operatorname{codes}^{3}$ we convert IPC codes into CPC codes according to the concordance table proposed by EPO and $\mathrm{USPTO}^{4}$. Hence, we exploit information contained in patent documents and extract CPC codes classifying patented technologies from PATSTAT 2016a. Finally, we assign patents to ENV-TECH codes accordingly.

In this dissertation, we use INPADOC patent families as our unit of analysis (B. H. Hall and Helmers, 2013). Patent families are collections of patents that can be linked to one or more common 'ancestor' patent documents. These collections typically contain documents relating to the multiple applications involved in protecting the same invention, or variant of this invention, in multiple countries. This results in a series of equivalent filings that patent examiners and attorneys can cite indifferently. Simple patent families are quite restrictive sets of equivalents, all sharing the same priority (an original filing at one or another patent once, before extension elsewhere). For a complete discussion about the opportunity of correcting citations for patent families, see Martinez (2010).

The overall green patenting trend by ENV-TECH families is reported in Figure 2.2. Therein we observe that patenting in most green technologies was almost non-existent during the 19th century and the first half of the 20th century (except for Environmental Management technologies), experience a first increase

\footnotetext{
${ }^{3}$ Almost all the IPC codes are present in the CPC classification but not the other way around.

${ }^{4}$ http://www . cooperativepatentclassification.org/cpcConcordances.html
} 


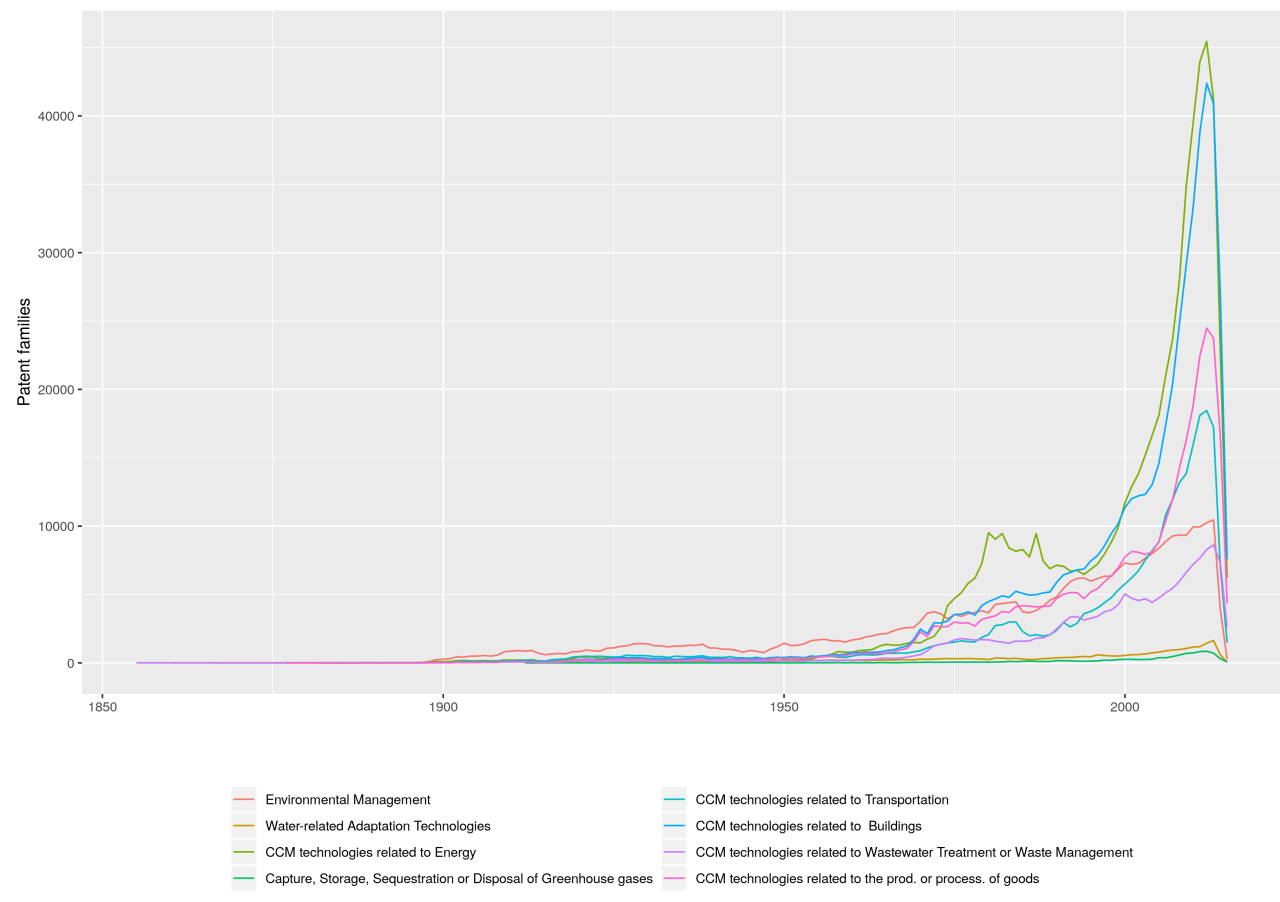

Figure 2.2: Evolution of the number of green patent families by ENV-TECH families, 1850 - 2015. The sharp decrease at the end of the series is an artefact of the database, as discussed later in section 2.5 . 


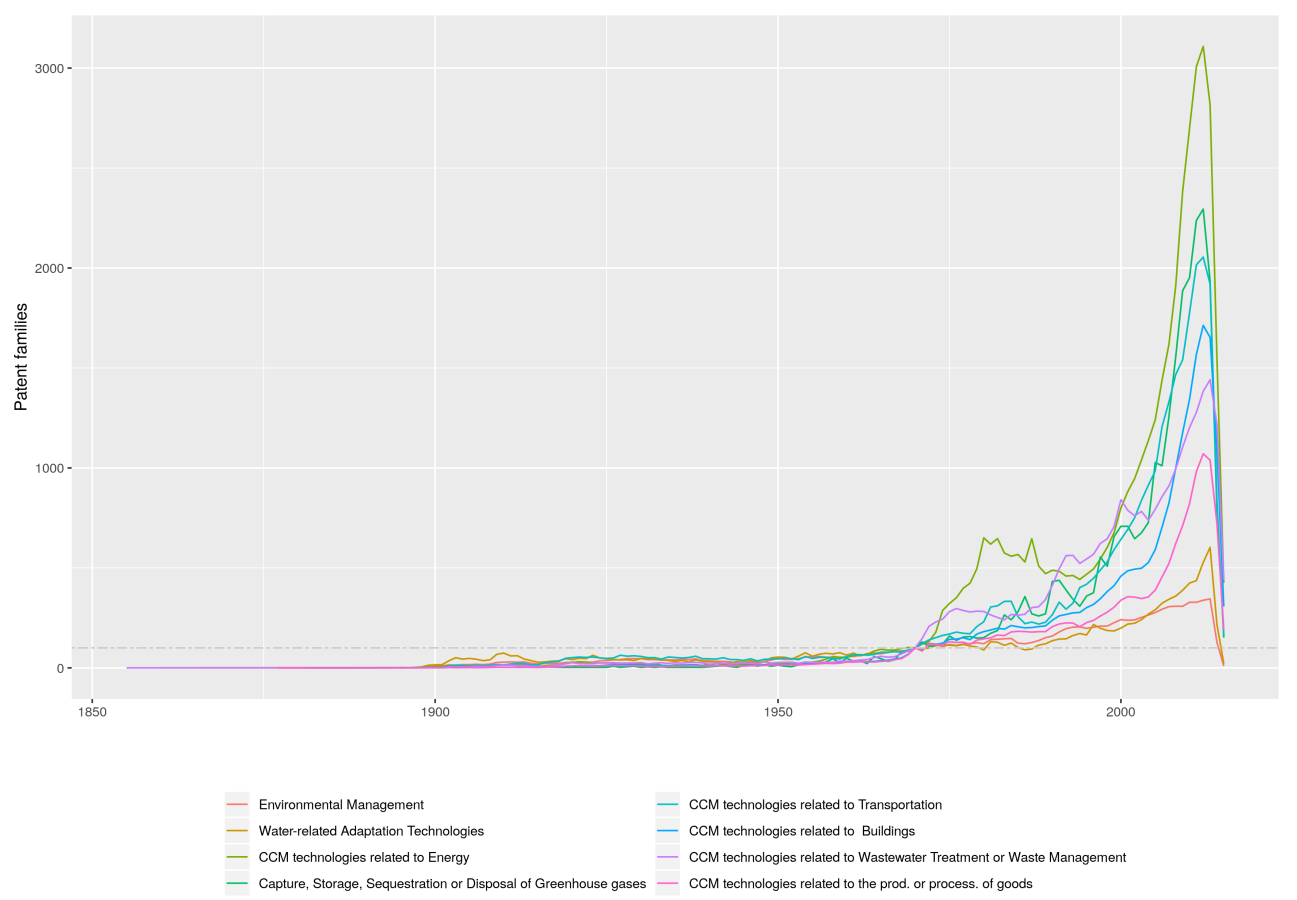

Figure 2.3: Evolution of the indexed number of green patent families by ENV-TECH families, 1850 - 2015. Base year for the indexation is 1970 .

after 1970 and an acceleration after 2000. Technologies that improve the sustainability of the energy and building sector lead the trend, followed by green products and processes and transportation. The number of patent families related to water-related and carbon capture and storage technologies is relatively smaller compared to other green technologies. However, the latter increases at a faster pace compared to 1970 levels, as showed in Figure 2.3. Patenting on transportation and energy efficiency buildings experiences a sharp increase after 2005. Conversely, environmental management and water-related technologies exhibit lower growth rates over the period. 


\subsection{Geolocalisation of Inventors}

Our goal of developing a worldwide analysis calls for accurate geographical localisation of inventive activities. To this end, we use information on inventors' addresses to geocode each patent family at city level. Information on the location of inventors from PATSTAT is parsed through GeoNames ${ }^{5}$ and Google Maps API.

The procedure entails 5 steps. First, we rely on the Institut Francilien Recherche Innovation Société (IFRIS) version of PATSTAT. IFRIS recovers missing addresses combining several external patent sources (REGPAT, National Patent Databases, etc). Second, we geo-localise patent families by identifying the postal codes within the address string and searching in GeoNames. Third, for patent families in which the postal code information is missing, or for which it is not possible to detect the geographical coordinates, we identify the city name in the address using the city table of the GeoNames database (limiting the search to cities with at least 5000 inhabitants in order to reduce potential noises) and we manually check the results. Fourth, for the remaining addresses without geographical coordinates, we use the Google Maps API, a programmable interface to the geographical database developed by Google since 2005 which allows obtaining for an address its coordinates and the administrative entities it belongs to. Finally, we propagate inventors' coordinates inside patent families when inventors appear several times. For example, we can find

\footnotetext{
${ }^{5}$ GeoNames is a geographical database available under a Creative Commons attribution license which contains over 10 million geographical names corresponding to over 9 million unique features whereof 2.8 million populated places and 5.5 million alternate names. A feature can be physical (mountain, lake?), political (country, territory?), a human settlement (city, village...), etc. See http://www.geonames.org for more information.
} 
in the same patent family two inventors with different IDs, the first one with a complete address, the second one with a missing one: "Gehri, Martin Christian Adrian" and "GEHRI, MARTIN, CHRISTIAN, ADRIAN". As the levenshtein distance between the two names is less than 3 when both strings are converted to uppercase, we assume it is the same person and we use the complete address to fill the missing one.

This procedure allows us to geolocalize 929,829 patent families (with at least 1 inventor geolocalized $-57.2 \%$ patent families have more than half of their inventors geolocalized), in 146 countries. Patent families without geo-localised inventor (either because inventor information is missing or because address is not found) have been dropped from the dataset. Variations of the geo-localisation rate across ENV-TECH families and patent offices are very small: the standard deviation is 0.089 in the first case and 0.118 in the second case, when taken into account the top 10 patent offices (accounting for $93 \%$ of all the patent families), thus we can conclude that the bias introduced by dropping non geo-localised inventors is negligible.

The precise geolocalization of inventors allows us to work on different levels of geographical aggregation: countries in chapter 3 and 5, US federal states in chapter 6 and US commuting zones in chapter 7 .

We repeat this operation for all US inventors (green and non-green patents) to be able to calculate shares of green patent in chapter 6 and 7 .

Figure 2.4 and 2.5 show the inventors' localisation projected on a world map for patent families filled respectively before 1991 and after 1990. In both maps, 


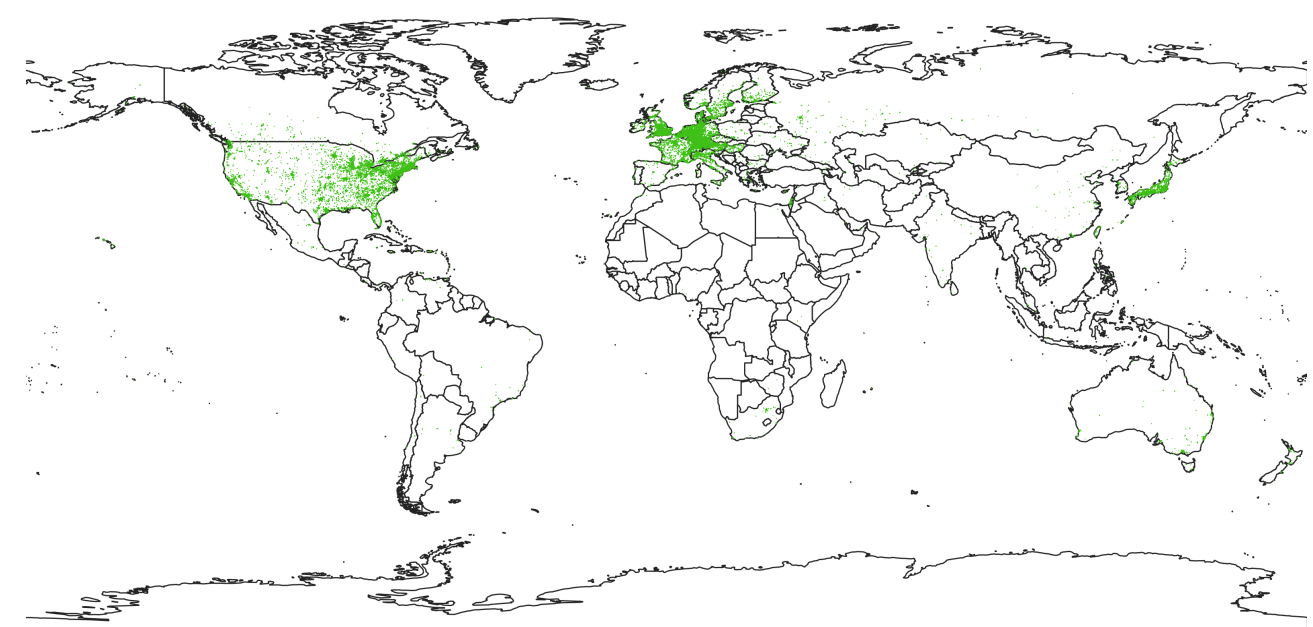

Figure 2.4: World map of inventors' localisation for green patent families filled until 1990 .

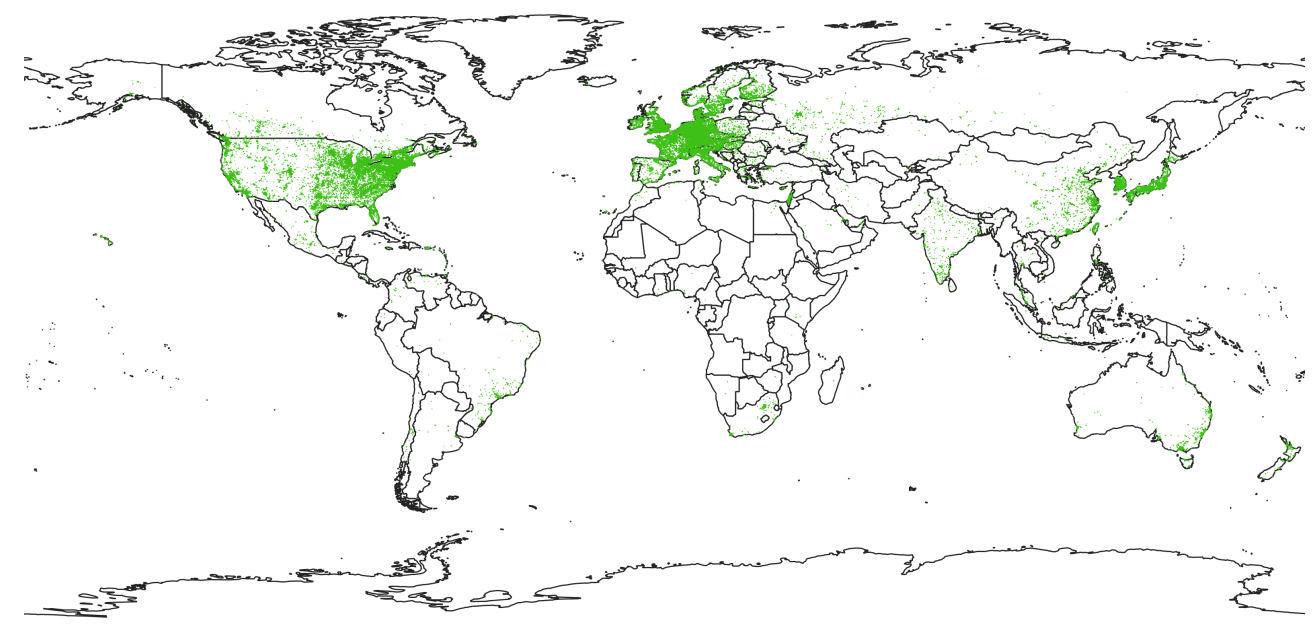

Figure 2.5: World map of inventors' position for green patent families filled after 1990 . 
we can appreciate that the development of green technologies is localised in some specific regions: east and west coast of North America (mainly in the US), central part of Europe, eastern coast of Asia (Japan, Korea and China). South America and Africa are almost not contributing to green technologies, except some very specific areas in Brazil and South Africa. Comparing these 2 maps brings out interesting differences: even if there is a general increase of the number of green patent after 1990, some areas that were practically not contributing before 1990 have increase there production substantially. This the case of China, South Korea, India, Portugal, Spain, Brazil, inland areas of the US and Canada and some former communist countries in the eastern part of Europe.

This is confirmed if we observe the contribution to green technologies by country shown in figure 2.6. This chart represents the top 10 biggest contributor to green technologies, from 1970 to 2015. Even if all countries increase their contribution over time, the share of China $(\mathrm{CHN})$, South Korea (KOR) and to a lesser extent Taiwan (TWN) is increasing significantly since 2000.

\subsection{Time frame and data aggregation}

All the figures available in the previous sections of this chapter (e.g. figure 2.2) suggest that the time window we study and its length can have a significant effect on the results of the analysis. For instance, Figure 2.7a shows that the number of active technology classes (figure 2.7a) and active countries (figure $2.7 b)$ has grown considerably over time, which implies that a clear trade-off 


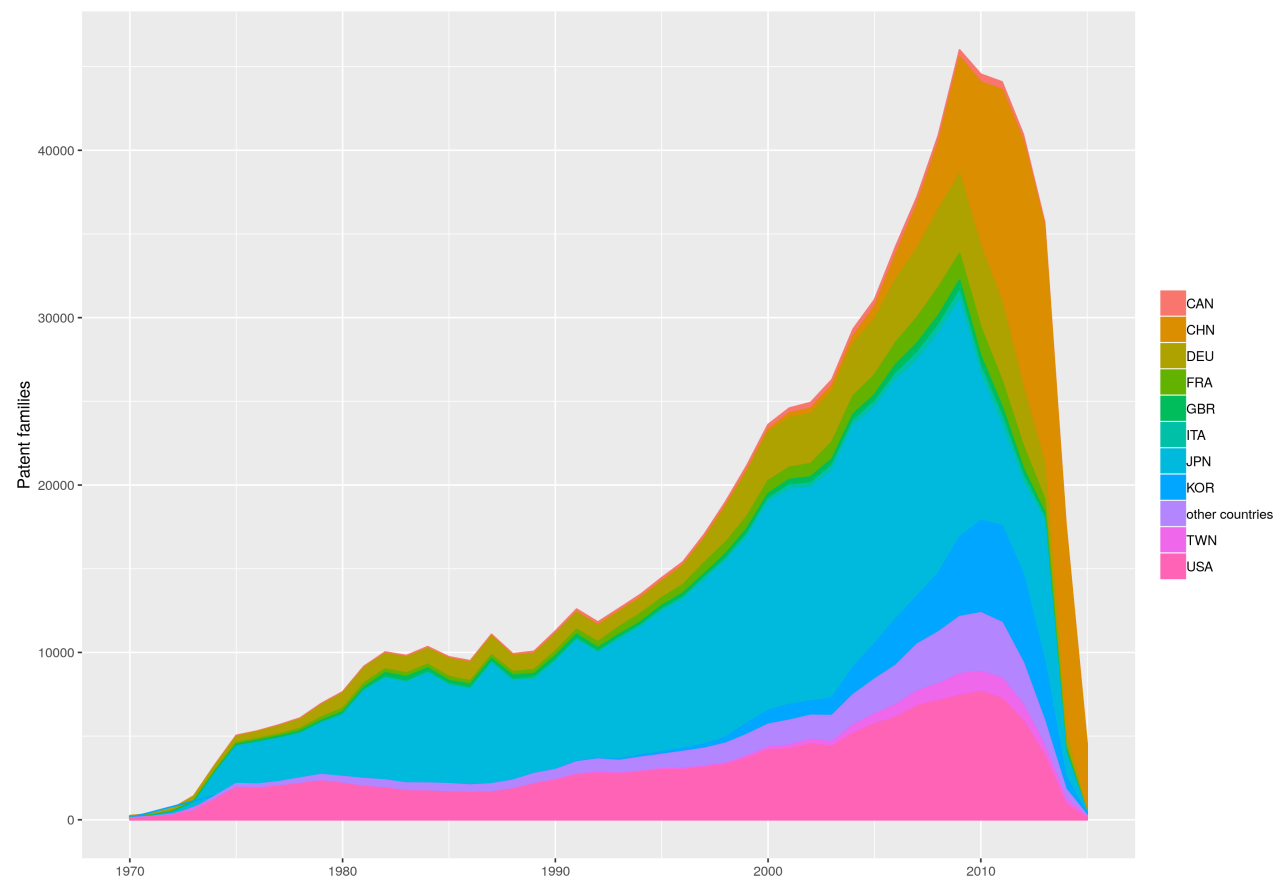

Figure 2.6: Evolution of the countries' contribution to green technologies. Only the top 10 biggest contributors are represented, by inventor's country. 
exists between the length of the time series and the size of the intersection of the data available in each year.

This is also due to the fact that the the number of applications containing green technologies has remained quite small until the 1970s (figure 2.2). Notice that the trade-off is quite sharp also if we move the right extreme of the time interval too far forward, since there is a sharp drop in the number of filed patent applications after 2010. This is compatible with the presence of a constant backlog of applications that have been filed but not yet examined and, for this reason, not yet added to the databases. The delay between filing and inclusion into PATSTAT varies depending on the patent office that received the application. For example, the backlog at the United States Patent and Trademark Office (USPTO) is estimated at around 40 months on average ; this implies that the data for 2012 contained in the 2016a edition of the database is most likely still incomplete.

Based on these considerations, the time frame used in this dissertation is from 1970 to 2010.

On the other hand, as explained in section 2.2, ENV-TECH is a hierarchical classification with 4 levels (from 1 to 4 digits). To remain comparable between them, we should use the same level for all the green technologies; we can not compare a 2-digits ENV-TECH class with a 4-digits one, the latter being much more specific. 4-digits classes are used only in two cases, they can not be our choice to define green technologies. On the other side, 1-digit categories are too 


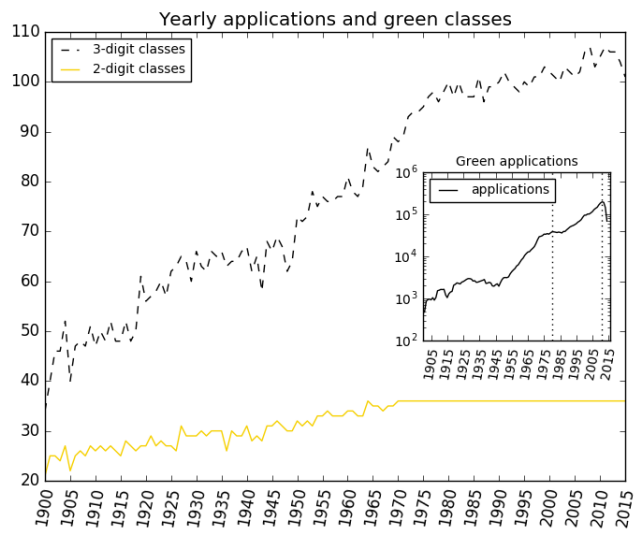

(a) Time series of the number of green classes and applications.

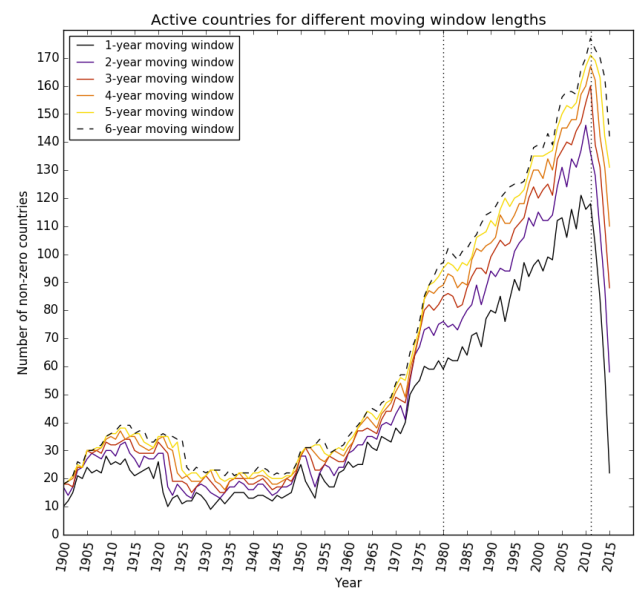

(b) Time series of the number of active countries for different time windows.

Figure 2.7: Yearly green classes, applications, and active countries. 


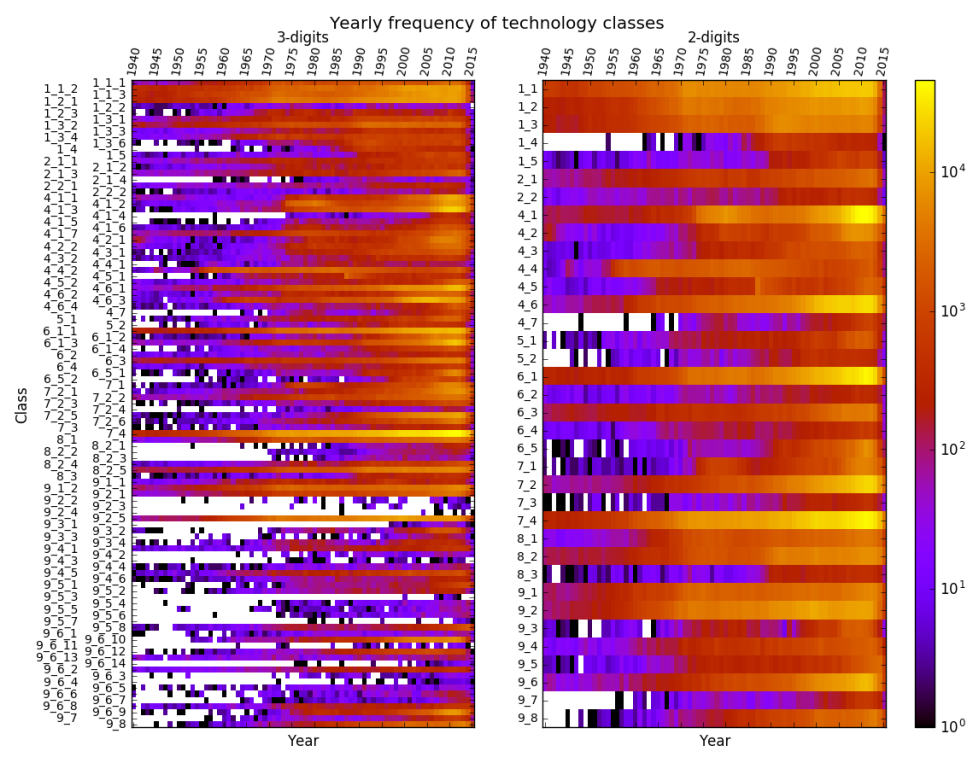

Figure 2.8: Yearly frequency of green technology classes (left:3-digits, right: 2-digits).

broad to capture fine-grained technologies. Then, our preferred ENV-TECH level should be 2 or 3 digits.

Figure 2.8 shows the year frequency of technology classes for 3 (left panel) and 2 digits (right panel) over the period 1940-2015. We can see in both sides "holes" (representing years without any patent families assigned to the corresponding class) before 1970, which validates the selection of this year as a starting point. But even after 1970, we can still see a significant portion of 3-digits technology without any observation, in particular in CCMTs related to waste water treatment or waste management and CCMTs in the production or processing of goods (ENV-TECH 8 \& 9). This observation, combined with the absence of 3-digits classes in some 2-digits groups, tips the scale in favour of choosing 2-digits level as our definition for green technologies. 


\subsection{Recombination of green technologies}

Once we extrapolated the global patterns of green technologies evolution in section 2.3 and 2.4, it is interesting to identify the structure of the ENV-TECH database from the functional point of view, to appreciate how related the main green technologies are.

Each patent identified as "green" can belong to various green technologies, because its IPC/CPC classes can be associated to several ENV-TECH codes. Using these patents as ties between green technologies, we can perform a network analysis and a cluster detection, in order to detect broad bodies of green innovations and their evolution over time.

To do so, we first create a network using technologies as nodes and association to the same patent as ties. At this stage, we have a network with an large amount of ties and nodes, but we can hardly identify components and evolution over time. To disentangle significant relations, we use a community detection using Louvain algorithm developped by Blondel et al. (2008) over overlapping time periods of 5 years. This algorithm is implemented by Cortext $^{6}$, the digital platform of the Laboratoire Interdisciplinaire Sciences Innovations Sociétés (LISIS), a project launched and sustained by the Institut Francilien Recherche Innovation Société (IFRIS) and the Institut National de la Recherche Agronomique (INRA).

Figure 2.9 shows the resulting clusters for the first overlapping time period (1970-1986) and figure 2.10 represents the alluvial diagram of the evolution of

\footnotetext{
${ }^{6}$ Available at https://www. cortext.net/
} 

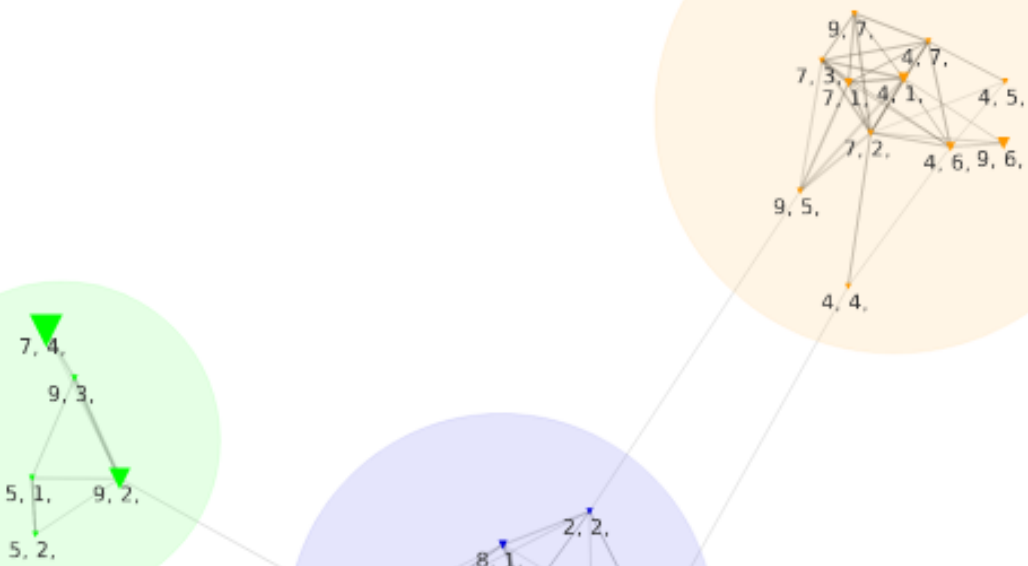

4. $3,6,3$

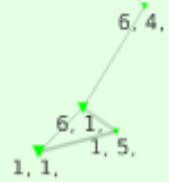

Figure 2.9: Clusters of green technologies for time period 1970-1986 


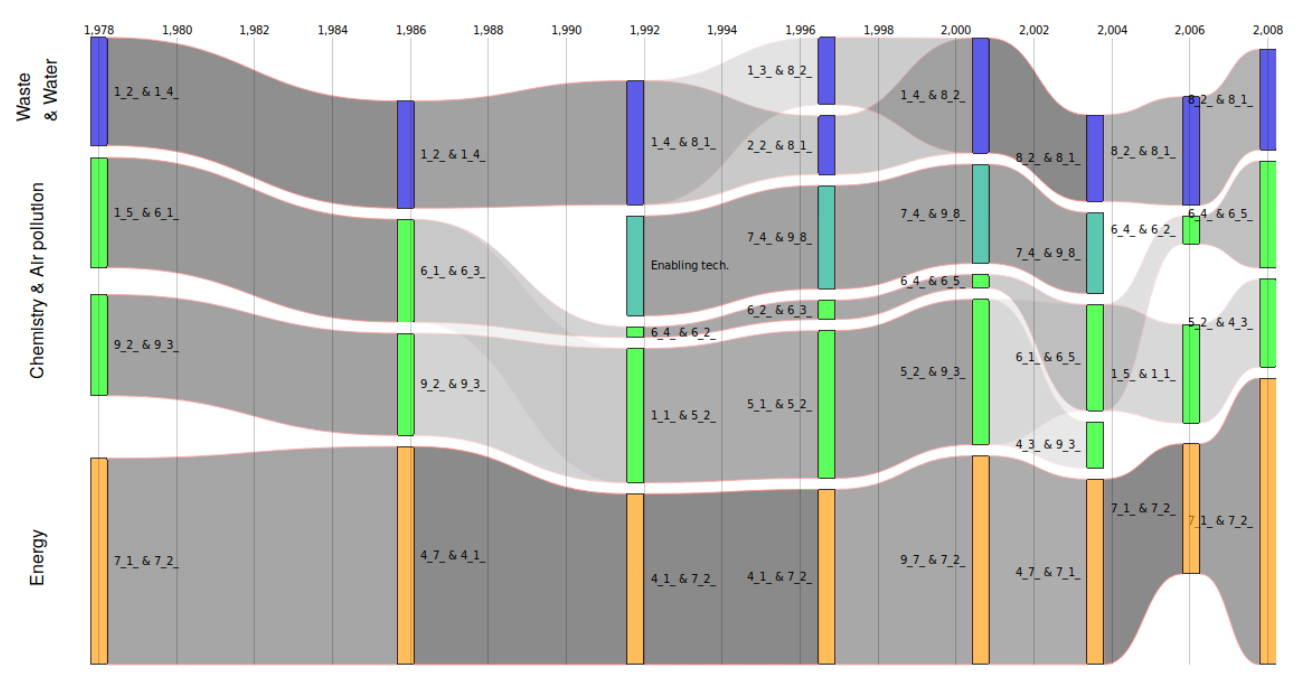

Figure 2.10: Evolution of the clusters of green technologies [1970-2010]

these clusters over time, from 1970 to $2010^{7}$. Each node is a green technology labelled by ENV-TECH 2 digits code, clusters are represented by the same color on the network and on the alluvial diagram.

We observe a relative stability over time of the relations among green technologies, with 4 clusters that last the whole time period, except the teal cluster (labelled "7.4 \& 9.8"), which appears in the 1987-1997 time period and disappears in 2002-2006.

The most stable cluster is the orange one (labelled "7.1 \& 7.2"), it contains green technologies related to energy production without combustion, in particular all the climate change mitigation technologies related to energy (4) - except

\footnotetext{
${ }^{7} \mathrm{An}$ interactive version of this diagram and the high resolution networks are available at http: //personales.upv.es/franperr/relation_gt/
} 
4.2 (energy from non-fossil fuels) and 4.3 (mitigated combustion) - and energy consumption in buildings (7.1, 7.2 and 7.3).

The second important and stable cluster is the blue one (labelled "1.2 \& 1.4"). It brings together technologies related to waste and water management. It only splits during the time period 1993-2001, where technologies related to waste management separate from the ones related to water management.

The teal cluster mentioned above appears only during 10 years, and combines enabling green technologies in buildings (7.4) and in the production or processing of goods (9.8). This could mean that enabling technologies were important and singular enough at the end of the $20^{\text {th }}$ century to appear as a distinct cluster during 4 time periods, while 7.4 was present previously inside the green cluster. Finally, the green cluster is the most dynamic one: it started as 2 different parts, one related to air pollution and the other related to chemistry. In the 1990s, it recombines in a small cluster with technologies related to transport - labelled $6.4 \& 6.2$ - (except 6.1, road transport) and in a bigger cluster containing technologies related to chemistry and air pollution, including the one produced by road transport - labelled $1.1 \& 5.2$. In 2000, it recombines again in 2 parts, one cluster about chemistry and water (2.1) that last only one time period labelled $4.3 \&$ 9.3. The other cluster splits again in 2 during the 2000 s, one around mitigation technologies related to transport and nuclear energy, the other one containing the remaining technologies.

Summing up, we observe that the structure of green technologies is organized around 4 broad domains (energy, chemistry, air pollution, water and waste, 
named after the main technologies described previously). Though broadly stable, they permanently evolve and recombine their inner components over time, according to the grade of development and the knowledge base of each technology. This indicate that green technologies is an heterogeneous body with technologies in different stages of the life cycle. In the next chapter, we will explore this universe more in detail. 



\title{
Chapter 3
}

\section{Exploratory analysis over time}

\author{
and space
}

\subsection{Introduction}

Economic development builds on existing local capabilities to generate distinctive technological and industrial profiles (D. L. Rigby and Essletzbichler, 1997; Capello, 2010). A major driver of the distinctiveness of these trajectories is indeed the composition of knowledge, that is, the number of underlying inputs and the interdependence between them (Kogut and Zander, 1993; Frenken and Ron A Boschma, 2007; Neffke, Henning, and R. Boschma, 2011). The 
greater and more diverse the spectrum of know-how, the more complex the domains to which this knowledge is applied, be they products (Hidalgo, Winger, et al., 2007; Zaccaria et al., 2014), industries (Vona and Consoli, 2015) or technologies (Balland and D. Rigby, 2017). Empirical evidence provides clear indications about these patterns. First, there are significant differences in the complexity of knowledge produced across geographical locations. Second, only a few areas exhibit proficiency in complex activities, and this usually correlates with their long economic development. However, by virtue of path-dependence, while investing in complex technologies is beneficial in principle, many areas simply lack the necessary competences and, most fundamentally, their underlying conditions prevent them from creating a new path of development. As a consequence, and third, these features are dynamically self-reinforcing.

In this chapter, we employ analytic techniques developed within the Economic Fitness-Complexity (EFC) approach to economic prediction (Tacchella, Cristelli, et al., 2012) in order to assess the development and geographical distribution of green technologies between 1970 and 2010. EFC is a data-driven methodology that originally targeted the relation between the composition of the export baskets of countries and their potential to become more developed economies. The idea behind this methodology is that for a country to become competitive in the production of a given good, it must first acquire the necessary skills. However, the process leading to the acquisition of new capabilities is by its very nature cumulative and highly path-dependent, which is consistent with the fundamental intuition that complex products requiring advanced skills will be exported mostly, if not only, by high fitness countries that will also be 
competitive in the production and trade of less complex goods. Capabilities are generally not observable, and can be conceived as a latent intermediate layer between countries and products in an ideal tri-partite network. Some recent successful applications of EFC (Cristelli, Tacchella, et al., 2017; Tacchella, Mazzilli, and Pietronero, 2018) have aimed to extract information about the effects of accumulated capabilities by studying the bipartite network of countries and exported goods. These studies have shown that the EFC algorithm has considerable predictive power of the future development of countries, as measured by their future per capita GDP. Among its outputs, the algorithm features a ranking of country fitness values that proxy how advanced the set of capabilities of each country is, and a ranking of product complexity values that proxies how advanced are the capabilities required to produce each product.

For this study, we use patent applications identified in the previous chapter as a proxy of capability. The transliteration of the EFC approach to this hitherto unexplored empirical context rests on the idea that the criteria for assigning patent applications to specific domains (i.e., technological classes) are identifying characteristics of the expertise that is necessary for successful invention. In particular, the co-occurrence of technological classes in a country allows us to identify the extent to which inventions and the attending capabilities are common across countries. Accordingly, a country that has a diversified portfolio of technologies spanning from the most to the least complex ones will have higher fitness while, in turn, complex technologies appear almost exclusively in the portfolio of high-fitness countries. As a consequence, more specialised (or less diversified) countries operate almost exclusively in less complex sectors. 
In other words, the portfolio of activities of low-fitness countries is (almost) nested in that of higher-fitness countries.

In particular, the set of indicators proposed here informs a ranking of countries propensity to create new green technology as well as of the development of these technologies. While we remain agnostic about the pathways through which countries develop and apply capabilities to environmental issues, we provide insights into the extent to which each country contributes to the global network of technological capabilities, as well as into the extent to which the technologies grow and develop as a result of distributed inventive efforts. Furthermore, we expect that a thorough mapping of who is inventing and in what can enrich the current debate on leaders and laggards in the transition to sustainable societies.

\subsection{A Fitness Approach to Green Technology}

In this chapter, we focus on the green sector-fitness of countries that host inventors of green technologies and the complexity of the green technology classes included in the inventions. Recall that the peculiarity of sector-fitness lies therein, to compute it, we do not extract information from the whole technology spectrum (all possible IPC and/or CPC classes) but, rather, we restrain to a subset of classes that identify the relevant area for the study of a particular sector of activity, in our case, green technologies. Furthermore, recall that this approach has already been employed successfully in the study of country exports to break down the fitness profile into individual industries. No doubt, applying sector-fitness to technologies does imply some risks. The 
main issue is that the interpretation of the sector fitness might not be as straightforward for technologies as it is for industries. In fact, defining an industrial sector from an aggregation of products implies grouping together objects that are classified unequivocally and generally assigned to only one sector. The same cannot be said for technologies, since multiple technological fields, namely the objects that we use to define the technological equivalent of a sector, usually contribute to the same patent, and these fields tend to be quite distant within the classification tree. For this reason, studying green technology classes in isolation neglects a wealth of non-green classes that however are part of green inventions. Bearing in mind these caveats, we expect that the selection of the data involved in applying the sector fitness approach to studying green technologies still yields reasonable results.

Computations involve EFC algorithm wherein inputs are binary matrices of countries (rows) and classes (columns). The underlying assumption is that each patent family weights one unit which is shared between (country, class) pairs. Since patent applications can be unambiguously attributed to their filing year, it is natural to build a series of yearly weighted matrices $\mathbf{W}(y)$, where each matrix element $W_{c, t}(y)$ is the sum of the shares of applications filed in year $y$ that can be traced back to country $c$ and green-technology class $t$. The EFC algorithm requires a binary matrix as input, thus, for each year $y$, we binarize $\mathbf{W}(y)$ based on Revealed Comparative Advantage Balassa, $1965^{1}$ and obtain

\footnotetext{
${ }^{1}$ We do not expect the binarization strategy to have crucial effects on the results, especially if the matrices are sparse to begin with
} 
$\mathbf{M}(y)$ such that:

$$
M_{c, t}(y)= \begin{cases}1 & \text { if } \frac{W_{c, t}}{\sum_{t^{\prime}} W_{c, t^{\prime}}}>\frac{\sum_{c^{\prime}} W_{c^{\prime}, t}}{\sum_{c^{\prime}, t^{\prime}} W c^{\prime}, t^{\prime}} \\ 0 & \text { otherwise. }\end{cases}
$$

The binary matrices are then fed to the EFC algorithm to yield non-negative scores and rankings for fitness as well as complexity. In formulae:

$$
\begin{cases}\widetilde{F}_{c}^{(n)}=\sum_{t} M_{c, t} Q_{t}^{(n-1)}, & Q_{t}^{(n)}=\frac{\widetilde{Q}_{t}^{(n)}}{<\widetilde{Q}_{t}^{(n)}>} \\ \widetilde{Q}_{t}^{(n)}=\frac{1}{\sum_{c} M_{c, t} \frac{1}{F_{c}^{(n)}}}, & F_{c}^{(n)}=\frac{\widetilde{F}_{c}^{(n)}}{<\widetilde{F}_{c}^{(n)}>}\end{cases}
$$

with initial condition:

$$
\sum_{t} Q_{t}^{(0)}=1 \forall t
$$

The fitness of a country is thus defined as the average complexity of its technologies. The definition of the complexity of a technology, instead, involves a non-linear equation that attributes lower complexity to the technologies patented by low-fitness countries. It should be noted that, depending on the structure of $\mathbf{M}(y)$, the scores of the lower-ranked entities can converge to zero (Pugliese, Zaccaria, and Pietronero, 2016). Fortunately, rankings remain consistent and can therefore be trusted. For this reason, focusing on country and technology rankings is a good strategy. 
It is worth mentioning that patenting intensity (and coverage) in several countries has grown sharply in the past decades. Moreover, filing of new patent applications in specific technological areas is relatively intermittent, meaning that for a given pair $(c, t)$, the corresponding cell in matrix $\mathbf{M}(y)$ is often different from that in $\mathbf{M}(y+1)$. This is more apparent if technological codes are disaggregated, and can induce some noise. As proposed in 2.5, we use 2 digits ENV-TECH classes to increase for inter-temporal stability. A further complementary approach entails averaging over multiple yearly snapshots of $\mathbf{W}(t)$

$$
\mathbf{W}(y, \delta)=\frac{1}{\delta} \sum_{t=0}^{\delta-1} \mathbf{W}(y-t)
$$

before bin arising to obtain $\mathbf{M}(y, \delta)$. For our analysis, we choose $\delta=10$ and divide the data into four non-overlapping windows-1971-1980, 19811990, 1991-2000, and 2000-2010 - each labelled using the latest included year (e.g., 2010 stands for the period 2000-2010). Unless otherwise stated, 2-digit technology classes are employed throughout.

\subsection{Column Selection and Technological Sector Fitness}

In general, the fitness and complexity rankings produced by the EFC algorithm are not invariant to the addition (or subtraction) of rows or columns in the binary matrix. 

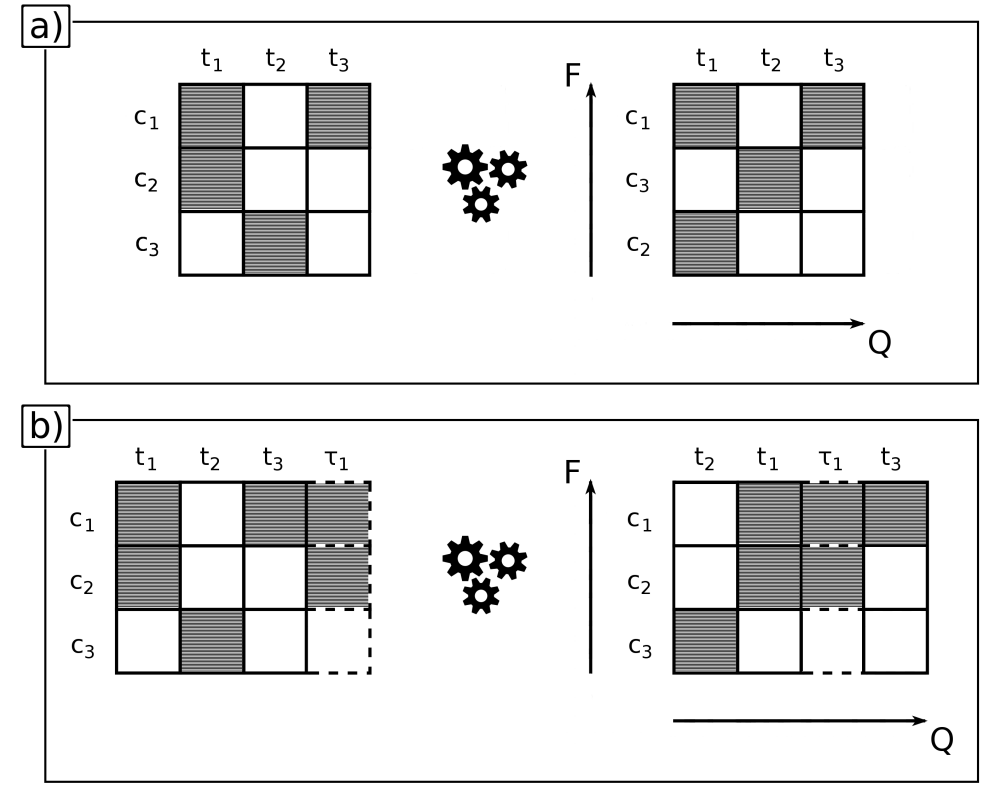

Figure 3.1: Example of the influence of column selection on fitness and complexity rankings. Panel $a$ ) depicts a binary country-technology matrix $M$ consisting of three countries $\left(c_{1}, c_{2}\right.$, and $\left.c_{3}\right)$ and three technologies $\left(t_{1}, t_{2}\right.$, and $\left.t_{3}\right)$; ordering the rows by fitness and the columns by complexity (right), we see that $t_{1}$ is more complex than $t_{2}$ and $c_{3}$ has higher fitness than $c_{2}$. Panel $b$ ) depicts the same matrix $M$ of panel $a$ ), to which an additional column $\tau_{1}$ has been added; ordering the rows by fitness and the columns by complexity (right), we see that now $t_{2}$ is more complex than $t_{1}$ and $c_{2}$ has higher fitness than $c_{3}$. The figure shows that, in general, the addition (or subtraction) of columns to $\mathbf{M}(y)$ can potentially affect fitness and complexity rankings. 
Figure 3.1 depicts a toy example illustrating this point. The right part of panel (a) depicts a 3-by-3 matrix $\mathbf{M}$ with rows and columns sorted by fitness and complexity respectively. In particular, row $c_{1}$ has higher fitness than $c_{3}$, which in turn has higher fitness than $c_{2}$; columns instead can be ordered in decreasing order of complexity as follows: $t_{1}, t_{2}, t_{3}$. Panel (b) represents the same matrix to which one additional column $\tau_{1}$ was added. Ordering the rows and columns of the new matrix with the EFC algorithm, both the ranking of rows and columns changes. In particular, $c_{2}$ is now fitter than $c_{3}$ and $t_{2}$ is more complex than $t_{1}$.

This example indicates that applying sector fitness to technologies might yield biased results. However, two remarks mitigate this concern. First, while the figure shows that it is in general possible to alter the ranking by simply adding a column, we had to choose a rather extreme case to make the point. In fact, column $\tau_{1}$ is built in such a way to bring very close together the compositions of the most and least fit row of panel (a). However, this is quite unrealistic because it would be much harder to achieve if the matrix were substantially larger (as are the empirical matrices of the analysis). On the other hand, adding $\tau_{1}$ is akin to adding the information that a country the was thought to patent only in a very ubiquitous agricultural field and nothing else, also patents in ground breaking medical technologies. This however looks intuitively implausible and contrasts with the evidence shown e.g., in Figure 3.5.

Finally, it is worth noting that, although it is true that applying sector fitness to green technologies cuts some potentially relevant columns from $\mathbf{M}$, it is also the case that these omitted fields are not exclusively linked to green technologies, 
otherwise they would certainly be included in the classification. Hence, even if we were to include them, we would only account for them partially, and, since we know that they can potentially influence the fitness and complexity rankings, adding them to the analysis would not make us feel any safer about the eventual introduction of biases in the results of the analysis performed with the EFC algorithm. For this reason, we believe that omitting the columns that are not exclusively (or very predominantly) linked to green technologies should not be a major shortcoming.

\subsection{Results and Discussion}

\subsubsection{Green Fitness Ranking: Countries and Technologies}

Figure 3.2 shows the green fitness rankings of all countries across all four time windows. The higher the ranking the more complex the country's portfolio of green technologies and, thus, the more advanced the invention competences. We provide a synthetic sketch focus on how countries' innovation capacity evolves over time using colour coding to distinguish three groups depending on the initial ranking: leaders (black), followers (purple), and laggards (orange). To begin with, most of the countries that were leaders in 1980 are still in the top ranking in 2010. Even so, we observe some heterogeneity in their long-term paths. A first group of global leaders such as the United States (USA), France (FRA), Germany (DEU) (in black in Figure 3.2) maintained a steady high ranking throughout the period, while others - e.g., Japan (JPN), Sweden (SWE), India (IND)-remained mostly in the upper echelons, but also 
declined slightly and were caught up with in the ranking by some follower and laggard countries. Among these, it is worth mentioning some fast-growing countries, listed by increase in the green fitness ranking, such as Malaysia (MYS), South Korea (KOR), China (CHN), Slovakia (SVK), Portugal (PRT) and Saudi Arabia (SAU), confirming our intuition in section 2.4. These all started from mid-to bottom positions in 1980 and after an impressive, and steady, acceleration have reached the top part of the ranking. Notice that over time the geographical distribution of inventive activity spreads out, primarily towards Asia, while the presence of Latin American and African countries is only marginal. As regards Europe, the distinction between leaders and followers resonates with the differences between countries in the core and those in the periphery. Notice also that laggard countries exhibit similar stability to leaders, meaning that countries starting in such groups in the 1980 time window tend, with some notable exceptions, to remain in the same group throughout.

Figure 3.3 lists the Green Complexity of 2-digit environmental technologies in our database and the associated ranking. Again, the idea is that a higher complexity ranking indicates that a technology entails a more advanced array of capabilities. Compared to countries, green technologies exhibit more fluidity, at least in the bottom half of the list, as about half of them have at least one appearance in the top 10 (conversely, only 4 have been in the the top 5). Looking more in detail, three groups of green technologies emerge. The first cluster comprises technologies that consistently rank highest (black in Figure 3.3), namely 'Nuclear Energy' (4_4), 'Environmental Monitoring' (1_5), 'Enabling Technologies for GHG Emissions Mitigation' (8_3) and 'Enabling 


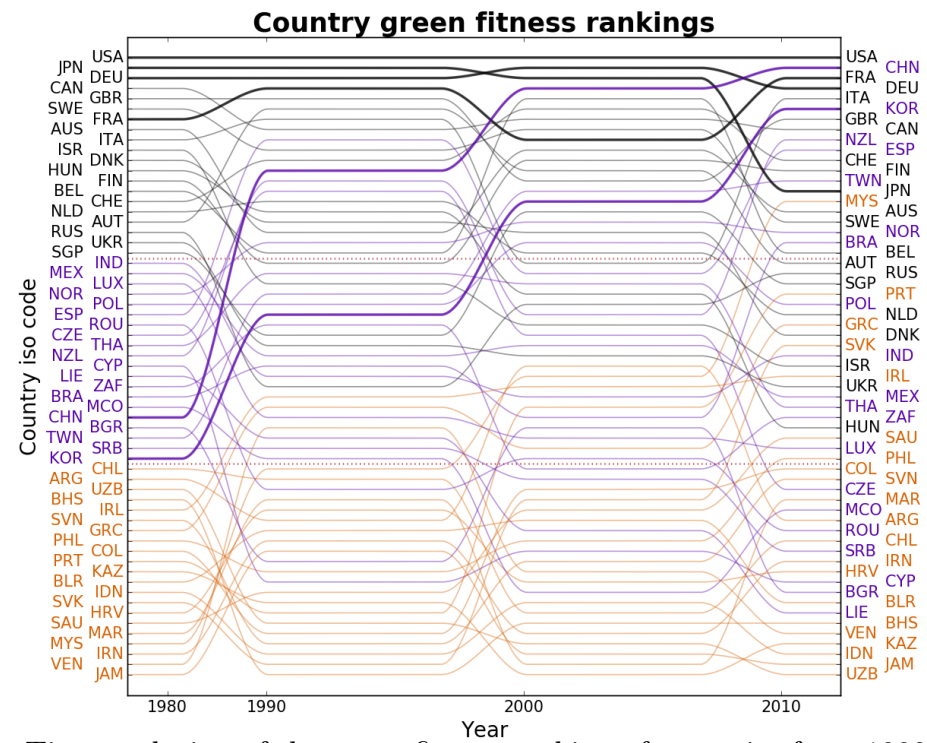

Figure 3.2: Time evolution of the green fitness ranking of countries from 1980 to 2010. The country labels on the left and right vertical axes are listed from bottom to top in order of increasing fitness in the first and last period of analysis respectively. The lines trace the changes in ranking of each country across decades. Label and line colours refer to the position of countries in the initial ranking: black, violet and purple are associated respectively to the top-, middle-, and bottom-third of the 1980 green fitness ranking. Colours are mixed in 2010, meaning that positions in the ranking have changed substantially for several countries (see e.g., the constant growth of China and South Korea highlighted by the thicker purple lines). The names of the countries associated to the abbreviations reported on the y-axis of the plot are reported in section 9.1 of Appendix. 
Technologies in Transport' (6_5) - in fact, each one of them has been top of the list in the period under analysis. In the second cluster (purple in Figure 3.3) are technologies that, while being consistently high ranking, have at least once slipped out of the top 10. Among these we observe a variety of patterns, some stable technologies - such as 'Capture or Disposal of Greenhouse Gases other than $\mathrm{CO}_{2}{ }^{\prime}\left(5 \_2\right)$ - some oscillating technologies — such as 'Technologies for Efficient Electrical Power Generation, Transmission or Distribution' (4_5), ' $\mathrm{CO}_{2}$ Capture or Storage' (5_1) or 'Air Transport' (6_3) - as well as steady growers -i.e., 'Road Transport' (6_1), 'Rail Transport' (6_2), 'Enabling Technologies' (4_6) — and steady decliners - like 'Technologies Relating to Chemical Industry' (9_2) and 'Climate Change Mitigation Technologies for Sector-Wide Applications' $\left(9 \_7\right.$ ). The third cluster (orange in Figure 3.3) contains technologies that have only been in the top 10 once, e.g., 'Water Pollution Abatement' (1_2) and 'Renewable Energy Generation' (4_1).

Again, a closer look indicates heterogeneity of patterns over time: the most notable are the ascent of 'Road Transport' (6_1) and 'Technologies in the Production Process for Final Industrial or Consumer Products' (9_6) in contrast with the decline of 'Soil Remediation' (1_4) and 'Architectural or Constructional Elements Improving the Thermal Performance of Buildings' (7_3). An interesting indication is that Mitigation technologies rank in general higher than Adaptation. Another notable feature is that almost all Enabling Environmental Technologies - that is, horizontal technologies with potential applicability in a variety of fields - feature high in the ranking, thus reaffirming the complex 


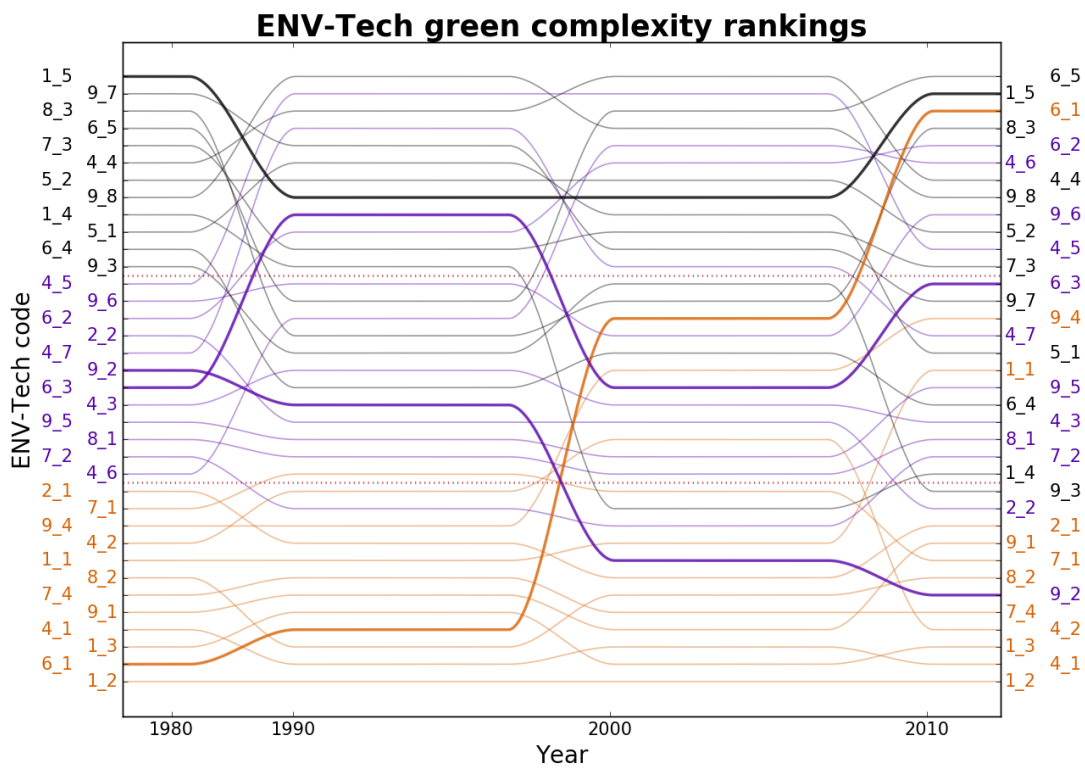

Figure 3.3: Time evolution of green complexity ranking of ENV-TECH technologies from 1980 to 2010. The technology labels on the left and right vertical axes are listed from bottom to top in order of increasing complexity in the first and last period of analysis respectively. The lines trace the changes in ranking of each technology across decades. Label and line colours refer to the position of technologies in the initial ranking: black, violet and purple are associated respectively to the top-, middle-, and bottom-third of the 1980 green complexity ranking. Colours are mixed in 2010, meaning that positions in the ranking have changed substantially for several technologies. For instance, notice the constant growth of the ENV-Tech technology 'Road Transport' (6_1), and the steady decline of the ENV-TECH technology 'Technologies Relating to Chemical Industry' (9_2), highlighted respectively by a thicker orange and purple line. The definitions of the technological codes associated to the abbreviations reported on the y-axis of the plot are reported in table 2.1 of chapter 2 . 
nature of the underlying capabilities that are needed for their design and creation.

\subsubsection{The Most Complex Green Technologies and the Main Innovators}

Let us now juxtapose the information gathered so far and look into combined country-green technology patterns. In Figure 3.4 we plot the green fitness based on the country-green technology matrices $\mathbf{M}(y, 10)$ against per capita $G D P(y)$, for $y \in[1980,2010]$. By pooling all countries and years in our database, we estimate the expected value of green fitness through a non-parametric NadarayaWatson estimation with a Gaussian kernel Nadaraya, 1964. The corresponding $95 \%$ confidence interval is computed with a bootstrap resampling. Figure 3.4 provides a generalization of what has emerged so far, namely that there is a positive relationship between average GDP per capita and our measure of green fitness. We opt for GDP as a proxy of living standards in a country for two reasons. The first is that GDP is a gold standard which helps us ground our exploratory study on green innovation better within the existing literature, primarily prior studies that use EFC approach on trade. For all the known limitations that GDP carries it remains the most widely used measure. The second reason is that when we contemplated the Human Development Index $(\mathrm{HDI})^{2}$ as an alternative (and more comprehensive) measure, we found a strong correlation with GDP and, thus, that findings were substantially unaltered.

\footnotetext{
${ }^{2}$ The HDI is a composite statistics developed within the United Nations Development Program to account for the intersection of three dimensions of a country well-being: health (proxied by life expectancy), education (mean years of schooling), and per capita income.
} 


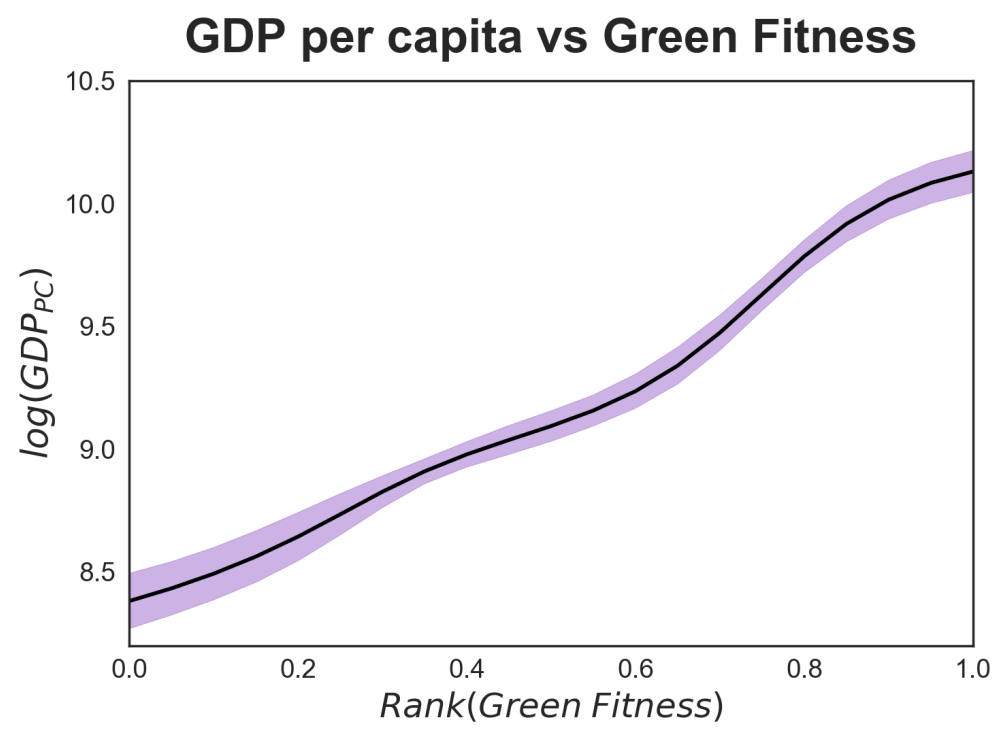

Figure 3.4: Correlation between green fitness ranking and per capita GDP over the time interval 1980-2010. Green fitness, as a proxy for the green innovative capacity of countries, is positively correlated with income per capita. The figure is obtained by pooling countries and years in our database. The expected value of green fitness is obtained through a nonparametric kernel estimation (purple line), while the $95 \%$ confidence interval of the expected value (purple shadow) is computed with bootstrap. 
Shares of technologies in country portfolios

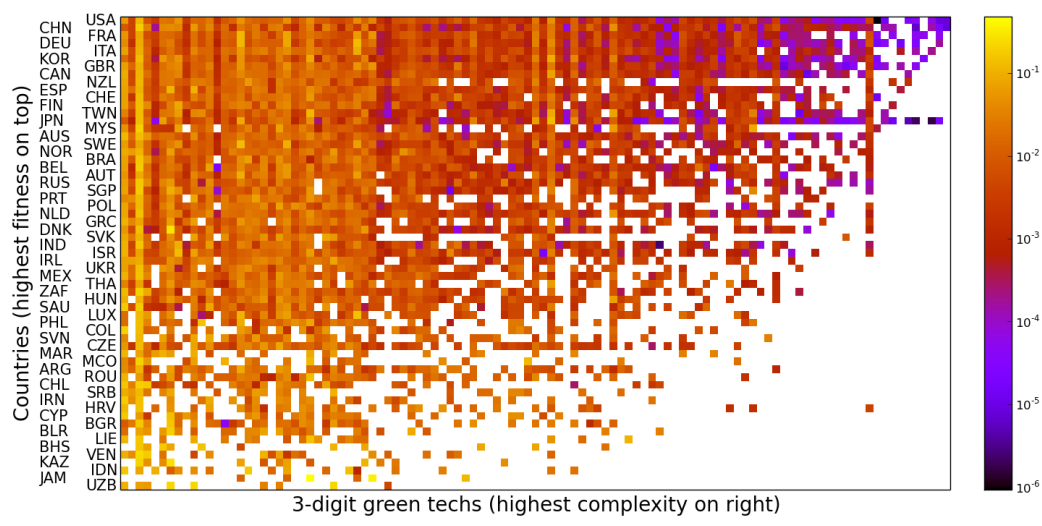

Figure 3.5: 3-digit $\mathbf{M}(2010,10)$ with rows and columns ordered by green fitness and green complexity respectively. Colour represents the share of each technology within the technology basket of each country. The matrix shows a semi-triangular shape, accordingly to the EFC narrative, the highest green fitness countries are competitive in almost all technologies, from the most to the least complex, while the basket of technologies of lower fitness countries is limited to less complex technologies.

In turn, the triangular shape of the country-technology matrix of Figure 3.5 indicates that countries with higher levels of GDP per capita possess, as several scholars advocate, more developed capabilities that allow them to be major producers of more complex green technologies. By the same token, inventive efforts in poorer countries are limited to less complex technologies as a reflection of overall lower capabilities. These two snapshots confirm that the distribution of inventive capacity in green technology is broadly in line with prior literature (Tacchella, Cristelli, et al., 2012; Pugliese, Chiarotti, et al., 2017; Sbardella, Pugliese, and Pietronero, 2017).

Looking more in detail, Table 3.1 shows the ten most complex green technologies over the entire time period of the analysis (1971-2010) and, for each 
one, it lists the top five inventor countries, the share in total world green innovation and the corresponding RCA index. A few features emerge from this table. First, eight out of ten of the most complex technologies are for Climate Change Mitigation - the only two exceptions being GHG Capture and Storage, and Environmental Management. Second, in the upper part of the list are three types of enabling technologies, which indicates that the most advanced inventive efforts are currently devoted to perfecting existing technologies for wide, cross-sectoral purposes. Third, and related to the former, the list provides a balanced mix between mature technologies (i.e., enabling or nuclear energy) and very experimental ones (i.e., carbon capture, superconducting elements for efficient energy distribution). Fourth, the table also portrays a balanced picture as the key environmental priorities encompass areas like transport, waste, industrial production, energy and buildings. Fifth, as already anticipated earlier, the leading producers are all high-income countries. Another notable feature is the recurrence of Asian catching-up countries in various domains. South Korea ranks high in all but two (i.e., environmental management and rail transport) as a reflection of the environmental challenges due to a wide industrial mix (e.g., (Oh, Wehrmeyer, and Mulugetta, 2010)). China excels in waste management, rail transport, industrial production and energy, a profile that resonates with the heterogeneity of emission sources due to remarkable regional and sectoral differences (Liu et al., 2012). Conversely, Taiwan only appears in waste management, plausibly as a result of targeted policy efforts (e.g., (Yang and Innes, 2007)). Table 3.2 reports the same information as Table 3.1 , but for the lower-complexity technologies. Unsurprisingly, also in this case the top 5 innovators per technology are high-fitness countries, which consistently 
with the triangular structure of Figure 3.5, have the necessary capabilities to excel across the spectrum, while low-fitness countries perform relatively well only in mundane technologies.

Figure 3.6 focuses on a sample of top countries as of 2010 and shows that there is heterogeneity in the composition of the portfolios of such top innovators. Therein each panel contains the shares of patenting in all green technologies (ordered by increasing green complexity from left to right) in the first and final decade. For instance, Japan is relatively focused on the the most complex technologies. This contrasts with the country profiles of, say, the US or France which instead have a more balanced portfolio of green innovation across the complexity spectrum. The above is informative of the differential contribution of countries to the advancement of the green technology frontier. Moreover, this broad and long-term view allows us to discern countries that have been leaders since the beginning of the period, such as Japan, the US, France and Germany, from the latecomers like China and South Korea, which indeed only started to patent in the 1990s. The distribution of the patenting shares for each country-decade panel reveals the direction of inventive efforts. For instance, in the last decade Japan (Panel A of Figure 3.6) stands out as rather proactive in complex technologies with high and low complexity, rather than those in the middle. By contrast, the relative contribution of the US (Panel B of Figure 3.6) has decreased after the 1990s, due to the entry of other actors. In relative terms, and compared to Japan, the distribution of US shares in green technology is higher in technologies with middle levels of complexity. The relative shares of 


\begin{tabular}{|c|c|c|c|c|}
\hline Technology Family & Technology Group & $\begin{array}{lll}\text { Top } & 5 & \text { Innova- } \\
\text { tors } & & \\
\end{array}$ & Share & RCA \\
\hline \multirow{5}{*}{ CCMT for transportation } & \multirow{5}{*}{$\begin{array}{l}\text { Enabling Technologies } 6.5 \text { (example: } \\
\text { Electric vehicle charging) }\end{array}$} & JPN & 0.441 & 1.126 \\
\hline & & USA & 0.196 & 1.100 \\
\hline & & $\mathrm{DEU}$ & 0.172 & 1.543 \\
\hline & & FRA & 0.054 & 1.394 \\
\hline & & KOR & 0.049 & 0.676 \\
\hline \multirow{5}{*}{ Environmental management } & \multirow{5}{*}{$\begin{array}{l}\text { Environmental Monitoring } 1.5 \text { (ex- } \\
\text { ample: Tools for environmental data } \\
\text { analysis) }\end{array}$} & JPN & 0.279 & 0.713 \\
\hline & & DEU & 0.267 & 2.400 \\
\hline & & USA & 0.243 & 1.366 \\
\hline & & FRA & 0.104 & 2.706 \\
\hline & & SWE & 0.020 & 3.700 \\
\hline \multirow{5}{*}{$\begin{array}{l}\text { CCMT for wastewater treat- } \\
\text { ment or waste management }\end{array}$} & \multirow{5}{*}{$\begin{array}{l}\text { Enabling Technologies } 8.3 \text { (example: } \\
\text { Landfilling with gas recovery) }\end{array}$} & JPN & 0.522 & 1.333 \\
\hline & & USA & 0.177 & 0.991 \\
\hline & & $\mathrm{CHN}$ & 0.082 & 1.039 \\
\hline & & KOR & 0.066 & 0.901 \\
\hline & & TWN & 0.037 & 1.980 \\
\hline \multirow{5}{*}{ CCMT for transportation } & \multirow{5}{*}{$\begin{array}{l}\text { Rail Transport } 6.2 \text { (example: Re- } \\
\text { ducing energy consumption) }\end{array}$} & JPN & 0.461 & 1.176 \\
\hline & & DEU & 0.129 & 0.725 \\
\hline & & USA & 0.112 & 1.420 \\
\hline & & FRA & 0.094 & 0.847 \\
\hline & & KOR & 0.056 & 1.464 \\
\hline \multirow{5}{*}{$\begin{array}{l}\text { Capture, storage, sequestra- } \\
\text { tion, or disposal of GHGs }\end{array}$} & \multirow{5}{*}{$\begin{array}{l}\text { Capture or Disposal of Gases other } \\
\text { than } \mathrm{CO}_{2} 5.2 \text { (example: Chemical } \\
\text { nitrification inhibitors) }\end{array}$} & JPN & 0.430 & 1.098 \\
\hline & & USA & 0.238 & 1.333 \\
\hline & & DEU & 0.080 & 0.720 \\
\hline & & KOR & 0.049 & 0.669 \\
\hline & & FRA & 0.041 & 1.068 \\
\hline \multirow{5}{*}{$\begin{array}{l}\text { CCMT for production or pro- } \\
\text { cessing of goods }\end{array}$} & \multirow{5}{*}{$\begin{array}{l}\text { Enabling Technologies } 9.8 \text { (example: } \\
\text { Direct digital manufacturing) }\end{array}$} & JPN & 0.492 & 1.254 \\
\hline & & USA & 0.165 & 0.927 \\
\hline & & $\mathrm{CHN}$ & 0.124 & 1.585 \\
\hline & & DEU & 0.088 & 0.789 \\
\hline & & KOR & 0.033 & 0.458 \\
\hline \multirow{5}{*}{$\begin{array}{l}\text { CCMT for energy generation, } \\
\text { transmission or distribution }\end{array}$} & \multirow{5}{*}{$\begin{array}{l}\text { Nuclear Energy } 4.4 \text { (example: Nu- } \\
\text { clear fusion reactors) }\end{array}$} & $\mathrm{JPN}$ & 0.501 & 1.277 \\
\hline & & USA & 0.163 & 0.915 \\
\hline & & KOR & 0.135 & 1.853 \\
\hline & & FRA & 0.053 & 1.373 \\
\hline & & DEU & 0.047 & 0.424 \\
\hline \multirow{5}{*}{$\begin{array}{l}\text { CCMT for energy generation, } \\
\text { transmission or distribution }\end{array}$} & \multirow{5}{*}{$\begin{array}{l}\text { Technologies for Efficient Electri- } \\
\text { cal Power Generation, Transmission } \\
\text { or Distribution } 4.5 \text { (example: Su- } \\
\text { perconducting electric elements or } \\
\text { equipment) }\end{array}$} & JPN & 0.384 & 0.979 \\
\hline & & $\mathrm{CHN}$ & 0.228 & 2.901 \\
\hline & & USA & 0.120 & 0.671 \\
\hline & & KOR & 0.076 & 1.048 \\
\hline & & $\mathrm{DEU}$ & 0.073 & 0.657 \\
\hline \multirow{5}{*}{ CCMT for transportation } & \multirow{5}{*}{$\begin{array}{l}\text { Road Transport (example: Hybrid } \\
\text { vehicles) }\end{array}$} & JPN & 0.548 & 1.397 \\
\hline & & DEU & 0.145 & 1.307 \\
\hline & & USA & 0.124 & 0.696 \\
\hline & & FRA & 0.049 & 1.284 \\
\hline & & $\mathrm{KOR}$ & 0.048 & 0.662 \\
\hline \multirow{5}{*}{ CCMT for buildings } & \multirow{5}{*}{$\begin{array}{l}\text { Architectural or Constructional El- } \\
\text { ements Improving Thermal Perfor- } \\
\text { mance } 7.3 \text { (example: Retrofit insu- } \\
\text { lation) }\end{array}$} & JPN & 0.437 & 1.114 \\
\hline & & DEU & 0.124 & 1.117 \\
\hline & & USA & 0.104 & 0.582 \\
\hline & & $\mathrm{CHN}$ & 0.098 & 1.242 \\
\hline & & KOR & 0.088 & 1.207 \\
\hline
\end{tabular}

Table 3.1: Top innovators in the most complex green technologies. 


\begin{tabular}{|c|c|c|c|c|}
\hline Technology Family & Technology Group & Top 5 Innovators & Share & RCA \\
\hline \multirow{5}{*}{ Environmental Management } & \multirow{5}{*}{$\begin{array}{l}\text { Water Pollution Abatement } 1.2 \text { (ex- } \\
\text { ample: Oil spill cleanup) }\end{array}$} & USA & 0.338 & 1.899 \\
\hline & & DEU & 0.1340 & 1.255 \\
\hline & & JPN & 0.110 & 0.281 \\
\hline & & FRA & 0.065 & 1.681 \\
\hline & & KOR & 0.038 & 0.526 \\
\hline \multirow{5}{*}{$\begin{array}{l}\text { CCMT related to energy gen- } \\
\text { eration, transmission or dis- } \\
\text { tribution }\end{array}$} & \multirow{5}{*}{$\begin{array}{l}\text { Renewable Energy Generation } 4.1 \\
\text { (example: Wind energy) }\end{array}$} & JPN & 0.278 & 0.707 \\
\hline & & USA & 0.168 & 0.944 \\
\hline & & $\mathrm{CHN}$ & 0.127 & 1.616 \\
\hline & & KOR & 0.111 & 1.524 \\
\hline & & DEU & 0.102 & 0.920 \\
\hline \multirow{5}{*}{ Environmental Management } & \multirow{5}{*}{$\begin{array}{l}\text { Waste Management } 1.3 \text { (example: } \\
\text { Material recycling) }\end{array}$} & USA & 0.281 & 1.58 \\
\hline & & JPN & 0.132 & 0.339 \\
\hline & & DEU & 0.122 & 1.110 \\
\hline & & FRA & 0.081 & 2.098 \\
\hline & & ITA & 0.050 & 4.199 \\
\hline \multirow{5}{*}{ CCMT for buildings } & \multirow{5}{*}{$\begin{array}{l}\text { Energy Efficiency in Buildings } 7.2 \\
\text { (example: Lighting) }\end{array}$} & JPN & 0.303 & 0.773 \\
\hline & & USA & 0.213 & 1.197 \\
\hline & & $\mathrm{CHN}$ & 0.132 & 1.683 \\
\hline & & KOR & 0.121 & 1.661 \\
\hline & & $\mathrm{DEU}$ & 0.055 & 0.497 \\
\hline \multirow{5}{*}{ CCMT for buildings } & \multirow{5}{*}{$\begin{array}{l}\text { Enabling Technologies in Buildings } \\
7.4 \text { (example: Enabling technologies } \\
\text { or technologies with a potential or } \\
\text { indirect contribution to GHG emis- } \\
\text { sions mitigation) }\end{array}$} & JPN & 0.418 & 1.066 \\
\hline & & USA & 0.162 & 0.911 \\
\hline & & $\mathrm{CHN}$ & 0.116 & 1.472 \\
\hline & & KOR & 0.079 & 1.080 \\
\hline & & $\mathrm{DEU}$ & 0.077 & 0.696 \\
\hline \multirow{5}{*}{$\begin{array}{l}\text { CCMT in the production or } \\
\text { processing of goods }\end{array}$} & \multirow{5}{*}{$\begin{array}{l}\text { Technologies Related to Metal Pro- } \\
\text { cessing } 9.1 \text { (example: Reduction of } \\
\text { greenhouse gas [GHG] emissions) }\end{array}$} & JPN & 0.412 & 1.052 \\
\hline & & $\mathrm{CHN}$ & 0.166 & 2.119 \\
\hline & & USA & 0.096 & 0.542 \\
\hline & & DEU & 0.084 & 0.754 \\
\hline & & KOR & 0.063 & 0.866 \\
\hline \multirow{5}{*}{$\begin{array}{l}\text { CCMT for energy generation, } \\
\text { transmission or distribution }\end{array}$} & \multirow{5}{*}{$\begin{array}{l}\text { Energy Generation from Fuels of } \\
\text { Non-Fossil Origin } 4.2 \text { (example: Bio- } \\
\text { fuels) }\end{array}$} & JPN & 0.279 & 0.7111 \\
\hline & & USA & 0.245 & 1.378 \\
\hline & & $\mathrm{CHN}$ & 0.120 & 1.526 \\
\hline & & DEU & 0.086 & 0.777 \\
\hline & & KOR & 0.059 & 0.815 \\
\hline \multirow{5}{*}{$\begin{array}{l}\text { CCMT in the production or } \\
\text { processing of goods }\end{array}$} & \multirow{5}{*}{$\begin{array}{l}\text { Technologies Relating to Chemical } \\
\text { Industry } 9.2 \text { (example: Improve- } \\
\text { ments relating to chlorine produc- } \\
\text { tion) }\end{array}$} & JPN & 0.313 & 0.797 \\
\hline & & USA & 0.233 & 1.306 \\
\hline & & $\mathrm{CHN}$ & 0.123 & 1.572 \\
\hline & & DEU & 0.086 & 0.774 \\
\hline & & KOR & 0.0515 & 0.707 \\
\hline \multirow{5}{*}{$\begin{array}{l}\text { CCMT for wastewater treat- } \\
\text { ment or waste management }\end{array}$} & \multirow{5}{*}{$\begin{array}{l}\text { Solid Waste Management } 8.2(\mathrm{ex}- \\
\text { ample: Waste collection, transporta- } \\
\text { tion, transfer or storage) }\end{array}$} & JPN & 0.439 & 1.121 \\
\hline & & $\mathrm{CHN}$ & 0.125 & 1.593 \\
\hline & & USA & 0.108 & 0.604 \\
\hline & & KOR & 0.104 & 1.434 \\
\hline & & $\mathrm{DEU}$ & 0.055 & 0.499 \\
\hline \multirow{5}{*}{$\begin{array}{l}\text { CCMT for energy generation, } \\
\text { transmission or distribution }\end{array}$} & \multirow{5}{*}{$\begin{array}{l}\text { Enabling Technologies } 4.6 \text { (example: } \\
\text { Energy storage) }\end{array}$} & JPN & 0.614 & 1.566 \\
\hline & & USA & 0.113 & 0.635 \\
\hline & & KOR & 0.089 & 1.219 \\
\hline & & DEU & 0.058 & 0.520 \\
\hline & & $\mathrm{CHN}$ & 0.045 & 0.579 \\
\hline
\end{tabular}

Table 3.2: Top innovators in the least complex green technologies. 
a) - JPN

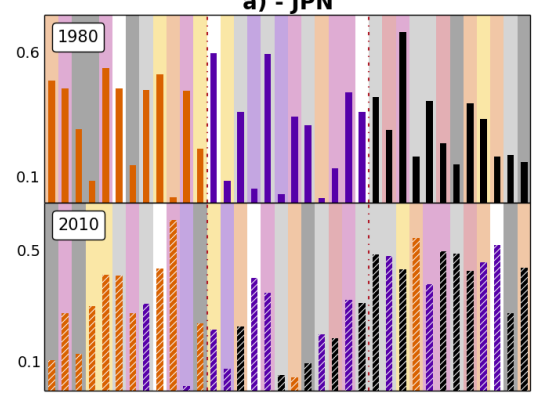

c) - DEU

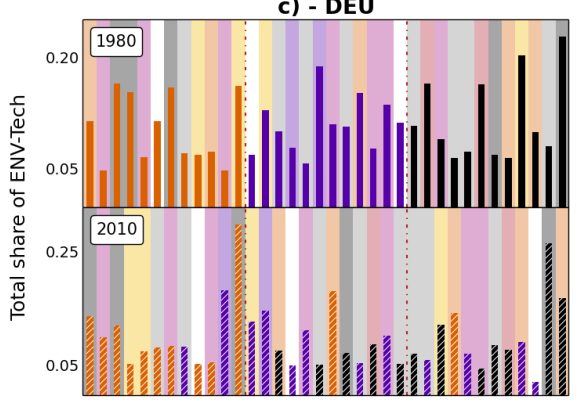

e) - CHN

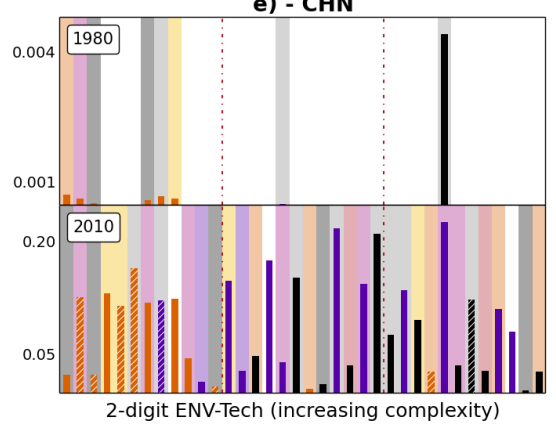

b) - USA

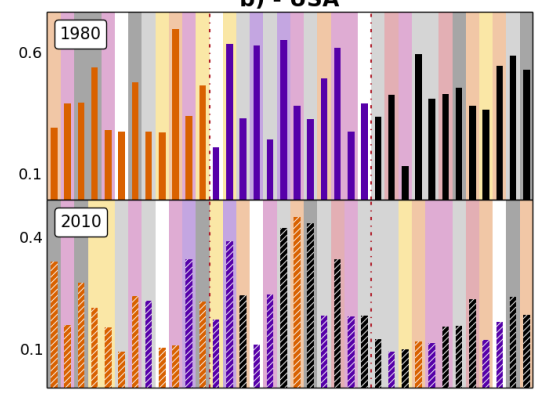

d) - FRA

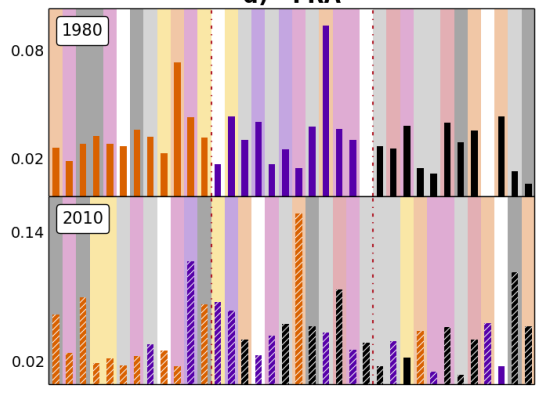

f) - KOR

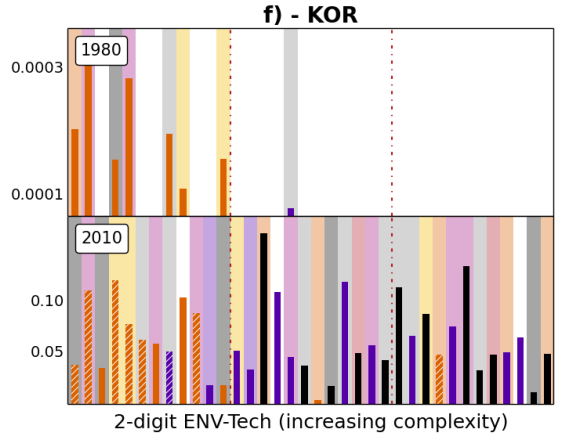

$\square$ 1_* $\square$ 2_* $\square$ 4_* $\square$ 5_* $\square$ 6_* $\square$ 7_* $\square$ 8_* $\square$ 9_*

Figure 3.6: Composition of national green technology baskets. Each panel illustrates the share of patents produced by a selection of countries in each 2-digit technological field in 1980 (upper part) and 2010 (bottom). Technologies are ordered by increasing complexity. The colour of the bars indicates the ranking of each technology in 1980, while the background colour stands for the 1-digit technology to which each bar belongs (see list on p. 3). The hatched pattern is for technologies that are observed in both time windows. 
Germany and France (Panels C and D of Figure 3.6) are somewhat constant over time and spread evenly across the whole technological spectrum. Interestingly, newcomers like China and South Korea (Panels E and F of Figure 3.6) join the global path of green technology innovation with contributions to both less and more complex technologies.

\subsubsection{How Does Green Innovation Capacity Vary with Income and Trade?}

Coherent with the argument that the accumulation of competences is a vehicle for fostering growth (Nelson and Phelps, 1966), Figure 3.4 in the previous subsection hints at a strong positive correlation between green innovation and per capita income. At the same time, Figure 3.2 highlights a divide between mid-ranking countries, whereby some manage to climb up the green technology complexity ladder (i.e., China and South Korea) while others do not (i.e., Argentina, Bulgaria). No doubt, the structural characteristics of a country play a fundamental role in unleashing the innovation potential, and in this part of the chapter we investigate some of these characteristics and the extent of their impulse. Given the exploratory nature of our analysis, in Figure 3.7 we focus on GDP per capita (as a proxy of standards of living and economic growth potential in each country) and export fitness (as a proxy of the trade performance of each country) ${ }^{3}$.

\footnotetext{
${ }^{3}$ This is the sum of the complexities of the products exported by each country Tacchella, Cristelli, et al., 2012. The economic fitness measure based on export data from the UN-COMTRADE database (available online at http://comtrade.un.org) is available for the period 1995-2015 at https: //datacatalog.worldbank.org/dataset/economic-fitness (accessed in January 2017). However, in the present chapter we employ the most recent version of the export fitness database, provided to us by the PIL group of the Institute of Complex Systems-CNR in Rome.
} 


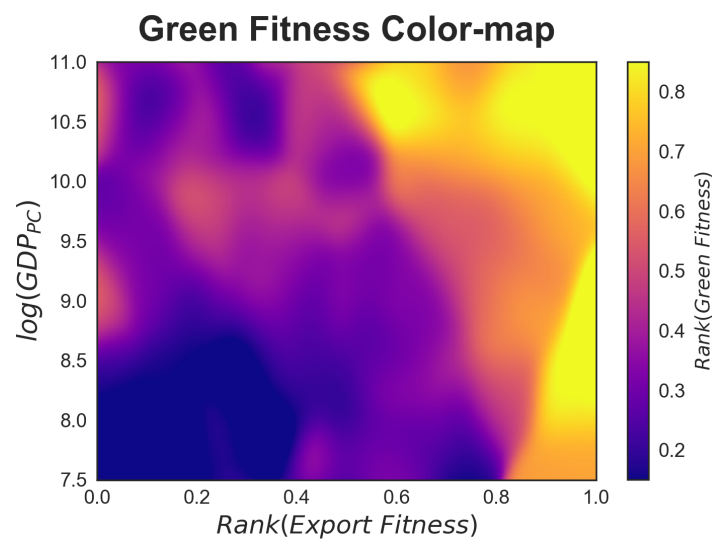

Figure 3.7: The three-dimensional relation between export fitness, GDP per capita, and green fitness. The colour map represents the variation of green fitness obtained with a non-parametric Nadaraya-Watson kernel estimation by pooling all countries in our database over the time interval 1980-2010.

We propose a graphical analysis based on a colour map which portrays the relation between GDP per capita and export fitness on the $x-y$ axes, and the entire range of green technological fitness for all the countries in our database on the $z$-axis, represented with colour variation. In this case, as for Figure 3.4, green fitness is computed for each year as a moving average over a $\delta=10$. The colour map is obtained through a 3-dimensional Nadaraya-Watson nonparametric estimation (Nadaraya, 1964) fed with a pooling of all countries in our database over the period 1980-2010.

The areas of Figure 3.7 with higher intensity are those of greater interest. The purple-coloured portion at the bottom left-hand of the graph indicates that, as expected, countries with low GDP and low export fitness exhibit the lowest green technology fitness; also expected is the growth of green fitness as one moves towards the top right corner of the plot. 
Another interesting portion of this diagram is on the right-hand side, where intermediate levels of (log) GDP per capita (between 8 and 9.5) and very high export fitness correspond to very high levels of green fitness. This indicates that a highly diversified portfolio of trade matters for unleashing innovation capacity among both high- and mid-level income countries. Put otherwise, a country's level of wealth is not a barrier to developing advanced competences for environmental innovation insofar as they engage trade of more complex products. The diagonal movement of colour is in agreement with the EFC narrative according to which countries with higher export fitness than per capita GDP show a level of complexity that has not yet translated into higher income, but indicates higher development and growth potential (Pugliese, Chiarotti, et al., 2017). This finding resonates with the descriptive analysis of the rankings in the previous subsections, where the performance of emerging countries in green innovation has been commented on. It also resonates with the recombinant nature of the technology at hand, and the fact that green patents exhibit more diversity of technical components and of know-how relative to non-green ones (Barbieri, Marzucchi, and Rizzo, 2018). Openness to trade and strategic specialization in key components for green technologies are thus likely to enable middle-income countries to accelerate in the pursuit of environmental innovation. This is especially true if we consider the high levels of fitness of enabling technologies that bring together different pools of know-how into coherent solutions for wide applicability. 


\subsection{Conclusions}

The main questions addressed in this chapter are: which countries innovate the most? What are the most complex green technologies? What is the relationship between economic development and specialisation in environmental technologies?

First, we provide an overview of spatial and temporal characteristics of green innovation by exploiting the geo-localisation of patent data. Second, we move beyond aggregate trends and delve into the relative performance of each country in relation to the complexity of the technology. This allows us to identify three typologies of countries: leaders, followers, and laggards. As expected, there is a direct relationship between GDP per capita and innovation capacity. That said, we also observe the growing relevance of countries that started from behind but that managed to become prominent actors. Most of these are based in East Asia. Third, we complement previous studies on green technology with a deeper understanding of how innovation capacity is distributed across areas of specialisation. The fitness ranking approach reveals that, after a period of deeper specialisation within diverse domains, innovation in green technology has become more horizontal, with bigger efforts being observed in cross-domain, or enabling, technologies. This trend seems to indicate that while the relative stage of development of individual areas - such as renewable energy generation or waste management-may have peaked in terms of technology life cycle, there is now demand for greater interoperability across green technologies - the integration of Information and Communication Technologies for monitoring 
energy distribution. Such findings leads us to develop in the next chapter a methodology to measure life cycle stages, to deeply analyse the determinants of specialization and diversification of countries in green technologies throughout their life cycle. 



\section{Chapter 4}

\section{The life cycle of technologies}

\subsection{Introduction}

The exploratory analysis of chapter 3 shows that green technologies are not a homogeneous body, but that some are more complex than others. Furthermore, their ranking is not static over time: technologies composing the first and the second cluster at the beginning of the period change position but mainly stay in the top 2 clusters, while technologies among the third cluster in 1970 mainly remain in the third cluster in 2010.

The fitness methodology employed in the previous chapter is an analysis of a bipartite network composed by countries and green technologies. Therein 
the technology's positions in the ranking represent to a certain degree their geographical diffusion and patenting activity. But this ranking does not provide detailed information about the inner composition of technologies. Are these technologies always based on the same components or is there a change in the relevant knowledge base over time? Moreover, we could expect that only a stabilisation of the knowledge base will be associated with a growth in patenting activity and probably a wider geographical diffusion (William J Abernathy and J. M. Utterback, 1978).

Like industries or products, technology evolves along a S-shaped (or double-Sshaped) life cycle moving from a period of introduction to growth, maturity and decline (Achilladelis, Schwarzkopf, and Cines, 1990; Achilladelis, 1993; Andersen, 1999; Haupt, Kloyer, and Lange, 2007). In the introduction phase different pieces of knowledge are recombined to obtain a new technology that differs from what has been developed before. In this phase, a small number of firms are involved in the experimentation and aim at solving the technological problems that characterise this activity. The technology that emerges in this phase is often associated with high production costs, low penetration in the market and uncertainty in the potential use of the technology itself (Callon, 1998). In the growth phase the lower uncertainty that surrounds the new technology triggers a phase of development in which $\mathrm{R} \& \mathrm{D}$ risk decreases, innovation is less radical and the number of innovators increases (Haupt, Kloyer, and Lange, 2007). Finally, when a dominant design is reached the technology enters a maturity phase that is mainly characterised by incremental innovation, high standardisation and widespread diffusion. 
There is no consensus in the literature about the assessment of the stage of technologies development through patent data. Haupt, Kloyer, and Lange (2007) rely on patent indicators and empirically test their difference along the technology life cycle stages. Although they do not directly use patent indicators to detect the stage of development of technologies, the authors show that these indicators follow specific patterns depending on the stage of development of the technology - whose life cycle stages are defined a priori by a pool of experts and literature review.

Other studies directly employ patent indicators to identify the life cycle stages of technologies (Gao et al., 2013; Chang and Fan, 2016). These works define life cycle stages of a benchmark technology through expert interviews and assess the trends of patent indicators over its technological evolution. Subsequently, they compare patent indicators of the technologies under analysis with the ones calculated on the benchmark technology assigning the life cycle stage of the latter to the former. Finally, stochastic techniques are also employed to measure technology life cycle. Lee et al. $(2012 ; 2016)$ run Hidden Markov Models to analyse patent indicators time-series. This technique allows calculating the highest probability path that gives the most probable stage of development at each step of the time series.

We cannot apply here these methodologies because they rely on benchmark technologies from which the life cycle stages are derived, or focus just on the number of patents as in the case of Hidden Markov Models. In fact, we study here a broad number of heterogeneous environmental-related technologies for which a benchmark technology is hard to identify - even with the contribution 
of a pool of experts. In addition, we acknowledge that the stage of development of green technologies should take into account how technologies diffuse over time and not just the intensity of patenting. Moreover, it should also take into account that not all intermediate stages are achieved by technologies. Finally, our desired indicator should be able to provide information on the life cycle stage of broad technological domains not just single patents.

After reviewing the relevant literature in section 4.2, we will present a novel approach in section 4.3 using a network analysis to describe the knowledge base evolution and the co-occurrence with a variation in the patenting rate. Then, in section 4.4, we add to patenting activity a geographical component to propose a measure of the life cycle stages.

\subsection{Industry life cycle and agglomeration economies}

In economic geography, two complementary pathways are usually seen as triggers for regional development. One dates back to Marshall's (1920) idea of interaction and proximity of goals and of competences, whereas the other stems out the work of Jane Jacobs (1969) and thrives on the diversity of competences of the local economy. (Glaeser et al., 1992) have further extended this framework emphasising the importance of diversification for urban growth. The question of whether industries benefit in different ways from agglomeration externalities depending on their stage of maturity has been recently explored from both empirical and theoretical perspectives. The life cycle heuristic has been a staple of scholarly research on the opportunities and the challenges 
associated with innovation. Empirical evidence both from regional economics (R. D. Norton, 1979; R. Norton and Rees, 1979; Markusen and Svensson, 1985) and industrial dynamics (e.g. Gort and S. Klepper, 1982; William J. Abernathy and Clark, 1985; David B. Audretsch and Maryann P. Feldman, 1996; S. Klepper, 1996; Klepper and Steven, 1997; Agarwal and Gort, 2002) supports the conjecture that emerging industries grow at a faster pace than those locked into old, mature industries ${ }^{1}$. Duranton and Puga (2001) elaborate a conceptual framework that explains how diversification and specialisation favour, respectively, young and mature industries. At the beginning of the life cycle young firms need experimentation of their new products or prototypes. Diversified local environments act as the seedbed for alternative production processes that can be tried, adopted or discarded by firms. However, when firms reach maturity and need to switch to mass production, specialised cities are more suitable due to lower production costs. These findings are confirmed by empirical studies that have investigated the association between agglomeration economies and industry life cycle. Neffke, Henning, and R. Boschma (2011) confirm Henderson et al.'s (1995) insights showing that Marshallian specialisation externalities exert a positive impact as long as maturity is reached. On the contrary, young industries benefit from local diversity that becomes even negative for mature ones (Neffke, Henning, R. Boschma, et al., 2011).

The process that links together agglomeration externalities and industry growth along the life cycle has been studied in depth in a strand of economic geography

\footnotetext{
${ }^{1}$ For instance, R. Norton and Rees (1979) find that the decline of the US Manufacturing Belt during the late sixties was essentially a core-periphery realignment, which has theoretical roots in the product life cycle framework. The decentralisation of production to peripheral Southern and Western states followed the dispersion of innovative capacity and the rise of new, high-tech sectors at the beginning of the life cycle.
} 
that places diversification at the heart of the innovation process. In particular, diversification leads to regional growth due to the knowledge spillovers and learning opportunities that urban diversity brings about (Glaeser et al., 1992; Duranton and Puga, 2001; Frenken and Ron A Boschma, 2007). In turn, empirical evidence confirms that Jacobs externalities are associated with the adoption of new production processes or the development of new product, whereas Marshall externalities are often perceived as detrimental (Harrison, Kelley, and Gant, 1996; Kelley and Helper, 1999; Maryann P Feldman and David B Audretsch, 1999; Carolina Castaldi, Frenken, and Los, 2015). The theoretical explanation of the positive relationship between diversification of the regional structure and the generation of innovation can be found in the recombinant innovation theory (Schumpeter, 1939; R. Nelson and Winter, 1982; Weitzman, 1998; Fleming, 2001). Therein, the higher the availability of pieces of knowledge the higher the likelihood of successfully recombining knowledge in an original manner that leads to innovation.

In this context, local search and bounded rationality are important dimensions (March and Simon, 1958; R. Nelson and Winter, 1982), so innovators tend to recombine bits of knowledge they are familiar with in order to decrease the risk of failure. In so doing, however, they reduce the chances of developing radical innovation. On the contrary, when innovators recombine cognitive distant bits of knowledge they face higher uncertainty but, if successful, the resulting innovative output exerts higher impacts. The recent evolutionary turn in economic geography builds on tenet that Jacobs externalities do not merely lead to a more efficient division of labour within regions. Rather, in a diversified 
environment the opportunities for innovation increase due to the availability of different types of knowledge that is geographically close and can be recombined. Along these lines, Frenken and Ron A Boschma (2007) moved the debate on agglomeration economies further by acknowledging that diversification per se does not fully capture the mechanism that brings about regional economic growth. The flow of knowledge within regions requires a balance of cognitive distance to avoid lock-ins and of cognitive proximity to enable effective learning (Nooteboom, 2002; R. Boschma and Iammarino, 2009).

The notion of related (unrelated) variety has been put forth to explain how agglomeration externalities lead to regional growth. Related industries share some cognitive structures that enhance learning opportunities and knowledge spillovers that enable regions to growth faster - a result that has been confirmed by an increasing number of studies (Frenken and Ron A Boschma, 2007; Essletzbichler, 2007; Bishop and Gripaios, 2010). These studies have directly or indirectly assumed that diversified local contexts are supportive of knowledge spillovers and recombinant innovation. (Castaldi and Giarratana, 2014) have directly tested to what extent diversified regional knowledge bases trigger the generation of innovation. Their findings are in line with the recombinant nature of innovation put forward by evolutionary studies. More radical innovations seem to emerge in regions whose knowledge base is diversified across cognitive distant technological domains, whereas incremental innovation are developed in regions characterised by related variety in local knowledge. 


\subsection{Approaching the technology life cycle with network analysis}

The International Patent Classification (IPC), and its successor the Cooperative Patent Classification (CPC), are used to describe the knowledge base of a patent (see section 2.3 for details). The recombinant innovation theory (Schumpeter, 1939; R. Nelson and Winter, 1982; Weitzman, 1998; Fleming, 2001) tells use that inventions appear when there a recombination of existing knowledge in a new way. Here, each IPC/CPC code assigned to a patent is a knowledge piece and the invention described in the patent is the new recombination (we used the same idea in chapter 6 to measure the knowledge variety).

In practice, since ENV-TECH is mainly based on CPC (6 families out of 8 use only $\mathrm{CPC}$ codes), we use the recombination of $\mathrm{CPC}$ codes to describe the evolution of the knowledge base. We create a mode-1 network for each green technology, where nodes are CPC codes and a tie is created between 2 codes when they describe the same patent family. For example, if patent family A of green technology X is described with CPC codes F02P5/15, F02D41/04 and F02B11/00, then 3 nodes will be created in the X network with a tie between the first and the second code, the second and the third, and the first and the third. We have then a network for each green technology and each year that represents the knowledge base this year.

At this stage, we have only a certain number of networks with an important amount of ties and nodes, but hardly understandable, as a lot of CPC code recombinations appear only a few times. To disentangle significant knowledge 


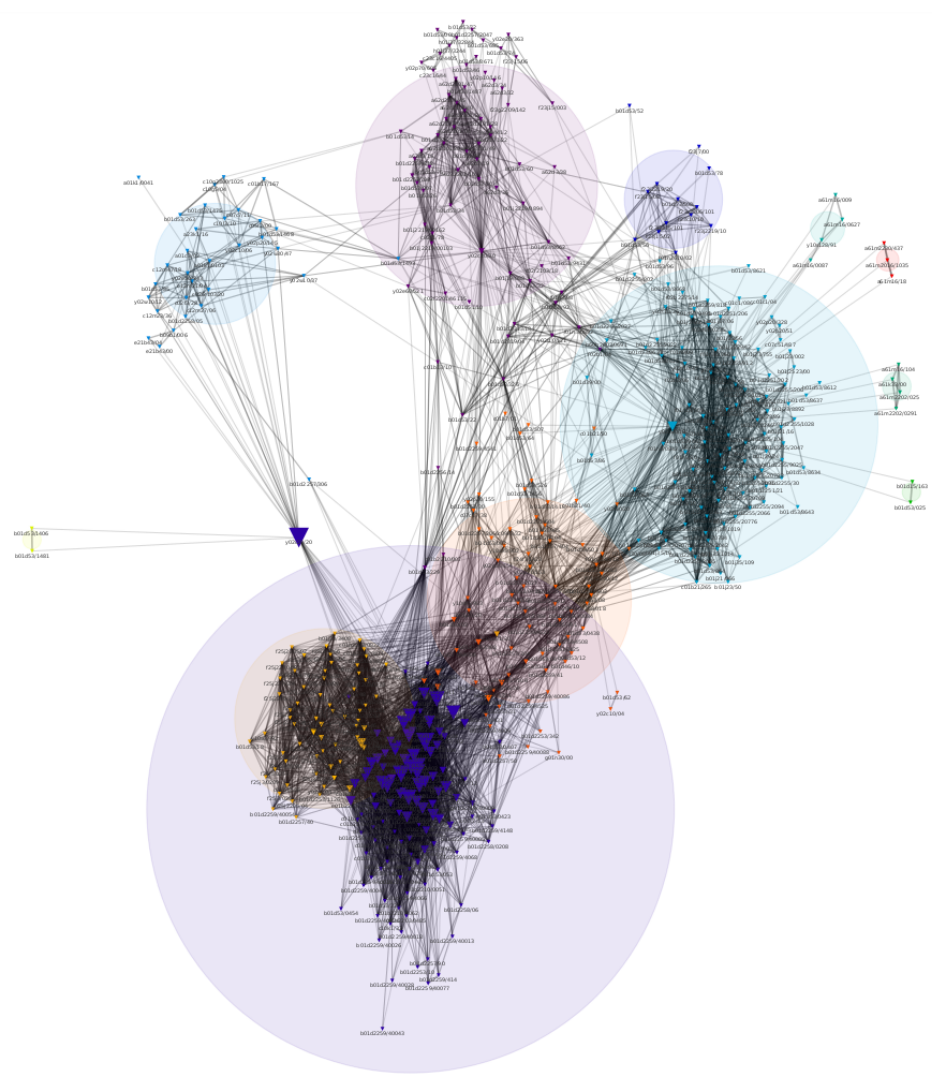

Figure 4.1: Knowledge base of green technology 5.2 - Capture or disposal of greenhouse gases other than $\mathrm{CO}_{2}$ (1970-1994). Clusters of CPC codes are identified with different colors.

recombinations from this noise, we use the same methodology as already explained in section 2.6: a cluster detection algorithm (Louvain, Blondel et al., 2008) with an overlapping time periods of 5 years.

Figure 4.1 illustrates an example of cluster detection for technology 5.2 - Capture or disposal of greenhouse gases other than $\mathrm{CO}_{2}$ during the period 1970-1994. It is worth noting that is the algorithm itself that calculates the optimal time frame, we just defined the number of time period from 1970 to 2010. Consequently, a 


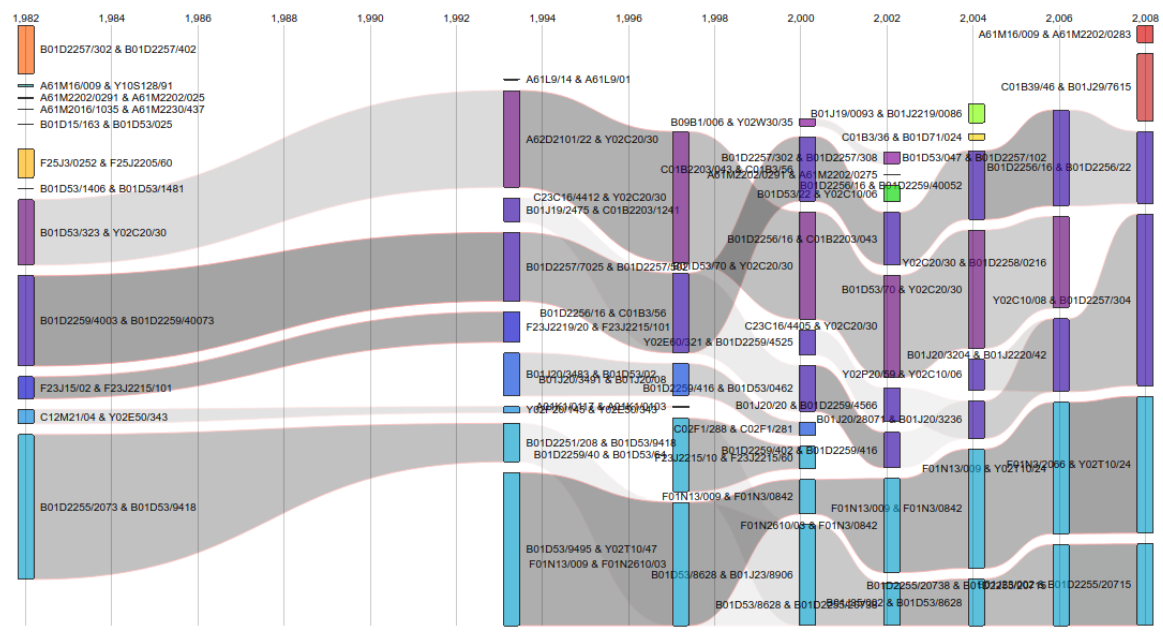

Figure 4.2: Evolution of the knowledge base of green technology 5.2 - Capture or disposal of greenhouse gases other than $\mathrm{CO}_{2}$ (1970-2010). Colours represent clusters detected through network analysis as illustrated in figure 4.1.

technology with long time periods has a stable knowledge base, so it is either in a phase where they are very few ongoing developments (emergence) or where dominants design are stabilized. The algorithm implemented by Cortext is also able to calculate the evolution of these clusters across the time period, representing them using Alluvial diagram (see Figure 4.2 as an example of clusters' evolution for technology 5.2). The Size of each "flow" represents the size of each cluster, the color remains stable across time periods to easily identify the cluster on the network map.

For each green technology, these networks are assembled over time as flows of cluster represented by alluvial diagrams. To ease the exploration of these diagrams, we created a web application available at https://franperr.github . io/envtech-networks where users can select a green technology in the dropdown menu at the top of the page to obtain its alluvial diagram and network 


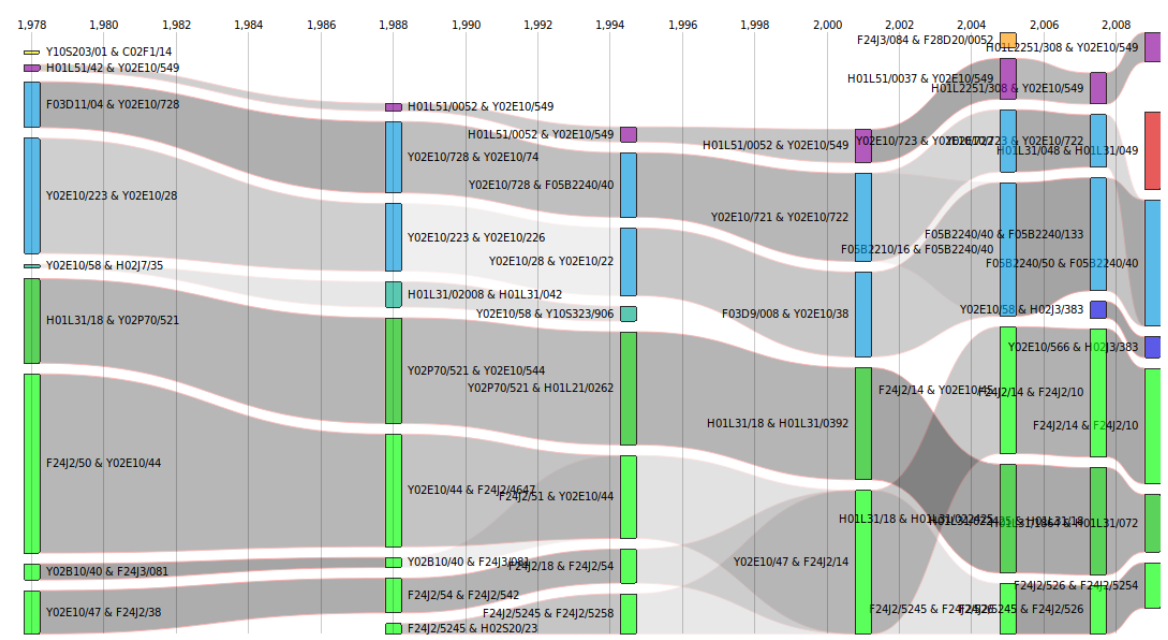

Figure 4.3: Evolution of the knowledge base of green technology 4.1 - Renewable energy generation (1970-2010). Colours represent clusters detected through network analysis.

maps (available at the bottom of the page for each time period). Each CPC code is clickable to have a description and its position in the $\mathrm{CPC}$ classification. Below the network maps, we also represent the evolution of the number of patent families included in this technology.

Using this application, we observe phases of stability, where flows maintain almost the same size and number, and phases of recombination where some flows split, merge, disappear or change significantly their size. For example, green technology 4.1 - Renewable energy generation knowledge base (figure 4.3 and also available at https://franperr.github.io/envtech-networks/?data=4 . 1) remains stable over time, there is mainly some variation at the end of the period (appearance of several clusters). Looking at the growth rate (available at the same url, below the alluvial diagram), we can see an increasing in the patenting activity when there is a recombination of knowledge, and a decrease 
(or a smaller growth) when knowledge base remains stable. Another example can be green technology 1.1 - Air pollution abatement (https://franperr. github.io/envtech-networks/?data=1.1): we can see a significant growth of patenting activity in the last decade of the 20th century when there is significant movement in the knowledge base.

Even if comparing evolution of patent families growth and knowledge base gives us insights about the life cycle of a technology, we are still missing information about the localisation of its developments: is this recombination occurring because new designs are emerging in some specific places, or is it because recombination helps to create a design with a broader contribution ? It is an arduous task to define the threshold to identify one situation from the other. That is why we propose to add to our measure of technology life cycle a geographical component, as detailed in the next section.

\subsection{A proposition of technology life cycle stages}

\subsubsection{Ubiquity and patenting activity}

Our methodology to measure the life cycle of technologies is based on the idea developed by William J Abernathy and J. M. Utterback (1978) and Vona and Consoli (2015) where they defined different stages of technologies, which co-evolve with the know-how needed to implement, use and adapt these technologies. 
As explained in the previous section, in the early stage, knowledge exploration and experimentation are going on, different designs appear and compete among them, highly localised and only in few places. As the technology develops, designs started to be standardised, inferior variants disappear and dominant designs start to have some diffusion. As technology goes toward maturity, some dominant designs appear with a high level of standardisation and a wider degree of geographical diffusion.

Therefore, instead of using the knowledge base recombination and patent families growth, which are somehow correlated as we saw previously, we construct our measure of life cycle along two axis: inventing activity (proxied through patenting activity) and geographical ubiquity. we can then create a quadrant along these two dimensions as represented in Table 4.1, with four different stages: Emergence, Development, Diffusion, Maturity.

Table 4.1: Life cycle stages

\begin{tabular}{|l|l|ll|}
\hline \multicolumn{1}{c}{} & \multicolumn{3}{c|}{ Ubiquity } \\
\cline { 2 - 4 } Patenting & How & Development & Digh \\
\cline { 2 - 4 } intensity & Low & Emergence & Maturity \\
\hline
\end{tabular}

The emergence phase is characterised by a low level of technological diffusion and intensity. It represents the lowest level of maturity of the technology where inventive activities are highly concentrated in few countries and the number of patents is relatively low. Once the patenting intensity increases, a development phase begins. In this case, the technological advances are still geographically concentrated and characterised by an intense patenting 
activity that favours the development of the green technology. In the diffusion phase both the geographical scope and patenting activities grow. Therein, a high number of countries specialise in the development of the technology with an increase in inventive activities. Finally, in the maturity phase where standardisation in the design and knowledge-related activities are obtained, patenting intensity decreases while the geographical diffusion of the inventive activities remains relatively high. It is worth stressing that we allow for nonlinearity in technological evolution, which implies that not all stages are required, maturity may represent an intermediate step before subsequent developments and jumps along the maturity stages are feasible.

\subsubsection{Measuring the life cycle of green technologies}

To identify the maturity of green technologies, we develop a measure of technology life cycle based on two indicators: the geographical ubiquity and the intensity of patenting.

The ubiquity indicator captures the extent to which innovative activities are geographically spread relative to countries' specialisation in green technologies. Following Balland and D. Rigby (2017), the geographical scope of inventions is calculated using the Revealed Technological Advantage (RTA) for each green technology, country and time period as follows:

$$
R T A_{j c t}=\frac{\text { Patents }_{j c t} / \sum_{j} \text { Patents }_{j c t}}{\sum_{c} \text { Patents }_{j c t} / \sum_{j c} \text { Patent }_{j c t}}
$$


The RTA measures the intensity of the contribution of each country $c$ to the development of technology $j$ at time $t$. That is, it captures the efforts spent by a country in developing a specific green technology (numerator) with respect to global efforts in developing the same technology (denominator). The ubiquity of each technological domain is given by the number of countries that exhibit a given RTA in a particular green technology at time $t$ :

$$
U B I Q U I T Y_{j t}=\sum_{c} M_{c j}
$$

Where $M_{c j}=1$ if $R T A>1$. Therefore, the higher the number of countries specialised in the development of a particular technology, the higher the UBIQUITY of that technology. In other words, the indicator is a proxy for diffusion of innovative activities. The advantage of this measure with respect to other potential patent indicators of diffusion (such as i.e. citations, family size, etc.) is that it allows capturing specialisation patterns in specific technologies relative to their global counterparts.

The second indicator is on the number of patent families in green technologies at country level. This is a proxy of patenting intensity of each country in the development of technologies. Finally, we measure the average growth rate over four years of both patenting intensity and the ubiquity indicator. This enables us to smooth the trends in both indicators and capture their dynamics over time. 


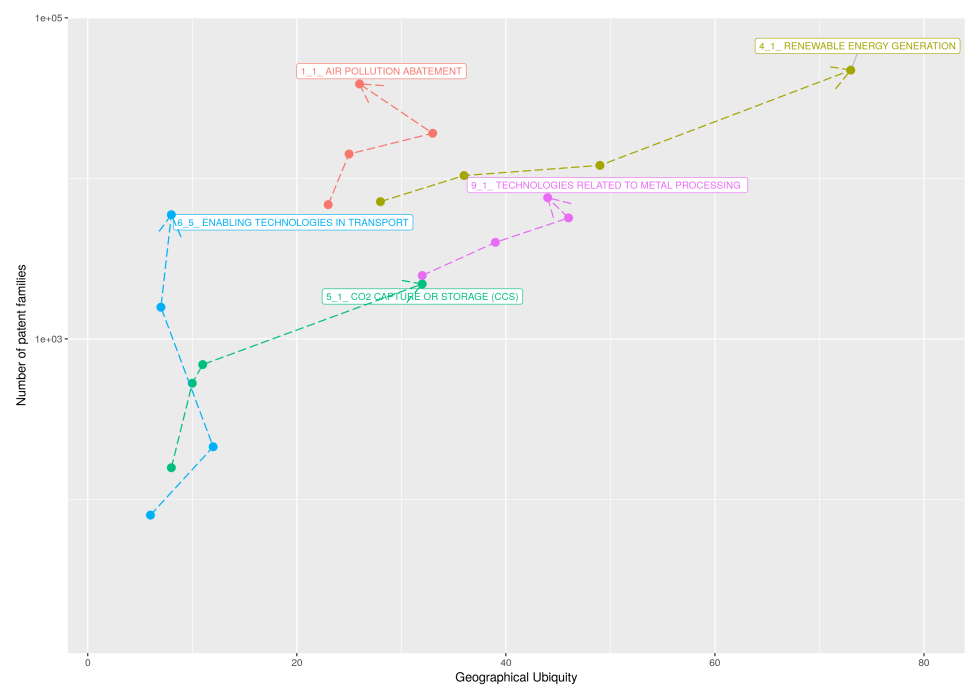

Figure 4.4: Evolution of a selection of Green Technologies (1971 - 2010). Each dot represents the relative position of a technology in each decade, the arrow indicating the last decade.

Figure 4.4 combines information about these indicators on a sample of technologies as an example. The more vertical is the direction of the line, the higher is the growth of the patenting activity and the lower is the number of countries who participate in its development in relative terms, meaning we are in a case of a technology in a development phase. On the opposite, the more horizontal is the line, the lower is the variation of the patenting activity and the higher is its geographical ubiquity, which is the case of technologies in a diffusion phase. The majority of GTs exhibit a tendency to move from the bottom left part of the graph to the top right over time, meaning an increase in both patenting activity and geographical ubiquity.

Let us provide some illustrative examples from the technologies under analysis. Figure 4.4 shows that the technologies related to renewable energy generation 
maintain a fairly stable level of patenting activity since 1981-1990 while geographical ubiquity reaches the highest value among all the other technologies. This is in line with what we expect from a set of technologies in a diffusion stage (US National Academy of Sciences, National Academy of Engineering, and National Research Council, 2010). On the other hand, a small number of countries contribute to the enabling technologies in transport (application of fuel cell or hydrogen technology to transportation and charging of electric vehicle) but the patenting activity is increasing decade after decade, which means these technologies are not mature yet and still in a development phase, in line with the reality (US Department of Energy, 2017). The other three set of technologies (air pollution abatement - 1.1, $\mathrm{CO}_{2}$ capture and storage -5.1 and technologies related to metal processing - 9.1) shown in figure 4.4 present a shifting pattern from a development stage towards maturity: they present an important growth in patenting activities during the whole period, but the ubiquity starts to increase only in the last two decades, in line with what is observed in these sets of technologies (Lim et al., 2009). This pattern is slightly different for technologies related to efficiency and reduction of greenhouse gas emissions in metal processing (9.1): between 1981-1990 and 1991-2000, the amount of patenting activities is stable but they are spread among a higher number of countries, meanwhile in the last decade, the ubiquity diminishes and the patenting activity growths again. This trajectory variation may indicate a future change in the trend of the life cycle of these technologies (The Boston Consulting Group, 2015). 


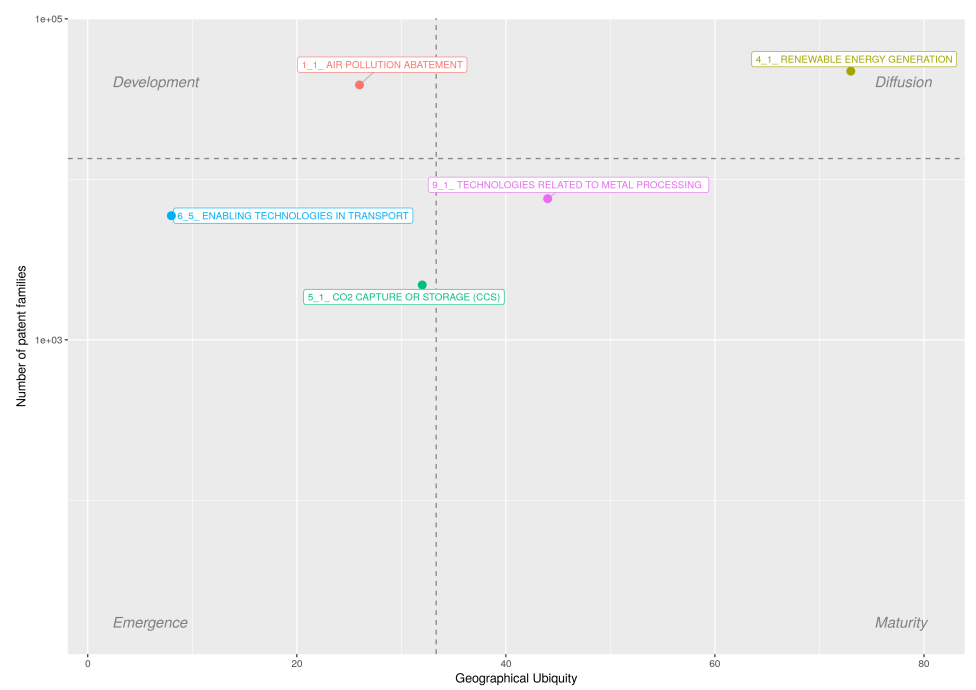

Figure 4.5: Selected green technologies by stage of life-cycle, 2001-2010. Dashed lines represent the means for all the Green Technologies in the time period.

All the technologies follow a similar path, but some are more advanced in the TLC than others. For example, even if air pollution abatement and $\mathrm{CO}_{2}$ capture or storage are moving toward the diffusion stage, their movements start later compared to the average of all the other technologies. To characterize this evolution in the context of all the green technologies, we calculate the average value of ubiquity and patenting growth rate for all the GT in each time period. We can then identify the 4 quadrants defined in table 4.1. "Emergence" is assigned to technologies with a value of patenting intensity and ubiquity below the average, "development" to a patenting intensity above average but an ubiquity below average, "diffusion" to both intensity and ubiquity above average, and "maturity" to an ubiquity above average but a patenting intensity below the average of all the technologies for the time period. In Figure 4.5, we illustrate the 4 phases of TLC during the period 2001-2010 for the same set 


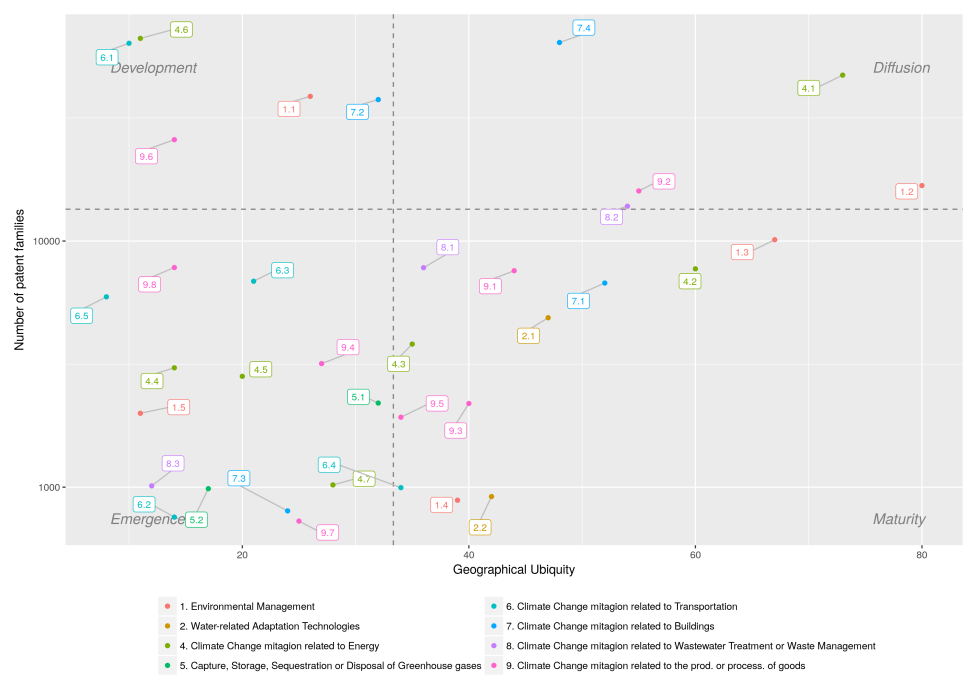

Figure 4.6: All green technologies by stage of life-cycle, 2001-2010. Dashed lines represent the means for all the Green Technologies in the time period.

of technologies shown in Figure 4.4, the means being represented with dashed lines. In this example, $\mathrm{CO}_{2}$ capture or storage (5.1) and enabling technologies in transport (6.5) are in the "emergence" phase, air pollution abatement (1.1) in the "development" phase, renewable energy generation (4.1) would be in the "diffusion" phase and technologies related to metal processing (9.1) in the "maturity" phase. We apply this methodology to all green technologies at 2 digit level. Figure 4.6 is an illustration of this calculation for the last decade 2001 - 2010, where each number is the ENV-TECH code of the technology and colours represent ENV-TECH families.

Table 4.2 shows the lifecycle stage calculated for each green technology in each decade over the period (column headers are the last year of the decade). We can observe that the indicator captures the heterogeneity that characterises 
Table 4.2: Life cycle stages of green technologies

\begin{tabular}{|c|c|c|c|c|c|}
\hline ID & ENV-TECH & 1980 & 1990 & 2000 & 2010 \\
\hline 1.1 & AIR POLLUTION ABATEMENT & 4 & 4 & 4 & 4 \\
\hline 1.2 & WATER POLLUTION ABATEMENT & 3 & 4 & 4 & 4 \\
\hline 1.3 . & WASTE MANAGEMENT & 3 & 3 & 4 & 4 \\
\hline 1.4 & SOIL REMEDIATION & 1 & 1 & 3 & 3 \\
\hline 1.5 & ENVIRONMENTAL MONITORING & 1 & 1 & 1 & 1 \\
\hline 2.1 & DEMAND-SIDE TECH (water conservation) & 1 & 3 & 3 & 3 \\
\hline 2.2 & SUPPLY-SIDE TECH (water availability) & 1 & 1 & 1 & 3 \\
\hline 4.1 & RENEWABLE ENERGY GENERATION & 4 & 4 & 4 & 4 \\
\hline 4.2 & $\begin{array}{l}\text { ENERGY GENERATION FROM FUELS OF NON-FOSSIL ORI- } \\
\text { GIN }\end{array}$ & 1 & 3 & 3 & 4 \\
\hline 4.3 & COMBUSTION TECH WITH MITIGATION POTENTIAL & 1 & 1 & 1 & 3 \\
\hline 4.4 & NUCLEAR ENERGY & 2 & 2 & 1 & 1 \\
\hline 4.5 & $\begin{array}{l}\text { EFFICIENCY IN ELECTRICAL POWER GENERATION, } \\
\text { TRANSMISSION OR DISTRIBUTION }\end{array}$ & 1 & 2 & 1 & 1 \\
\hline 4.6 & ENABLING TECH IN ENERGY SECTOR & 1 & 2 & 2 & 2 \\
\hline 4.7 & $\begin{array}{l}\text { OTHER ENERGY CONVERSION OR MANAGEMENT SYS- } \\
\text { TEMS REDUCING GHG EMISSIONS }\end{array}$ & 1 & 1 & 1 & 3 \\
\hline 5.1 & $\mathrm{CO}_{2}$ CAPTURE OR STORAGE (CCS) & 1 & 1 & 1 & 3 \\
\hline 5.2 & $\begin{array}{l}\text { CAPTURE OR DISPOSAL OF GREENHOUSE GASES OTHER } \\
\text { THAN CARBON DIOXIDE (N2O, CH4, PFC, HFC, SF6) }\end{array}$ & 1 & 1 & 1 & 3 \\
\hline 6.1 & ROAD TRANSPORT & 2 & 4 & 2 & 2 \\
\hline 6.2 & RAIL TRANSPORT & 1 & 1 & 1 & 1 \\
\hline 6.3 & AIR TRANSPORT & 1 & 1 & 1 & 3 \\
\hline 6.4 & MARITIME OR WATERWAYS TRANSPORT & 1 & 1 & 1 & 3 \\
\hline 6.5 & ENABLING TECH IN TRANSPORT & 1 & 1 & 1 & 2 \\
\hline 7.1 & $\begin{array}{l}\text { INTEGRATION OF RENEWABLE ENERGY SOURCES IN } \\
\text { BUILDINGS }\end{array}$ & 1 & 1 & 1 & 4 \\
\hline 7.2 & ENERGY EFFICIENCY IN BUILDINGS & 1 & 3 & 4 & 4 \\
\hline 7.3 & $\begin{array}{l}\text { ARCHITECTURAL OR CONSTRUCTIONAL ELEMENTS IM- } \\
\text { PROVING THE THERMAL PERFORMANCE OF BUILDINGS }\end{array}$ & 1 & 1 & 1 & 1 \\
\hline 7.4 & ENABLING TECH IN BUILDINGS & 4 & 4 & 4 & 4 \\
\hline 8.1 & WASTEWATER TREATMENT & 1 & 3 & 4 & 4 \\
\hline 8.2 & SOLID WASTE MANAGEMENT & 3 & 3 & 4 & 4 \\
\hline 8.3 & $\begin{array}{l}\text { ENABLING TECH OR TECH WITH A POTENTIAL OR INDI- } \\
\text { RECT CONTRIBUTION TO GHG MITIGATION }\end{array}$ & 1 & 1 & 1 & 1 \\
\hline 9.1 & TECH RELATED TO METAL PROCESSING & 3 & 3 & 3 & 4 \\
\hline 9.2 & TECH RELATING TO CHEMICAL INDUSTRY & 1 & 4 & 4 & 4 \\
\hline 9.3 & $\begin{array}{l}\text { TECH RELATING TO OIL REFINING AND PETROCHEMICAL } \\
\text { INDUSTRY }\end{array}$ & 1 & 1 & 1 & 3 \\
\hline 9.4 & TECH RELATING TO THE PROCESSING OF MINERALS & 1 & 3 & 1 & 3 \\
\hline 9.5 & $\begin{array}{l}\text { TECH RELATING TO AGRICULTURE, LIVESTOCK OR } \\
\text { AGROALIMENTARY INDUSTRIES }\end{array}$ & 1 & 3 & 1 & 3 \\
\hline 9.6 & $\begin{array}{l}\text { TECH IN THE PRODUCTION PROCESS FOR FINAL INDUS- } \\
\text { TRIAL OR CONSUMER PRODUCTS }\end{array}$ & 1 & 1 & 2 & 4 \\
\hline 9.7 & $\begin{array}{l}\text { CLIMATE CHANGE MITIGATION TECH FOR SECTOR-WIDE } \\
\text { APPLICATIONS }\end{array}$ & 1 & 1 & 1 & 1 \\
\hline 9.8 & $\begin{array}{l}\text { ENABLING TECH WITH A POTENTIAL CONTRIBUTION TO } \\
\text { GHG EMISSIONS MITIGATION }\end{array}$ & 1 & 1 & 1 & 4 \\
\hline
\end{tabular}


green technologies allowing for non-linear transition between life cycle stages. For instance, ENV-TECH 7.1 "Integration of renewable energy sources in buildings" falls in the emergence stage until 2000 moving to the diffusing phase until maturity is reached in 2010. Green technologies aimed at reducing the environmental impact of nuclear energy follow an opposite pattern starting in the development phase moving to the emergence stage from 1990 onwards.

Table 4.3: Technology maturity ranking

\begin{tabular}{lll}
\hline ENV-TECH (1-DIGIT) & Technological field & Ranking \\
\hline ENV-TECH 5 & Capture, storage, sequestration or disposal of GHG & 1 (Less mature) \\
ENV-TECH 6 & CCMT Transportation & 2 \\
ENV-TECH 4 & CCMT Energy generation, transmission or distribution & 3 \\
ENV-TECH 9 & CCMT Production or processing of goods & 4 \\
ENV-TECH 2 & CCMT Water-related adaptation technologies & 5 \\
ENV-TECH 8 & CCMT Wastewater treatment or waste management & 6 \\
ENV-TECH 7 & CCMT Buildings & 7 \\
ENV-TECH 1 & Environmental management & 8 (More Mature) \\
\hline
\end{tabular}

While table 4.2 shows expected results, we can calculate the average stage of each ENV-TECH family during the time period 1970-2010, and rank them from less mature to more mature. This is presented in table 4.3. As expected, technologies for capture, storage, sequestration or disposal of greenhouse gases and CCMT related to Transportation are less mature, while mature technologies are those related to the management of water, waste and environment, which are well-known local environment issues since the 19th century (Tarr et al., 1984).

Summing up, this chapter has presented a novel methodology to classify technologies along the life cycle.

Drawing on established literature (William J Abernathy and J. M. Utterback, 1978;S. Klepper, 1996;J. Utterback, 1994;Vona and Consoli, 2015), we transliterate the heuristic of maturity stages to the case of green technologies, with a 
view to disentangle the differential degree of development of this rather diverse set of technologies.

This exercise complements the descriptive information provided in chapter 3 by adding a "functional" dimension to the mapping of green technologies. The classification that emerges from the present chapter will be used in the remainder of the thesis as a guideline to capture various nuances of the development of green innovative capacity. 
Chapter 5

\section{Green specialisation and}

\section{diversification across countries}

\subsection{Introduction}

In chapter 3, we ranked countries according to their capacity to produce complex green technologies. We found that high-income countries were producing complex green technologies, but also that mid-income countries were also capable of complex green innovation when they were exporting complex products. To explore why some countries are capable of green innovation while others are not in spite of similar wealth levels, this chapter elaborates an empirical analy- 
sis of the temporal and geographical distribution of environmental inventive activities, and on how specific country characteristics enable the development of green technology. We analyse patterns of diversification and specialization in a restricted panel of 63 countries over the period 1970-2012. Our empirical approach adopts and extends the methodology proposed by Petralia, Balland, and Morrison (2017): we set out to uncover the general trends of green technological specialization, and identify country-specific factors that enable or hinder the diversification in new areas of green technology.

We propose to identify whether and to what extent local competences hinder or facilitate the development of green technologies across countries. Prior research leads us to expect that there are significant cross-country differences both in the ability to enter existing technological domains, as well as setting in motion new trajectories (Jean Olson Lanjouw and Mody, 1996; Veugelers, 2012; Costantini and Mazzanti, 2012; Fankhauser et al., 2013; Calel and Dechezleprêtre, 2016). Only few areas possess the necessary competences to invest in complex technologies, and this capacity is plausibly correlated with their long-run path of economic development (see chapter 3). A recent study by Petralia, Balland, and Morrison (2017) has tackled this issue by exploring the entire landscape of technologies across a large selection of countries. Their analysis disentangles the role of country-specific characteristics - namely, possessing technological competences - as well as technology-specific characteristics - namely, complexity of technology - on the paths of specialisation and diversification.

In the remainder of the chapter we employ a similar approach to map the geographical distribution of environmental technology development, and to 
assess how specific country characteristics enable or thwart the development of inventive activities. In so doing we seek to fill a gap concerning how countries build green innovation capabilities, and how such a capacity differs along the gradient of economic development.

\subsection{Data and Variables}

In this chapter, we use green technology data from 63 countries, to be able to compare our findings with research by Petralia, Balland, and Morrison (2017) on all technologies.

\section{Complexity of green technologies}

The second key dimension in this analysis is the complexity of green technologies. This time, and again in order to facilitate the comparison, we employ the methodology used by Petralia, Balland, and Morrison (2017), built on the seminal work of Hidalgo, Winger, et al. (2007). Both methodologies build a matrix between Green Technologies and Countries to obtain a mode-2 network, and then interact several times a measure of diversity / ubiquity of technologies / countries in order to obtain an average value of complexity. In our study, technologies are the 36 items identified in table 2.1 and countries are those of the inventors.

In Hidalgo's methodology, the first step is to calculate the Reveal Technological Advantage (RTA), to identify countries' technological trajectories and capabilities over time. To this end we calculate: 


$$
\begin{gathered}
R T A_{c j t}=\frac{\text { Patents }_{c j t} / \sum_{j} \text { Patent }_{c j t}}{\sum_{c} \text { Patents }_{c j t} / \sum_{c j} \text { Patent }_{c j t}} \\
S_{c j t}=I\left[R T A_{c j t}>1\right]
\end{gathered}
$$

Where $c$ stands for country, $j$ for ENV-TECH subgroup, $t$ for the year between 1970 and 2012, and I[.] represents the indicator function. This measure provides information on country's specialization in each technology, comparing the share of that technology in country's technology production with the worldwide average share of that technology for each year. A country has an advantage when its share in a green technology domain is bigger than the world average, identified when $S_{c j t}$ is equal to one. This indicator identifies the year $t$ in which a country $c$ starts to diversify in a technology $j\left(S_{c j t-1}=0\right.$ and $\left.S_{c j t}=1\right)$ or the circumstance in which a country had not entered a technology domain at the beginning of the period $\left(S_{c j t}=0\right.$ with $\left.t=1970\right)$.

To construct our Index of Technological Complexity (ITC), we only consider countries that are significant producers of particular green technology (GT) $\left(S_{c j t}=1\right)$. To this end, we build a two-mode matrix $M=\left(M_{c, j}\right)$ for each year, where $M_{c, j}$ reflects whether a country $c$ has RTA in the production of GT $j$. Following the method of reflections, the ITC is an iteration between two variables : the diversity of countries and the ubiquity of GT. These two variables measure the degree of centrality for both sets of nodes, in the country - green technology network.

The degree of centrality of countries is given by the number of GT in which a country has an RTA (diversity): 


$$
k_{c, 0}=\sum_{j} M_{c, j}
$$

In the same manner, the degree of centrality of GT is given by the number of countries with a RTA in this technology (ubiquity):

$$
k_{j, 0}=\sum_{c} M_{c, j}
$$

Hidalgo and Hausmann (2009) demonstrates that the measure of complexity for countries and technologies can be calculated as an iteration of these two degrees of centrality as follows:

$$
\begin{aligned}
k_{c, n} & =\frac{1}{k_{c, 0}} \sum_{j} M_{c, j} k_{j, n-1} \\
k_{j, n} & =\frac{1}{k_{j, 0}} \sum_{c} M_{c, j} k_{c, n-1}
\end{aligned}
$$

Each iteration of $n$ provides finer-grained estimates of the knowledge complexity of technologies they produce. To illustrate, when $n=1, k_{j, 1}$ represents the average diversity of countries that have an RTA in technology $j$. In the next iteration, $k_{j, 2}$ represents the average ubiquity of the green technologies produced in countries that have a RTA in GT $j$. ITC for technology $j$ is defined as the value of $k_{j, n}$ with the maximum number of iterations for each year under analysis. 


\section{Green technological space}

ENV-TECH defines 3 levels of classification, from the broader level which we call family to the more detailed one, called technology. Families are too broad to help us understand the specialization patterns of countries, but technologies have too few patent families to capture the contribution to green technologies of low-middle income countries, as defined in Petralia, Balland, and Morrison, 2017 (Appendix A). As already explained in section 2.5, we use the 2-digits level, for a total of 36 green technologies (GT).

Each ENV-TECH family aggregates a set of technologies by topic (transportation, energy, building, etc...) and objective (climate change adaptation or mitigation), but the technologies belonging to a family can have a different gradient of relatedness, and can even be more related to other technologies outside their own family. In order to measure relatedness, we follow Petralia, Balland, and Morrison (2017), Hidalgo, Winger, et al. (2007) and Balland and D. Rigby (2017) in seeing the Technological Space as a network-based representation of the production of technologies, defined as nodes, the relatedness of each couple of technologies being a tie between two nodes. Accordingly, relatedness between green technology $i$ and $j$ is calculated as follows:

$$
R_{i j t}=\frac{C_{c j t}}{\sqrt{S_{i t} S j t}}
$$

Where $C_{c j t}$ counts the co-occurrences of technologies $i$ and $j$, and $S_{i}$ and $S_{j}$ count the size of GT at period $t$. Therefore, the more two technologies are 
associated to the same patent families, the more related they are controlling for size, the higher is $R_{i j t}$.

\section{Density of green technologies}

Once we have a measure to estimate the proximity of green technologies between them, we can calculate how close is a technology to the country's portfolio of all technologies. This variable varies from 0 to 1 , with higher values indicating a country has capacity to produce GT nearby a given technology. It is measured as follows:

$$
\text { Density }_{c j t}=\frac{\sum_{i} R_{i j t} X_{c i t}}{\sum_{i} R_{i j t}}
$$

Where $X_{\text {cit }}$ is a dummy variable that takes value 1 if country $c$ is patenting in GT $i$ during the year $t$. This variable illustrates the capacities of country $c$ to produce patents in technologies related to technology $j$ in year $t$, which help to understand if capacities in the production of related technologies are linked to diversification in other technologies.

\section{Other variables}

We calculate for each ENV-TECH class and each year, the number of patent families produced (Size), and the Herfindhal Index. The size will be used to control for scale effects. As is common in the literature, the Herfindhal Index is 
used here as an indicator of competition among countries in each technology ${ }^{1}$. We also control for the level of development of each country's economy over time through proxied by GDP (Source: Green Growth Knowledge Platform²).

\subsection{Empirical Analysis}

\section{Descriptive Statistics}

Table 5.1 shows descriptive statistics of the main variables of interest. To facilitate comparability with Petralia, Balland, and Morrison (2017) we limit the dataset to 63 (our 146) countries, covering 35 green technologies, from 1970 to 2012 . About $28 \%$ of countries specialized in a technology at year $t$ $\left(S_{c j t}=1\right)$ were not specialized in the same technology a year before (identified in the column $N P A_{c j t-1}$ ), which we define as a diversification event. On the other hand, $22 \%$ of the observations were having a patent activity in year $t-1$ (identified in the column $P A_{c j t-1}$ ) and lost their technological advantages on year $t\left(S_{c j t}=0\right)$. These proportions are respectively higher and lower than those reported by Petralia, Balland, and Morrison (2017), in that we find stronger frequency of specialisation in green technologies but, once a country has started to invent, it tends to retain a technological advantage.

\footnotetext{
${ }^{1}$ Given the specificities of the ENV-TECH classification, we do not use technology value added like Petralia, Balland, and Morrison (2017). This is because, first, ENV-TECH associates various IPC and CPC codes to a technology, which makes difficult to associate an industrial sector to a specific technology, so makes inappropriate the use of manufactures surveys. Second, and in particular in the case of emergent technologies like for example $\mathrm{CO}_{2}$ capture and sequestration, the value added could be important in the future but this kind of technology is not used enough at present to be able to estimate it.

${ }^{2}$ Available at http://www.greengrowthknowledge.org/
} 
Table 5.1: Main Descriptive Statistics

\begin{tabular}{|c|c|c|c|c|c|c|}
\hline & & Obs & Mean & SD & Min & $\operatorname{Max}$ \\
\hline Specialization & & 95976 & 0.179 & 0.384 & 0 & 1 \\
\hline Log Size & & 95976 & 4.983 & 2.022 & 0 & 9.231 \\
\hline Herfindhal Index & & 95294 & 0.300 & 0.180 & 0 & 1 \\
\hline ITC & & 95294 & 12.338 & 3.266 & 3.556 & 23.5 \\
\hline Density & & 94550 & 0.416 & 0.404 & 0 & 1 \\
\hline GDP Per Capita & & 77065 & 12822.7 & 15636.0 & 97.2 & 113239.6 \\
\hline \multicolumn{7}{|l|}{ Correlation Table } \\
\hline Specialization & 1 & & & & & \\
\hline Log Size & 0.213 & 1 & & & & \\
\hline Herfindhal Index & -0.100 & 0.036 & 1 & & & \\
\hline ITC & -0.113 & -0.562 & -0.098 & 1 & & \\
\hline Density & 0.398 & 0.163 & -0.070 & 0.042 & 1 & \\
\hline GDP & 0.232 & 0.240 & -0.120 & 0.038 & 0.484 & 1 \\
\hline Specialization & & \multicolumn{2}{|c|}{$P A_{c j t-1}$} & \multicolumn{2}{|c|}{$N P A_{c j t-1}$} & Total \\
\hline$S_{c j t}=1$ & & \multicolumn{2}{|c|}{0.723} & \multicolumn{2}{|c|}{0.277} & 1 \\
\hline$S_{c j t}=0$ & & \multicolumn{2}{|c|}{0.217} & \multicolumn{2}{|c|}{0.783} & 1 \\
\hline
\end{tabular}

Number of countries: 63

Number of technologies: 35

Coverage: $1970-2012$ 


\section{Regression analysis}

Our objective is to characterize patterns of technological diversification and specialization in green technologies, in relation with the intrinsic characteristics of the technology (size and complexity), but also with the characteristics of the country, in particular activity in other proximate green technologies (Density) and whether there is prior technological advantage as per RTA. We characterise diversification in two ways: first, by restricting the dataset to cases in which there was no patenting activity at the beginning of the sample $\left(R T A_{c j t}<0.1\right.$ where $\left.t=1970\right)$ and, second, by accounting only for the cases

in which there was no patenting activity in the prior year $\left(R T A_{c j t-1}<0.1\right)$. Contrary to what Petralia, Balland, and Morrison (2017) find, using patents from PATSTAT instead of USPTO mitigates the uncertainty on the detection of global knowledge production, as PATSTAT is a worldwide patent database and is not limited to the United States only. All the other limitations identified (patent production depending on firm strategies and rate of patenting varying over time and space could lead to a misrepresentation of the real knowledge production) apply.

We estimate two different linear probability models, one for diversification and the other for specialization. Both models include dummies for green technologies, countries and years in order to control for potential biases introduced by peculiarities of certain green technologies, countries or years. We specify two models as follows: 
- Diversification equation

$$
\begin{aligned}
S_{c j t}=\Theta_{1} \text { Density }_{c j t-1}+ & \Theta_{2} \text { Density }_{c j t-1} \times G D P_{c t}+\beta_{1} \log \text { Size }_{j t}+\beta_{2} H I_{j t} \\
& +\beta_{3} I T C_{j t}+\delta_{c} D_{c}+\delta_{j} D_{j}+\delta_{t} D_{t}+\varepsilon_{c} j t
\end{aligned}
$$

- Specialization equation

$$
\begin{array}{r}
S_{c j t}=\Theta_{1} \text { Density }_{c j t-1}+\beta_{1} \log \text { Size }_{j t} \times G D P_{c t}+\beta_{2} H I_{j t} \times G D P_{c t} \\
+\beta_{3} I T C_{j t} \times G D P_{c t}+\delta_{c} D_{c}+\delta_{j} D_{j}+\delta_{t} D_{t}+\varepsilon_{c} j t
\end{array}
$$

Where $c, j$, and $t$ identify respectively countries, green technologies and years, $S_{c j t}$ takes the value of unity when a country $c$ has an RTA above unity in a technology $j$ in year $t, G D P_{c t}$ is the GDP per capita for country $c$ and year $t$, Density $y_{c j t}$ is the proximity of surrounding green technologies in country $c$ to technology $j$ in year $t, H I_{j t}, I T C_{j t}$ and $S i z e_{j t}$ are the technology-related variables defined in Table 5.1, and $\varepsilon_{c} j t$ is the error term.

The first model seeks to capture the effect of a country possessing competences in proximate technologies on diversification, and to further assess if the effect is higher when the diversification is recent or if it dates back to the beginning of the sample. The second equation aims at identifying the patterns of specialization in green technologies, measuring the effects of the technology determinants themselves and those of surrounding technologies in a country, regardless of whether a country has previously produced that technology. When we run regressions for this model, we interact all the variables with GDP to assess 
if there are patterns according to the level of development. Last but not least, we extend the framework of Petralia, Balland, and Morrison (2017) by estimating diversification and specialization in a model adding a variable called maturity, which represents green technology life cycle stage (as defined in the previous chapter, section 4.4, table 4.3). In so doing we evaluate whether green technologies behaviour is homogeneous across families, or if intrinsic characteristics of ENV-TECH domains have a differential influence.

\subsection{Results and discussion}

Table 5.2: Results of the Econometric Model

\begin{tabular}{|c|c|c|c|}
\hline & $\begin{array}{c}\text { Diversification Equation }(\mathrm{RTA}<0.1 \\
\text { in the previous period) }\end{array}$ & $\begin{array}{c}\text { Diversification Equation (RTA }<0.1 \\
\text { at the beginning of the sample) }\end{array}$ & $\begin{array}{l}\text { Specialization } \\
\text { Equation }\end{array}$ \\
\hline Density & $\begin{array}{c}0.02746^{* * *} \\
(0.01)\end{array}$ & $\begin{array}{c}0.11723^{* * *} \\
(0.01)\end{array}$ & $\begin{array}{c}0.13949^{* * *} \\
(0.01)\end{array}$ \\
\hline Density $\times$ GDP & $\begin{array}{c}0.00049 \\
(0.00)\end{array}$ & $\begin{array}{c}0.00030 \\
(0.00)\end{array}$ & \\
\hline \multicolumn{4}{|l|}{ Technological-level Variables } \\
\hline Log Size & $\begin{array}{c}0.00497^{* *} \\
(0.00)\end{array}$ & $\begin{array}{l}0.00658^{* * *} \\
(0.00)\end{array}$ & $\begin{array}{l}0.01495^{* * *} \\
\quad(0.00)\end{array}$ \\
\hline Herfindahl Index & $\begin{array}{c}-0.01898^{* * *} \\
(0.01)\end{array}$ & $\begin{array}{c}-0.04997^{* * *} \\
(0.01)\end{array}$ & $\begin{array}{c}0.01416^{*} \\
(0.01)\end{array}$ \\
\hline ITC & $\begin{array}{l}0.00169^{* * *} \\
(0.00)\end{array}$ & $\begin{array}{c}0.00389^{* * *} \\
(0.00)\end{array}$ & $\begin{array}{l}0.00484^{* * *} \\
(0.00)\end{array}$ \\
\hline GDP & $\begin{array}{c}0.00012 \\
(0.00)\end{array}$ & $\begin{array}{c}0.00016 \\
(0.00)\end{array}$ & $\begin{array}{l}0.00736^{* * *} \\
(0.00)\end{array}$ \\
\hline GDP $\times$ Log Size & & & $\begin{array}{c}-0.00049 * * * \\
(0.00)\end{array}$ \\
\hline GDP $\times$ Herfindahl Index & & & $\begin{array}{c}-0.01453^{* * *} \\
(0.00)\end{array}$ \\
\hline GDP $\times$ ITC & & & $\begin{array}{c}-0.00012^{* *} \\
(0.00)\end{array}$ \\
\hline$R^{2}$ & 0.098 & 0.209 & 0.228 \\
\hline Tech Fixed Effects & Yes & Yes & Yes \\
\hline Time Fixed Effects & Yes & Yes & Yes \\
\hline Country Fixed Effects & Yes & Yes & Yes \\
\hline Obs & 51149 & 70547 & 77065 \\
\hline
\end{tabular}

Table $5.2 \& 5.3$ show the results obtained from the regressions. Both tables report the results of three models: in columns (1) and (2) are the diversification 
Table 5.3: Regression results with technology life cycle

\begin{tabular}{|c|c|c|c|}
\hline & $\begin{array}{l}\text { Diversification Equation (RTA }<0.1 \\
\text { in the previous period) }\end{array}$ & $\begin{array}{l}\text { Diversification Equation (RTA }<0.1 \\
\text { at the beginning of the sample) }\end{array}$ & $\begin{array}{l}\text { Specialization } \\
\text { Equation }\end{array}$ \\
\hline Density & $\begin{array}{c}0.02746^{* * *} \\
(0.01)\end{array}$ & $\begin{array}{c}0.11723^{* * *} \\
(0.01)\end{array}$ & $\begin{array}{c}0.13872^{* * *} \\
(0.01)\end{array}$ \\
\hline Density $\times$ GDP & $\begin{array}{c}0.00049 \\
(0.00)\end{array}$ & $\begin{array}{l}0.00030 \\
(0.00)\end{array}$ & \\
\hline \multicolumn{4}{|c|}{ Technological-level Variables } \\
\hline Log Size & $\begin{array}{l}0.00497^{* *} \\
(0.00)\end{array}$ & $\begin{array}{l}0.00658^{* * *} \\
\quad(0.00)\end{array}$ & $\begin{array}{l}0.01555^{* * *} \\
\quad(0.00)\end{array}$ \\
\hline Herfindahl Index & $\begin{array}{l}-0.01898^{* * *} \\
\quad(0.01)\end{array}$ & $\begin{array}{l}-0.04997^{* * *} \\
\quad(0.01)\end{array}$ & $\begin{array}{c}0.00558 \\
(0.01)\end{array}$ \\
\hline ITC & $\begin{array}{l}0.00169^{* * *} \\
\quad(0.00)\end{array}$ & $\begin{array}{l}0.00389^{* * *} \\
\quad(0.00)\end{array}$ & $\begin{array}{l}0.00464^{* * *} \\
\quad(0.00)\end{array}$ \\
\hline Maturity & $\begin{array}{l}0.02568^{* * *} \\
\quad(0.00)\end{array}$ & $\begin{array}{l}0.04474^{* * *} \\
\quad(0.00)\end{array}$ & $\begin{array}{l}0.04034^{* * *} \\
\quad(0.00)\end{array}$ \\
\hline GDP & $\begin{array}{c}0.00012 \\
(0.00)\end{array}$ & $\begin{array}{c}0.00016 \\
(0.00)\end{array}$ & $\begin{array}{l}0.00523^{* * *} \\
\quad(0.00)\end{array}$ \\
\hline GDP $\times$ Log Size & & & $\begin{array}{c}-0.00053^{* * *} \\
(0.00)\end{array}$ \\
\hline GDP $\times$ HHI & & & $\begin{array}{l}-0.01311^{* * *} \\
\quad(0.00)\end{array}$ \\
\hline GDP $\times$ ITC & & & $\begin{array}{c}-0.00008 \\
(0.00)\end{array}$ \\
\hline GDP $\times$ Maturity & & & $\begin{array}{l}0.00037^{* * *} \\
(0.00)\end{array}$ \\
\hline$R^{2}$ & 0.09796 & 0.20889 & 0.22834 \\
\hline Tech Fixed Effects & Yes & Yes & Yes \\
\hline Time Fixed Effects & Yes & Yes & Yes \\
\hline Country Fixed Effects & Yes & Yes & Yes \\
\hline Obs & 51149 & 70547 & 77065 \\
\hline
\end{tabular}


models, the difference being the sample selection, and column (3) shows results from the specialisation model. Our benchmark for the interpretation of results are the findings of Petralia, Balland, and Morrison (2017) with the proviso that we focus on green technologies.

The specification of Table 5.2 shows a positive and significant correlation between density and diversification. This result holds if we consider diversification with respect to the previous year as well as diversification with respect to the first year at the beginning country time-series. This positive relationship suggests that having technological capabilities in cognitive related technologies increases the likelihood of entering into a new-to-the-country green technological domain. The result is in line with section 3.4 .3 of chapter 3 that emphasise the pivotal role of related capabilities in the green knowledge generation process. Indeed, knowledge stemming from existing capabilities reduces the costs and uncertainty that exploratory mechanisms entail and triggers technological variety across different - though related - fields (Carolina Castaldi, Frenken, and Los, 2015). Similar results have been provided by Noailly and Shestalova (2017) who point out that renewable energy technologies benefit, among other factors, from intra and inter-technology spillovers.

The positive correlation between density and diversification indicates that the finding of Petralia, Balland, and Morrison (2017) holds also for green technologies. However, in our study the interaction between Density and GDP is not statistically different from zero (Column 1 and 2). Petralia, Balland, and Morrison (2017) find a negative coefficient, meaning that existing capabilities in related technologies are less relevant for developed countries relative to 
developing ones, and, thus, that the costs and uncertainty of exploring new technological domains is a major concern when the endowment of financial resources is lower. We ascribe the lack of a significant relationship in our results to a peculiarity of green technologies, namely that they are altogether at an early stage of development (OECD, 2011). Operating in such a technological domain characterised by a high level of uncertainty, due to lack of established practices and gaps in know-how, entails that financial capacity does not influence diversification capacity.

We also find positive and significant coefficients for the technology-level variables (i.e. Size and ITC) with the exception of a negative and significant coefficient for the Herfindhal index. This suggests that diversification is higher when patenting activities are spread across different countries, i.e. diversification in new green technological fields is favoured by worldwide distribution of green technological advances. The main difference with respect to Petralia, Balland, and Morrison (2017) is the effect of technology complexity: whereas their reported coefficient is negative and significant, ours is positive and significant. This implies that in the case of green technologies the likelihood of diversification and specialisation increases with technological complexity. To support this finding, we recall the intrinsic features of green technologies. In a recent paper, Barbieri, Marzucchi, and Rizzo (2018) compare green and non-green technologies across different knowledge dimensions. It has been observed that green technologies are more complex, radical and exert higher impacts on subsequent technologies with respect to non-green ones. In particular, the authors find that green technical knowledge emerges from a variety of knowledge sources that spans a wide 
spectrum of cognitively distant knowledge fields. Moreover, environmentalrelated technologies recombine a higher amount of technological components that are drawn from different domains. That is, directing technological change towards a sustainable path requires substantial efforts in bringing together different knowledge sources, more so than in established technological domains.

Results from the specialization equation are shown in the third column of Table 5.2. Therein the coefficient of technology density is positive and significant in line with Petralia, Balland, and Morrison (2017). This corroborates the idea that, even in the domain of green technologies, operating in proximate fields increases the likelihood of specialisation. Size is also positive and significant while the Herfindhal index is not. We also find that technology complexity has a positive and significant association with specialisation, in contrast with Petralia, Balland, and Morrison (2017). However when we interact these variables with GDP, our findings suggest that the likelihood of specialising in a given green technological field decreases as far as complexity and GDP increase. Although the size of the coefficient is low, important non-linearities arising from this interaction will be discussed below. On the one hand, it seems that top countries of the GDP per capita distribution are more likely to specialise in less complex green technologies. On the other hand, low income countries have lower probability of specialising in more complex technologies relative to developed, but they are characterised by an increasing probability of specialisation as technological complexity increases.

Given the idiosyncratic features of our domain of analysis, we investigate whether and to what extent the degree of maturity of green technologies affects 
our results. To this end, we refer to the methodology proposed in chapter 4. Table 4.3 reports the macro-technological groups ranked in relation to their level of maturity. In that table, technologies such as i.e. "Capture, storage, sequestration or disposal of GHG" (ENV-TECH 2) are at early stages of development while other domains such as i.e. "Environmental or Waste management" (ENV-TECH 1-2) are at a more mature stage ${ }^{3}$.

Table 5.3 shows results of the regressions articulated according to this life-cycle classification. Therein, the coefficient of technological maturity (i.e. TLC) is positive and significant in all specifications. That is, high levels of technological maturity are associated with an increased probability to diversify in green technological fields that had not previously been explored by the country. The result holds if we focus on the specialisation equation (Column 3). Not surprisingly the finding suggests that countries tend to diversify and specialise, i.e. spend effort to explore new-to-the-country green domains, in more mature technological domains. This is particularly relevant as far as developed countries are concerned. Indeed, the interaction term between GDP and TLC suggests that the more a country is developed, the higher is the likelihood of specialising in mature technologies.

Figure 5.1 summarizes the probability of diversification taking into account the margins at different levels of GDP (left panel) and technological complexity (right panel) with darker colors showing a higher probability and isolines indicating probability values.

\footnotetext{
${ }^{3}$ It is worth noting that the level of maturity is calculated relative to the stage of development of all green technologies.
} 

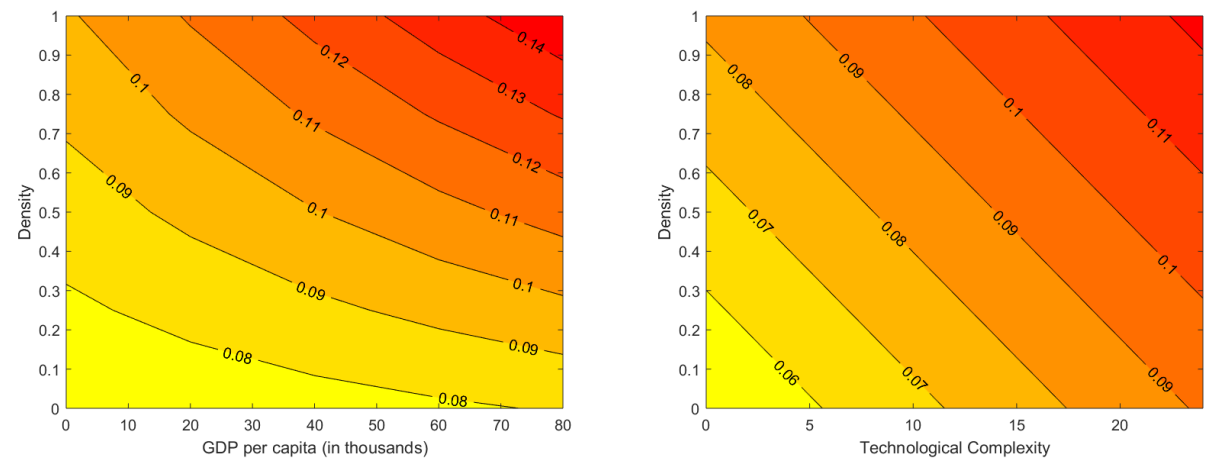

Figure 5.1: Diversification probabilities according to the characteristics of technologies and countries.
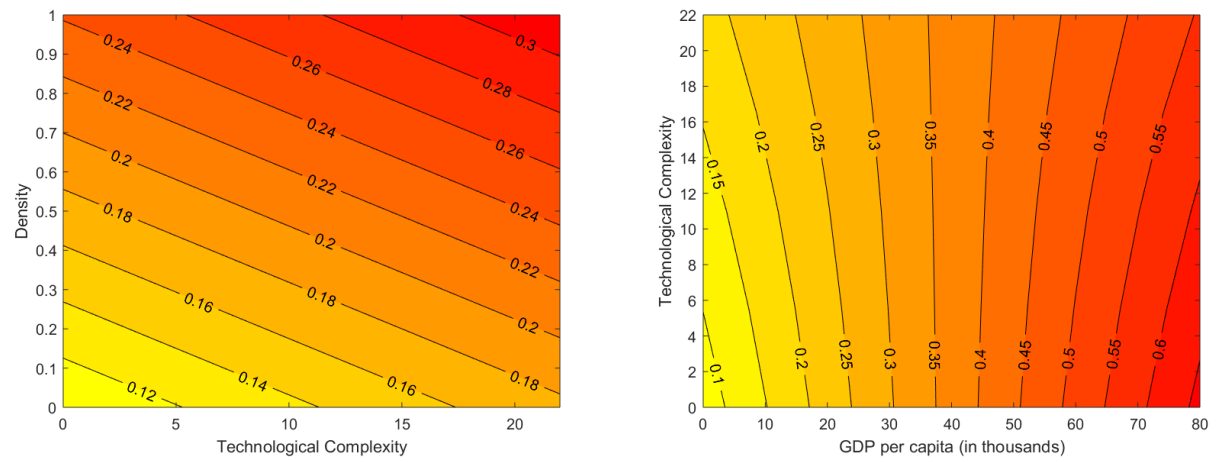

Figure 5.2: Specialization probabilities according to the characteristics of technologies and countries. 
On the left-hand panel, the probability of diversification increases when both the country's capabilities in producing inventions in related green technologies and the GDP increase. However, the presence of related capabilities is more important for developed countries since their probability of diversification increases from $8 \%$ at low values of Density to $14 \%$ for high values of Density. Also developing and emerging countries experience a similar trend, although they move from almost $7 \%$ at low level of relatedness to less than $10 \%$ at high levels of Density. On the right-hand panel of figure 5.1, we focus on the relationship between Density and technological complexity and the probability of diversification. In Table 5.2 we observe that Density and technological complexity have a positive relationship with diversification. That is, having technological capabilities in neighbouring green technologies increases diversification. The same result holds when we consider technological complexity. At a constant level of related capabilities (i.e. Density) the probability of diversification increases at high values of complexity meaning that the latter does not represent a barrier for diversification. In comparison, Petralia, Balland, and Morrison (2017) report a negative relationship: the more complex is a technology, the lower is the probability of diversification with a similar level of density. Our reading of this difference is that diversifying into new green technological domains entails operating in a more complex system due to less established know-how. As a consequence, possessing capabilities in related domains enables diversification, even towards more complex green technologies. 
Figure 5.2 illustrates how the probability of specialization in new green technologies depends on the characteristics of the technology and on the economic performances.

The left-hand panel shows the extent to which the probability of specialization changes according to green technologies density and the complexity. These results confirm the finding associated with diversification. That is, the probability of specialisation tends to be higher when complex green technologies (usually associated with a higher economical value) are concerned and when countries have inventive capabilities in surrounding green technologies (density) in the country increases. Conversely, the right-hand panel of Figure 5.2 represents the effects of the technology complexity and the economic performances of the countries (proxied through GDP per capita) on the probability of specialization. We observe two main trends. First, when GDP is high the probability of specialising in green technological fields is higher for low values of technological complexity. In other words, as expected, more developed countries specialise in less complex technologies. Second, however, countries with low levels of GDP are more likely to specialise into more complex technological fields. In this case the probability of specialisation is clearly lower compared to developed countries', but it increases together with technology complexity. The non-linearities emerging from Figure 5.2 (right panel) therefore indicate that the complexity of green technologies is not per se a barrier to specialisation for countries in the middle of the income distribution.

This, other than adding to previous literature, including but not limited to Petralia, Balland, and Morrison (2017), offers interesting insights for policy. 
Our reading is that, akin to several other societal challenges, dealing with environmental sustainability calls upon the capacity to build rich and diverse knowledge structures with the proactive participation of both firms and the attendant institutions (Nelson, 2008). The evidence provided here shows that countries that successfully develop domestic capabilities can overcome technological barriers. More than this, we find that these opportunities are not precluded to countries with lower income levels, and therefore to the places that according to many are most vulnerable to climate change hazards.

\subsection{Conclusions}

The present chapter has analysed cross-country patterns of diversification and specialization in environmental technology development, and their drivers. This exercise yields two main findings. First, countries are more likely to diversify into new domains of green technology that are close to the portfolio of existing competences as proxied by prior technological orientation. While this is coherent with prior literature, our results are peculiar in that the observed effect does not exhibit strong association with the stage of development of a country - as in Petralia, Balland, and Morrison (2017) - but, rather, with the maturity of the green technology. In particular, differences in competences are a bigger obstacle than differences in wealth. Second, in line with prior studies, we find that countries move along cumulative paths of specialization, and towards more complex technologies. At the same time, and contrary to other studies the complexity of green technologies is not an obstacle to specialisation. 
This chapter has filled the gap in the literature about how countries build green innovation capabilities, and how these capabilities differ along their economic development. Even if the use of patent data is not exempt of limitations, this chapter provides interesting insights that contribute to the scholarly and the policy debate about how countries could tackle climate change, water scarcity and environment degradation while fostering their economic development. 
Chapter 6

\section{Co-evolution of green}

\section{technologies and the knowledge}

base

\subsection{Introduction}

The objective of this chapter is to establish an empirical correspondence between the degree of maturity of green technologies (as per the life cycle) and the knowledge base of the attending local economy. 
Economic geographers and innovation scholars concur that the more diverse the spectrum of know-how available in a region, the greater the potential of successfully exploiting available inputs as well as unexplored interdependences between them (D. L. Rigby and Essletzbichler, 1997; Frenken and Ron A Boschma, 2007; Balland and D. Rigby, 2017). This rests on the premise that the composition of activities through which knowledge is channelled into productive uses affects the rate and direction of technical change in a region. In this vein, it has been argued, the more sectors are related, the easier is recombination stemming from the transfer of knowledge from one context of application to another. A thorough review of empirical studies by Content and Frenken (2016) confirms that relatedness is an important driver of regional diversification across a broad spectrum of dimensions (e.g., products, industries, technologies) and of spatial units (e.g., countries, regions, cities, labour market areas) of analysis. In particular, related diversification is observed to be a stronger driver compared to unrelated diversification. This is, to some extent, not surprising considering the nature of these constructs. Diversification is an uncertain process that can be better dealt with by relying on available local resources, and on well-tested connections across them, both trademark features of related variety. Unrelated diversification, on the other hand, entails implementing new forms of coordination across different and formerly unassociated capabilities (Desrochers and Leppälä, 2011; R. Boschma, Coenen, et al., 2017). At the same time, Ron A. Boschma and Frenken (2006) call for caution against determinism, highlighting that spatial contingencies are of minor importance at the initial stage of development of a sector, because a gap is likely to exist between the requirements of new knowledge and the established environment. Within this 
debate, the question of whether and to what extent related and unrelated variety actually affect technological innovation has been addressed only recently by Carolina Castaldi, Frenken, and Los (2015). Their empirical analysis on the United States (US) shows that the two forms of regional diversification are not opposite but, rather, complementary forces. In particular, radical innovations are observed more frequently in federal states with a diversified knowledge base across unrelated domains, whereas incremental innovation has a stronger association with related variety in local knowledge.

Based on this premise, this chapter aims to move this analysis forward by distinguishing between related and unrelated variety along the path of development of green technology. In so doing we take issue with the notion that either related or unrelated variety are drivers of innovation regardless of the life-cycle stage of the technology.

We propose that it is important to consider simultaneously region-specific and external factors that may trigger opportunities for new industry and technologies to emerge. To this end, we adopt a regional knowledge production function (RKP) approach that incorporates qualitative features of the local knowledge base as well as the degree of maturity of technology. So far, the analysis of regional innovation has focused mainly on the extent to which $\mathrm{R} \& \mathrm{D}$ and human capital interact (Charlot, Riccardo Crescenzi, and Musolesi, 2015) and affect (Riccardo Crescenzi, Gagliardi, and Iammarino, 2015) the innovation generation process. However, following the evolutionary tenet that innovation is the result of successful recombination of existing ideas (Schumpeter, 1939; Basalla, 1989; Weitzman, 1998; Arthur, 2007), we account for the fact that the structure 
of the regional knowledge base and the relatedness between its components influence the recombination process (Frenken and Ron A Boschma, 2007; Carolina Castaldi, Frenken, and Los, 2015). Against this backdrop, we expect the life cycle stage of technology to determine whether local diversification (or specialisation) across knowledge domains provides the highest benefits for innovation. The study builds on the above to test two conjectures. The first is that unrelated variety of the local knowledge stock matters for innovation at early stages of the technology life-cycle while related variety has little or no effect. The second is that, as the technology approaches maturity, related variety of the local knowledge base is the major driver, while unrelated variety loses progressively prominence. The empirical analysis is on green technology development in a panel of 48 US federal states and District of Columbia (D.C.) between 1980 and 2009, using the data built in chapter 2, but limiting it to these regions. In order to study the relationship between technology life cycle and regional knowledge structure we build entropy indicators that are decomposed at different levels of relatedness between technological domains (Jacquemin et al., 1979; Attaran, 1986; Frenken and Ron A Boschma, 2007; Carolina Castaldi, Frenken, and Los, 2015). Finally, we follow the parametric approach proposed by Charlot, Riccardo Crescenzi, and Musolesi (2015) and adopt a random growth specification of the unobservable part of the model to control for time-invariant regional characteristics, common time effects and time-varying unobservable features whose exclusion would bias the econometric estimation. 
The analysis yields two main findings. First, green technology development exhibits stronger association with unrelated variety than with related variety. This is not surprising considering that, first, the transition towards environmentally sustainable production is still at early stages (OECD, 2015) and, second, that green technology, being more complex than non-green technology, requires the orchestration of diverse and cognitively distant knowledge inputs (Barbieri, Marzucchi, and Rizzo, 2018). The second key finding is that unrelated variety has stronger association with the early stages of the green technology life cycle, while related variety becomes more important as technology enters into maturity. On the whole, the chapter claims novelty on three fronts. First, we operationalise the empirical connection between the technology life cycle and the knowledge base, which had so far only been approached on conceptual grounds (Vona and Consoli, 2015). The second contribution is to the debate spurred by Castaldi and Giarratana (2014) on whether and to what extent related and unrelated variety affect technological innovation, with the additional benefit of the life-cycle perspective. Third, last but not least, we add empirical evidence on the connection between environmental sustainability and regional studies on which, according to Truffer and Coenen (2012), the sub-discipline of environmental economic geography has been largely silent.

This chapter is organised as follow. The next section extends the theoretical background presented in chapter 4 . Section 6.3 describes additional data used, variables and empirical strategy. Finally, whereas Section 6.4 presents the descriptive statistics and discuss the results, Section 6.5 concludes the chapter and illustrates the policy implications. 


\subsection{Technology life cycle in the regional knowledge production function}

Along the life cycle, industries rely on different types of innovation that require different sources (R. Norton and Rees, 1979). The birth of new industries typically follows radical innovation and the development of immature technologies, whereas once a dominant design is established, technological disruptions are less likely and the industry reaches a maturity stage in which innovation is mostly incremental (Neffke, Henning, and R. Boschma, 2011). Such a mechanism implies that industries exploit different types of agglomeration externalities according to their stage of maturity. So far, we have observed that existing studies treat technology as a latent element that evolves and leads to industry maturity. Agglomeration economies are beneficial for industry and regional growth because of their indirect effect in terms of knowledge spillovers and learning opportunities. However, no study has provided a direct test to explore why agglomeration externalities should trigger industrial technology.

A critical issue in the diffusion literature is the implicit assumption is that neither the new technology nor the one that is being replaced change (B. Hall and Trajtenberg, 2004). This static view stands in sharp contrast with empirical evidence on the incremental adaptations that ultimately leads to improvement of technology (Christensen, 1997; Foster, 1986). Moreover, and closer to the goals of our analysis, central to the dynamics technology is the balance between intrinsic performance characteristics and the specific features of the selection environment (Vona and Consoli, 2015). These features 
can be bottlenecks - see e.g. the analysis of the American machine tool industry by Rosenberg (1976) or Hughes' 1993 account of the evolution of the electrical power system - or can be facilitating circumstances of the ecosystem - as is the case in Constant's (1980) study on aircraft piston-engine or in Henderson's (1995) analysis on optical lithography. The broader point is that acknowledging the role of the context of adoption entails shifting the focus from substitution between new and old technology to the evolution of the selection environment. This resonates with Boschma and Frenken's (2006) cautionary remark concerning deterministic accounts of regional variety: spatial contingencies, and the associated uncertainties, matter.

Building on these premises, we look at how agglomeration economies and technology life cycle interact. In the geography of innovation literature, the RKP function approach provides a suitable theoretical framework to investigate these issues (see e.g. R. Crescenzi, Rodriguez-Pose, and Storper, 2007, 2012; Ponds, Oort, and Frenken, 2010; M. Feldman and Graddy-Reed, 2014; Charlot, Riccardo Crescenzi, and Musolesi, 2015). Therein the regional perspective is embedded in the knowledge production function framework proposed by Griliches (1979) to observe the regional determinants of the generation of innovation. However, whether regional innovation inputs (e.g. human capital and R\&D investments) and agglomeration economies exert heterogeneous effects on innovation output according to the maturity of the technology remains an unexplored question. Delving into details provides insights into the type of knowledge base structure that enables regions to intensify their innovative activities and evolve along the life cycle. To do so, we extend the RKP 
framework to incorporate knowledge diversification at different levels of variety (Frenken and Ron A Boschma, 2007; Carolina Castaldi, Frenken, and Los, 2015). Moreover, since the regional endowment of innovation inputs and given the heterogeneity of regional structural characteristics, we also test whether specific features of the local knowledge base exert different impacts on innovation output depending on the level of development of regions.

\subsection{Empirical application}

Figure 6.1 shows the geographical distribution of green and total patenting activities per million inhabitants at state level (Panel A and B, respectively). Not surprisingly, the two distributions follow a similar pattern with states such as Massachusetts, Connecticut, Alabama, Georgia, Maryland and Kansas that fall in the top quintile in both panels. It is worth noting that states in the Great Lakes (e.g. Michigan, Indiana, etc.) and New England (e.g. Massachusetts, Connecticut, etc.) are particularly effective in the production of green technological knowledge, whereas states in the West (e.g. California, Oregon, Washington, etc.) perform better in total patenting over time. Another noticeable element is that some states rank high in the distribution of green patent families per million inhabitants and low in total patenting activities, for example Illinois, Michigan and Ohio. 


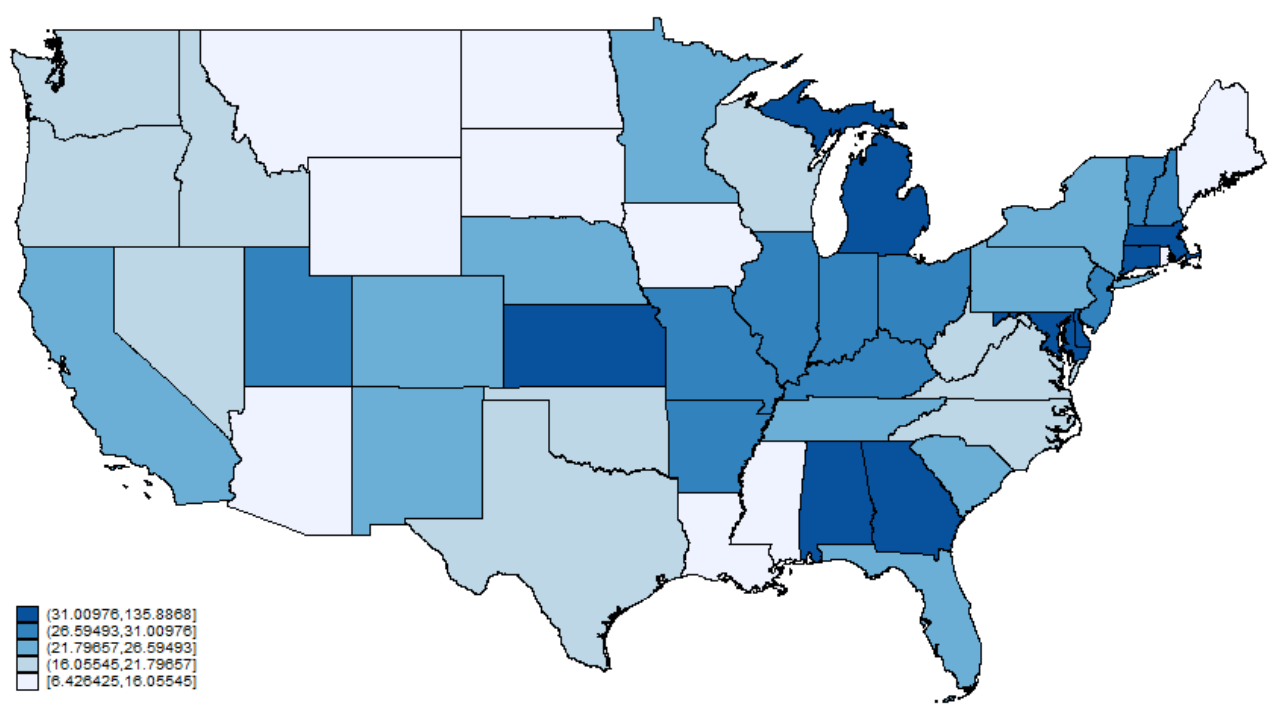

(a) Green Technologies

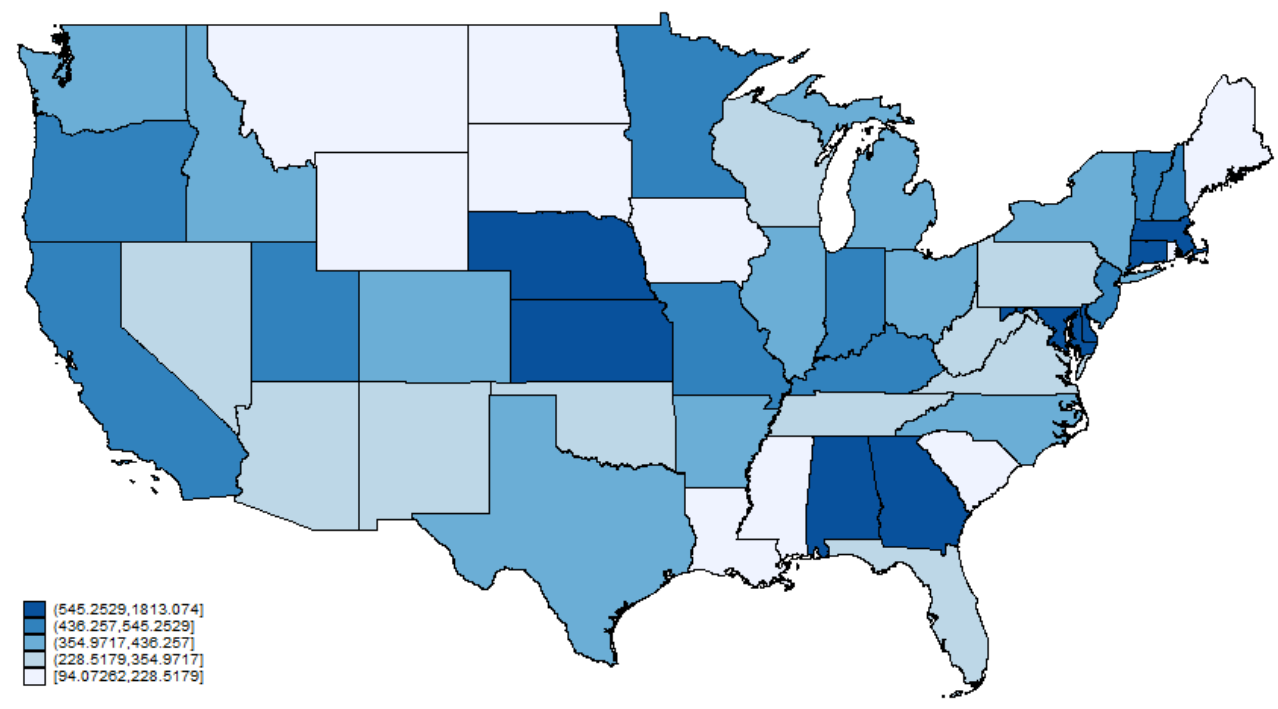

(b) All Technologies

Figure 6.1: Quintiles of green and total patent families per million inhabitants (average 1980-2010). Darker colours correspond to top quintiles. 48 US federal states and District of Columbia are included in the maps. Alaska and Hawaii are left out from the analysis. The cartographic boundary shapefile is provided by the US Census Bureau (Accessed in 2018). 


\subsubsection{Measuring regional knowledge base diversification}

We calculate entropy indicators to measure diversification of regional innovative activities. The advantage is that such measure can be scaled up or down at different levels of aggregation associated with specific degrees of relatedness. In the seminal paper by Frenken and Ron A Boschma (2007), the entropy measure is decomposed into related and unrelated variety to capture the extent to which relatedness and diversification characterise the regional cognitive structures. Recently, Carolina Castaldi, Frenken, and Los (2015) employ the same measure to assess diversification in technological capabilities of US federal states. In the present chapter, we follow Carolina Castaldi, Frenken, and Los (2015) in the use of geographical information on patent families to calculate the entropy indicators using patent data at the state level in US. To do so, we exploit the technological classification codes assigned to each patent. The hierarchical structure of the International Patent Classification (IPC) system can be used to measure variety at different code digits. We calculate related, semi-related and unrelated variety of patenting activities assuming relatedness between two patents when they share the same IPC code. Moreover, this relatedness increases when the number of IPC digits rises. Specifically, unrelated variety (UV) is measured using the entropy of the patent family distribution over IPC 1-digit classes:

$$
U V_{i t}=\sum_{k} s_{k, i t} \ln \left(\frac{1}{s_{k, i t}}\right)
$$


Where $\sum_{k} s_{k, i t}$ is the share of patent families in technological field $k=[1 . . N]$ at IPC 1-digit level, with at least one inventor located in state $i$ at time $t$. Semi-related variety (SRV) is equal to the entropy at 4-digit within each IPC 1-digit level. Given the decomposition theorem developed by Theil (1972), SRV is the difference between the entropy measure calculated at 4-digit and 1-digit level (i.e. UV):

$$
S R V_{i t}=\sum_{l} s_{l, i t} \ln \left(\frac{1}{s_{l, i t}}\right)-\sum_{k} s_{k, i t} \ln \left(\frac{1}{s_{k, i t}}\right)
$$

Where $\sum_{l} s_{l, i t}$ represents the share of patent families in each state over technological fields $l=[1 . . P]$ (IPC 4-digit level). Finally, we calculate related variety $(\mathrm{RV})$ at the IPC 8-digit level. As before, RV is obtained by subtracting to the entropy at 8-digit, the one at 4-digit level. In so doing, we calculate variety across narrow technological fields (i.e. IPC 8-digit level) within each broader technological field (i.e. 4-digit level):

$$
R V_{i t}=\sum_{m} s_{m, i t} \ln \left(\frac{1}{s_{m, i t}}\right)-\sum_{l} s_{l, i t} \ln \left(\frac{1}{s_{l, i t}}\right)
$$

Where $\sum_{m} s_{m, i t}$ is the share of patent families in state $i$ at time $t$ over technological fields $m=[1 . . R]$. As far as we move from UV to RV, the cognitive distance between technological fields decreases. RV is calculated across very similar and specific technological domains compared to UV, which is measured across distant and broad technological fields. 
Finally, we obtain the regional green technological efforts at each stage of the technology life cycle as follow:

$$
G P_{i t}^{L}=\sum_{j} P_{i j(L) t}
$$

for each $L=$ [Emergence, Development, Diffusion, Maturity]

where the green patent families in state $i$ and time $t$ are summed according to the life cycle stage $L$ of green technology $j$ they belong to (see Table 4.1 in chapter 4). The resulting four variables capture the geographical distribution of green patenting activities in each stage of the technology life cycle.

Figure 6.2 shows the distribution of population-weighted green patenting across US states per life cycle stages, i.e. $G P_{i t}^{L}$. A quick comparison across the different panels of the figure shows persistence of leading states in the top quintile of all stages of the life cycle. These states are also characterised by a medium-high patenting activity when the size of green patenting is concerned. Other states are more effective in the production of green technological knowledge just in some stages of the life cycle. Thus, for example, Washington ranks high in the development of green technologies in the developing stage, whereas New York in the development and diffusion stages. Michigan is effective especially in the production of knowledge related to developing and mature green technologies but not in those in the diffusion phase. Conversely, South Carolina falls in the top quintile in the diffusion stage. 


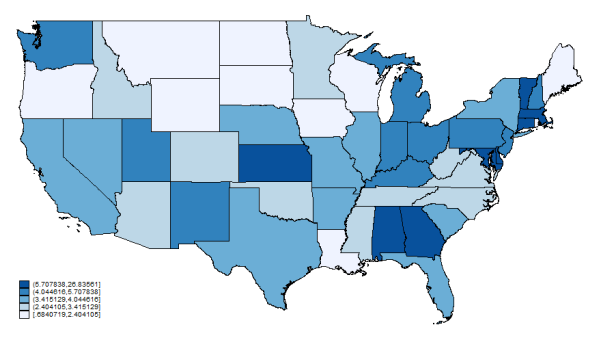

(a) Emergence phase

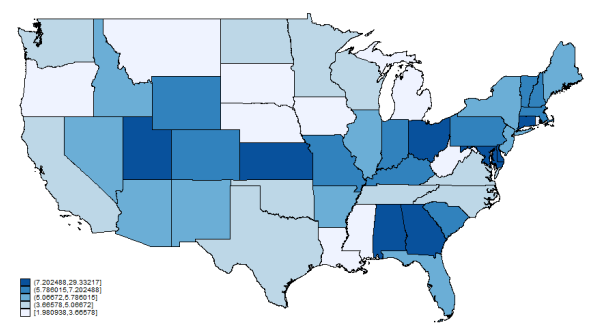

(c) Diffusion phase

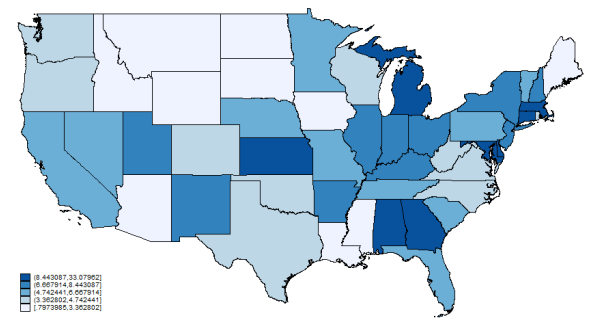

(b) Development phase

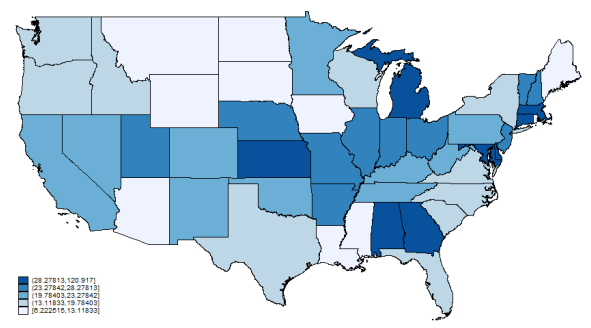

(d) Maturity phase

Figure 6.2: Quintiles of green patent families per million inhabitants over technology life cycle stages (average 1980-2009). Darker colours correspond to top quintiles. 48 US federal states and District of Columbia are included in the maps. Alaska and Hawaii are left out from the analysis. The cartographic boundary shapefile is provided by the US Census Bureau (Accessed in 2018). 


\subsubsection{The empirical model}

To test whether and what type of knowledge base diversification is associated with the generation of new environmental technical knowledge, this chapter employs a Knowledge Production Function (KPF) inspired approach previously formalised by Griliches (1979) that is extended in three directions. First, following Adam B Jaffe (1989) and R. Crescenzi, Rodriguez-Pose, and Storper (2007) we exploit the geographical dimension of the dataset (in our case US states), rather than focussing on firms (Adam B Jaffe, 1986), as unit of analysis to investigate the spatial organisation of innovative activities. Second, we acknowledge that local knowledge diversification plays a pivotal role in the knowledge production process (Jacobs, 1969; Glaeser et al., 1992) and that various forms of variety are associated with different degrees of relatedness between technological domains (Frenken and Ron A Boschma, 2007; Carolina Castaldi, Frenken, and Los, 2015). Third, we integrate the technology life-cycle heuristic into the KPF framework in order to assess which type of variety in the knowledge base is associated with knowledge production process at different the levels of technological maturity. We estimate the following empirical model:

$$
G P_{j t}^{L}=\beta_{1} \text { Variety }_{j t}+\beta_{2} R \& D_{j t}+\beta_{3} H C_{j t}+\text { Controls }_{j t}+\tau_{j}+\gamma_{t}+\delta_{j t}+e_{j t}
$$

where the dependent variable is the number of patent families per million inhabitants in all green technologies and separately for green technologies at different stages of the technology life cycle $(L)$ in state $j$ and year $t$. Variety is 
a proxy for regional knowledge base diversification discussed above that includes UV, SRV and RV. R\&D are research and development expenditures and $H C$ human capital. In some specifications we also include a battery of controls that capture R\&D and human capital in neighbouring states and population density $(\text { Controls })^{1}$. We also include time fixed effects $\left(\gamma_{t}\right)$, state fixed effects $\left(\tau_{j}\right)$ and region specific time trends that control for unobservable heterogeneity that varies linearly over time in each state. The latter enables us to capture, among others, state-specific time patterns that we are not able to control for due to data availability, such as policy intervention, green fiscal reforms, etc. which are usually introduced at federal state level. Finally, $e_{j t}$ captures the residual variation. Table 6.1 provides descriptive statistics of the variables employed in the econometric analysis.

Table 6.1: Descriptive statistics

\begin{tabular}{|c|c|c|c|c|c|c|}
\hline Variable & Description & Obs & Mean & Std. Dev. & Min & $\operatorname{Max}$ \\
\hline UV (IPC 3-dig) & Unrelated variety at 3-digit level & 1,470 & 3.773 & .221 & 2.832 & 4.204 \\
\hline SRV (IPC 4-dig) & Semi-Related Variety at 4-digit level & 1,470 & 1.248 & .205 & .268 & 1.528 \\
\hline RV (IPC 8-dig) & Related Variety at 8-digit level & 1,470 & 1.453 & .361 & .246 & 1.916 \\
\hline GP & Green patent families, pmi & 1,470 & 27.69 & 26.64 & 0 & 300.94 \\
\hline Tot Pat & Total patent families, pmi & 1,470 & 429.6 & 351.24 & 36.18 & 2810.15 \\
\hline Emergence & Green patents, Emergence stage, pmi & 1,470 & 4.451 & 4.781 & 0 & 51.61 \\
\hline Development & Green patents, Development stage, pmi & 1,470 & 6.821 & 9.026 & 0 & 95.21 \\
\hline Diffusion & Green patents, Diffusion stage, pmi & 1,470 & 6.163 & 6.345 & 0 & 83.79 \\
\hline Maturity & Green patents, Maturity stage, pmi & 1,470 & 24.08 & 25.93 & 0 & 320.18 \\
\hline $\mathrm{R} \& \mathrm{D}$ & Research and Development expenditures (w.r.t. GDP) & 1,470 & .014 & .011 & .001 & .066 \\
\hline $\mathrm{HC}$ & $\%$ Population with bachelor degree or more & 1,470 & .057 & .021 & .0321 & .541 \\
\hline R\&D Neighb & Research and Development expenditures in neighbouring states (w.r.t. GDP) & 1,470 & .015 & .007 & .002 & .047 \\
\hline HC Neighb & $\%$ Population with bachelor degree or more in neighbouring states & 1,470 & .055 & .007 & .037 & .093 \\
\hline Pop Dens & Population Density & 1,470 & 4.80 & 1.476 & 1.53 & 9.14 \\
\hline
\end{tabular}

Number of States: 49; Coverage: 1980-2009; pmi= per million inhabitants

\footnotetext{
${ }^{1}$ Neighbour states are defined as states that share a border.
} 


\subsection{Econometric results}

Before exploring the results of the econometric analysis, Figure 6.3 provides a graphical indication of the extent to which green and total patenting are associated with the regional diversification of the knowledge base. There is a positive relationship between patenting activities and variety at different level of relatedness. As far as related variety is concerned, green and total patents follow an almost-overlapping pattern with a relative majority of patents that are generated where greater related variety characterises regional knowledge. However, the distribution of patenting activities over quintiles of unrelated variety shows that this type of diversification is particularly relevant at supporting the generation of green knowledge compared to all patents. At lower levels of unrelated variety, total patenting prevails over green patenting. Conversely, as far as unrelated diversification of the regional knowledge base increases, green patenting is favoured and shows a higher association with this type of variety.

These results are confirmed by the econometric estimation of the model detailed in section 6.3.2 (Table 6.2). Two main specifications are proposed in order to observe the differences between green and total patent families as dependent variable. Common to all specifications is that whereas UV and RV variety are positive and statistically significant in the case of green patents, SRV and RV are positively associated with total (i.e. green plus non green) patenting. This suggests that green inventive activities emerge in states where the knowledge base is diversified across unrelated technological domains. On the other hand, total patenting activities proliferate in states characterised by semi-related and 


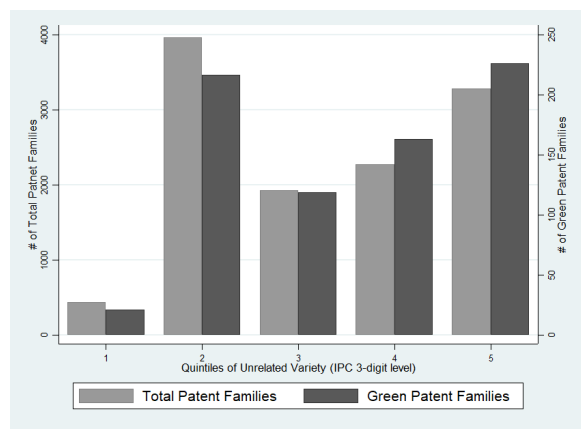

(a) Unrelated variety

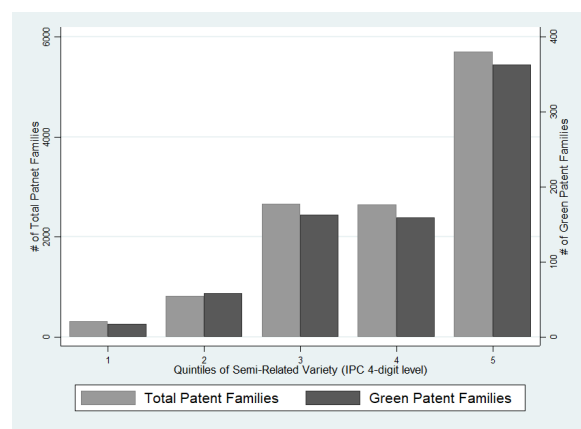

(b) Semi-related variety

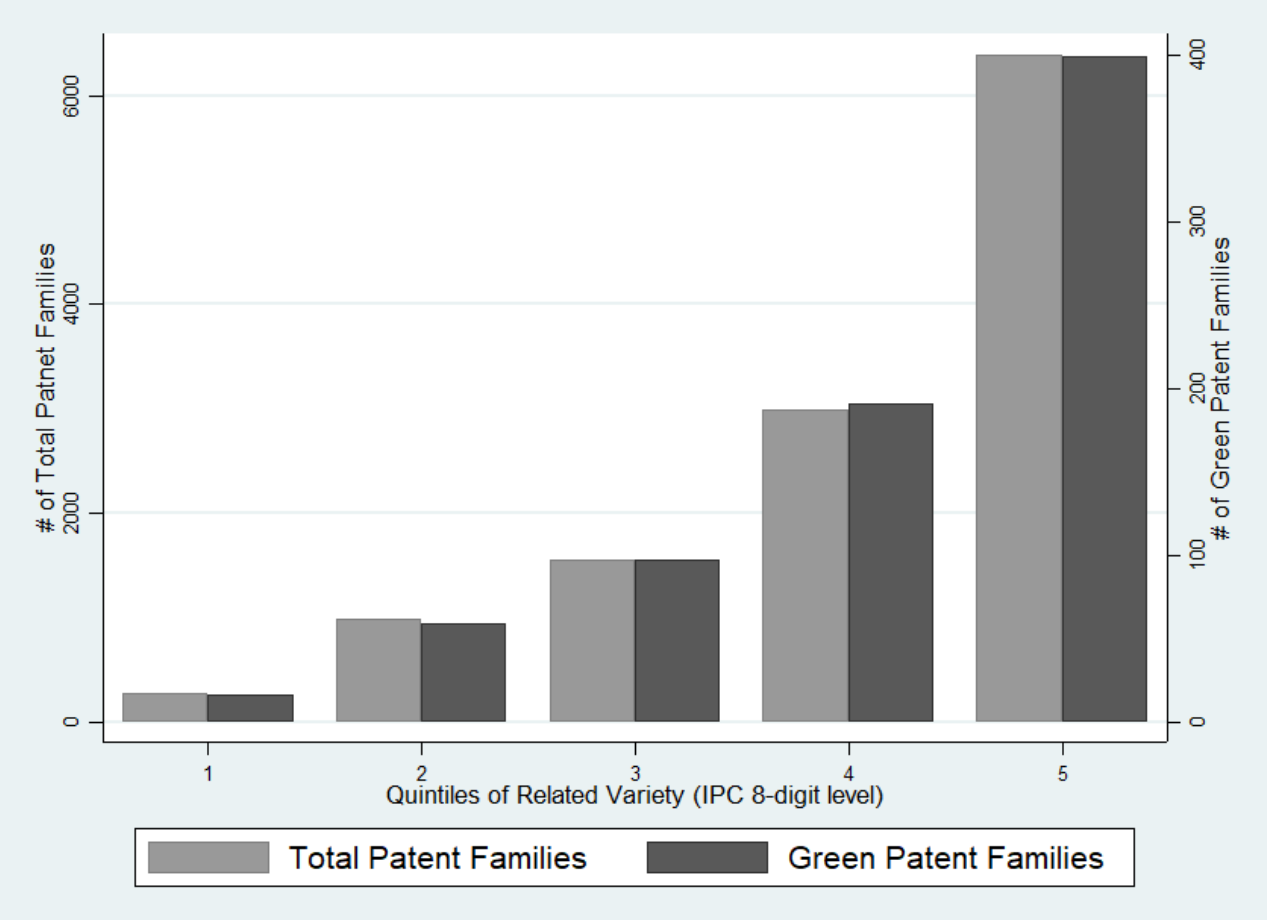

(c) Related variety

Figure 6.3: Distribution of green and total patent families over quintiles of different type of variety (average 1980-2009) 
related diversification across knowledge fields. In addition, when testing the difference between the coefficients in each respective specification, we observe that while UV and RV are significantly different just at 10\%, in the case of total patenting the null hypothesis of equality between SRV and RV coefficients is rejected ${ }^{2}$. This lends support to the notion that green technologies need both diversification across unrelated and related knowledge domains, and differ from total patenting that require more related diversification. The result is in line with studies that emphasise the different nature of green technologies. Barbieri, Marzucchi, and Rizzo (2018) provide evidence of the higher complexity of green innovation, suggesting that the recombination process in the green field requires bits of knowledge with higher cognitive distance. Here we observe this peculiar feature of green technologies from a local perspective. Finally, looking at the innovation input we can observe that human capital is positive and slightly significant across all specifications. On the contrary, the coefficient of R\&D expenditures is not statistically significant in both the green and non-green RKP functions.

Moving to the core of the analysis, Table 6.3 presents the estimates of the model using green patents per capita as dependent variable. First, the coefficient of UV is statistically significant for emerging technologies, thus implying that diversification across unrelated technological fields favours green technologies in the emerging phase. According to the recombinant innovation theory, in the early stage of the life cycle technological development benefits from the richness of cognitively distant bits of knowledge. Together with unrelated variety,

\footnotetext{
${ }^{2}$ The null hypothesis is rejected at $5 \%$
} 
Table 6.2: Regression results

\begin{tabular}{|c|c|c|c|c|c|c|}
\hline & $\begin{array}{c}(1) \\
\text { GP }(\log )\end{array}$ & $\begin{array}{c}(2) \\
\text { Tot Pat (log) }\end{array}$ & $\begin{array}{c}(3) \\
\text { GP }(\log )\end{array}$ & $\begin{array}{c}(4) \\
\text { Tot Pat (log) }\end{array}$ & $\begin{array}{c}(5) \\
\text { GP }(\log ) \\
\end{array}$ & $\begin{array}{c}(6) \\
\text { Tot Pat }(\log )\end{array}$ \\
\hline UV (IPC 3-digit) (log) & $\begin{array}{c}1.413^{* * *} \\
(0.460)\end{array}$ & $\begin{array}{l}-0.875 \\
(0.539)\end{array}$ & $\begin{array}{c}1.403^{* * *} \\
(0.445)\end{array}$ & $\begin{array}{l}-0.881 \\
(0.519)\end{array}$ & $\begin{array}{c}1.386^{* * *} \\
(0.421)\end{array}$ & $\begin{array}{l}-0.931^{*} \\
(0.507)\end{array}$ \\
\hline SRV (IPC 4-digit) (log) & $\begin{array}{l}0.317^{*} \\
(0.179)\end{array}$ & $\begin{array}{l}0.232^{* * *} \\
(0.0655)\end{array}$ & $\begin{array}{c}0.301 \\
(0.179)\end{array}$ & $\begin{array}{c}0.215^{* * *} \\
(0.0682)\end{array}$ & $\begin{array}{c}0.286 \\
(0.184)\end{array}$ & $\begin{array}{c}0.193 * * * \\
(0.0668)\end{array}$ \\
\hline RV (IPC 8-digit) (log) & $\begin{array}{c}0.397 * * * \\
(0.143)\end{array}$ & $\begin{array}{c}0.523^{* * *} \\
(0.0952)\end{array}$ & $\begin{array}{c}0.394^{* * * *} \\
(0.142)\end{array}$ & $\begin{array}{c}0.521^{* * *} \\
(0.0956)\end{array}$ & $\begin{array}{c}0.392^{* *} \\
(0.154)\end{array}$ & $\begin{array}{c}0.515^{* * *} \\
(0.0987)\end{array}$ \\
\hline R\&D (log) & & & $\begin{array}{c}0.0233 \\
(0.0196)\end{array}$ & $\begin{array}{l}0.00806 \\
(0.0112)\end{array}$ & $\begin{array}{c}0.0222 \\
(0.0181)\end{array}$ & $\begin{array}{l}0.00694 \\
(0.0103)\end{array}$ \\
\hline $\mathrm{HC}(\log )$ & & & $\begin{array}{l}0.134^{* *} \\
(0.0644)\end{array}$ & $\begin{array}{c}0.140^{*} \\
(0.0689)\end{array}$ & $\begin{array}{l}0.0960^{*} \\
(0.0545)\end{array}$ & $\begin{array}{l}0.0995^{*} \\
(0.0532)\end{array}$ \\
\hline R\&D Neighb (log) & & & & & $\begin{array}{c}0.0427 \\
(0.0634)\end{array}$ & $\begin{array}{c}0.0278 \\
(0.0280)\end{array}$ \\
\hline HC Neighb (log) & & & & & $\begin{array}{c}0.294 \\
(0.218)\end{array}$ & $\begin{array}{l}0.224^{* *} \\
(0.0829)\end{array}$ \\
\hline Pop Dens & & & & & $\begin{array}{l}-0.502 \\
(0.813)\end{array}$ & $\begin{array}{c}-0.889^{* * *} \\
(0.196)\end{array}$ \\
\hline State FE & $\mathrm{x}$ & $\mathrm{x}$ & $\mathrm{x}$ & $\mathrm{x}$ & $\mathrm{x}$ & $\mathrm{x}$ \\
\hline Time Dummies & $\mathrm{x}$ & $\mathrm{x}$ & $\mathrm{x}$ & $\mathrm{x}$ & $\mathrm{x}$ & $\mathrm{x}$ \\
\hline Random growth & $\mathrm{x}$ & $\mathrm{x}$ & $\mathrm{x}$ & $\mathrm{x}$ & $\mathrm{x}$ & $\mathrm{x}$ \\
\hline Obs. & 1466 & 1470 & 1466 & 1470 & 1466 & 1470 \\
\hline $\mathrm{R}^{2}$ & 0.856 & 0.965 & 0.857 & 0.965 & 0.857 & 0.966 \\
\hline $\mathrm{F}$ & 906429.2 & 216914.8 & 52052121.7 & 225300.1 & 128242.3 & 12321.1 \\
\hline
\end{tabular}

Notes: The analysis covers 48 US Federal States and the District of Columbia over 1980-2009. (Driscoll and Kraay, 1998) standard errors, robust to heteroskedasticity and serial and spatial correlation, in parentheses. ${ }^{*} \mathrm{p}<0.1{ }^{* *} \mathrm{p}<0.05 ;{ }^{* * *} \mathrm{p}<0.01$. 
$R \& D$ expenditures play a key role in this stage of technology evolution. In the subsequent stage of the life cycle, characterised by higher patenting intensity, all types of variety exert a positive effect on green innovative activities. In this phase human capital is positively associated with green patent production. Moving to the diffusion phase, related variety in the local knowledge base is positively correlated with the generation of environmental-related patents. In addition, both the main innovation inputs, i.e. R\&D and human capital are positive and significant. Finally, when maturity is achieved, related variety becomes the main driver of green innovative activities. These results confirm the propositions outlined in the introduction, and are coherent with the conceptual framework of section 6.2. The development of technology along the life cycle requires different types of regional knowledge base diversification and innovation inputs. These elements interact with the selection environment of the surrounding states, in this case, and enable technology to advance. Unrelated variety exerts more influence at the beginning of the life cycle when technologies are at an early stage. Knowledge recombination of cognitive distant knowledge is required to enable experimentation and trial and error. In these early phases also R\&D and human capital are fundamental to trigger patenting activity. However, in the maturity phase, when a dominant design is established, regional diversification is the main driver of green knowledge production though at a higher level of technological relatedness. 
Table 6.3: Regression results over the life cycle

\begin{tabular}{llllll}
\hline & GP (log) & Emergence & Development & Diffusion & Maturity \\
& & & & & \\
\hline UV (IPC 3-digit) (log) & $1.386^{* * *}$ & $0.958^{*}$ & $1.214^{* *}$ & 0.597 & 0.716 \\
& $(0.421)$ & $(0.523)$ & $(0.590)$ & $(0.786)$ & $(0.473)$ \\
SRV (IPC 4-digit) (log) & 0.286 & -0.356 & $0.783^{* * *}$ & 0.166 & -0.205 \\
& $(0.184)$ & $(0.338)$ & $(0.201)$ & $(0.249)$ & $(0.147)$ \\
RV (IPC 8-digit) (log) & $0.392^{* *}$ & 0.421 & $0.516^{* * *}$ & $0.434^{*}$ & $0.554^{* * *}$ \\
& $(0.154)$ & $(0.313)$ & $(0.157)$ & $(0.247)$ & $(0.0848)$ \\
R\&D (log) & 0.0222 & $0.0784^{* *}$ & 0.0192 & $0.0628^{* *}$ & -0.0296 \\
& $(0.0181)$ & $(0.0290)$ & $(0.0414)$ & $(0.0235)$ & $(0.0217)$ \\
HC (log) & $0.0960^{*}$ & -0.0164 & $0.333^{* *}$ & $0.251^{*}$ & -0.000803 \\
& $(0.0545)$ & $(0.105)$ & $(0.127)$ & $(0.143)$ & $(0.0578)$ \\
R\&D Neighb (log) & 0.0427 & $0.197^{* * *}$ & 0.0772 & 0.137 & -0.0518 \\
& $(0.0634)$ & $(0.0517)$ & $(0.102)$ & $(0.0889)$ & $(0.0482)$ \\
HC Neighb (log) & 0.294 & -0.00881 & 0.366 & 0.0946 & $0.860^{* * *}$ \\
& $(0.218)$ & $(0.375)$ & $(0.891)$ & $(0.358)$ & $(0.261)$ \\
Pop Dens & -0.502 & 0.662 & 0.999 & -0.301 & -0.338 \\
& $(0.813)$ & $(0.828)$ & $(0.965)$ & -1.210 & $(0.587)$ \\
State FE & $\mathrm{x}$ & $\mathrm{x}$ & $\mathrm{x}$ & $\mathrm{x}$ & $\mathrm{x}$ \\
Time Dummies & $\mathrm{x}$ & $\mathrm{x}$ & $\mathrm{x}$ & $\mathrm{x}$ & $\mathrm{x}$ \\
Random growth & $\mathrm{x}$ & $\mathrm{x}$ & $\mathrm{x}$ & $\mathrm{x}$ & $\mathrm{x}$ \\
Obs. & \multicolumn{2}{c}{1466} & \multicolumn{2}{c}{1392} & \multicolumn{2}{c}{1371} & \multicolumn{2}{c}{1424} & \multicolumn{1}{c}{1452} \\
r2.w & 0.857 & 0.542 & 0.760 & 0.662 & 0.885 \\
F & 128242.3 & 644300.7 & 86586.6 & 168032.5 & 451319.1 \\
\hline
\end{tabular}

Notes: The analysis covers 48 US Federal States and the District of Columbia over 1980-2009. (Driscoll and Kraay, 1998) standard errors, robust to heteroskedasticity and serial and spatial correlation, in parentheses. ${ }^{*} \mathrm{p}<0.1 ;{ }^{* *} \mathrm{p}<0.05 ;{ }^{* * *} \mathrm{p}<0.01$. 


\subsection{Conclusions}

The present chapter has explored empirically the relationship between local knowledge structures and the generation of green technology in the US over a thirty-year period. We framed the analysis in the life cycle heuristic to test whether the development of green technology benefits from specific types of agglomeration economies at different levels of technological relatedness. While prior literature in economic geography had acknowledged the existence of a life cycle path, this chapter is the first attempt to operationalise the heuristic by means of an empirical framework. The main finding is that local environmentrelated innovation are positively correlated with a knowledge base that is diversified across unrelated technological fields. This is coherent with the notion that green technology is on average more radical and complex than non-green technology, and that it requires a higher variety across cognitively distant domains (De Marchi, 2012; Barbieri, Marzucchi, and Rizzo, 2018). We also find that diversification across unrelated technological domains in local innovative activities favours green innovation mostly at early stages of development. On the other hand, more mature technologies benefit from a diversification across related knowledge domains. This confirms our main conjecture, and is consistent with Castaldi and Giarratana (2014) with regards to the influence of local economic variety on technological innovation. 


\section{Chapter 7}

\section{Public procurement and local}

\section{labour markets}

\subsection{Introduction}

While in previous chapter we focused on the interaction between knowledge base, green technologies and the economical characteristics of the producing territories, being countries or federal states, we look in this chapter at the effects of two important and yet much neglected factors, i.e. public procurement and the skills configuration of employees in local labour markets. On the one hand, public procurement represents an important macroeconomic policy lever, which 
can be considered a demand-side instrument. While extant literature has largely investigated the impact of public procurement on innovation (Nelson, 1982; Geroski, 1990; Ruttan, 2006), the analysis of the impact of public procurement for green inventions is still at an infancy stage (Ghisetti, 2017). On the other hand, skills configurations are the outcome of evolutionary processes of localized learning and accumulation of competences. The composition of the skills bundle at the territorial level represents in this respect a crucial dimension of local knowledge bases, which has not been investigated yet in relationship to the generation of green technologies (GTs). In sum, public procurement and skills composition can be considered as a novel view on demand-pull and technologypush policy levers respectively. Moreover, we present an empirical investigation focusing on territorial units, i.e. commuting zones (CZs). The analysis of the geography of eco-innovation has emerged only recently, and it is still an underdeveloped area of investigation (Ghisetti and Quatraro, 2017; Montresor and Quatraro, 2017). Finally, we provide evidence on the determinants of ecoinnovation in the US, while most of the extant empirical studies have brought forward European evidence.

This chapter is structured as it follows. Section 7.2 articulates the theoretical framework and develops the hypotheses. In Section 7.3 we outline the research design. Section 7.4 presents the results of the econometric analysis. In Section 7.5 we provide a critical discussion of our findings and derive concluding remarks. 


\subsection{Theory and hypotheses development}

Eco-innovations feature a number of characteristics that to some extent make them different from other generic kinds of innovations (Rennings, 2000). On one hand, R\&D efforts leading to the generation of every kind of innovation are likely to be featured by knowledge spillovers. In this context, one expects the allocation of resources to innovation efforts to be optimal because of the difficult appropriability conditions. On the other hand, the specific character of eco-innovation concerns the reduction of external costs related to environment degradation. Unless these external effects can be fully internalized by firms generation GTs, the case for policy intervention emerges to ensure optimal investments levels by private economic agents. This leads to another important aspect, which is related to the role of regulation as a determinant of eco-innovation. Environmental policy is important in that it can set technological standards, prices and pollution thresholds pushing firms to renew their production processes to comply with the prescriptions of environmental regulations and hence reducing their costs. This inducement effect creates new market for GTs, pulling R\&D efforts dedicated to their generation (Johnstone et al., 2012; Nemet, 2009; Hoppmann et al., 2013; Costantini, Crespi, et al., 2015).

Such specificities of GTs bring the institutional context to the core of the analyses of the determinants of their generations. Institutions are in fact placespecific, so that both micro, and meso, and macro-level empirical studies include some proxy of the regulatory framework at the regional or the country level as 
a key variable to explain differences in the production of eco-innovations across firms, regions and countries Barbieri, Ghisetti, et al., 2016. Fewer studies have considered the role of supply side policies, aiming at fostering the development of technological capabilities in green domains through the R\&D supporting schemes (Costantini, Crespi, et al., 2015).

Innovative green public procurement (GPP) has been instead largely neglected in the empirical literature (Ghisetti, 2017). This is particularly problematic for the analysis of the geography of eco-innovation. Public procurement is indeed strongly place-specific, showing a high variance across regions and within regions over time (Heald and Short, 2002; Morgenroth, 2010). Moreover, GPP has been indicated as a key channel favouring the introduction of technologies allowing for meeting targets of environmental sustainability, because of the strong radical, and hence uncertain, nature of this kind of technologies (Mowery, Richard R. Nelson, and Martin, 2010). GPP can be therefore regarded as a direct form of public intervention on the demand side for GTs, by means of the government expenditure macroeconomic lever bearing effects on the development of environmentally sound products (Parikka-Alhola, 2008). The arguments developed so far lead us to spell out our first hypothesis:

H1: Territorial differences in GPP are associated with green technological change differentials across regions.

The full appreciation of the mechanisms underlying knowledge production is crucial to gain a comprehensive view on the spatial dynamics of GTs generation. Knowledge recombination has long been acknowledged as the main dynamics 
underlying the generation of new knowledge, and eventually new technologies (Weitzman, 1996 and 1998; Fleming and Sorenson, 2001). Knowledge shows a co-relational structure emerging from the connections that innovating agents establish amongst the different ideas to produce novelty (Saviotti, 2007). The accumulation of competences through learning dynamics make it easier to combine together pieces of knowledge with which innovating are familiar, rather than to combine pieces of knowledge that are far away from agents' competences. Successful innovation processes appears to be grounded therefore on highly coherent knowledge bases (Quatraro, 2010; Krafft et al., 2014). Recent empirical evidence would suggest that eco-innovations are specific also in this respect, as they are more likely to emerge out of the hybridization of technologies that do not share important commonalities. GTs are often the result of the combination of green and dirty technologies in new and unprecedented ways (Zeppini and van der Bergh, 2011; Dechezlepetre et al., 2004; Colombelli and Quatraro, 2017). The combination of knowledge inputs that loosely related requires the capacity to manage exploration-oriented search processes to move beyond the fences of established technological domains (Nightingale, 1988). At the territorial level, the accumulation of tacit skills that enhance the capacity to explore heterogeneous technological domains to envisage new recombination opportunities represents therefore an enabling condition for green technological change. This leads us to our second hypothesis:

H2: The prevalence of exploration-oriented skills in local contexts is associated with higher levels of green technological change. 
Skills configuration and GPP have been indicated as two main drivers of green technological change at the local level. However, due to the double externality problem, the endowment of exploration-oriented skills at the local level can hardly display its full potential in terms of GTs enablers, because of the reluctance of economic agents to undertake such uncertain ventures like innovation activities in presence of strong externalities and low appropriability conditions. On the other hand, high levels of GPP are likely to be more effective in the stimulation of the production of environmentally sound technologies in areas that are characterized by local availability of exploration-oriented skills. The two dimensions are likely to show a high degree of interdependence and mutual enforcing dynamics. These considerations lead us to spell us our third hypothesis.

H3: The prevalence of exploration-oriented skills and high levels of GPP in local context are mutually enforcing in affecting the rate of green technological change.

In view of the hypotheses developed in this section, the rest of the chapter will provide an empirical analysis based on the US evidence. Next section illustrates the empirical strategy.

\subsection{Research design}

Following the literature on US local labour market dynamics, we focus our analysis at the level of Commuting Zones (CZs). Both public procurement and innovation dynamics are indeed likely to be strongly attached to local features 
of employment and skills endowments. The spatial level of analysis should thus be cautiously selected when innovation and procurement dynamics are under scrutiny. CZs seem to be really suitable in this sense. The concept of CZs was firstly developed by Tolbert and Sizer (1996) who used county-level commuting data from the 1990 Census data to create 741 clusters of counties that are characterized by strong commuting ties within $\mathrm{CZs}$, and weak commuting ties across CZs. Since the contribution by Dorn (2009), this geographic construction for defining regional economies in the US has been widely accepted as the best tool for studying local labour market dynamics. Even if we do not directly focus on labour market dynamics, local occupational-task compositions play a crucial role in our analysis. This justifies our choice.

\subsubsection{Data and variables}

We exploit three main sources of data at the level of CZs to measure: i) the green innovative local effort, proxied by patenting activity; ii) the level of local green procurement expenditures and iii) the local composition of occupational tasks.

The local level of green innovation activity is measured through the fractionalized $^{1}$ stock of US-invented green patent families, as defined in chapter 2 . The stock of green patents is weighted by forward (family) citations received ${ }^{2}$.

\footnotetext{
${ }^{1}$ Patent $p$ is assigned to $\mathrm{CZ} c$ according to the fraction of inventors resident in $\mathrm{CZ} c$ over the total number of inventors filing the patent $p$.

${ }^{2}$ In order to make citations comparable across years and ENV-TECH technologies, we calculate a weighted number of citations, dividing the raw number of citations by the average number of citations in the same year $t$ and the same technology $j$, and then by the average number of citations in the same year $t$, following the method proposed by Hall et al. (2001): N.cit.weighted $=\frac{N . c i t}{\frac{A v g N . c i t}{t, j}}$
} 
Weighting by forward citations allows us to account for the intrinsic technological value of the local protected inventions.

The green patent stock per $\mathrm{CZ} j$ at time $t$ is thus calculated as:

$$
\text { Stock }_{j, t}=N \cdot \text { Pat }_{j, t}+\left[(1-\delta) \times \text { Stock }_{j, t-1}\right],
$$

where $\delta$ is the decay rate. ${ }^{3}$

Furthermore, by exploiting the ENV-TECH classification, we differentiate the GT-stock between two macro-technology groups: i) green adaptation technologies (ENV-TECH families (1) and (2)); and ii) green mitigation technologies (ENV-TECH families from (4) to (9)). Figure 7.1 plots the geographic quintile distribution of GT patents at the level of CZs for the period 2000-2011. Precisely, panel c) refers to the total number of GT patents, panel a) to green mitigation technologies and panel b) to green adaptation technologies, respectively.

\section{Procurement data}

Second, we collect data on environmental-related procurement expenditures by exploiting public information provided by the USAspending.gov resource (https://www. usaspending.gov). Procurement information is available from 2000 on.

The Federal Funding Accountability and Transparency Act of 2006 (FFATA) was signed into law on September 26, 2006. The legislation required that federal

\footnotetext{
${ }^{3}$ We calculate patent stocks with the permanent inventory method, applying a $15 \%$ annual rate of obsolescence.
} 


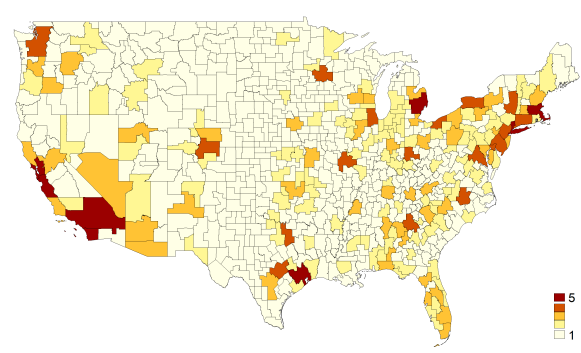

(a) GT-mitigation patents

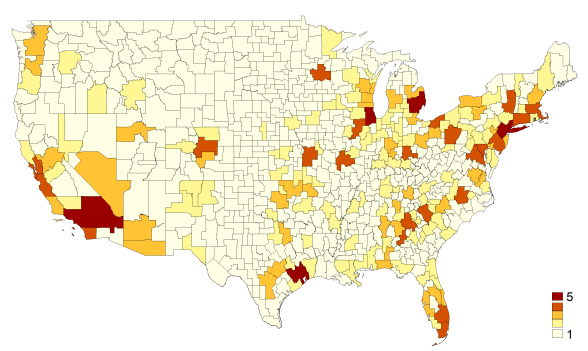

(b) GT-adaptation patents

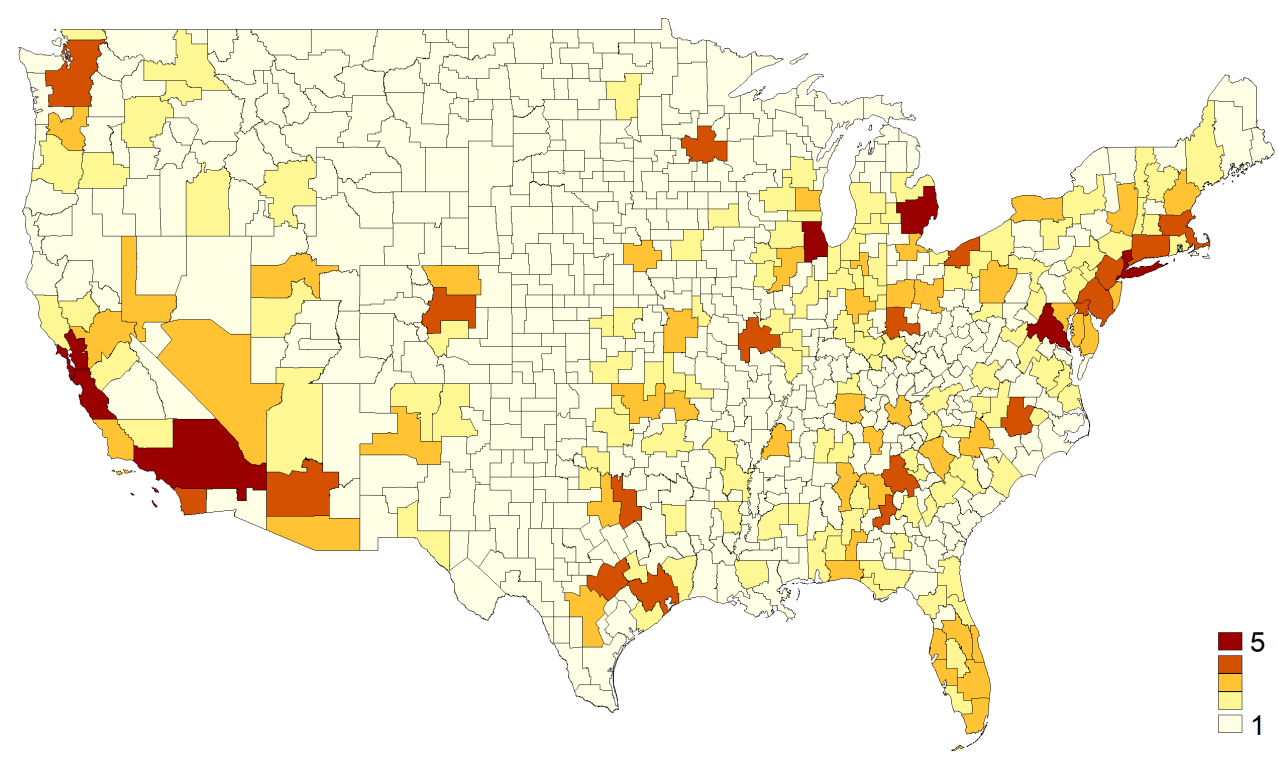

(c) Total GT patents

Figure 7.1: Geographic distribution of GT patents, 2000-2011 (quintiles) 
contract, grant, loan, and other financial assistance awards of more than $\$ 25,000$ be displayed on a searchable, publicly accessible website, USAspending.gov, to give the American public access to information on how their tax dollars are being spent. As a matter of discretion, USAspending.gov also displays certain federal contracts of more than $\$ 3,000$. The initial site went live in 2007. Federal agencies are required to report the name of the entity receiving the award, the amount of the award, the recipient's location, the place of performance location, as well as other information.

Precisely, we exploit data on all registered federal contracts. From each funded contract we extract information about the place of performance location (5-digits Zipcode $)^{4}$ where the contract is executed and the amount of resources dedicated (in 2010 USD). According to the Product and Service Codes Manual (PSC, August 2015 Edition), we are able to individuate procured "green" contracts and to distinguish them between product-, and service-related. ${ }^{5}$ Indeed, the PSC Manual provides codes to describe products, services, and R\&D purchased by the federal government for each contract action reported in the Federal Procurement Data System (FPDS). Since a contract may include multiple products/services, with and without environmental attributes, the PSC data element code has been selected based on the predominant product or service that is being purchased.

\footnotetext{
${ }^{4} 5$-digits Zipcodes allow us to assign precise levels of expenditures to counties and, consequently, to CZs.

${ }^{5}$ Statutory requirements and Executive Order 13514 direct the Office of Management and Budget (OMB) Office of Federal Procurement Policy (OFPP) to report on procurement of products and services with environmental attributes including recycled content, bio-based, and energy efficient. Data collected in the Federal Procurement Data System include these three environmental attributes plus an "environmentally preferable" attribute. This last attribute means products or services that have a lesser or reduced effect on human health and the environment when compared with competing products or services that serve the same purpose.
} 
Figure 7.2 plots the geographic quintile distribution of GPP expenditures at the level of CZs for the period 2000-2011. Precisely, panel c) refers to the total level of expenditures, panel a) to GPP for products, panel b) to GPP for services, respectively.

\section{Occupational-task data}

To capture the role of human capital in local labour markets, we rely on the task-based framework originally proposed by (Autor, Levy, and Murnane, 2003) and recently extended to the analysis at geographical level by Autor and Dorn (2013). This line of empirical research represents a significant break from the traditional approach to human capital. Rather than traditional indicators such as i.e. the average number of years of education in the workforce or the share of individuals with postgraduate degrees human capital endowment is analysed by looking at the relative importance of typologies of occupations. These are identified by focusing on work activities and the attending skills needed to perform the essential tasks of a job.

In this framework work activities are grouped in three broad categories. First, routine tasks that entail executing codified instructions with minimal discretion on the part of the worker. Routine tasks are characteristic of middle-skilled jobs that entail repetitive cognitive (i.e. clerks) or manual (i.e. blue-collar) duties. The second main category of work task include activities that require creativity, problem-solving, intuition and social perceptiveness. These abstract tasks are characteristic of professional, managerial, technical and creative occupations that require high levels of formal education. Since analytic and 


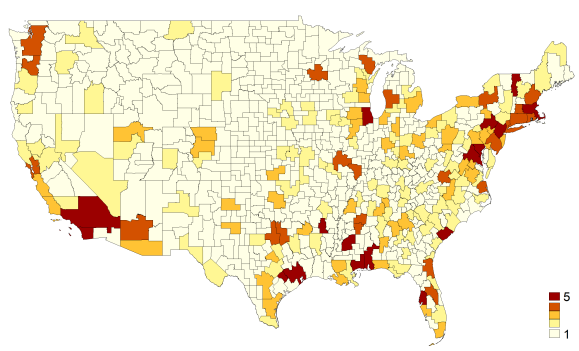

(a) Product GPP

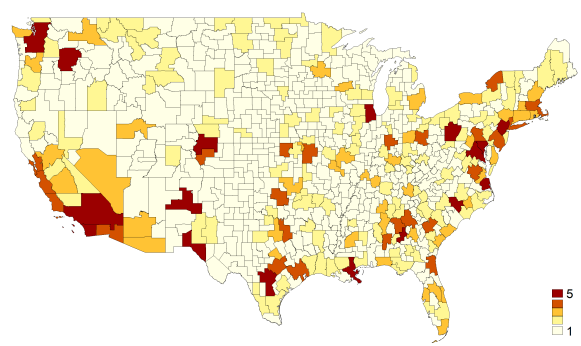

(b) Service GPP

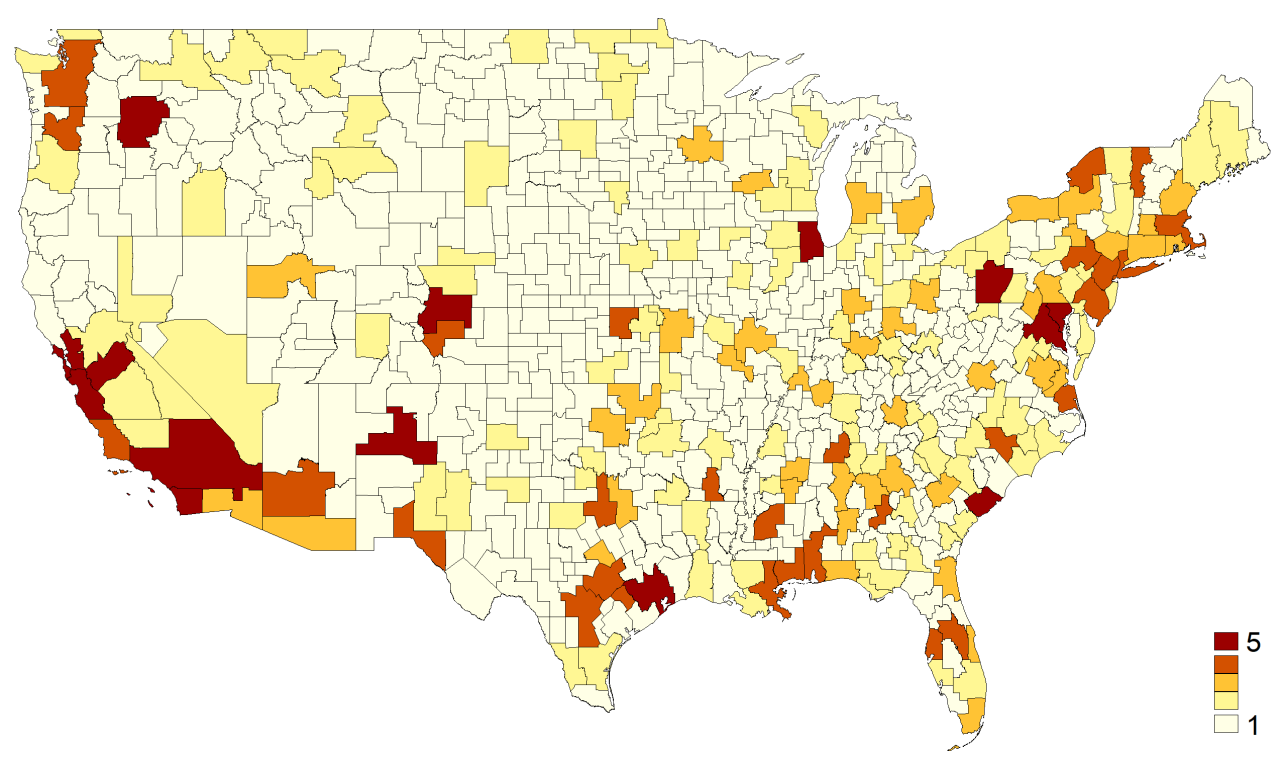

(c) Total GPP

Figure 7.2: Geographic distribution of GPP expenditures, 2000-2011 (quintiles) 
interpersonal capabilities are so important, technology accrue productivity benefits to these workers by facilitating the transmission, organization, and processing of information. On the other side of the skill spectrum are manual tasks, which demand visual and language recognition, personal interaction and physical dexterity. Occupations that use intensively these tasks are typically low-skill service jobs such as food preparation, catering, driving and cleaning.

Following prior empirical studies along these tracks (Autor, Levy, and Murnane, 2003; Autor, Katz, and Kearney, 2006; Dorn, 2009; Autor and Dorn, 2013) we merge job task requirements from the fourth edition of the US Department of Labour's Dictionary of Occupational Titles (DOT) (US Department of Labor 1977) to their corresponding Census occupation classifications to measure routine, abstract, and manual task content by occupation. ${ }^{6}$ We combine these measures to create summary indicators of task-intensity by occupation (routine RTI, abstract ATI and manual MTI), calculated as

$$
\begin{aligned}
& A T I_{k}=\ln \left(T_{k, 1980}^{A}\right)-\ln \left(T_{k, 1980}^{R}\right)-\ln \left(T_{k, 1980}^{M}\right), \\
& R T I_{k}=\ln \left(T_{k, 1980}^{R}\right)-\ln \left(T_{k, 1980}^{A}\right)-\ln \left(T_{k, 1980}^{M}\right), \\
& M T I_{k}=\ln \left(T_{k, 1980}^{M}\right)-\ln \left(T_{k, 1980}^{A}\right)-\ln \left(T_{k, 1980}^{R}\right),
\end{aligned}
$$

where, $T_{k}^{R}, T_{k}^{A}$ and $T_{k}^{M}$ are, respectively, the routine, abstract, and manual task inputs in each occupation $k$ in $1980 .{ }^{7}$ For each kind of task, this measure

\footnotetext{
${ }^{6}$ The DOT permits an occupation to comprise multiple tasks at different levels of intensity.

${ }^{7}$ Tasks are measured on a zero to ten scale.
} 
rises in its importance in each occupation and declines in the importance of the other two tasks.

Next, to operationalize these measures constructs at the geographic level, we take two additional steps. We first use the task intensity index to identify the set of occupations that are in the top employment-weighted third of task-intensity in 1980. We refer to these as either abstract-, routine- or manual-intensive occupations. We next calculate for each $\mathrm{CZ} j$ a task employment share measure $\left(R S H_{j t}, A S H_{j t}\right.$ and $\left.M S H_{j t}\right)$ equal to:

$$
\begin{aligned}
A S H_{j t} & =\left(\sum_{k=1}^{K} L_{j k t} \cdot \mathbb{1}\left[A T I_{k}>A T I^{P 66}\right]\right)\left(\sum_{k=1}^{K} L_{j k t}\right)^{-1}, \\
R S H_{j t} & =\left(\sum_{k=1}^{K} L_{j k t} \cdot \mathbb{1}\left[R T I_{k}>R T I^{P 66}\right]\right)\left(\sum_{k=1}^{K} L_{j k t}\right)^{-1}, \\
M S H_{j t} & =\left(\sum_{k=1}^{K} L_{j k t} \cdot \mathbb{1}\left[M T I_{k}>M T I^{P 66}\right]\right)\left(\sum_{k=1}^{K} L_{j k t}\right)^{-1},
\end{aligned}
$$

where $L_{j k t}$ is the employment in occupation $k$ in $\mathrm{CZ} j$ at time $t$, and $\mathbb{1}[\cdot]$ is the indicator function, which takes the value of one if the occupation is task intensive by our definition.

Finally, according to the shares calculated from (7.5) to (7.7), we assign a set of dummies equal to 1 if the $\mathrm{CZ} j$ is in the top third of national task share at time $t$ :

$$
A I_{j t}=\mathbb{1}\left[A S H_{j t}>A S H_{t}^{P 66}\right],
$$




$$
\begin{aligned}
R I_{j t} & =\mathbb{1}\left[R S H_{j t}>R S H_{t}^{P 66}\right], \\
M I_{j t} & =\mathbb{1}\left[M S H_{j t}>M S H_{t}^{P 66}\right] .
\end{aligned}
$$

This characterization of local labour markets allows us to investigate whether diverse occupational task compositions moderate the effect of green public procurement on the generation of GTs.

Figure 7.3 plots the geographic quintile distribution of task-intensive occupations at the level of CZs in 2005. Precisely, panel a) refers to abstract-intensive occupations, panel b) to routine-intensive occupations, panel c) to manualintensive occupations, respectively.

\subsubsection{Empirical strategy}

Using the full sample of 722 CZs observed from 2000 to 2011, we fit models of the following form to investigate the relationship between green public procurement and the local level of green technological activity:

$$
Y_{j, t}=\beta_{0}+\beta_{1} G P P_{j, t-1}+\boldsymbol{X}_{j, t}^{\prime} \beta_{2}+\epsilon_{j, t}
$$

where $Y_{j, t}$ is the (log transformed) fractionalized stock of green patent families (weighted by forward citations) at time $t$ filed by inventors resident in $\mathrm{CZ}$ $j ; G P P_{j, t-1}$ is the (log transformed) level of expenditures for green public procurement performed in CZ $j$ at time $t-1$ (2010 USD); additionally, the vector $\boldsymbol{X}_{\boldsymbol{j}, \boldsymbol{t}}^{\prime}$ contains (in most specifications) a rich set of controls for CZs' 


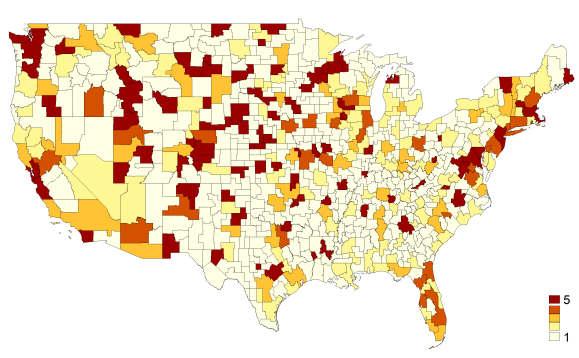

(a) Abstract

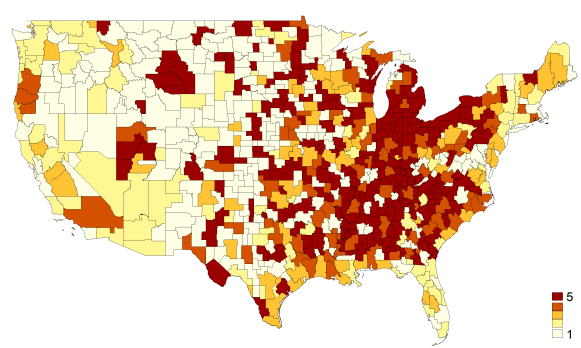

(b) Routine

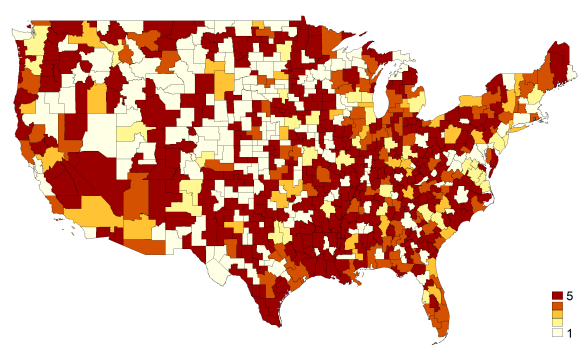

(c) Manual

Figure 7.3: Geographic distribution of task-intensive occupations, 2005 (quintiles) 
labour force and demographic composition that might independently affect innovation outcomes. Standard errors are clustered at the State level to account for spatial correlations across CZs.

To test for moderating effects of local heterogeneity in terms of $\mathrm{CZ}$ occupational task compositions on green innovation activities, we estimate three models, augmenting (7.11) as follows:

$$
\begin{gathered}
Y_{j, t}=\beta_{0}+\beta_{1} G P P_{j, t-1}+\beta_{2} R I_{j, t-1}+\beta_{3} G P P_{j, t-1} \times R I_{j, t-1}+\boldsymbol{X}_{j, t}^{\prime} \beta_{4}+\epsilon_{j, t} . \\
Y_{j, t}=\beta_{0}+\beta_{1} G P P_{j, t-1}+\beta_{2} A I_{j, t-1}+\beta_{3} G P P_{j, t-1} \times A I_{j, t-1}+\boldsymbol{X}_{j, t}^{\prime} \beta_{4}+\epsilon_{j, t} .
\end{gathered}
$$

$$
\begin{aligned}
Y_{j, t}= & \beta_{0}+\beta_{1} G P P_{j, t-1}+\beta_{2} M I_{j, t-1}+\beta_{3} G P P_{j, t-1} \times M I_{j, t-1}+ \\
& +\boldsymbol{X}_{\boldsymbol{j}, \boldsymbol{t}}^{\prime} \beta_{4}+\epsilon_{j, t} .
\end{aligned}
$$

where dummy variables $R I_{j, t-1}, A I_{j, t-1}$ and $M I_{j, t-1}$ are calculated according to equations from $(7.8)$ to $(7.10){ }^{8}$

\footnotetext{
${ }^{8}$ Due to occupational data availability, the period considered for this second step of the analysis reduces (2005-2011).
} 
Exploiting the ENV-TECH classification, we are also able to differentiate between diverse types of green technologies. In the final step of the analysis we thus change our dependent variable accordingly, re-estimating equations from (7.11) to (7.14). Precisely, we aggregate technologies in two precise groups: mitigation and adaptation GTs. ${ }^{9}$

\subsection{Results}

Section 7.2 puts forward the key hypotheses driving our study, according to which we expect that GPP exerts a positive impact on the local dynamics of GT generation, because of the double externality problem and the regulatory push/pull effect. Moreover, we expect that the configuration of the skill bundle in local labour markets also affect the process by which green inventions are brought about, because of the spanning of the recombinant innovation process over a large number of heterogeneous technological components.

\footnotetext{
${ }^{9}$ Mitigation technologies aggregate ENV-TECH technologies from (4) to (9). Adaptation technologies are the ones related to groups (1) and (2).
} 


\begin{tabular}{|c|c|c|c|c|c|c|}
\hline & (I) & (II) & (III) & $(\mathrm{IV})$ & $(\mathrm{V})$ & $(\mathrm{VI})$ \\
\hline tot GPP & $\begin{array}{c}0.082^{* * *} \\
(0.009)\end{array}$ & $\begin{array}{c}0.068^{* * *} \\
(0.009)\end{array}$ & $\begin{array}{c}0.067^{* * *} \\
(0.009)\end{array}$ & $\begin{array}{c}0.064^{* * *} \\
(0.009)\end{array}$ & $\begin{array}{c}0.063^{* * *} \\
(0.009)\end{array}$ & $\begin{array}{c}0.077^{\text {*** }} \\
(0.010)\end{array}$ \\
\hline pop density & & $\begin{array}{l}0.003^{* *} \\
(0.001)\end{array}$ & $\begin{array}{c}0.004^{* * *} \\
(0.001)\end{array}$ & $\begin{array}{c}0.003^{* * *} \\
(0.001)\end{array}$ & $\begin{array}{c}0.003^{* * *} \\
(0.001)\end{array}$ & $\begin{array}{c}-0.000 \\
(0.000)\end{array}$ \\
\hline employment share & & & $\begin{array}{c}-0.000^{* * * *} \\
(0.000)\end{array}$ & $\begin{array}{c}-0.000^{* * * *} \\
(0.000)\end{array}$ & $\begin{array}{c}-0.000^{* * *} \\
(0.000)\end{array}$ & $\begin{array}{c}-0.000^{*} \\
(0.000)\end{array}$ \\
\hline N. of firms & & & & $\begin{array}{c}0.000^{*} \\
(0.000)\end{array}$ & $\begin{array}{c}0.000^{*} \\
(0.000)\end{array}$ & $\begin{array}{c}0.000^{* * *} \\
(0.000)\end{array}$ \\
\hline share of R\&D employment & & & & & $\begin{array}{c}6.686^{*} \\
(3.824)\end{array}$ & $\begin{array}{l}8.584^{* *} \\
(4.260)\end{array}$ \\
\hline $\mathrm{r} 2{ }_{-} \mathrm{w}$ & 0.383 & 0.399 & 0.403 & 0.404 & 0.405 & 0.386 \\
\hline r2_o & 0.147 & 0.127 & 0.073 & 0.084 & 0.085 & 0.501 \\
\hline r2_b & 0.551 & 0.125 & 0.071 & 0.082 & 0.082 & 0.508 \\
\hline$N$ & 7937 & 7937 & 7937 & 7937 & 7937 & 7937 \\
\hline \multirow{2}{*}{\multicolumn{7}{|c|}{$\begin{array}{l}\text { Dep. Var.: Stock of fractionalized patent families weighted by forward citations (log). } \\
\text { GPP lagged 1-year. Standard errors clustered at the level of State. }\end{array}$}} \\
\hline & & & & & & \\
\hline \multicolumn{7}{|c|}{ Models I to V, estimated in fixed effect, include a constant and year dummies. } \\
\hline \multicolumn{7}{|c|}{ Model VI includes also geographic dummies (9 Census divisions). } \\
\hline
\end{tabular}

Table 7.1: Effect of total green procurement on GT stock (2001-2011) 
Table 7.2: Effect of GPP for products on GT stock (2001-2011)

\begin{tabular}{|c|c|c|c|c|c|c|}
\hline & (I) & (II) & (III) & $(\mathrm{IV})$ & $(\mathrm{V})$ & $(\mathrm{VI})$ \\
\hline product GPP & $\begin{array}{c}0.073^{* * *} \\
(0.013)\end{array}$ & $\begin{array}{c}0.050^{* * *} \\
(0.012)\end{array}$ & $\begin{array}{c}0.049^{* * *} \\
(0.012)\end{array}$ & $\begin{array}{c}0.041^{* * *} \\
(0.012)\end{array}$ & $\begin{array}{c}0.041^{* * *} \\
(0.012)\end{array}$ & $\begin{array}{c}0.053^{* * *} \\
(0.013)\end{array}$ \\
\hline pop density & & $\begin{array}{l}0.004^{* *} \\
(0.002)\end{array}$ & $\begin{array}{c}0.004^{* * *} \\
(0.001)\end{array}$ & $\begin{array}{c}0.004^{* * *} \\
(0.001)\end{array}$ & $\begin{array}{c}0.004^{* * *} \\
(0.001)\end{array}$ & $\begin{array}{l}-0.000 \\
(0.000)\end{array}$ \\
\hline employment share & & & $\begin{array}{c}-0.000^{* * * *} \\
(0.000)\end{array}$ & $\begin{array}{c}-0.000^{* * * *} \\
(0.000)\end{array}$ & $\begin{array}{c}-0.000^{* * * *} \\
(0.000)\end{array}$ & $\begin{array}{c}-0.000^{* *} \\
(0.000)\end{array}$ \\
\hline N. of firms & & & & $\begin{array}{l}0.000^{* *} \\
(0.000)\end{array}$ & $\begin{array}{l}0.000^{* *} \\
(0.000)\end{array}$ & $\begin{array}{c}0.000^{* * *} \\
(0.000)\end{array}$ \\
\hline share of R\&D employment & & & & & $\begin{array}{l}6.972^{*} \\
(3.888)\end{array}$ & $\begin{array}{l}8.609^{* *} \\
(4.378)\end{array}$ \\
\hline $\mathrm{r} 2 \mathrm{w}$ & 0.365 & 0.385 & 0.389 & 0.391 & 0.392 & 0.371 \\
\hline r2_o & 0.067 & 0.118 & 0.069 & 0.082 & 0.083 & 0.472 \\
\hline $\mathrm{r} 2 \mathrm{~b}$ & 0.432 & 0.118 & 0.068 & 0.080 & 0.081 & 0.478 \\
\hline$N^{-}$ & 7933 & 7933 & 7933 & 7933 & 7933 & 7933 \\
\hline $\begin{array}{l}\text { Dep. Var.: Stock of fractionalized } \\
\text { GPP lagged } 1 \text {-year. Standard error } \\
\text { Models I to V, estimated in fixed e } \\
\text { Model VI includes also geographic } \\
{ }^{*} p<.1,{ }^{* *} p<.05,{ }^{* * *} p<.01\end{array}$ & $\begin{array}{l}\text { tent families } \\
\text { clustered at } \\
\text { ect, include } \\
\text { ummies (9 C }\end{array}$ & $\begin{array}{l}\text { weighted by } \\
\text { the level of } \\
\text { constant al } \\
\text { nsus divisio }\end{array}$ & $\begin{array}{l}\text { Orward cita } \\
\text { ate. } \\
\text { year dumn }\end{array}$ & ns $(\log )$. & & \\
\hline
\end{tabular}


Table 7.3: Effect of GPP for services on GT stock (2001-2011)

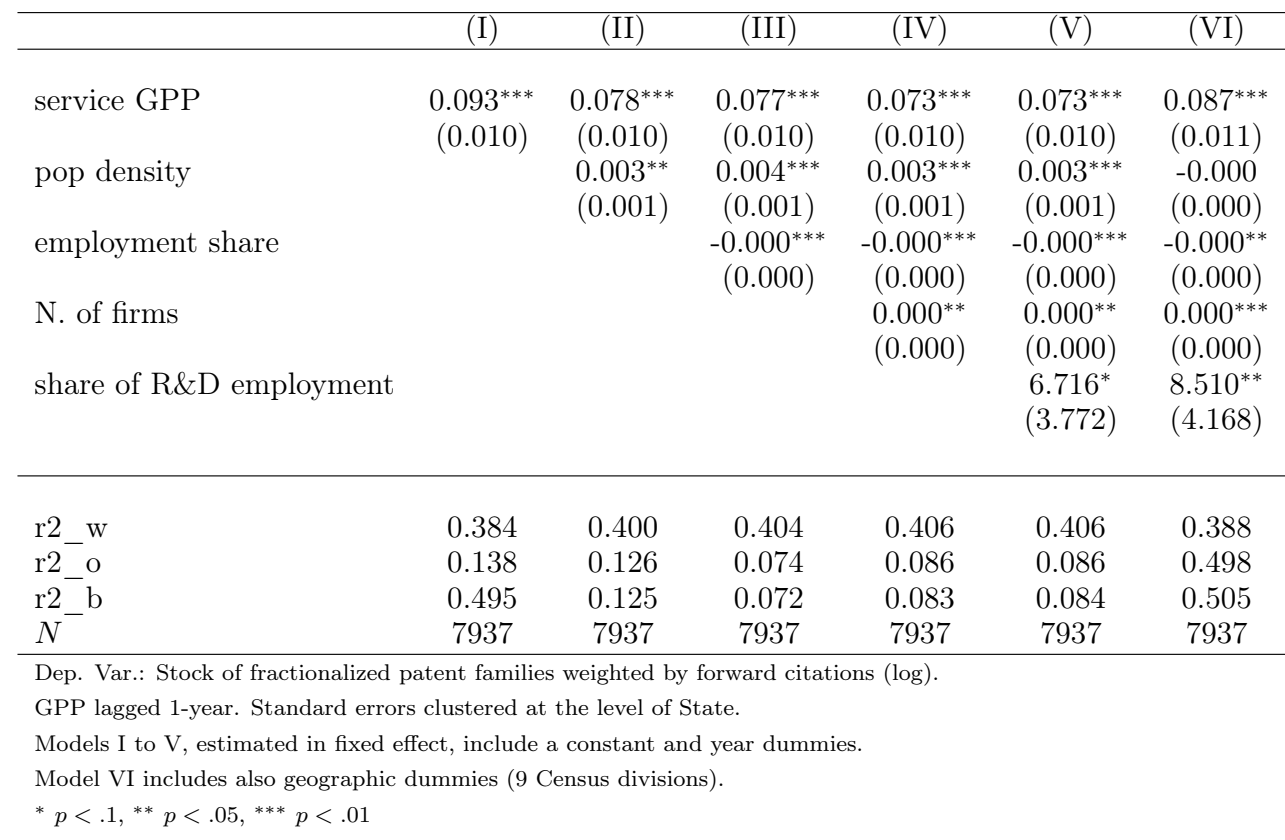

Tables 7.1, 7.2 and 7.3 present the results of the baseline estimates of the relationship between expenditures in GPP and the local environmental innovation capacity. Table 7.1 shows the estimates for the effect of the overall levels of GPP. Tables 7.2 and 7.3 focus instead on product-related and service-related GPP, respectively. Our dependent variable is the log transformed level of fractionalized stock of local environmental patents, weighted by forward citations corrected for patent equivalents (patent families).

Columns from I to $\mathrm{V}$ of Table 7.1 provide the results of $\mathrm{CZ}$ fixed-effect estimations of equation (7.11), by gradually saturating the empirical model with the controls described in Section 7.3.1. GPP in column one shows a positive and 
significant coefficient. Although we use CZ fixed effects, this result can hide some effects of unobserved variables that one may want to mitigate. For this reasons in Column II we add a control for the population density of the area. This variable is used in empirical studies to proxy the effect of agglomeration economies. The coefficient of this variable is positive and significant as one could have expected. Most importantly, the coefficient of GPP is still positive and significant, though its magnitude is slightly lower than in the previous estimation. Estimates reported in Column III also include employment share, the coefficient of which is negative and significant . The other coefficients are in line with previous estimations. In Columns IV and V we add to the estimated models the number of firms observed in the area and the share of R\&D employment respectively. Both coefficient are positive and significant. Still, the coefficient of GPP preserves the sign and statistical significance.

Column VI estimates equation (7.11) obtained by substituting fixed effects for the nine US Census macro-areas for CZ fixed-effects. The overall results suggest that the effect of GPP is robust across different model specifications. In particular, we can quantify the positive and significant impact of GPP on local green innovation activities: a 1\% increase in GPP leads to some $0.077 \%$ increase in the stock of green patents in the local areas.

Tables 7.2 and 7.3 replicate the same strategy as the one proposed in Table 7.1 but focusing on the effects of, respectively, GPP for products and GPP for services on the total stock of green technological knowledge at the local level. We find a significant and positive effect of both types of public procurement expenditures. Importantly, we do observe that expenditures for procured green 
services show higher effectiveness in boosting the overall level of local green innovation activity than expenditures for procured green products. If one looks at Column VI of both tables, it comes that a $1 \%$ increase in GPP for products yields a $0.053 \%$ increase in the local stock of GTs, while the same variation in GPP for services yields a $0.087 \%$ increase in the local stock of GTs.

The overall picture emerging from this first set of estimates provides empirical support to our Hypothesis 1, according to which GPP is expected to positively affect the local accumulation of GT stock.

We can now turn to investigation of the effects of the local occupational task compositions on GTs stock, drawing upon the measures proposed in Section 7.3.1. Our aim is to test for the direct of the local skills configuration on the local stock of GTs, as well as how they moderate the relationship between GPP and local green innovation capacity. 
Table 7.4: Effect of total GPP and task composition on GT stock (2006-2011)

\begin{tabular}{|c|c|c|c|c|c|c|}
\hline & (I) & (II) & (III) & (IV) & (V) & (VI) \\
\hline tot GPP & $\begin{array}{c}0.039^{* * *} \\
(0.008)\end{array}$ & $\begin{array}{c}0.039^{* * *} \\
(0.009)\end{array}$ & $\begin{array}{c}0.039^{* * *} \\
(0.008)\end{array}$ & $\begin{array}{c}0.021^{* *} \\
(0.008)\end{array}$ & $\begin{array}{c}0.040^{* * *} \\
(0.008)\end{array}$ & $\begin{array}{c}0.048^{* * *} \\
(0.009)\end{array}$ \\
\hline RI & $\begin{array}{c}0.003 \\
(0.013)\end{array}$ & $\begin{array}{c}0.004 \\
(0.012)\end{array}$ & & & & \\
\hline GPP*RI & & $\begin{array}{c}-0.000 \\
(0.011)\end{array}$ & & & & \\
\hline AI & & & $\begin{array}{c}0.041^{* * * *} \\
(0.014)\end{array}$ & $\begin{array}{c}0.017 \\
(0.015)\end{array}$ & & \\
\hline $\mathrm{GPP}^{*} \mathrm{AI}$ & & & & $\begin{array}{c}0.042^{* * * *} \\
(0.010)\end{array}$ & & \\
\hline MI & & & & & $\begin{array}{l}-0.013 \\
(0.010)\end{array}$ & $\begin{array}{c}0.001 \\
(0.010)\end{array}$ \\
\hline $\mathrm{GPP}^{*} \mathrm{MI}$ & & & & & & $\begin{array}{c}-0.037^{* * * *} \\
(0.012)\end{array}$ \\
\hline pop density & $\begin{array}{l}-0.000 \\
(0.000)\end{array}$ & $\begin{array}{c}-0.000 \\
(0.000)\end{array}$ & $\begin{array}{c}-0.000 \\
(0.000)\end{array}$ & $\begin{array}{l}-0.000 \\
(0.000)\end{array}$ & $\begin{array}{c}-0.000 \\
(0.000)\end{array}$ & $\begin{array}{l}-0.000 \\
(0.000)\end{array}$ \\
\hline employment share & $\begin{array}{c}-0.000^{* * * *} \\
(0.000)\end{array}$ & $\begin{array}{c}-0.000^{* * *} \\
(0.000)\end{array}$ & $\begin{array}{c}-0.000^{* * * *} \\
(0.000)\end{array}$ & $\begin{array}{c}-0.000^{* * * *} \\
(0.000)\end{array}$ & $\begin{array}{c}-0.000^{* * * *} \\
(0.000)\end{array}$ & $\begin{array}{c}-0.000^{* * * *} \\
(0.000)\end{array}$ \\
\hline N. of firms & $\begin{array}{c}0.000^{* * * *} \\
(0.000)\end{array}$ & $\begin{array}{c}0.000^{* * * *} \\
(0.000)\end{array}$ & $\begin{array}{c}0.000^{* * * *} \\
(0.000)\end{array}$ & $\begin{array}{c}0.000^{* * * *} \\
(0.000)\end{array}$ & $\begin{array}{c}0.000^{* * * *} \\
(0.000)\end{array}$ & $\begin{array}{c}0.000^{* * * *} \\
(0.000)\end{array}$ \\
\hline share of $R \& D$ employment & $\begin{array}{c}6.101 \\
(6.303)\end{array}$ & $\begin{array}{l}6.100 \\
(6.298)\end{array}$ & $\begin{array}{c}6.533 \\
(6.272)\end{array}$ & $\begin{array}{c}6.378 \\
(6.264)\end{array}$ & $\begin{array}{c}6.455 \\
(6.348)\end{array}$ & $\begin{array}{l}6.561 \\
(6.418)\end{array}$ \\
\hline r2_w & 0.328 & 0.328 & 0.328 & 0.331 & 0.327 & 0.329 \\
\hline r2_o & 0.458 & 0.458 & 0.464 & 0.469 & 0.461 & 0.464 \\
\hline $\mathrm{r} 2^{-} \mathrm{b}$ & 0.467 & 0.467 & 0.473 & 0.478 & 0.471 & 0.473 \\
\hline$N^{-}$ & 3851 & 3851 & 3851 & 3851 & 3851 & 3851 \\
\hline
\end{tabular}

Table 7.4 takes as a benchmark Column VI proposed in Tables 7.1 to 7.3. As explained in Section 7.3.1, we built dummy variables equal to 1 if a $\mathrm{CZ}$ is in the top $33 \%$ of task-intensive occupations shares: abstract (AI), routine (RI) and manual (MI). We include these dummy variables in the estimations, as well as their interaction with (total) GPP. Column I and II focus on RI. Both the coefficient of the direct and moderating effects do not appear to significantly affect local GTs generation. Columns III and IV deal with AI. The coefficient of the direct effect is positive and significant in column III, but it loses significance in column IV, when the interaction with GPP is introduced. The moderating 
effect shows a positive and significant coefficient. Columns V and VI report the estimations of the effect of RI. The direct effect does not appear to be significant in any of the estimations, while the moderating effect is negative. The prevalence of routine skills appears to reduce the impact of GPP on local accumulation of GTs.

Overall, the inclusion of the local skills composition in the empirical framework seems to reduce the magnitude of the direct effect of GPP. In table 7.4 a $1 \%$ increase in GPP yields an increase in GTs ranging from $0.021 \%$ to $0.048 \%$, which is far lower than the $0.077 \%$ increase found in table 7.1 . AI is the only skill category yielding a positive impact on GTs at the local level. If one sums the coefficient of GPP and the one of the interaction of AI with GPP, the overall effect of GPP appears to be much closer to the evidence reported in table 7.1. Focusing on Column IV, in the areas in the top $33 \%$ of abstract-task intensive occupations $(\mathrm{AI}=1)$, the overall impact of $1 \%$ increase in GPP consists of some $0.063 \%$ increase in local GTs stock. 
Table 7.5: Effect of GPP for products and task composition on GT stock (2006-2011)

\begin{tabular}{|c|c|c|c|c|c|c|}
\hline & (I) & (II) & (III) & $(\mathrm{IV})$ & $(\mathrm{V})$ & $(\mathrm{VI})$ \\
\hline product GPP & $\begin{array}{l}0.020^{*} \\
(0.010)\end{array}$ & $\begin{array}{l}0.021^{* *} \\
(0.011)\end{array}$ & $\begin{array}{l}0.020^{* * *} \\
(0.010)\end{array}$ & $\begin{array}{c}0.008 \\
(0.012)\end{array}$ & $\begin{array}{l}0.021^{* *} \\
(0.010)\end{array}$ & $\begin{array}{l}0.023^{* *} \\
(0.010)\end{array}$ \\
\hline RI & $\begin{array}{c}0.005 \\
(0.013)\end{array}$ & $\begin{array}{c}0.006 \\
(0.013)\end{array}$ & & & & \\
\hline $\mathrm{GPP}^{*} \mathrm{RI}$ & & $\begin{array}{c}-0.006 \\
(0.018)\end{array}$ & & & & \\
\hline AI & & & $\begin{array}{c}0.038^{* * *} \\
(0.014)\end{array}$ & $\begin{array}{l}0.036^{* *} \\
(0.014)\end{array}$ & & \\
\hline $\mathrm{GPP}^{*} \mathrm{AI}$ & & & & $\begin{array}{c}0.021 \\
(0.014)\end{array}$ & & \\
\hline MI & & & & & $\begin{array}{l}-0.012 \\
(0.010)\end{array}$ & $\begin{array}{l}-0.009 \\
(0.010)\end{array}$ \\
\hline GPP*MI & & & & & & $\begin{array}{l}-0.031 \\
(0.023)\end{array}$ \\
\hline pop density & $\begin{array}{l}-0.000 \\
(0.000)\end{array}$ & $\begin{array}{c}-0.000 \\
(0.000)\end{array}$ & $\begin{array}{l}-0.000 \\
(0.000)\end{array}$ & $\begin{array}{l}-0.000 \\
(0.000)\end{array}$ & $\begin{array}{l}-0.000 \\
(0.000)\end{array}$ & $\begin{array}{l}-0.000 \\
(0.000)\end{array}$ \\
\hline employment share & $\begin{array}{c}-0.000^{* * * *} \\
(0.000)\end{array}$ & $\begin{array}{c}-0.000^{* * * *} \\
(0.000)\end{array}$ & $\begin{array}{c}-0.000^{* * * *} \\
(0.000)\end{array}$ & $\begin{array}{c}-0.000^{* * *} \\
(0.000)\end{array}$ & $\begin{array}{c}-0.000^{* * * *} \\
(0.000)\end{array}$ & $\begin{array}{c}-0.000^{* * *} \\
(0.000)\end{array}$ \\
\hline N. of firms & $\begin{array}{c}0.000^{* * *} \\
(0.000)\end{array}$ & $\begin{array}{c}0.000^{* * *} \\
(0.000)\end{array}$ & $\begin{array}{c}0.000^{* * *} \\
(0.000)\end{array}$ & $\begin{array}{c}0.000^{* * *} \\
(0.000)\end{array}$ & $\begin{array}{c}0.000^{* * *} \\
(0.000)\end{array}$ & $\begin{array}{c}0.000^{* * *} \\
(0.000)\end{array}$ \\
\hline share of $R \& D$ employment & $\begin{array}{c}5.782 \\
(6.243)\end{array}$ & $\begin{array}{c}5.845 \\
(6.248)\end{array}$ & $\begin{array}{c}6.243 \\
(6.220)\end{array}$ & $\begin{array}{c}6.257 \\
(6.233)\end{array}$ & $\begin{array}{c}6.164 \\
(6.302)\end{array}$ & $\begin{array}{c}6.248 \\
(6.320)\end{array}$ \\
\hline $\mathrm{r} 2 \mathrm{w}$ & 0.327 & 0.327 & 0.327 & 0.327 & 0.326 & 0.326 \\
\hline r2_o & 0.440 & 0.440 & 0.446 & 0.447 & 0.444 & 0.444 \\
\hline $\mathrm{r} 2$ & 0.449 & 0.449 & 0.455 & 0.455 & 0.453 & 0.453 \\
\hline$N^{-}$ & 3849 & 3849 & 3849 & 3849 & 3849 & 3849 \\
\hline
\end{tabular}

Dep. Var.: Stock of fractionalized patent families weighted by forward citations (log).

GPP, RI, AI and MI lagged 1-year. Standard errors clustered at the level of State.

All models include a constant, year and geographic dummies (9 Census divisions).

${ }^{*} p<.1,{ }^{* *} p<.05,{ }^{* * *} p<.01$ 
Table 7.6: Effect of GPP for services and task composition on GT stock (2006-2011)

\begin{tabular}{|c|c|c|c|c|c|c|}
\hline & (I) & (II) & (III) & $(\mathrm{IV})$ & $(\mathrm{V})$ & $(\mathrm{VI})$ \\
\hline service GPP & $\begin{array}{c}0.047^{* * *} \\
(0.010)\end{array}$ & $\begin{array}{c}0.048^{* * *} \\
(0.011)\end{array}$ & $\begin{array}{c}0.048^{* * *} \\
(0.010)\end{array}$ & $\begin{array}{l}0.025^{* *} \\
(0.011)\end{array}$ & $\begin{array}{c}0.048^{* * *} \\
(0.010)\end{array}$ & $\begin{array}{c}0.057^{* * * *} \\
(0.011)\end{array}$ \\
\hline RI & $\begin{array}{c}0.003 \\
(0.013)\end{array}$ & $\begin{array}{c}0.005 \\
(0.012)\end{array}$ & & & & \\
\hline GPP*RI & & $\begin{array}{l}-0.004 \\
(0.012)\end{array}$ & & & & \\
\hline AI & & & $\begin{array}{c}0.041^{* * * *} \\
(0.014)\end{array}$ & $\begin{array}{c}0.018 \\
(0.015)\end{array}$ & & \\
\hline $\mathrm{GPP}^{*} \mathrm{AI}$ & & & & $\begin{array}{c}0.050^{* * *} \\
(0.012)\end{array}$ & & \\
\hline MI & & & & & $\begin{array}{l}-0.013 \\
(0.010)\end{array}$ & $\begin{array}{c}0.001 \\
(0.011)\end{array}$ \\
\hline $\mathrm{GPP}^{*} \mathrm{MI}$ & & & & & & $\begin{array}{c}-0.042^{* * *} \\
(0.016)\end{array}$ \\
\hline pop density & $\begin{array}{c}-0.000 \\
(0.000)\end{array}$ & $\begin{array}{l}-0.000 \\
(0.000)\end{array}$ & $\begin{array}{l}-0.000 \\
(0.000)\end{array}$ & $\begin{array}{l}-0.000 \\
(0.000)\end{array}$ & $\begin{array}{c}-0.000 \\
(0.000)\end{array}$ & $\begin{array}{c}-0.000 \\
(0.000)\end{array}$ \\
\hline employment share & $\begin{array}{c}-0.000^{* * *} \\
(0.000)\end{array}$ & $\begin{array}{c}-0.000^{* * * *} \\
(0.000)\end{array}$ & $\begin{array}{c}-0.000^{* * *} \\
(0.000)\end{array}$ & $\begin{array}{c}-0.000^{* * *} \\
(0.000)\end{array}$ & $\begin{array}{c}-0.000^{* * *} \\
(0.000)\end{array}$ & $\begin{array}{c}-0.000^{* * * *} \\
(0.000)\end{array}$ \\
\hline N. of firms & $\begin{array}{c}0.000^{* * * *} \\
(0.000)\end{array}$ & $\begin{array}{c}0.000^{* * * *} \\
(0.000)\end{array}$ & $\begin{array}{c}0.000^{* * * *} \\
(0.000)\end{array}$ & $\begin{array}{c}0.000^{* * * *} \\
(0.000)\end{array}$ & $\begin{array}{c}0.000^{* * * *} \\
(0.000)\end{array}$ & $\begin{array}{c}0.000^{* * * *} \\
(0.000)\end{array}$ \\
\hline share of $R \& D$ employment & $\begin{array}{c}5.875 \\
(6.254)\end{array}$ & $\begin{array}{c}5.881 \\
(6.249)\end{array}$ & $\begin{array}{c}6.324 \\
(6.230)\end{array}$ & $\begin{array}{c}6.167 \\
(6.224)\end{array}$ & $\begin{array}{c}6.245 \\
(6.301)\end{array}$ & $\begin{array}{c}6.292 \\
(6.383)\end{array}$ \\
\hline r2_w & 0.331 & 0.331 & 0.331 & 0.334 & 0.330 & 0.331 \\
\hline r2_o & 0.458 & 0.459 & 0.465 & 0.470 & 0.462 & 0.464 \\
\hline $\mathrm{r} 2^{-} \mathrm{b}$ & 0.468 & 0.468 & 0.474 & 0.479 & 0.472 & 0.474 \\
\hline$N^{-}$ & 3851 & 3851 & 3851 & 3851 & 3851 & 3851 \\
\hline
\end{tabular}

Tables 7.5 and 7.6 complement the analysis proposed in Table 7.4 by investigating whether there are differences in the effect of GPP expenditures for, respectively, products and services on total GT stock. Results show that the direct impact found before exists for both types of expenditures. However, it is strongly driven by GPP expenditures for services, confirming the initial estimates proposed in Tables 7.1, 7.2 and 7.3. Moreover, the moderating effect of ASH holds for what concern GPP for services, while when one focuses on GPP for products, only the direct effect of ASH shows a positive and significant coefficient. 
Figure 7.4 plots average marginal effects calculated on the basis of the results from Tables 7.4, 7.5 and 7.6. The bottom parts of the three panels plot average marginal effects of respectively, total, product- and service-related GPP when the $\mathrm{CZ}$ is in the top third share of task-intensive occupations (abstract, routine and manual alternatively). Top areas plot the reverse case (average marginal effects when the $\mathrm{CZ}$ is not in the top third share of task-intensive occupations).

Focusing on areas in the top third, we find that the local knowledge base proxied by means of occupations brings about heterogeneity in the results. In particular, the coefficient for abstract occupations is always significant, with a stronger effect of expenditure on services as compared to product. Recall that abstract occupations are intensive in activities that require problem-solving, intuition, persuasion, and creativity. These characteristics are over-represented in professional, managerial, technical and creative occupations in areas as diverse as law, medicine, science, engineering, design, and management. Workers who are most adept in these tasks typically have high levels of education and analytic capability. This resonates with the high level of knowledge intensity of service activities that entail personal interaction, social perceptiveness and adaptability and which, in our model, augment the innovation outcome of public procurement. The coefficient for routine occupations is only significant for service procurement. These jobs encompass many middle-skilled cognitive (i.e., bookkeeping, clerical work) or manual activities (i.e., repetitive physical operations in production jobs). Even though the growth routine jobs has been in decline for some time (Autor, Levy, and Murnane, 2003; Autor and Dorn, 2013), routine occupations still make up the bulk of employment in the United 
States. In the case under analysis, we ascribe the positive effect of routine occupations to the persistent important role of clerical and administrative workers in services. Lastly, the endowment of manual skills is only mildly significant in the general category of public procurement but not in the subcomponents. This is not surprising considering that low-skill manual intensive jobs are mainly in areas such as assistance and hospitality, and thus we expect them to be only marginally related to the relation between innovation and public procurement. 


\subsubsection{A comparison between GTs for adaptation and mitigation}

Table 7.7: Effect of GPP on GT stock: mitigation and adaptation (2001-2011)

\begin{tabular}{|c|c|c|c|c|c|c|}
\hline & \multicolumn{3}{|c|}{ Mitigation GT } & \multicolumn{3}{|c|}{ Adaptation GT } \\
\hline & (I) & (II) & (III) & (IV) & $(\mathrm{V})$ & $(\mathrm{VI})$ \\
\hline total GPP & $\begin{array}{c}0.086^{* * *} \\
(0.011)\end{array}$ & & & $\begin{array}{c}0.043^{* * *} \\
(0.008)\end{array}$ & & \\
\hline product GPP & & $\begin{array}{c}0.061^{* * *} \\
(0.014)\end{array}$ & & & $\begin{array}{c}0.036^{* * *} \\
(0.010)\end{array}$ & \\
\hline service GPP & & & $\begin{array}{c}0.096^{* * *} \\
(0.011)\end{array}$ & & & $\begin{array}{c}0.049^{* * *} \\
(0.009)\end{array}$ \\
\hline pop density & $\begin{array}{l}-0.000 \\
(0.000)\end{array}$ & $\begin{array}{l}-0.000 \\
(0.000)\end{array}$ & $\begin{array}{l}-0.000 \\
(0.000)\end{array}$ & $\begin{array}{l}-0.000 \\
(0.000)\end{array}$ & $\begin{array}{c}-0.000 \\
(0.000)\end{array}$ & $\begin{array}{l}-0.000 \\
(0.000)\end{array}$ \\
\hline employment share & $\begin{array}{c}-0.000^{* *} \\
(0.000)\end{array}$ & $\begin{array}{c}-0.000^{* * * *} \\
(0.000)\end{array}$ & $\begin{array}{c}-0.000^{* *} \\
(0.000)\end{array}$ & $\begin{array}{l}-0.000^{*} \\
(0.000)\end{array}$ & $\begin{array}{c}-0.000^{* *} \\
(0.000)\end{array}$ & $\begin{array}{c}-0.000^{* *} \\
(0.000)\end{array}$ \\
\hline N. of firms & $\begin{array}{c}0.000^{* * * *} \\
(0.000)\end{array}$ & $\begin{array}{c}0.000^{* * *} \\
(0.000)\end{array}$ & $\begin{array}{c}0.000^{* * *} \\
(0.000)\end{array}$ & $\begin{array}{c}0.000^{* * *} \\
(0.000)\end{array}$ & $\begin{array}{c}0.000^{* * * *} \\
(0.000)\end{array}$ & $\begin{array}{c}0.000^{* * * *} \\
(0.000)\end{array}$ \\
\hline share of $R \& D$ employment & $\begin{array}{c}7.089 \\
(4.438)\end{array}$ & $\begin{array}{c}7.115 \\
(4.379)\end{array}$ & $\begin{array}{c}7.016 \\
(4.367)\end{array}$ & $\begin{array}{c}4.603 \\
(4.983)\end{array}$ & $\begin{array}{c}4.640 \\
(5.283)\end{array}$ & $\begin{array}{c}4.558 \\
(4.917)\end{array}$ \\
\hline $\mathrm{r} 2{ }_{-} \mathrm{w}$ & 0.381 & 0.364 & 0.382 & 0.245 & 0.236 & 0.247 \\
\hline r2_o & 0.510 & 0.479 & 0.507 & 0.558 & 0.539 & 0.556 \\
\hline $\mathrm{r} 2-\mathrm{b}$ & 0.519 & 0.486 & 0.516 & 0.576 & 0.555 & 0.573 \\
\hline$N^{-}$ & 7937 & 7933 & 7937 & 7937 & 7933 & 7937 \\
\hline $\begin{array}{l}\text { Dep. Var.: Stock of fractionalized } \mathrm{p} \\
\text { GPP variables lagged } 1 \text {-year. Stand } \\
\text { All models include a constant, year } \\
{ }^{*} p<.1,{ }^{* *} p<.05,{ }^{* * *} p<.01\end{array}$ & $\begin{array}{l}\text { ent familie } \\
\text { d errors cl } \\
\text { ad geograpl }\end{array}$ & $\begin{array}{l}\text { mitigation } \\
\text { ered at the } \\
\text { dummies }\end{array}$ & $\begin{array}{l}\text { adaptatio } \\
\text { el of State } \\
\text { ensus divi }\end{array}$ & $\begin{array}{l}\text { weighted } \\
\text { ns). }\end{array}$ & & \\
\hline
\end{tabular}

As a further step of the analysis, we exploit the OECD ENV-TECH classification to test for the differential effects of GPP on the two main groups of green technological stock: adaptation and mitigation, respectively. Columns I, II and III of Table 7.7 present estimates for the effect of, respectively, total, productand service-related GPP on the stock of green mitigation technologies. Columns IV, V and VI report the similar estimates concerning the determinants of green 
adaptation technologies. Results demonstrate that the overall level of GPP positively affects both kinds of green technological stock (Columns I and IV). The magnitude is higher for mitigation technologies. When splitting GPP between product- and service-related, we do find a significant positive effect of both, with service-related GPP expenditures showing higher effectiveness within both groups of green technologies. The highest effect is found for servicerelated GPP on mitigation GT stock (results from Column III suggest that a $1 \%$ increase in service-related GPP leads to a $0.096 \%$ increase in the stock of green mitigation patents).

Table 7.8: Effect of total GPP and task composition on GT-mitigation stock (2006-2011)

\begin{tabular}{|c|c|c|c|c|c|c|}
\hline & (I) & (II) & (III) & (IV) & $(\mathrm{V})$ & $(\mathrm{VI})$ \\
\hline tot GPP & $\begin{array}{c}0.043^{* * *} \\
(0.009)\end{array}$ & $\begin{array}{c}0.044^{* * * *} \\
(0.010)\end{array}$ & $\begin{array}{c}0.044^{* * *} \\
(0.009)\end{array}$ & $\begin{array}{c}0.023^{* * *} \\
(0.008)\end{array}$ & $\begin{array}{c}0.045^{* * *} \\
(0.009)\end{array}$ & $\begin{array}{c}0.053^{* * * *} \\
(0.010)\end{array}$ \\
\hline RI & $\begin{array}{c}0.001 \\
(0.013)\end{array}$ & $\begin{array}{c}0.003 \\
(0.013)\end{array}$ & & & & \\
\hline $\mathrm{GPP}^{*} \mathrm{RI}$ & & $\begin{array}{l}-0.003 \\
(0.011)\end{array}$ & & & & \\
\hline AI & & & $\begin{array}{c}0.044^{* * *} \\
(0.016)\end{array}$ & $\begin{array}{l}0.016 \\
(0.017)\end{array}$ & & \\
\hline $\mathrm{GPP}^{*} \mathrm{AI}$ & & & & $\begin{array}{c}0.049^{* * *} \\
(0.011)\end{array}$ & & \\
\hline MI & & & & & $\begin{array}{c}-0.010 \\
(0.011)\end{array}$ & $\begin{array}{c}0.005 \\
(0.011)\end{array}$ \\
\hline GPP*MI & & & & & & $\begin{array}{c}-0.040^{* * * *} \\
(0.013)\end{array}$ \\
\hline pop density & $\begin{array}{c}-0.000 \\
(0.000)\end{array}$ & $\begin{array}{c}-0.000 \\
(0.000)\end{array}$ & $\begin{array}{c}-0.000 \\
(0.000)\end{array}$ & $\begin{array}{c}-0.000 \\
(0.000)\end{array}$ & $\begin{array}{c}-0.000 \\
(0.000)\end{array}$ & $\begin{array}{l}-0.000 \\
(0.000)\end{array}$ \\
\hline employment share & $\begin{array}{c}-0.000^{* * *} \\
(0.000)\end{array}$ & $\begin{array}{c}-0.000^{* * * *} \\
(0.000)\end{array}$ & $\begin{array}{c}-0.000^{* * *} \\
(0.000)\end{array}$ & $\begin{array}{c}-0.000^{* * * *} \\
(0.000)\end{array}$ & $\begin{array}{c}-0.000^{* * *} \\
(0.000)\end{array}$ & $\begin{array}{c}-0.000^{* * *} \\
(0.000)\end{array}$ \\
\hline N. of firms & $\begin{array}{c}0.000^{* * * *} \\
(0.000)\end{array}$ & $\begin{array}{c}0.000^{* * * *} \\
(0.000)\end{array}$ & $\begin{array}{c}0.000^{* * *} \\
(0.000)\end{array}$ & $\begin{array}{c}0.000^{* * * *} \\
(0.000)\end{array}$ & $\begin{array}{c}0.000^{* * * *} \\
(0.000)\end{array}$ & $\begin{array}{c}0.000^{* * * *} \\
(0.000)\end{array}$ \\
\hline share of R\&D employment & $\begin{array}{c}5.863 \\
(6.416)\end{array}$ & $\begin{array}{l}5.870 \\
(6.413)\end{array}$ & $\begin{array}{c}6.360 \\
(6.391)\end{array}$ & $\begin{array}{c}6.177 \\
(6.384)\end{array}$ & $\begin{array}{c}6.206 \\
(6.451)\end{array}$ & $\begin{array}{c}6.320 \\
(6.528)\end{array}$ \\
\hline r2_w & 0.319 & 0.319 & 0.319 & 0.322 & 0.318 & 0.320 \\
\hline r2_o & 0.463 & 0.463 & 0.469 & 0.476 & 0.466 & 0.469 \\
\hline r2_b & 0.473 & 0.473 & 0.479 & 0.485 & 0.476 & 0.479 \\
\hline$N$ & 3851 & 3851 & 3851 & 3851 & 3851 & 3851 \\
\hline
\end{tabular}


Table 7.9: Effect of GPP for products and task composition on GT-mitigation stock (2006-2011)

\begin{tabular}{|c|c|c|c|c|c|c|}
\hline & (I) & (II) & (III) & $(\mathrm{IV})$ & $(\mathrm{V})$ & $(\mathrm{VI})$ \\
\hline product GPP & $\begin{array}{l}0.024^{* *} \\
(0.011)\end{array}$ & $\begin{array}{l}0.026^{* *} \\
(0.012)\end{array}$ & $\begin{array}{l}0.025^{* *} \\
(0.011)\end{array}$ & $\begin{array}{c}0.009 \\
(0.013)\end{array}$ & $\begin{array}{l}0.026^{* *} \\
(0.011)\end{array}$ & $\begin{array}{l}0.028^{* *} \\
(0.011)\end{array}$ \\
\hline RI & $\begin{array}{c}0.003 \\
(0.013)\end{array}$ & $\begin{array}{c}0.004 \\
(0.013)\end{array}$ & & & & \\
\hline $\mathrm{GPP}^{*} \mathrm{RI}$ & & $\begin{array}{l}-0.006 \\
(0.020)\end{array}$ & & & & \\
\hline AI & & & $\begin{array}{c}0.041^{* * *} \\
(0.016)\end{array}$ & $\begin{array}{l}0.037^{* *} \\
(0.016)\end{array}$ & & \\
\hline $\mathrm{GPP}^{*} \mathrm{AI}$ & & & & $\begin{array}{l}0.027^{*} \\
(0.016)\end{array}$ & & \\
\hline MI & & & & & $\begin{array}{l}-0.008 \\
(0.011)\end{array}$ & $\begin{array}{l}-0.005 \\
(0.011)\end{array}$ \\
\hline $\mathrm{GPP}^{*} \mathrm{MI}$ & & & & & & $\begin{array}{l}-0.035 \\
(0.024)\end{array}$ \\
\hline pop density & $\begin{array}{c}-0.000 \\
(0.000)\end{array}$ & $\begin{array}{c}-0.000 \\
(0.000)\end{array}$ & $\begin{array}{l}-0.000 \\
(0.000)\end{array}$ & $\begin{array}{l}-0.000 \\
(0.000)\end{array}$ & $\begin{array}{c}-0.000 \\
(0.000)\end{array}$ & $\begin{array}{l}-0.000 \\
(0.000)\end{array}$ \\
\hline employment share & $\begin{array}{c}-0.000^{* * * *} \\
(0.000)\end{array}$ & $\begin{array}{c}-0.000^{* * * *} \\
(0.000)\end{array}$ & $\begin{array}{c}-0.000^{* * * *} \\
(0.000)\end{array}$ & $\begin{array}{c}-0.000^{* * * *} \\
(0.000)\end{array}$ & $\begin{array}{c}-0.000^{* * * *} \\
(0.000)\end{array}$ & $\begin{array}{c}-0.000^{* * * *} \\
(0.000)\end{array}$ \\
\hline N. of firms & $\begin{array}{c}0.000^{* * *} \\
(0.000)\end{array}$ & $\begin{array}{c}0.000^{* * *} \\
(0.000)\end{array}$ & $\begin{array}{c}0.000^{* * *} \\
(0.000)\end{array}$ & $\begin{array}{c}0.000^{* * * *} \\
(0.000)\end{array}$ & $\begin{array}{c}0.000^{* * * *} \\
(0.000)\end{array}$ & $\begin{array}{c}0.000^{* * * *} \\
(0.000)\end{array}$ \\
\hline share of R\&D employment & $\begin{array}{c}5.514 \\
(6.337)\end{array}$ & $\begin{array}{c}5.581 \\
(6.345)\end{array}$ & $\begin{array}{c}6.046 \\
(6.320)\end{array}$ & $\begin{array}{c}6.055 \\
(6.336)\end{array}$ & $\begin{array}{c}5.890 \\
(6.388)\end{array}$ & $\begin{array}{c}5.983 \\
(6.411)\end{array}$ \\
\hline r2_w & 0.318 & 0.318 & 0.317 & 0.318 & 0.317 & 0.317 \\
\hline r2_o & 0.443 & 0.443 & 0.450 & 0.450 & 0.446 & 0.446 \\
\hline r2_b & 0.452 & 0.452 & 0.458 & 0.459 & 0.455 & 0.456 \\
\hline$N^{-}$ & 3849 & 3849 & 3849 & 3849 & 3849 & 3849 \\
\hline
\end{tabular}

Dep. Var.: Stock of fractionalized patent families weighted by forward citations (log).

GPP, RI, AI and MI lagged 1-year. Standard errors clustered at the level of State.

All models include a constant, year and geographic dummies (9 Census divisions).

${ }^{*} p<.1,{ }^{* *} p<.05,{ }^{* * *} p<.01$ 
Table 7.10: Effect of GPP for services and task composition on GT-mitigation stock (2006-2011)

\begin{tabular}{|c|c|c|c|c|c|c|}
\hline & (I) & (II) & (III) & (IV) & $(\mathrm{V})$ & (VI) \\
\hline service GPP & $\begin{array}{c}0.051^{* * *} \\
(0.010)\end{array}$ & $\begin{array}{c}0.053^{* * *} \\
(0.011)\end{array}$ & $\begin{array}{c}0.052^{* * *} \\
(0.010)\end{array}$ & $\begin{array}{c}0.026^{* *} \\
(0.011)\end{array}$ & $\begin{array}{c}0.052^{* * *} \\
(0.010)\end{array}$ & $\begin{array}{c}0.061^{* * *} \\
(0.011)\end{array}$ \\
\hline $\mathrm{RI}$ & $\begin{array}{c}0.001 \\
(0.013)\end{array}$ & $\begin{array}{c}0.005 \\
(0.013)\end{array}$ & & & & \\
\hline $\mathrm{GPP}^{*} \mathrm{RI}$ & & $\begin{array}{c}-0.009 \\
(0.013)\end{array}$ & & & & \\
\hline $\mathrm{AI}$ & & & $\begin{array}{c}0.044^{* * *} \\
(0.016)\end{array}$ & $\begin{array}{c}0.018 \\
(0.017)\end{array}$ & & \\
\hline $\mathrm{GPP}^{*} \mathrm{AI}$ & & & & $\begin{array}{c}0.057^{* * *} \\
(0.013)\end{array}$ & & \\
\hline MI & & & & & $\begin{array}{c}-0.009 \\
(0.011)\end{array}$ & $\begin{array}{c}0.005 \\
(0.011)\end{array}$ \\
\hline $\mathrm{GPP}^{*} \mathrm{MI}$ & & & & & & $\begin{array}{c}-0.045^{* * *} \\
(0.016)\end{array}$ \\
\hline pop density & $\begin{array}{c}-0.000 \\
(0.000)\end{array}$ & $\begin{array}{c}-0.000 \\
(0.000)\end{array}$ & $\begin{array}{c}-0.000 \\
(0.000)\end{array}$ & $\begin{array}{c}-0.000 \\
(0.000)\end{array}$ & $\begin{array}{c}-0.000 \\
(0.000)\end{array}$ & $\begin{array}{c}-0.000 \\
(0.000)\end{array}$ \\
\hline employment share & $\begin{array}{c}-0.000^{* * *} \\
(0.000)\end{array}$ & $\begin{array}{c}-0.000^{* * *} \\
(0.000)\end{array}$ & $\begin{array}{c}-0.000^{* * *} \\
(0.000)\end{array}$ & $\begin{array}{c}-0.000^{* * *} \\
(0.000)\end{array}$ & $\begin{array}{c}-0.000^{* * *} \\
(0.000)\end{array}$ & $\begin{array}{c}-0.000^{* * *} \\
(0.000)\end{array}$ \\
\hline N. of firms & $\begin{array}{c}0.000^{* * *} \\
(0.000)\end{array}$ & $\begin{array}{c}0.000^{* * * *} \\
(0.000)\end{array}$ & $\begin{array}{c}0.000^{* * *} \\
(0.000)\end{array}$ & $\begin{array}{c}0.000^{* * *} \\
(0.000)\end{array}$ & $\begin{array}{c}0.000^{* * *} \\
(0.000)\end{array}$ & $\begin{array}{c}0.000^{* * *} \\
(0.000)\end{array}$ \\
\hline share of R\&D employment & $\begin{array}{c}5.621 \\
(6.375)\end{array}$ & $\begin{array}{c}5.639 \\
(6.369)\end{array}$ & $\begin{array}{c}6.140 \\
(6.357)\end{array}$ & $\begin{array}{c}5.960 \\
(6.353)\end{array}$ & $\begin{array}{c}5.987 \\
(6.413)\end{array}$ & $\begin{array}{c}6.036 \\
(6.502)\end{array}$ \\
\hline r2_w & 0.321 & 0.321 & 0.321 & 0.325 & 0.320 & 0.322 \\
\hline r2_o & 0.463 & 0.463 & 0.470 & 0.476 & 0.466 & 0.469 \\
\hline $\mathrm{r} 2 \_\mathrm{b}$ & 0.473 & 0.473 & 0.479 & 0.486 & 0.476 & 0.479 \\
\hline$N^{-}$ & 3851 & 3851 & 3851 & 3851 & 3851 & 3851 \\
\hline
\end{tabular}


Table 7.11: Effect of total GPP and task composition on GT-adaptation stock (2006-2011)

\begin{tabular}{|c|c|c|c|c|c|c|}
\hline & $(\mathrm{I})$ & (II) & (III) & $(\mathrm{IV})$ & $(\mathrm{V})$ & $(\mathrm{VI})$ \\
\hline tot GPP & $\begin{array}{c}0.021^{* * *} \\
(0.007)\end{array}$ & $\begin{array}{c}0.020^{* * *} \\
(0.007)\end{array}$ & $\begin{array}{c}0.022^{* * *} \\
(0.007)\end{array}$ & $\begin{array}{c}0.012 \\
(0.008)\end{array}$ & $\begin{array}{c}0.022^{* * *} \\
(0.007)\end{array}$ & $\begin{array}{c}0.030^{* * *} \\
(0.008)\end{array}$ \\
\hline RI & $\begin{array}{c}0.003 \\
(0.007)\end{array}$ & $\begin{array}{c}0.002 \\
(0.007)\end{array}$ & & & & \\
\hline $\mathrm{GPP}^{*} \mathrm{RI}$ & & $\begin{array}{c}0.003 \\
(0.011)\end{array}$ & & & & \\
\hline AI & & & $\begin{array}{l}0.020^{* *} \\
(0.009)\end{array}$ & $\begin{array}{c}0.007 \\
(0.008)\end{array}$ & & \\
\hline $\mathrm{GPP}^{*} \mathrm{AI}$ & & & & $\begin{array}{l}0.023^{* *} \\
(0.010)\end{array}$ & & \\
\hline MI & & & & & $\begin{array}{c}-0.019^{* * * *} \\
(0.006)\end{array}$ & $\begin{array}{c}-0.006 \\
(0.007)\end{array}$ \\
\hline GPP*MI & & & & & & $\begin{array}{c}-0.036^{* * * *} \\
(0.008)\end{array}$ \\
\hline pop density & $\begin{array}{c}-0.000 \\
(0.000)\end{array}$ & $\begin{array}{c}-0.000 \\
(0.000)\end{array}$ & $\begin{array}{l}-0.000 \\
(0.000)\end{array}$ & $\begin{array}{c}-0.000 \\
(0.000)\end{array}$ & $\begin{array}{c}-0.000 \\
(0.000)\end{array}$ & $\begin{array}{c}-0.000 \\
(0.000)\end{array}$ \\
\hline employment share & $\begin{array}{c}-0.000^{* *} \\
(0.000)\end{array}$ & $\begin{array}{c}-0.000^{* *} \\
(0.000)\end{array}$ & $\begin{array}{c}-0.000^{* *} \\
(0.000)\end{array}$ & $\begin{array}{c}-0.000^{* *} \\
(0.000)\end{array}$ & $\begin{array}{c}-0.000^{* *} \\
(0.000)\end{array}$ & $\begin{array}{c}-0.000^{* *} \\
(0.000)\end{array}$ \\
\hline N. of firms & $\begin{array}{c}0.000^{* * * *} \\
(0.000)\end{array}$ & $\begin{array}{c}0.000^{* * * *} \\
(0.000)\end{array}$ & $\begin{array}{c}0.000^{* * * *} \\
(0.000)\end{array}$ & $\begin{array}{c}0.000^{* * * *} \\
(0.000)\end{array}$ & $\begin{array}{c}0.000^{* * * *} \\
(0.000)\end{array}$ & $\begin{array}{c}0.000^{* * * *} \\
(0.000)\end{array}$ \\
\hline share of R\&D employment & $\begin{array}{c}2.601 \\
(4.737)\end{array}$ & $\begin{array}{c}2.590 \\
(4.732)\end{array}$ & $\begin{array}{c}2.815 \\
(4.707)\end{array}$ & $\begin{array}{c}2.737 \\
(4.720)\end{array}$ & $\begin{array}{c}2.902 \\
(4.760)\end{array}$ & $\begin{array}{c}3.013 \\
(4.856)\end{array}$ \\
\hline r2_w & 0.188 & 0.188 & 0.187 & 0.188 & 0.187 & 0.190 \\
\hline r2_o & 0.511 & 0.511 & 0.515 & 0.520 & 0.516 & 0.520 \\
\hline $\mathrm{r} 2{ }_{-}^{-} \mathrm{b}$ & 0.525 & 0.525 & 0.530 & 0.535 & 0.530 & 0.535 \\
\hline$N^{-}$ & 3851 & 3851 & 3851 & 3851 & 3851 & 3851 \\
\hline
\end{tabular}

Dep. Var.: Stock of fractionalized patent families weighted by forward citations $(\log )$.

GPP, RI, AI and MI lagged 1-year. Standard errors clustered at the level of State.

All models include a constant, year and geographic dummies (9 Census divisions).

${ }^{*} p<.1,{ }^{* *} p<.05,{ }^{* * *} p<.01$ 
Table 7.12: Effect of GPP for products and task composition on GT-adaptation stock (2006-2011)

\begin{tabular}{|c|c|c|c|c|c|c|}
\hline & (I) & (II) & (III) & $(\mathrm{IV})$ & $(\mathrm{V})$ & $(\mathrm{VI})$ \\
\hline product GPP & $\begin{array}{c}0.009 \\
(0.009)\end{array}$ & $\begin{array}{c}0.008 \\
(0.009)\end{array}$ & $\begin{array}{c}0.009 \\
(0.009)\end{array}$ & $\begin{array}{c}0.007 \\
(0.010)\end{array}$ & $\begin{array}{c}0.009 \\
(0.009)\end{array}$ & $\begin{array}{c}0.011 \\
(0.009)\end{array}$ \\
\hline $\mathrm{RI}$ & $\begin{array}{c}0.004 \\
(0.007)\end{array}$ & $\begin{array}{c}0.004 \\
(0.007)\end{array}$ & & & & \\
\hline $\mathrm{GPP}^{*} \mathrm{RI}$ & & $\begin{array}{c}0.003 \\
(0.014)\end{array}$ & & & & \\
\hline AI & & & $\begin{array}{l}0.018^{* *} \\
(0.009)\end{array}$ & $\begin{array}{l}0.018^{* *} \\
(0.009)\end{array}$ & & \\
\hline GPP*AI & & & & $\begin{array}{c}0.003 \\
(0.012)\end{array}$ & & \\
\hline MI & & & & & $\begin{array}{c}-0.018^{* * *} \\
(0.006)\end{array}$ & $\begin{array}{c}-0.017^{* * * *} \\
(0.006)\end{array}$ \\
\hline $\mathrm{GPP}^{*} \mathrm{MI}$ & & & & & & $\begin{array}{c}-0.022^{*} \\
(0.012)\end{array}$ \\
\hline pop density & $\begin{array}{c}-0.000 \\
(0.000)\end{array}$ & $\begin{array}{c}-0.000 \\
(0.000)\end{array}$ & $\begin{array}{c}-0.000 \\
(0.000)\end{array}$ & $\begin{array}{c}-0.000 \\
(0.000)\end{array}$ & $\begin{array}{c}-0.000 \\
(0.000)\end{array}$ & $\begin{array}{c}-0.000 \\
(0.000)\end{array}$ \\
\hline employment share & $\begin{array}{c}-0.000^{* *} \\
(0.000)\end{array}$ & $\begin{array}{c}-0.000^{* *} \\
(0.000)\end{array}$ & $\begin{array}{c}-0.000^{* *} \\
(0.000)\end{array}$ & $\begin{array}{c}-0.000^{* * *} \\
(0.000)\end{array}$ & $\begin{array}{c}-0.000^{* *} \\
(0.000)\end{array}$ & $\begin{array}{c}-0.000^{* * *} \\
(0.000)\end{array}$ \\
\hline N. of firms & $\begin{array}{c}0.000^{* * * *} \\
(0.000)\end{array}$ & $\begin{array}{c}0.000^{* * *} \\
(0.000)\end{array}$ & $\begin{array}{c}0.000^{* * * *} \\
(0.000)\end{array}$ & $\begin{array}{c}0.000^{* * * *} \\
(0.000)\end{array}$ & $\begin{array}{c}0.000^{* * * *} \\
(0.000)\end{array}$ & $\begin{array}{c}0.000^{* * *} \\
(0.000)\end{array}$ \\
\hline share of R\&D employment & $\begin{array}{c}2.474 \\
(4.790)\end{array}$ & $\begin{array}{c}2.488 \\
(4.783)\end{array}$ & $\begin{array}{c}2.708 \\
(4.771)\end{array}$ & $\begin{array}{c}2.713 \\
(4.774)\end{array}$ & $\begin{array}{c}2.799 \\
(4.826)\end{array}$ & $\begin{array}{c}2.867 \\
(4.844)\end{array}$ \\
\hline r2_w & 0.189 & 0.189 & 0.188 & 0.187 & 0.188 & 0.188 \\
\hline r2_o & 0.497 & 0.498 & 0.502 & 0.502 & 0.502 & 0.503 \\
\hline $\mathrm{r} 2{ }_{-}^{-} \mathrm{b}$ & 0.511 & 0.511 & 0.516 & 0.516 & 0.516 & 0.517 \\
\hline$N^{-}$ & 3849 & 3849 & 3849 & 3849 & 3849 & 3849 \\
\hline
\end{tabular}


Table 7.13: Effect of GPP for services and task composition on GT-adaptation stock (2006-2011)

\begin{tabular}{|c|c|c|c|c|c|c|}
\hline & (I) & (II) & (III) & $(\mathrm{IV})$ & $(\mathrm{V})$ & $(\mathrm{VI})$ \\
\hline service GPP & $\begin{array}{c}0.031^{* * * *} \\
(0.008)\end{array}$ & $\begin{array}{c}0.030^{* * *} \\
(0.008)\end{array}$ & $\begin{array}{c}0.032^{* * *} \\
(0.008)\end{array}$ & $\begin{array}{l}0.017^{*} \\
(0.010)\end{array}$ & $\begin{array}{c}0.032^{* * *} \\
(0.008)\end{array}$ & $\begin{array}{c}0.040^{* * *} \\
(0.009)\end{array}$ \\
\hline RI & $\begin{array}{c}0.003 \\
(0.007)\end{array}$ & $\begin{array}{c}0.001 \\
(0.007)\end{array}$ & & & & \\
\hline $\mathrm{GPP}^{*} \mathrm{RI}$ & & $\begin{array}{c}0.003 \\
(0.010)\end{array}$ & & & & \\
\hline AI & & & $\begin{array}{l}0.020^{* *} \\
(0.009)\end{array}$ & $\begin{array}{c}0.005 \\
(0.008)\end{array}$ & & \\
\hline $\mathrm{GPP}^{*} \mathrm{AI}$ & & & & $\begin{array}{c}0.033^{* * *} \\
(0.010)\end{array}$ & & \\
\hline MI & & & & & $\begin{array}{c}-0.018^{* * *} \\
(0.006)\end{array}$ & $\begin{array}{l}-0.006 \\
(0.007)\end{array}$ \\
\hline $\mathrm{GPP}^{*} \mathrm{MI}$ & & & & & & $\begin{array}{c}-0.041^{* * * *} \\
(0.009)\end{array}$ \\
\hline pop density & $\begin{array}{l}-0.000 \\
(0.000)\end{array}$ & $\begin{array}{l}-0.000 \\
(0.000)\end{array}$ & $\begin{array}{c}-0.000 \\
(0.000)\end{array}$ & $\begin{array}{c}-0.000 \\
(0.000)\end{array}$ & $\begin{array}{l}-0.000 \\
(0.000)\end{array}$ & $\begin{array}{l}-0.000 \\
(0.000)\end{array}$ \\
\hline employment share & $\begin{array}{c}-0.000^{* * *} \\
(0.000)\end{array}$ & $\begin{array}{c}-0.000^{* * *} \\
(0.000)\end{array}$ & $\begin{array}{c}-0.000^{* *} \\
(0.000)\end{array}$ & $\begin{array}{c}-0.000^{* *} \\
(0.000)\end{array}$ & $\begin{array}{c}-0.000^{* *} \\
(0.000)\end{array}$ & $\begin{array}{c}-0.000^{* *} \\
(0.000)\end{array}$ \\
\hline N. of firms & $\begin{array}{c}0.000^{* * * *} \\
(0.000)\end{array}$ & $\begin{array}{c}0.000^{* * * *} \\
(0.000)\end{array}$ & $\begin{array}{c}0.000^{* * * *} \\
(0.000)\end{array}$ & $\begin{array}{c}0.000^{* * * *} \\
(0.000)\end{array}$ & $\begin{array}{c}0.000^{* * * *} \\
(0.000)\end{array}$ & $\begin{array}{c}0.000^{* * * *} \\
(0.000)\end{array}$ \\
\hline share of R\&D employment & $\begin{array}{c}2.453 \\
(4.653)\end{array}$ & $\begin{array}{c}2.444 \\
(4.649)\end{array}$ & $\begin{array}{c}2.677 \\
(4.625)\end{array}$ & $\begin{array}{c}2.585 \\
(4.649)\end{array}$ & $\begin{array}{c}2.762 \\
(4.677)\end{array}$ & $\begin{array}{c}2.815 \\
(4.785)\end{array}$ \\
\hline $\mathrm{r} 2 \_\mathrm{w}$ & 0.192 & 0.192 & 0.191 & 0.194 & 0.191 & 0.194 \\
\hline $\mathrm{r} 2{ }_{-}^{-} \mathrm{O}$ & 0.514 & 0.514 & 0.519 & 0.525 & 0.519 & 0.523 \\
\hline $\mathrm{r} 2{ }_{-}^{-} \mathrm{b}$ & 0.529 & 0.528 & 0.533 & 0.540 & 0.534 & 0.538 \\
\hline$N^{-}$ & 3851 & 3851 & 3851 & 3851 & 3851 & 3851 \\
\hline
\end{tabular}

Next, we investigate more in depth the moderating effect of local labour market composition in the relation between green public procurement and green innovation capacity across macro-families of green technology. In particular, we analyse separately the effects on GT stock in mitigation (Tables 7.8, 7.9 and 7.10) and in adaptation technologies (Tables 7.11, 7.12 and 7.13). In short, mitigation strategies, and the attendant technologies, seek to tackle the causes of climate change such as accumulation of greenhouse gases in the atmosphere. Mitigation is understood as having a global character as opposed 
to adaptation strategies which, instead, aim at reducing the local impact of climate change. Mitigation is a priority in a broad range of domains such as energy, transportation, manufacturing and waste management. Conversely, adaptation strategies target primarily water and health sectors.

We find that the average marginal effects for mitigation technologies are the same as those observed in the general case above. This applies to both the significance and the magnitude of the coefficients. Once again, a high endowment of managerial, scientific and interpersonal (viz. abstract) skills yields an innovation premium (Figure 7.5) for public procurement in both products and services. Routine intensive occupations have a significant moderating effect only for service expenditure. Conversely, among adaptation technologies, the coefficients of both routine and abstract occupations are significant only for service-related GPP (Figure 7.6). We ascribe this to the preponderance of intangible nature of coordinating, planning and implementing adaptation strategies at local level.

\subsection{Conclusions}

In this chapter we have investigated the impact of a somewhat neglected type of public intervention, i.e. green public procurement (GPP), on the generation of GTs. In this respect, our analysis marks an important difference with most of the extant literature, in that we consider a direct demand-side policy lever (i.e. government expenditure) instead of indirect demand-pull effects engendered by the implementation of stringent environmental regulatory frameworks. 
Figure 7.4: A.M.E. of GPP on total GT stock with $95 \%$ CIs

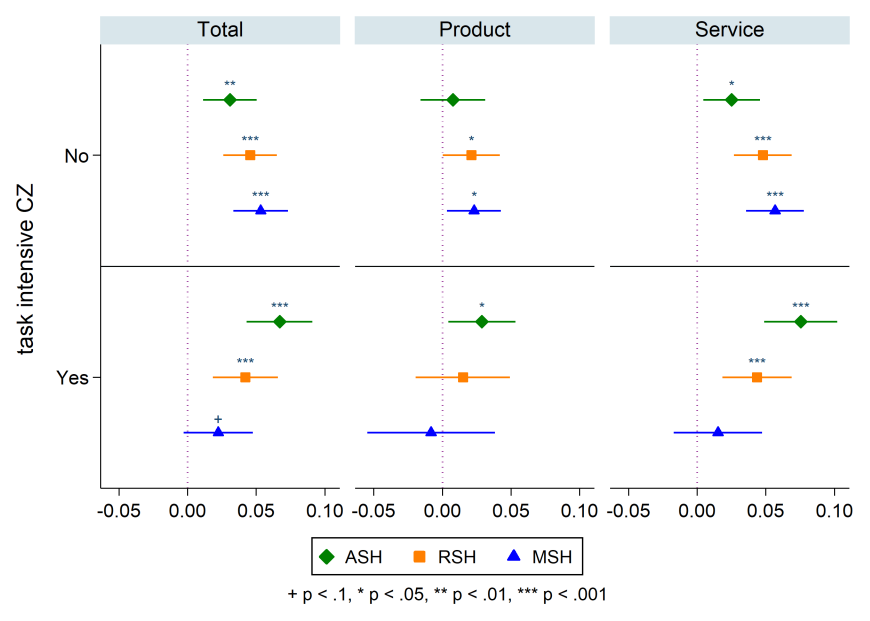

Our analysis of the link between GPP and the generation of GTs has been conducted at the territorial level, i.e. US commuting zones. We put forward the hypothesis that the local accumulation of competences represents a key enabling condition for the generation of new technologies in general. GTs show some specificities in this respect, in that they appear to emerge as an outcome of the hybridization of a variety of technologies that often are loosely related with one another. The configuration of the local bundle of skills is therefore important in affecting local differences in the capacity to sustain green inventive activities. The prevalence of abstract skills is crucial in this respect, in that it is related to cognitive abilities to combine ideas and inputs from different fields in new and previously untried ways.

Our results have provided empirical support to our hypotheses, showing that GPP actually exerts a positive impact on the generation of GTs. In particular, 
Figure 7.5: A.M.E. of GPP on GT-mitigation stock with $95 \%$ CIs

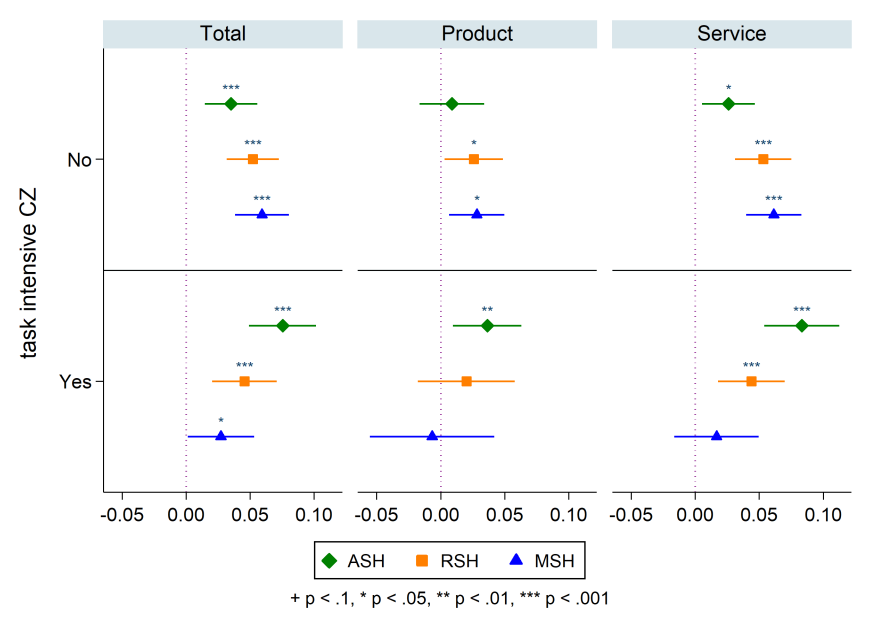

we have found that a 1\% increase in GPP engenders some $0.077 \%$ increase in the local stock of GTs. The government expenditure lever can therefore prove to be efficient in the promotion of technology-driven sustainability transitions. Moreover, we have found that GPP for services yield a stronger impact than GPP for products. This suggests the existence of bandwagon effects upwards in the value chain, for which the demand for green services stimulate the generation of the technologies that make them possible.

The configuration of the local skills bundle also proved to affect the dynamics of GTs generation. In particular, the prevalence of abstract skills is positively associated to the generation of GTs. Moreover, this specific set of skills moderates the effect of GPP on GTs, by magnifying its coefficient. According to our estimates, the overall impact of GPP in areas in which abstract skills are 
Figure 7.6: A.M.E. of GPP on GT-adaptation stock with 95\% CIs

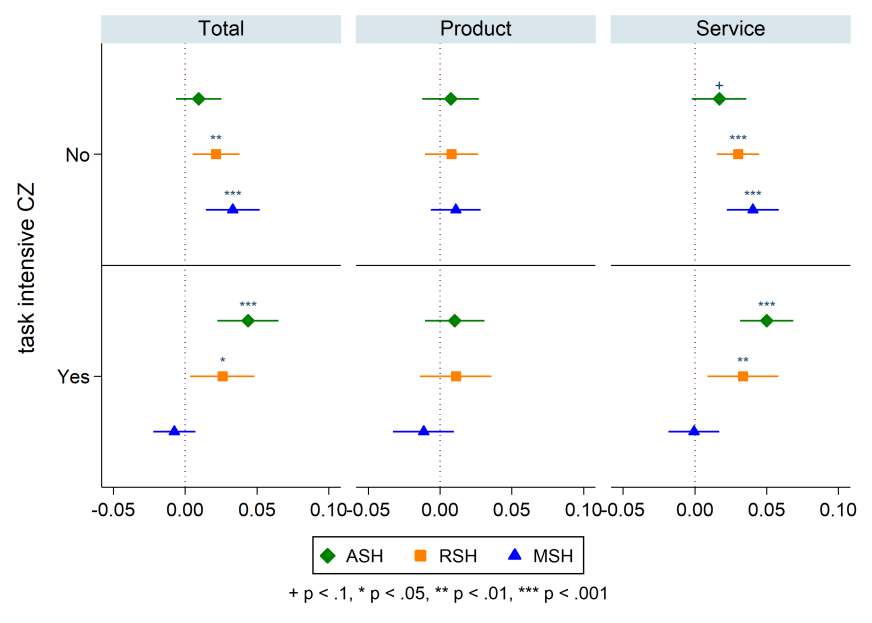

prevalent is almost twice the impact of GPP in areas in which this prevalence is not observed.

Finally, our analyses allowed to investigate the differential impact of GPP and local skills bundle configuration on mitigation vis-à-vis adaptation oriented green technologies.

Our results bear important policy implications. The most straightforward concerns the role of public expenditure in boosting technology-driven sustainable development. Most of the extant literature has focused on technology push or demand pull deployment policies. We do not deny the relevance of these policy instruments. However, we show that besides these options, policymakers can affect the rate and the direction of green inventive activities by demanding for specific green services or products. While these are expected to satisfy specific needs of public administrations, the GTs that are produced are expected to be 
relevant for a wider set of economic activities, bearing important spillovers for prospective adopters. 



\section{Chapter 8}

\section{Conclusions}

Green technologies are a means to successfully achieve the decoupling of economic growth and environmental degradation. Building climate change resilience within countries entail the reorganisation of existing, and in some case the creation of new, systems for generating and using natural resources. Against this backdrop, accelerating the development and diffusion of new low-carbon technologies remains a crucial ingredient of the environmental policy mix.

Progress in recent years has been significant if uneven, not only between green technology domains but also across countries, and the concern is that imbalances on the distribution of opportunities could further exacerbate these gaps and, paradoxically, become hurdles towards sustainability. Thus, continued innovation and deployment are crucial, but so is the capacity to put in place 
policies that facilitate diffusion, especially towards developing countries that are most exposed to climate hazards and yet lag behind the technological frontier.

Because climate change is a global phenomenon with local manifestations, we proposed in this dissertation an analysis that articulates green technology development across domains from a geographical perspective. Effective resource management cannot be divorced from characteristics of the institutional regime over which regulatory functions are to be undertaken. While the geographic distribution of natural resources may partially be determined by exogenous factors - such as i.e. availability of raw materials - the capacity for adaptation and mitigation stems from endogenous factors such as human capital and institutional flexibility. This dissertation contributes to the literature about technological development focusing on green technologies from the perspective of countries' development, knowledge recombination, public procurement and labour markets.

\subsection{Main contributions and findings}

The first contribution of this dissertation is the creation of a dataset collecting systematic information about green patents and the localisation of their inventors. This effort permitted a systematic exploration of green technologies from the perspective of economic geography.

A first overview proposed in chapter 3 provided us with a novel global mapping of green innovation capacity over time and across countries. In so doing we identified three typologies of countries: leaders, laggards and catch-up. As 
expected, GDP per capita is positively associated to the production of complex green technologies, but we also found that the production of complex green technologies in mid-income countries is associated with the export of complex products. This means that internal capabilities are as important as GDP to produce green technologies. On the technology side, the evolution of the fitness ranking reveals that green innovation has become more horizontal in the last decades with important efforts in cross-domain or enabling technologies, while there was a stronger development in individual areas at the beginning of the time period. The latter may have peaked in term of technology life cycle, while enabling technologies (i.e. ICT for monitoring energy distribution) may be in a development phase.

In order to test these conjectures, chapter 4 proposes a methodology to measure technology life cycle stages based on patenting activity and geographical ubiquity. This methodology is based on the life cycle heuristic proposed by William J Abernathy and J. M. Utterback (1978) and further refined by S. Klepper (1996) and J. Utterback (1994) and later works underlying the dynamics of the knowledge base by Nelson (1994) and Vona and Consoli (2015). It defines four stages: emergence, development, diffusion and maturity. The rationale of this exercise is that green technologies encompass a large and diverse domain, and that the underlying bodies of knowledge advance at uneven pace. This entails that progress across the problem solving spectrum will be diverse and that this, in turn, matters for the various domains that are interconnected, namely: cross-technology complementarities, the design of policy and the viability of 
the self endowment. This is why identifying and classifying green technologies over the life cycle heuristic is a central contribution of this thesis.

Using this framework, chapter 5 shows that countries are more likely to diversify into new domains of green technology that are close to the portfolio of existing competences as proxied by prior technological orientation. In particular, differences in competences are a bigger obstacle than differences in wealth. This observed effect is in line with previous literature, but the core difference resides in the association with countries development: while Petralia, Balland, and Morrison (2017) found a strong association with the stage of development of countries, we found a strong association with the maturity of technologies. On the specialization side, we found that complexity of technologies is not an obstacle, contrary to previous literature.

The life cycle framework was also used in chapter 6 to identify knowledge recombination types associated with green technology production. First, we found that green innovation is more associated to the recombination of distant knowledge than other innovations, confirming Barbieri, Marzucchi, and Rizzo (2018) findings that green technologies are more complex, radical, pervasive and impactful. Second, emergence stages of the green technology life cycle are more associated with the recombination of distant knowledge while recombination of related knowledge takes precedence when moving toward maturity stage. This is a clear confirmation of the idea that the advance of technology cannot be divorced from the dynamics of the underpinning know-how (Vona and Consoli, 2015). This is also a powerful reminder of the systemic nature of innovation, 
and the intrinsic importance of other domains, that are often neglected, such as education and training, policy design, mobility and international cooperation.

Finally, in the last chapter, using US procurement data at commuting zone level, we find a positive and significant impact of green public procurement on green innovation. When we enrich the model with occupational-task data, defining share of routine, manual and abstract skills, we also find that an important share of abstract skills in the territory is positively associated to the production of green innovation.

\subsection{Policy implications}

The present dissertation provides interesting findings that have relevance for policy, first because of the urgency to mitigate climate change and to adapt our societies to it, and second because the development of technological solution must be carried out without leaving aside low or mid-income countries. Climate change is a global phenomenon with markedly local manifestation, some territories may be tempted to foster the development of green technologies according to their needs without taking into account their local production configuration.

We saw in chapter 3 and 4 that green technologies are not at the same stage of development, and not all the countries are able to produce complex green technologies. Betting on emerging technologies to mitigate climate change (i.e. $\mathrm{CO}_{2}$ capture and sequestration) could be risky because they may be not mature in time to be massively used in order to remain below a $2^{\circ} \mathrm{C}$ increase of the average temperature. On the same vein, fostering the development of 
electric vehicles while enabling technologies in transport and in energy sector are still at an early stage of development could lead to an increase of greenhouse gases emissions, as electricity is still mainly produced using coal (BP Statistical Review of World Energy 2018) and these technologies could not be ready soon enough to meet the demand.

On the other hand, policy makers who want to promote the development of green technologies should take into account the characteristics of their territories. We saw in chapter 5 that the diversification in green innovation is associated not so much with a higher level of development but with already existing capacities in neighbouring technologies. They should also consider the stage of development of these technologies, as diversification is positively associated with mature technologies.

Technology life cycle should also be taken into consideration regarding local capabilities and labour market: territories willing to develop emerging green technologies should have an unrelated knowledge base, and public procurement will be more impactful if labour market has an important share of abstract skills. No country in isolation will have the capacity to develop green technologies, and barriers to knowledge and to shared understanding can become barriers to the ability to counter climate change on a global basis. 


\subsection{Future avenues and developments}

This dissertation draws a worldwide overview of green innovation, and focuses on the United States to explore the type of knowledge recombination associated and the efficiency of public procurement according to local labour market.

The immediate next step will be to exploit the dataset through the development of a web site, in order to contribute to the general debate about climate change mitigation and adaptation. Data would be made available on an open platform that allows to access, visualize and use.

Other developments will be to explore other territories, like the European Union, to investigate if we observe similar relations between knowledge base recombination, public procurement and labour market with green innovation.

Moreover, enriching this dataset with information about local use of technologies, greenhouse gases emissions and environmental pollution would make possible to analyse if the use of environment management, climate change adaption and mitigation technologies really leads to sustainable economies. This could be done by contrasting the environmental performance of each country, e.g. in terms of pollution, vis-à-vis their capacity to generate green technologies.

But there is also great potential to further extend the insights generated here by engaging qualitative analysis by country, in the hope to gain further insights into all the possible ways in which environmentally sustainable practices diffuse.

On the society side, while there is an extensive debate going on about increasing inequalities, to our knowledge, few developments have been done exploring the 
impact of inequalities on the development of technologies, in particular of green technologies. An extension of this dissertation would be to explore whenever inequalities within countries enable or thwart green innovation. It would be an interesting contribution to the general debate about growth, climate action and development, which are complementary objective according to the Sustainable Development Goals (SDGs) and Paris Agreement.

To reiterate, the contribution of this thesis is the elaboration of a detailed global map of green inventions. As such, a map is only useful to gain insights on the broad direction of the phenomenon at hand, as well as the main spots of interest - be they a burst of innovation or a lack of thereof. Once a point of interest has been identified, qualitative work is the best vehicle to deeper the analysis. We leave this step for future research. 
Chapter 9

\section{Appendix}

9.1 List of countries codes 


\begin{tabular}{llllll}
\hline ISO3 Code & Country Name & ISO3 Code & Country Name & ISO3 Code & Country Name \\
\hline ARG & Argentina & GRC & Greece & NOR & Norway \\
AUS & Australia & HRV & Croatia & NZL & New Zealand \\
AUT & Austria & HUN & Hungary & PHL & Philippines \\
BEL & Belgium & IDN & Indonesia & POL & Poland \\
BGR & Bulgaria & IND & India & PRT & Portugal \\
BHS & Bahamas & IRL & Ireland & ROU & Romania \\
BLR & Belarus & IRN & Iran & RUS & Russian Federation \\
BRA & Brazil & ISR & Israel & SAU & Saudi Arabia \\
CAN & Canada & ITA & Italy & SGP & Singapore \\
CHE & Switzerland & JAM & Jamaica & SRB & Serbia \\
CHL & Chile & MAR & Morocco & SVK & Slovakia \\
CHN & China & MCO & Monaco & SVN & Slovenia \\
COL & Colombia & MEX & Mexico & SWE & Sweden \\
CYP & Cyprus & MYS & Malaysia & THA & Thailand \\
CZE & Czech Republic & NLD & Netherlands & TWN & Taiwan \\
DEU & Germany & JPN & Japan & UKR & Ukraine \\
DNK & Denmark & KAZ & Kazakhstan & USA & United States of America \\
ESP & Spain & KOR & South Korea & UZB & Uzbekistan \\
FIN & Finland & LIE & Liechtenstein & VEN & Venezuela \\
FRA & France & LUX & Luxembourg & ZAF & South Africa \\
GBR & United Kingdom & & & & \\
\hline
\end{tabular}




\subsection{ENV-TECH 2016 Classification}

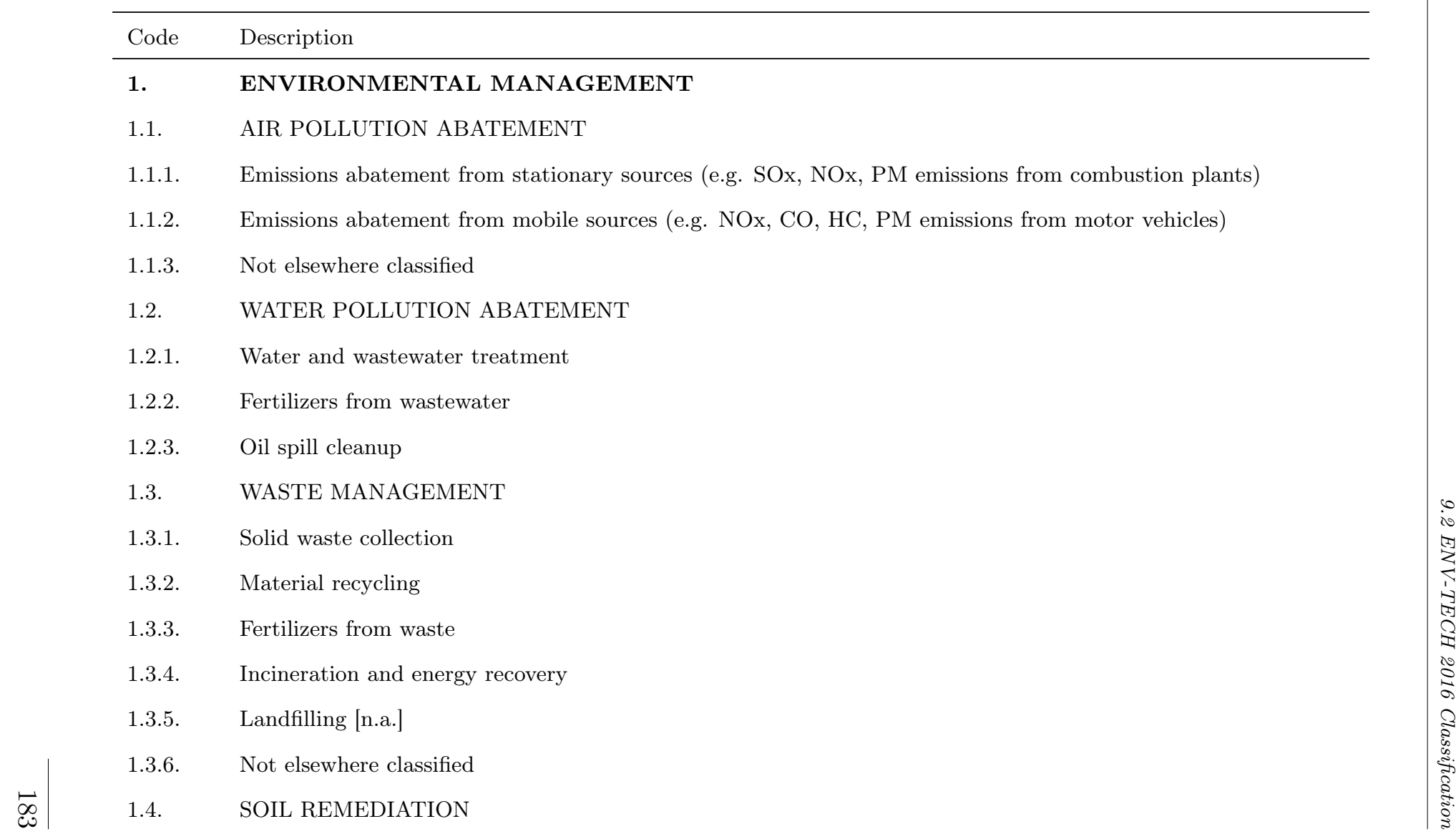




\section{WATER-RELATED ADAPTATION TECHNOLOGIES}

2.1. DEMAND-SIDE TECHNOLOGIES (water conservation)

2.1.1. Indoor water conservation (faucets, showers, sanitation, home appliances)

2.1.2. Irrigation water conservation

2.1.3. Water conservation in thermoelectric power production

2.1.4. Water distribution

2.2. SUPPLY-SIDE TECHNOLOGIES (water availability)

2.2.1. Water collection (rain, surface and ground-water)

2.2.2. Water storage

2.2.3. Desalination of sea water [n.a.] 


Code Description

\section{BIODIVERSITY PROTECTION AND ECOSYSTEM HEALTH [n.a.]}

search strategy currently not available

4. CLIMATE CHANGE MITIGATION technologies related to ENERGY generation, transmission or distribution

4.1. RENEWABLE ENERGY GENERATION

4.1.1. Wind energy

4.1.2. Solar thermal energy

4.1.3. Solar photovoltaic (PV) energy

4.1.4. Solar thermal-PV hybrids

4.1.5. Geothermal energy

4.1.6. Marine energy

4.1.7. Hydro energy (conventional, tidal, stream)

4.2. ENERGY GENERATION FROM FUELS OF NON-FOSSIL ORIGIN

4.2.1. Biofuels

4.2.2. Fuel from waste (e.g. methane)

4.3. COMBUSTION TECHNOLOGIES WITH MITIGATION POTENTIAL

(e.g. using fossil fuels, biomass, waste, etc.) 
4.4. NUCLEAR ENERGY

4.4.1. Nuclear fusion reactors

4.4.2. Nuclear fission reactors

4.5. EFFICIENCY IN ELECTRICAL POWER GENERATION, TRANSMISSION OR DISTRIBUTION

4.5.1. Superconducting electric elements or equipment

4.5.2. Not elsewhere classified (incl. FACTS, APF, etc.)

4.6. ENABLING TECHNOLOGIES IN ENERGY SECTOR

4.6.1. Energy storage

4.6.1.1. Batteries

4.6.1.2. Capacitors

4.6.1.3. Thermal storage

4.6.1.4. Pressurised fluid storage

4.6.1.5. Mechanical storage

4.6.1.6. $\quad$ Pumped storage

4.6.2. Hydrogen technology

4.6.3. Fuel cells

4.6.4. Smart grids in energy sector

4.7. OTHER ENERGY CONVERSION OR MANAGEMENT SYSTEMS REDUCING GHG EMISSIONS 
5. CAPTURE, STORAGE, SEQUESTRATION OR DISPOSAL OF GREENHOUSE GASES

5.1. CO2 CAPTURE OR STORAGE (CCS)

5.2. CAPTURE OR DISPOSAL OF GREENHOUSE GASES OTHER THAN CARBON DIOXIDE (N2O, CH4, PFC, HFC, SF6)

6. CLIMATE CHANGE MITIGATION technologies related to TRANSPORTATION

6.1. ROAD TRANSPORT

6.1.1. Conventional vehicles (based on internal combustion engine)

6.1.2. Hybrid vehicles

6.1.3. Electric vehicles

6.1.4. Fuel efficiency-improving vehicle design (common to all road vehicles)

6.2. RAIL TRANSPORT

6.3. $\quad$ AIR TRANSPORT

6.4. MARITIME OR WATERWAYS TRANSPORT

6.5. ENABLING TECHNOLOGIES IN TRANSPORT

6.5.1. Electric vehicle charging

6.5.2. Application of fuel cell and hydrogen technology to transportation 


\begin{tabular}{ll}
\hline Code & Description \\
\hline 7. & CLIMATE CHANGE MITIGATION technologies related to BUILDINGS
\end{tabular}

7.1. INTEGRATION OF RENEWABLE ENERGY SOURCES IN BUILDINGS

7.2. $\quad$ ENERGY EFFICIENCY IN BUILDINGS

7.2.1. Lighting

7.2.2. Heating, ventilation or air conditioning [HVAC]

7.2.3. Home appliances

7.2.4. Elevators, escalators and moving walkways

7.2.5. Information and communication technologies [ICT]

7.2.6. $\quad$ End-user side

7.3. ARCHITECTURAL OR CONSTRUCTIONAL ELEMENTS IMPROVING THE THERMAL PERFORMANCE OF BUILDINGS

7.4. ENABLING TECHNOLOGIES IN BUILDINGS

8. CLIMATE CHANGE MITIGATION technologies related to WASTEWATER TREATMENT or WASTE MANAGEMENT

8.1. WASTEWATER TREATMENT

8.2. SOLID WASTE MANAGEMENT

8.2.1. Waste collection, transportation, transfer or storage

8.2.2. Waste processing or separation 


Code Description

8.2.3. Landfill technologies aiming to mitigate methane emissions

8.2.4. Bio-organic fraction processing; Production of fertilisers from the organic fraction of waste or refuse

8.2.5. Reuse, recycling or recovery technologies

8.2.5.1. Dismantling or mechanical processing of waste for the recovery of materials during separation, disassembly, preprocessing or upgrading

8.2.5.2. Metal recycling

8.2.5.3. Disassembly of vehicles for recovery of salvageable parts

8.2.5.4. Construction or demolition [C\&D] waste

8.2.5.5. Glass recycling

8.2.5.6. Plastics recycling

8.2.5.7. Paper recycling

8.2.5.8. Disintegrating fibre-containing textile articles to obtain fibres for re-use

8.2.5.9. Rubber waste recycling

8.2.5.10. Recovery of polymers other than plastics or rubbers

8.2.5.11. Recovery of luminescent materials

8.2.5.12. Recovery of fats, fatty oils, fatty acids or other fatty substances, e.g. lanolin or waxes

8.2.5.13. Recovery of tanning agents from leather

8.2.5.14. Recycling of wood or furniture waste (production of fertilisers from the organic fraction of waste or refuse) 
Recycling of waste of electrical or electronic equipment

8.2.5.17. Recycling of batteries

8.2.5.18. Recycling of fuel cells

8.2.5.19. Nuclear fuel reprocessing

8.2.5.20. Reuse, recycling or recovery technologies cross-cutting to different types of waste

8.3. ENABLING TECHNOLOGIES OR TECHNOLOGIES WITH A POTENTIAL OR INDIRECT CONTRIBUTION TO GHG MITIGATION

9. CLIMATE CHANGE MITIGATION TECHNOLOGIES IN THE PRODUCTION OR PROCESSING OF GOODS

9.1. TECHNOLOGIES RELATED TO METAL PROCESSING

9.1.1. Reduction of greenhouse gas [GHG] emissions

9.1.2. Process efficiency

9.2. TECHNOLOGIES RELATING TO CHEMICAL INDUSTRY

9.2.1. General improvement of production processes causing greenhouse gases [GHG] emissions

9.2.2. Improvements relating to chlorine production

9.2.3. Improvements relating to adipic acid or caprolactam production

9.2.4. Improvements relating to chlorodifluoromethane [HCFC-22] production

9.2.5. Improvements relating to the production of other chemicals or pharmaceuticals 


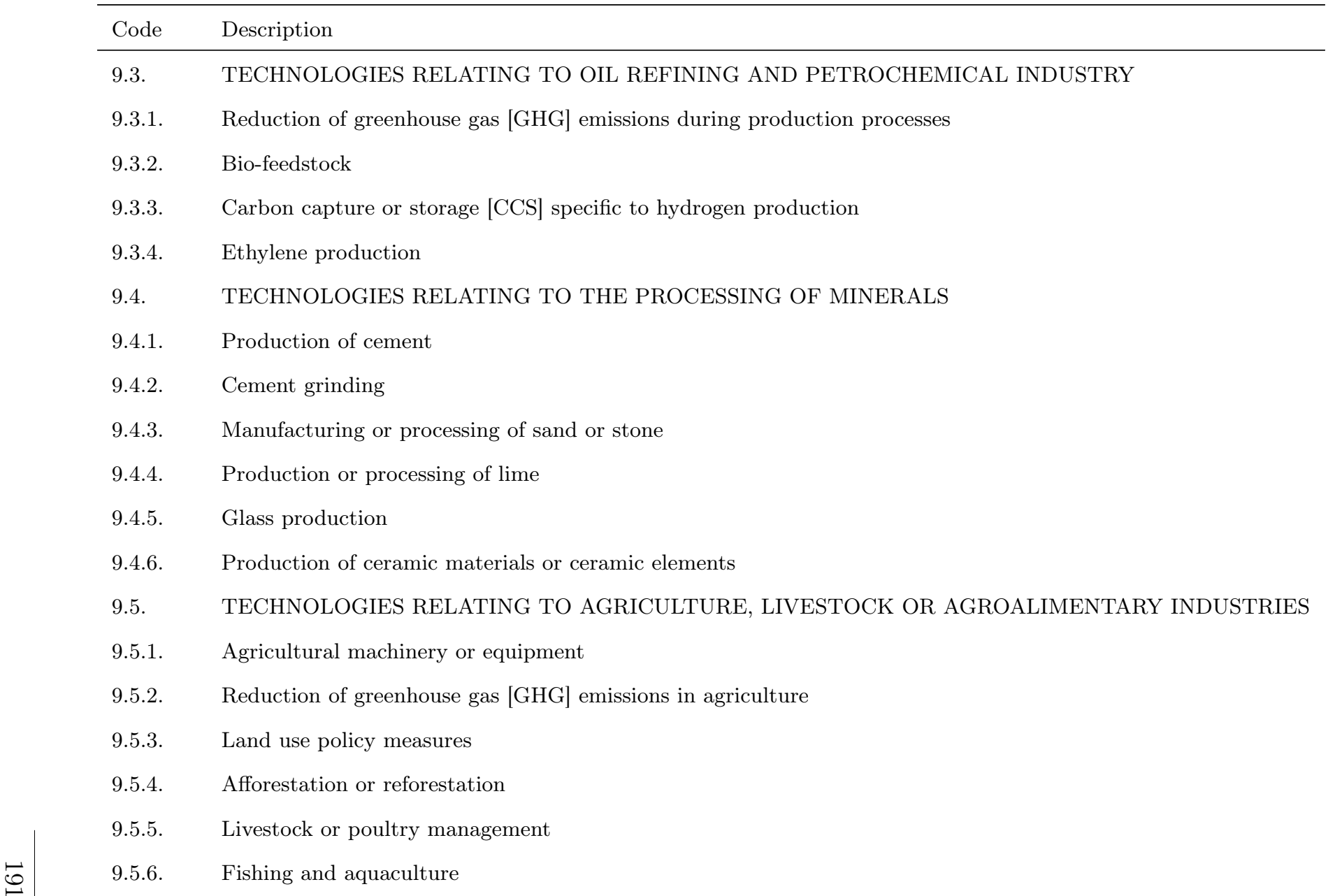

9.3.1. Reduction of greenhouse gas [GHG] emissions during production processes

9.3.2. Bio-feedstock

9.3.3. Carbon capture or storage [CCS] specific to hydrogen production

9.3.4. Ethylene production

9.4. TECHNOLOGIES RELATING TO THE PROCESSING OF MINERALS

9.4.1. Production of cement

9.4.2. Cement grinding

9.4.3. Manufacturing or processing of sand or stone

9.4.4. Production or processing of lime

9.4.5. Glass production

9.4.6. Production of ceramic materials or ceramic elements

9.5. TECHNOLOGIES RELATING TO AGRICULTURE, LIVESTOCK OR AGROALIMENTARY INDUSTRIES

9.5.1. Agricultural machinery or equipment

9.5.2. Reduction of greenhouse gas [GHG] emissions in agriculture

9.5.3. Land use policy measures

9.5.4. Afforestation or reforestation

9.5.5. Livestock or poultry management

• 
9.5.8. Food processing

9.6. TECHNOLOGIES IN THE PRODUCTION PROCESS FOR FINAL INDUSTRIAL OR CONSUMER PRODUCTS

9.6.1. Technologies for shaping products (e.g. rolling metal, forging, hammering, pressing or riveting)

9.6.2. Technologies for metal working

9.6.3. Technologies for printing, lining or stamping machines

9.6.4. Technologies for working on wood, veneer or plywood

9.6.5. Technologies for production of paper and paper articles

9.6.6. Technologies for working on or processing of plastics

9.6.7. Technologies for conveying, packing or storing of goods

9.6.8. Other manufacturing technologies (e.g., for mixing, separation, applying liquids, drying, etc.)

9.6.9. Manufacturing of products or systems for producing renewable energy (e.g. wind turbines)

9.6.10. Manufacturing of batteries and fuel cells

9.6.11. Manufacturing or assembling of vehicles

9.6.12. Manufacturing of electric and electronic components of products

9.6.13. Technologies for production or treatment of textiles and foot wear

9.6.14. Technologies for production of tobacco products

9.7. CLIMATE CHANGE MITIGATION TECHNOLOGIES FOR SECTOR-WIDE APPLICATIONS 


\begin{tabular}{ll}
\hline Code & Description \\
\hline 9.8. & ENABLING TECHNOLOGIES WITH A POTENTIAL CONTRIBUTION \\
& TO GHG EMISSIONS MITIGATION \\
\hline
\end{tabular}





\section{Bibliography}

Abernathy, William J. and Kim B. Clark (Feb. 1985). "Innovation: Mapping the winds of creative destruction". In: Research Policy 14.1, pp. 3-22 (cit. on p. 69).

Abernathy, William J and James M Utterback (1978). "Patterns of industrial innovation". In: Technology review 80.7, pp. 40-47 (cit. on pp. 5, 7, 66, 76, $85,175)$.

Achilladelis, Basil (1993). "The dynamics of technological innovation: The sector of antibacterial medicines". In: Research Policy 22.4, pp. 279-308 (cit. on p. 66).

Achilladelis, Basil, Albert Schwarzkopf, and Martin Cines (Feb. 1990). "The dynamics of technological innovation: The case of the chemical industry". In: Research Policy 19.1, pp. 1-34 (cit. on p. 66).

Adner, Ron and Rahul Kapoor (Mar. 2015). "Innovation ecosystems and the pace of substitution: Re-examining technology S-curves". In: Strategic Management Journal 37.4, pp. 625-648 (cit. on p. 5).

Agarwal, Rajshree and Michael Gort (Apr. 2002). "Firm and Product Life Cycles and Firm Survival". In: American Economic Review 92.2, pp. 184190 (cit. on p. 69). 
Andersen, Birgitte (Dec. 1999). "The hunt for S -shaped growth paths in technological innovation: a patent study *". In: Journal of Evolutionary Economics 9.4, pp. 487-526 (cit. on p. 66).

Arrow, Kenneth (1962). "Economic Welfare and the Allocation of Resources for Invention". In: The Rate and Direction of Inventive Activity: Economic and Social Factors. Princeton University Press, pp. 609-626 (cit. on p. 3).

Arthur, W. Brian (Mar. 2007). "The structure of invention". In: Research Policy 36.2 , pp. $274-287$ (cit. on p. 111).

Arts, Sam, Francesco Paolo Appio, and Bart Van Looy (2013). "Inventions shaping technological trajectories: do existing patent indicators provide a comprehensive picture?" In: Scientometrics 97.2, pp. 397-419 (cit. on p. 13).

Atkinson, Anthony B and Joseph E Stiglitz (1969). "A new view of technological change". In: The Economic Journal 79.315, pp. 573-578 (cit. on p. 4).

Attaran, Mohsen (July 1986). "Industrial diversity and economic performance in U.S. areas". In: The Annals of Regional Science 20.2, pp. 44-54 (cit. on p. 112).

Audretsch, David B. and Maryann P. Feldman (Apr. 1996). "Innovative clusters and the industry life cycle". In: Review of Industrial Organization 11.2, pp. 253-273 (cit. on p. 69).

Autor, David H. and David Dorn (Aug. 2013). "The Growth of Low-Skill Service Jobs and the Polarization of the US Labor Market". In: American Economic Review 103.5, pp. 1553-97 (cit. on pp. 141, 143, 158).

Autor, David H., Lawrence F. Katz, and Melissa S. Kearney (May 2006). "The Polarization of the U.S. Labor Market". In: American Economic Review 96.2, pp. 189-194 (cit. on p. 143).

Autor, David H., Frank Levy, and Richard J. Murnane (2003). "The Skill Content of Recent Technological Change: An Empirical Exploration". In: The Quarterly Journal of Economics 118.4, pp. 1279-1333 (cit. on pp. 10, $141,143,158)$. 
Ayres, Robert U and Jeroen C J M van den Bergh (2005). "A theory of economic growth with material/energy resources and dematerialization: Interaction of three growth mechanisms". In: Ecological Economics 55.1, pp. 96-118 (cit. on p. 3).

Balassa, Bela (1965). "Trade liberalisation and "revealed" comparative advantage". In: The manchester school 33.2, pp. 99-123 (cit. on p. 41).

Balland, Pierre Alexandre and David Rigby (2017). "The Geography of Complex Knowledge". In: Economic Geography 93.1, pp. 1-23 (cit. on pp. 4, 38, 78, $92,110)$.

Barbieri, Nicolò, Claudia Ghisetti, et al. (Mar. 2016). "A survey of the literature on environmental innovation based on main path analysis". In: Journal of Economic Surveys 30.3, pp. 596-623 (cit. on pp. 5, 134).

Barbieri, Nicolò, Alberto Marzucchi, and Ugo Rizzo (2018). "Knowledge sources and impacts on subsequent inventions: Do green technologies differ from non-green ones?" In: SPRU Working Paper Series 2018-11 (cit. on pp. 5, $61,101,113,126,130,176)$.

Basalla, George (1989). The Evolution of Technology. Cambridge Studies in the History of Science. Cambridge University Press (cit. on p. 111).

Bishop, Paul and Peter Gripaios (May 2010). "Spatial Externalities, Relatedness and Sector Employment Growth in Great Britain". In: Regional Studies 44.4, pp. 443-454 (cit. on p. 71).

Blondel, Vincent D et al. (2008). "Fast unfolding of communities in large networks". In: Journal of Statistical Mechanics: Theory and Experiment 2008.10, P10008 (cit. on pp. 31, 73).

Boschma, Ron A. and Koen Frenken (June 2006). "Why is economic geography not an evolutionary science? Towards an evolutionary economic geography". In: Journal of Economic Geography 6.3, pp. 273-302 (cit. on pp. 110, 115).

Boschma, Ron, Lars Coenen, et al. (Jan. 2017). "Towards a theory of regional diversification: combining insights from Evolutionary Economic Geography 
and Transition Studies". In: Regional Studies 51.1, pp. 31-45 (cit. on p. 110).

Boschma, Ron and Simona Iammarino (Apr. 2009). "Related Variety, Trade Linkages, and Regional Growth in Italy". In: Economic Geography 85.3, pp. 289-311 (cit. on p. 71).

BP Statistical Review of World Energy (2018). Tech. rep. BP (cit. on p. 178).

Calel, Raphael and Antoine Dechezleprêtre (Mar. 2016). "Environmental Policy and Directed Technological Change: Evidence from the European Carbon Market". In: Review of Economics and Statistics 98.1, pp. 173-191 (cit. on pp. 5, 88).

Callon, Michel (May 1998). "An Essay on Framing and Overflowing: Economic Externalities Revisited by Sociology". In: The Sociological Review 46.1 $1_{s}$ ppl, pp. 244-269 (cit. on p. 66).

Capello, R. (2010). "Space, growth and development". In: Handbook of regional growth and development theories. Ed. by R. Capello and P. Nijkamp. Edward Elg (cit. on p. 37).

Castaldi, C and M.S > Giarratana (2014). "Diversification, branding and performance of knowledge-intensive service firms". In: pp. 1-38 (cit. on pp. 71, $113,130)$.

Castaldi, Carolina, Koen Frenken, and Bart Los (May 2015). "Related Variety, Unrelated Variety and Technological Breakthroughs: An analysis of US State-Level Patenting". In: Regional Studies 49.5, pp. 767-781 (cit. on pp. 8, 9, 70, 100, 111, 112, 116, 118, 122).

Chang, Shu-Hao and Chin-Yuan Fan (Apr. 2016). "Identification of the technology life cycle of telematics: A patent-based analytical perspective". In: Technological Forecasting and Social Change 105, pp. 1-10 (cit. on p. 67).

Charlot, Sylvie, Riccardo Crescenzi, and Antonio Musolesi (Nov. 2015). "Econometric modelling of the regional knowledge production function in Europe". In: Journal of Economic Geography 15.6, pp. 1227-1259 (cit. on pp. 111, $112,115)$. 
Chatterjee, Sayan and Birger Wernerfelt (1991). "The link between resources and type of diversification: Theory and evidence". In: Strategic management journal 12.1, pp. 33-48 (cit. on p. 4).

Christensen, Clayton M (1997). Innovator's Dilemma:When new technologies cause great firms to fail (cit. on p. 114).

Cohen, Wesley M, Richard R Nelson, and John P Walsh (2000). Protecting Their Intellectual Assets: Appropriability Conditions and Why U.S. Manufacturing Firms Patent (or Not). Working Paper 7552. National Bureau of Economic Research (cit. on p. 14).

Cohen, Wesley and D A Levinthal (1990). "Absorptive capacity: A new perspective on learning and innovation". In: Administrative Science Quarterly 35, pp. 128-152 (cit. on p. 4).

Constant (1980). The origins of the turbojet revolution (cit. on p. 115).

Content, Jeroen and Koen Frenken (Dec. 2016). "Related variety and economic development: a literature review". In: European Planning Studies 24.12, pp. 2097-2112 (cit. on p. 110).

Costantini, Valeria, Francesco Crespi, et al. (2015). "Demand-pull and technologypush public support for eco-innovation: The case of the biofuels sector". In: Research Policy 44.3, pp. 577-595 (cit. on pp. 10, 133, 134).

Costantini, Valeria and Massimiliano Mazzanti (Feb. 2012). "On the green and innovative side of trade competitiveness? The impact of environmental policies and innovation on EU exports". In: Research Policy 41.1, pp. 132 153 (cit. on pp. 5, 88).

Crescenzi, R., A. Rodriguez-Pose, and M. Storper (May 2007). "The territorial dynamics of innovation: a Europe United States comparative analysis". In: Journal of Economic Geography 7.6, pp. 673-709 (cit. on pp. 115, 122).

Crescenzi, Riccardo, Luisa Gagliardi, and Simona Iammarino (Apr. 2015). "Foreign multinationals and domestic innovation: Intra-industry effects and firm heterogeneity". In: Research Policy 44.3, pp. 596-609 (cit. on p. 111). 
Crescenzi, Riccardo and Andrés Rodríguez-Pose (Aug. 2012). "Infrastructure and regional growth in the European Union*". In: Papers in Regional Science 91.3, pp. 487-513 (cit. on p. 115).

Cristelli, Matthieu, Andrea Gabrielli, et al. (2013). "Measuring the Intangibles: A Metrics for the Economic Complexity of Countries and Products". In: PLoS ONE 8.8. Ed. by Alain Barrat, e70726 (cit. on p. 4).

Cristelli, Matthieu, Andrea Tacchella, et al. (2017). On the predictability of growth. The World Bank (cit. on p. 39).

De Marchi, Valentina (Apr. 2012). "Environmental innovation and R\&D cooperation: Empirical evidence from Spanish manufacturing firms". In: Research Policy 41.3, pp. 614-623 (cit. on p. 130).

Desrochers, Pierre and Samuli Leppälä (Mar. 2011). "Creative Cities and Regions: The Case for Local Economic Diversity". In: Creativity and Innovation Management 20.1, pp. 59-69 (cit. on p. 110).

Dorn, David (2009). "Essays on Inequality, Spatial Interaction, and the Demand for Skills". PhD thesis. Dissertation University of St. Gallen no. 3613, September (cit. on pp. 137, 143).

Driscoll, John C. and Aart C. Kraay (Nov. 1998). "Consistent Covariance Matrix Estimation with Spatially Dependent Panel Data". In: Review of Economics and Statistics 80.4, pp. 549-560 (cit. on pp. 127, 129).

Duranton, Gilles and Diego Puga (Dec. 2001). "Nursery Cities: Urban Diversity, Process Innovation, and the Life Cycle of Products". In: American Economic Review 91.5, pp. 1454-1477 (cit. on pp. 69, 70).

Essletzbichler, Jürgen (2007). "Diversity, Stability and Regional Growth in the United States, 1975 - 2002". In: Applied Evolutionary Economics and Economic Geography. Ed. by Koen Frenken. Cheltenham, UK: Edward Elgar Publishing (cit. on p. 71).

Fankhauser, Sam et al. (Oct. 2013). "Who will win the green race? In search of environmental competitiveness and innovation". In: Global Environmental Change 23.5, pp. 902-913 (cit. on pp. 5, 88). 
Feldman, Maryann P. and Alexandra Graddy-Reed (June 2014). "Local champions: Entrepreneurs' transition to philanthropy and the vibrancy of place". English (US). In: Handbook of Research on Entrepreneurs' Engagement in Philanthropy. Edward Elgar Publishing Ltd., pp. 43-71 (cit. on p. 115).

Feldman, Maryann P and David B Audretsch (Feb. 1999). "Innovation in cities:: Science-based diversity, specialization and localized competition". In: European Economic Review 43.2, pp. 409-429 (cit. on p. 70).

Fischer, Carolyn and Richard G Newell (Mar. 2008). "Environmental and technology policies for climate mitigation". In: Journal of Environmental Economics and Management 55.2, pp. 142-162 (cit. on p. 6).

Fleming, Lee (Jan. 2001). "Recombinant Uncertainty in Technological Search". In: Management Science 47.1, pp. 117-132 (cit. on pp. 70, 72).

Foster, Richard N. (1986). Innovation : the attacker's advantage. Simon \& Schuster, p. 316 (cit. on p. 114).

Frenken, Koen and Ron A Boschma (2007). "A theoretical framework for evolutionary economic geography: industrial dynamics and urban growth as a branching process". In: Journal of economic geography 7.5, pp. 635-649 (cit. on pp. 4, 9, 37, 70, 71, 110, 112, 116, 118, 122).

Gagliardi, Luisa, Giovanni Marin, and Caterina Miriello (2016). "The greener the better? Job creation effects of environmentally-friendly technological change". In: Industrial and Corporate Change 25.5, pp. 779-807 (cit. on p. 5).

Gao, Lidan et al. (Mar. 2013). "Technology life cycle analysis method based on patent documents". In: Technological Forecasting and Social Change 80.3, pp. 398-407 (cit. on p. 67).

Geroski, Paul Andrew (1990). "Procurement policy as a tool of industrial policy". In: International Review of Applied Economics 4.2, pp. 182-198 (cit. on p. 132). 
Ghisetti, Claudia (2017). "Demand-pull and environmental innovations: Estimating the effects of innovative public procurement". In: Technological Forecasting and Social Change (cit. on pp. 132, 134).

Ghisetti, Claudia and Francesco Quatraro (2013). "Beyond inducement in climate change: Does environmental performance spur environmental technologies? A regional analysis of cross-sectoral differences". In: Ecological Economics 96.C, pp. 99-113 (cit. on p. 10).

Ghisetti, Claudia and Francesco Quatraro (2017). "Green Technologies and Environmental Productivity: A Cross-sectoral Analysis of Direct and Indirect Effects in Italian Regions". In: Ecological Economics 132.C, pp. 1-13 (cit. on p. 132).

Ginarte, Juan C and Walter G Park (Oct. 1997). "Determinants of patent rights: A cross-national study". In: Research Policy 26.3, pp. 283-301 (cit. on p. 14).

Glaeser, Edward L. et al. (Dec. 1992). "Growth in Cities". In: Journal of Political Economy 100.6, pp. 1126-1152 (cit. on pp. 68, 70, 122).

Gort, Michael and Steven Klepper (Sept. 1982). "Time Paths in the Diffusion of Product Innovations". In: The Economic Journal 92.367, p. 630 (cit. on p. 69).

Griliches, Zvi (1979). "Issues in Assessing the Contribution of Research and Development to Productivity Growth". In: The Bell Journal of Economics 10.1, p. 92 (cit. on pp. 115, 122).

Griliches, Zvi (1990). Patent Statistics as Economic Indicators: A Survey. Working Paper 3301. National Bureau of Economic Research (cit. on pp. 13, 14).

Haines, Andy and Jonathan A. Patz (2004). "Health Effects of Climate Change". In: Journal of the American Medical Association 291.1, pp. 99-103 (cit. on p. 2). 
Hall, Bronwyn H. and Christian Helmers (July 2013). "Innovation and diffusion of clean/green technology: Can patent commons help?" In: Journal of Environmental Economics and Management 66.1, pp. 33-51 (cit. on p. 20).

Hall, Bronwyn and Manuel Trajtenberg (Nov. 2004). Uncovering GPTS with Patent Data. Tech. rep. Cambridge, MA: National Bureau of Economic Research (cit. on p. 114).

Harrison, Bennett, Maryellen R. Kelley, and Jon Gant (1996). Specialization Versus Diversity in Local Economies: The Implications for Innovative PrivateSector Behavior (cit. on p. 70).

Haščič, Ivan and Mauro Migotto (2015). "Measuring environmental innovation using patent data". In: (cit. on p. 15).

Haupt, Reinhard, Martin Kloyer, and Marcus Lange (Apr. 2007). "Patent indicators for the technology life cycle development". In: Research Policy 36.3, pp. 387-398 (cit. on pp. 66, 67).

Heald, David and John Short (2002). "The Regional Dimension of Public Expenditure in England". In: Regional Studies 36.7, pp. 743-755 (cit. on p. 134).

Henderson, Rebecca (July 1995). "Of life cycles real and imaginary: The unexpectedly long old age of optical lithography". In: Research Policy 24.4, pp. 631-643 (cit. on p. 69).

Henderson, Vernon, Ari Kuncoro, and Matt Turner (Oct. 1995). "Industrial Development in Cities". In: Journal of Political Economy 103.5, pp. 10671090 (cit. on p. 115).

Hidalgo, C. A. and R. Hausmann (2009). "The building blocks of economic complexity". In: Proceedings of the National Academy of Sciences 106.26, pp. 10570-10575 (cit. on pp. 4, 91).

Hidalgo, C. A., B. Winger, et al. (2007). "The product space conditions the development of nations". In: Science 317.5837, pp. 482-487 (cit. on pp. 38, $89,92)$. 
Hoppmann, Joern et al. (2013). "The two faces of market support-How deployment policies affect technological exploration and exploitation in the solar photovoltaic industry". In: Research Policy 42.4, pp. 989-1003 (cit. on p. 133).

Horbach, Jens (2008). "Determinants of environmental innovation - New evidence from German panel data sources". In: Research Policy 37.1, pp. 163173 (cit. on p. 10).

Hughes, Thomas Parke (1993). Networks of Power: Electrification in Western Society, 1880-1930 (Softshell Books). Johns Hopkins University Press (cit. on p. 115).

Jacobs, Jane (1969). The economy of cities. Vintage Books, p. 268 (cit. on pp. 68,122$)$.

Jacquemin, Alexis P et al. (1979). "Entropy Measure of Diversification and Corporate Growth". In: Journal of Industrial Economics 27.4, pp. 359-69 (cit. on p. 112).

Jaffe, A. B., R. G. Newell, and R. N. Stavins (2005). "A tale of two market failures: Technology and environmental policy". In: Ecological Economics 54, pp. 164-174 (cit. on p. 3).

Jaffe, Adam B (1986). "Technological Opportunity and Spillovers of R\&D: Evidence from Firms' Patents, Profits, and Market Value". In: The American Economic Review 76.5, pp. 984-1001 (cit. on p. 122).

Jaffe, Adam B (1989). "Real Effects of Academic Research". In: The American Economic Review 79.5, pp. 957-970 (cit. on p. 122).

Jaffe, Adam B, Richard G Newell, and Robert N Stavins (2002). "Environmental Policy and Technological Change". In: Environmental and Resource Economics 22.1/2, pp. 41-70 (cit. on p. 14).

Johnstone, Nick et al. (June 2012). "Environmental policy stringency and technological innovation: evidence from survey data and patent counts". In: Applied Economics 44.17, pp. 2157-2170 (cit. on pp. 3, 10, 133). 
Kelley, Maryellen R. and Susan Helper (Jan. 1999). "Firm Size And Capabilities, Regional Agglomeration, And The Adoption Of New Technology". In: Economics of Innovation and New Technology 8.1-2, pp. 79-103 (cit. on p. 70).

Klepper, Steven (1996). "Entry, Exit, Growth, and Innovation over the Product Life Cycle". In: The American Economic Review 86.3, pp. 562-583 (cit. on pp. $5,7,69,85,175)$.

Klepper and Steven (1997). "Industry Life Cycles". In: Industrial and Corporate Change 6.1, pp. 145-181 (cit. on p. 69).

Kogut, Bruce and Udo Zander (1993). "Knowledge of the firm and the evolutionary theory of the multinational corporation". In: Journal of international business studies 24.4, pp. 625-645 (cit. on p. 37).

Lanjouw, Jean O, Ariel Pakes, and Jonathan Putnam (1998). "How to count patents and value intellectual property: The uses of patent renewal and application data". In: The Journal of Industrial Economics 46.4, pp. 405432 (cit. on p. 13).

Lanjouw, Jean Olson and Ashoka Mody (June 1996). "Innovation and the international diffusion of environmentally responsive technology". In: Research Policy 25.4, pp. 549-571 (cit. on pp. 5, 14, 88).

Leahy, Stephen (2018). "Climate change impacts worse than expected, global report warns". In: National Geographic (cit. on p. 2).

Lee, Changyong, Yangrae Cho, et al. (Jan. 2012). "A stochastic patent citation analysis approach to assessing future technological impacts". In: Technological Forecasting and Social Change 79.1, pp. 16-29 (cit. on p. 67).

Lee, Changyong, Juram Kim, et al. (May 2016). "Stochastic technology life cycle analysis using multiple patent indicators". In: Technological Forecasting and Social Change 106, pp. 53-64 (cit. on p. 67).

Lim, Melvin et al. (July 2009). "Development and potential of new generation photocatalytic systems for air pollution abatement: an overview". In: AsiaPacific Journal of Chemical Engineering 4.4, pp. 387-402 (cit. on p. 81). 
Liu, Zhu et al. (2012). "Uncovering China's greenhouse gas emission from regional and sectoral perspectives". In: Energy 45.1, pp. 1059-1068 (cit. on p. 54).

March, James G. and Herbert A. Simon (1958). Organizations (cit. on p. 70).

Marin, Giovanni (Mar. 2014). "Do eco-innovations harm productivity growth through crowding out? Results of an extended CDM model for Italy". In: Research Policy 43.2, pp. 301-317 (cit. on p. 5).

Markusen, James R. and Lars E. O. Svensson (Feb. 1985). "Trade in Goods and Factors with International Differences in Technology". In: International Economic Review 26.1, p. 175 (cit. on p. 69).

Marshall, Alfred (1920). "Industry and Trade." In: Journal of the Royal Statistical Society (cit. on p. 68).

Martinez, C. (2010). "Insight into Different Types of Patent Families". In: STI Working Paper 2010/2 (cit. on p. 20).

McMichael, Anthony J, R E Woodruff, and S Hales (2006). "Climate change and human health: present and future risks". In: Lancet 367.9513, pp. 859-869 (cit. on p. 2).

Montresor, Sandro and Francesco Quatraro (2017). "Regional Branching and Key Enabling Technologies: Evidence from European Patent Data". In: Economic Geography 93.4, pp. 367-396 (cit. on p. 132).

Morgenroth, Edgar (2010). "Regional Dimension of Taxes and Public Expenditure in Ireland". In: Regional Studies 44.6, pp. 777-789 (cit. on p. 134).

Mowery, David C., Richard R. Nelson, and Ben R. Martin (2010). "Technology policy and global warming: Why new policy models are needed (or why putting new wine in old bottles won't work)". In: Research Policy 39.8, pp. 1011-1023 (cit. on p. 134).

Nadaraya, Elizbar A (1964). "On estimating regression". In: Theory of Probability 85 Its Applications 9.1, pp. 141-142 (cit. on pp. 51, 60). 
Neffke, Frank, Martin Henning, and Ron Boschma (July 2011). "How Do Regions Diversify over Time? Industry Relatedness and the Development of New Growth Paths in Regions". In: Economic Geography 87.3, pp. 237265 (cit. on pp. 37, 69, 114).

Neffke, Frank, Martin Henning, Ron Boschma, et al. (Jan. 2011). "The Dynamics of Agglomeration Externalities along the Life Cycle of Industries". In: Regional Studies 45.1, pp. 49-65 (cit. on pp. 4, 69).

Nelson, R (1959). "The Simple Economics of Basic Scientific Research". In: Journal of Political Economy 67.3, pp. 297-306 (cit. on p. 3).

Nelson, R (1982). Government and technical progress : a cross-industry analysis. Ed. by R Nelson. Oxford: Pergamon Press (cit. on p. 132).

Nelson, R (1994). "The Co-evolution of Technology, Industrial Structure, and Supporting Institutions". In: Industrial and Corporate Change 3.1, pp. 4763 (cit. on pp. 5, 175).

Nelson, R (2008). "What enables rapid economic progress: What are the needed institutions?" In: Research Policy 37.1, pp. 1-11 (cit. on p. 107).

Nelson, R. and S.G. Winter (1982). An Evolutionary Theory of Economic Change. Cambridge: Harvard University Press, p. 437 (cit. on pp. 70, 72).

Nelson, R and E Phelps (1966). "Investment in humans, technological diffusion, and economic growth". In: The American economic review 56.1/2, pp. 6975 (cit. on p. 59).

Nemet, Gregory F. (2009). "Demand-pull, technology-push, and government-led incentives for non-incremental technical change". In: Research Policy 38.5, pp. 700-709 (cit. on p. 133).

Nesta, Lionel, Francesco Vona, and Francesco Nicolli (2014). "Environmental policies, competition and innovation in renewable energy". In: Journal of Environmental Economics and Management 67.3, pp. 396-411 (cit. on p. 6). 
Newell, R G (2010). "The role of markets and policies in delivering innovation for climate change mitigation". In: Oxford Review of Economic Policy 26.2, pp. 253-269 (cit. on p. 3).

Noailly, Joëlle and Victoria Shestalova (Mar. 2017). "Knowledge spillovers from renewable energy technologies: Lessons from patent citations". In: Environmental Innovation and Societal Transitions 22, pp. 1-14 (cit. on p. 100).

Nooteboom, Bart (2002). "A balanced theory of sourcing, collaboration and networks". In: ERIM Report Series Research in Management (cit. on p. 71).

Norton, R. D. (1979). City life-cycles and American urban policy. Academic Press, p. 182 (cit. on p. 69).

Norton, R.D. and J. Rees (Apr. 1979). "The product cycle and the spatial decentralization of American manufacturing". In: Regional Studies 13.2, pp. 141-151 (cit. on pp. 69, 114).

OECD (June 2003). Voluntary Approaches for Environmental Policy. OECD Publishing (cit. on p. 4).

OECD (May 2011). Towards Green Growth. OECD Green Growth Studies. OECD Publishing (cit. on pp. 3, 101).

Oh, Ilyoung, Walter Wehrmeyer, and Yacob Mulugetta (2010). "Decomposition analysis and mitigation strategies of $\mathrm{CO} 2$ emissions from energy consumption in South Korea". In: Energy Policy 38.1, pp. 364-377 (cit. on p. 54).

Parikka-Alhola, Katriina (2008). "Promoting environmentally sound furniture by green public procurement". In: Ecological Economics 68.1, pp. 472-485 (cit. on p. 134).

Patz, Jonathan A. et al. (2005). "Impact of regional climate change on human health". In: Nature 438.7066 , pp. 310-317 (cit. on p. 2). 
Petralia, Sergio, Pierre Alexandre Balland, and Andrea Morrison (2017). "Climbing the ladder of technological development". In: Research Policy 46.5, pp. 956-969 (cit. on pp. 8, 88, 89, 92, 94, 96, 98, 100-102, 105-107, 176).

Ponds, Roderik, F. v. Oort, and Koen Frenken (Mar. 2010). "Innovation, spillovers and university-industry collaboration: an extended knowledge production function approach". In: Journal of Economic Geography 10.2, pp. 231-255 (cit. on p. 115).

Popp, D., R.G. Newell, and A.B. Jaffe (2010). "Energy, the Environment, and Technological Change". In: Handbook of the Economics of Innovation- VolII. Ed. by Nathan Rosenberg and Bronwyn Halland. Burlington, USA: Academic Press, pp. 873-938 (cit. on p. 14).

Popp, David (2002). "Induced Innovation and Energy Prices". In: The American Economic Review 92, pp. 160-180 (cit. on p. 6).

Pugliese, Emanuele, Guido L Chiarotti, et al. (2017). "Complex economies have a lateral escape from the poverty trap". In: PloS one 12.1, e0168540 (cit. on pp. 53,61).

Pugliese, Emanuele, Andrea Zaccaria, and Luciano Pietronero (2016). "On the convergence of the Fitness-Complexity Algorithm". In: The European Physical Journal Special Topics 225.10, pp. 1893-1911 (cit. on p. 42).

Rennings, K. (2000). "Redefining innovation-eco-innovation research and the contribution from ecological economics". In: Ecological Economics 32.2, pp. 319-332 (cit. on pp. 9, 133).

Requate, Till (2005). "Timing and Commitment of Environmental Policy, Adoption of New Technology, and Repercussions on R\&D". In: Environmental E Resource Economics 31.2, pp. 175-199 (cit. on p. 10).

Rigby, David L and Jürgen Essletzbichler (1997). "Evolution, process variety, and regional trajectories of technological change in US manufacturing". In: Economic Geography 73.3, pp. 269-284 (cit. on pp. 4, 37, 110).

Romer, Paul M (1994). "The origins of endogenous growth". In: Journal of Economic perspectives 8.1, pp. 3-22 (cit. on p. 4). 
Rosenberg, Nathan (1976). Perspectives on technology. Cambridge University Press, p. 353 (cit. on p. 115).

Ruttan, Vernon W. (2006). Is War Necessary for Economic Growth? Military Procurement and Technology Development. Oxford: Oxford University Press (cit. on p. 132).

Sarewitz, Daniel and Richard Nelson (2008). "Three rules for technological fixes". In: Nature 456.7224, pp. 871-872 (cit. on p. 3).

Sbardella, Angelica, François Perruchas, et al. (2018). "Green Technology Fitness". In: Entropy 20.10 (cit. on p. iv).

Sbardella, Angelica, Emanuele Pugliese, and Luciano Pietronero (2017). "Economic development and wage inequality: A complex system analysis". In: PloS one 12.9, e0182774 (cit. on p. 53).

Schumpeter, Joseph A. (1939). Business cycles : a theoretical, historical, and statistical analysis of the capitalist process. Martino Pub, p. 1095 (cit. on pp. $70,72,111)$.

Stern, Nicholas (2007). The economics of climate change: the stern review. Cambridge University Press, p. 692 (cit. on p. 3).

Tacchella, Andrea, Matthieu Cristelli, et al. (2012). "A new metrics for countries' fitness and products' complexity". In: Scientific Reports 2 (cit. on pp. 38, $53,59)$.

Tacchella, Andrea, Dario Mazzilli, and Luciano Pietronero (2018). "A dynamical systems approach to gross domestic product forecasting". In: Nature Physics 14.8, p. 861 (cit. on p. 39).

Tarr, Joel A. et al. (1984). "Water and Wastes: A Retrospective Assessment of Wastewater Technology in the United States, 1800-1932". In: Technology and Culture 25.2, pp. 226-263 (cit. on p. 85).

The Boston Consulting Group (2015). Steel as a Model for Sustainable Metal Industry in 2050. Tech. rep. (cit. on p. 81). 
Theil, Henri (1972). Statistical decomposition analysis. With applications in the social and administrative sciences. Amsterdam: North-Holland Pub. Co (cit. on p. 119).

Truffer, Bernhard and Lars Coenen (Jan. 2012). "Environmental Innovation and Sustainability Transitions in Regional Studies". In: Regional Studies 46.1, pp. 1-21 (cit. on p. 113).

US Department of Energy (2017). Fuel Cell Technologies Market Report 2016. Tech. rep. Washington, DC (cit. on p. 81).

US National Academy of Sciences, National Academy of Engineering, and National Research Council (Mar. 2010). Electricity from Renewable Resources. Washington, D.C.: National Academies Press (cit. on p. 81).

Utterback, James (1994). "Mastering the dynamics of innovation". In: (cit. on pp. $5,7,85,175)$.

Veugelers, Reinhilde (2012). "Which policy instruments to induce clean innovating?" In: Research Policy 41.10, pp. 1770-1778 (cit. on pp. 5, 88).

Vona, Francesco and Davide Consoli (2015). "Innovation and skill dynamics: a life-cycle approach". In: Industrial and Corporate Change 24.6, pp. 13931415 (cit. on pp. 5, 38, 76, 85, 113, 114, 175, 176).

Weitzman, M. L. (May 1998). "Recombinant Growth". In: The Quarterly Journal of Economics 113.2, pp. 331-360 (cit. on pp. 4, 70, 72, 111).

Yang, Hai-Lan and Robert Innes (2007). "Economic incentives and residential waste management in Taiwan: an empirical investigation". In: Environmental and Resource Economics 37.3, pp. 489-519 (cit. on p. 54).

Zaccaria, Andrea et al. (2014). "How the taxonomy of products drives the economic development of countries". In: PloS one 9.12, e113770 (cit. on p. 38). 
